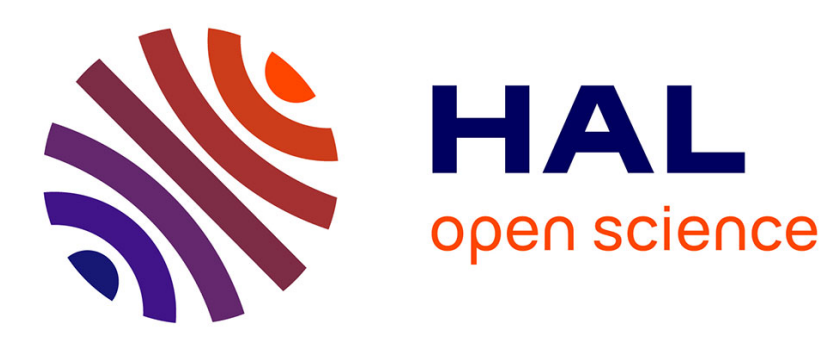

\title{
The 2020 version of the gene table of neuromuscular disorders (nuclear genome)
}

\author{
Louise Benarroch, Gisèle Bonne, Francois Rivier, Dalil Hamroun
}

\section{To cite this version:}

Louise Benarroch, Gisèle Bonne, Francois Rivier, Dalil Hamroun. The 2020 version of the gene table of neuromuscular disorders (nuclear genome). Neuromuscular Disorders, 2019, 29 (12), pp.980-1018. 10.1016/j.nmd.2019.10.010 . hal-02393145

\section{HAL Id: hal-02393145 \\ https://hal.science/hal-02393145}

Submitted on 1 May 2020

HAL is a multi-disciplinary open access archive for the deposit and dissemination of scientific research documents, whether they are published or not. The documents may come from teaching and research institutions in France or abroad, or from public or private research centers.
L'archive ouverte pluridisciplinaire HAL, est destinée au dépôt et à la diffusion de documents scientifiques de niveau recherche, publiés ou non, émanant des établissements d'enseignement et de recherche français ou étrangers, des laboratoires publics ou privés. 


\title{
The 2020 version of the gene table of neuromuscular disorders (nuclear genome)
}

\author{
Louise Benarroch ${ }^{\mathrm{a}}$, Gisèle Bonne ${ }^{\mathrm{a}, *}$, François Rivier $^{\mathrm{b}}$, Dalil Hamroun ${ }^{\mathrm{c}}$ \\ a Sorbonne Université, INSERM UMRS_974, Centre de Recherche en Myologie, Institut de Myologie, G.H. Pitié-Salpêtrière, Paris, France \\ ${ }^{\mathrm{b}}$ Neuropédiatrie \& CR Maladies Neuromusculaires, CHU de Montpellier, U1046 INSERM, UMR9214 CNRS, Université de Montpellier, France \\ ${ }^{\mathrm{c}}$ CHRU de Montpellier, Direction de la Recherche et de l'Innovation, Hôpital La Colombière, Montpellier, France
}

\section{General features}

This table is published annually in the December issue. Its purpose is to provide the reader of Neuromuscular Disorders with an updated list of monogenic neuromuscular diseases due to a primary defect residing in the nuclear genome. It comprises diseases in which the causative gene is known or at least localized on a chromosome, if not yet identified. Diseases for which the locus has not been mapped or which are due to defects involving mitochondrial genes are not included. ${ }^{1}$

As in past years the diseases are classified into 16 groups:

1. Muscular dystrophies;

2. Congenital muscular dystrophies;

3. Congenital myopathies;

4. Distal myopathies;

5. Other myopathies;

6. Myotonic syndromes;

7. Ion channel muscle diseases;

8. Malignant hyperthermias;

9. Metabolic myopathies;

10. Hereditary cardiomyopathies, subdivided into $10 A$ (non-arrhythmogenic) and $10 B$ (arrhythmogenic);

11. Congenital myasthenic syndromes;

12. SMA \& Motor neurone diseases;

13. Hereditary ataxias;

14. Hereditary motor and sensory neuropathies;

15. Hereditary paraplegias;

16. Other neuromuscular disorders.

* Corresponding author. Sorbonne Université, INSERM UMRS974, Centre de Recherche en Myologie, Paris, France. Fax: +33 142165700.

E-mail address: g.bonne@institut-myologie.org (G. Bonne).

${ }^{1}$ For diseases caused by mitochondrial genome mutations see: MITOMAP A human mitochondrial genome database. A compendium of polymorphisms and mutations of the human mitochondrial DNA http://www.mitomap.org/ MITOMAP.
In each group every entry corresponds to a clinicalgenetic entity and has an item number. ${ }^{2}$ A given gene may be involved in several different clinical entities (phenotypic heterogeneity such as in LMNA defects) and conversely a given clinical entity may be produced by a defect in several possible alternative genes (genotypic heterogeneity such as in CMT). In some diseases both kinds of heterogeneity may occur. As a consequence a gene or a disease may be cited in several places of the table.

\section{The two versions of the gene table ${ }^{3}$}

The annual printed version below is abridged and does not contain the Arrhythmogenic Hereditary Cardiomyopathies (Group 10-B), Hereditary Ataxias (Group 13), and Hereditary Paraplegias (Group 15). The list of references is restricted to new key references corresponding to the items added or implemented since the preceding year.

The full online version contains the complete data of the 16 groups and the cumulative list of key references since 1991. It is freely accessible at http://www.musclegenetable.fr. It is designed to cope with the complexity described above. In this version the data are cross-referenced and linked to PubMed and to major databases related to molecular medicine (Leiden Muscular Dystrophy, OMIM, NCBI, Genatlas, Orphanet, GeneCards). It contains several query tools allowing one to perform a variety of interrogations. This computerized version of the table is now surpassing the printed version which cannot accommodate the ever increasing volume and complexity of data. The statistics tool instantly provides the latest list of genes, proteins, phenotypes and cumulative bibliographic key references. Each list can be displayed, printed and exported in Excel format.

\footnotetext{
${ }^{2}$ The assigned item number is provisional and may change in the next annual version.

3 The history and development of both versions of the table are presented in the 2013 publication (Kaplan JC and Hamroun D. The 2013 version of the gene table of neuromuscular disorders. Neuromuscul Disord. 22 (12), 1108-1135.)
} 
Overview of the new data in the 2020 printed version of the gene table (pages 980 to 1018 of this issue)

There are 74 new items, marked by background shading. Altogether they comprise $\mathbf{3 6}$ additional genes out of which one presented allelic phenotype and $\mathbf{3 8}$ additional phenotypic variants caused by a gene already listed in the 2019 version (see box). One locus, previously identified, but still without identified gene was missing in the gene table (item \#16.20). Finally, one locus change causative gene (MED25 > PNKP for CMT2B2, item \#14.74).

The new key references of the printed version of the table are listed on pages $982-1018$ in this issue.

Of note, we implemented the revised nomenclature of LGMD (group 1) proposed by Straub et al. (2018), keeping the previous nomenclature in parallel in order to allow a smooth transition for users. For CMT (group 14), we decided not to implement the proposed revised nomenclature (Maguy et al. 2018) in the present released printed version of the gene table of neurouscular disorders, in order to allow further time for the neuromuscular community to fully validate these proposed nomenclatures.

\section{Citation of the gene table}

- Printed version: Benarroch L, Bonne G, Rivier F, Hamroun D. The 2020 version of the gene table of neuromuscular disorders. Neuromuscul Disord. 29 (12), 980-1018.

- Online version: GeneTable of Neuromuscular Disorders: http://www.musclegenetable.fr

\section{Contact}

Users of the gene table are kindly requested to send any comments on the printed and/or the online version to g.bonne@institut-myologie.org.

\section{Acknowledgements}

We are extremely thankful to Jean-Claude Kaplan for his constant trust and support in giving us the opportunity to take over the maintenance of the "Muscle Gene Table" he initiated in 1991. We sincerely wish him an enjoyable retirement from the Gene Table, knowing he will keep a kindly eye on it. We sincerely thank Tanya Stojkovic for her careful review of entries in groups 12 and 14, Volker Straub and Ichizo Nishino for their careful review of entries in group 1.

We acknowledge the help of Myobase, a bibliographic alert system of the AFM (Asscociation Française contre les Myopathies), URL: http://www.myobase.org/

We are extremely appreciative of the invaluable assistance provided by Jane Miller at all stages of elaboration and editing of this table.

This work received funding from the European Union's Horizon 2020 research and innovation programme under grant agreement No. 779257 (Solve-RD). L. Benarroch is supported by a MK-UK and Cure-CMD grant (\# 18GROIPG24-0140).
New in the 2020 printed version of the gene table

\section{6 genes added:}

ADCK3 (item \# 16.69)
AHNAK2 (item \# 14.33)
ATP1A2 (item \# 7.5)
Clorf194 (item \# 14.19)
CACNA1H (item \# 3.55)
COQ2 (item \# 16.68)
COQ4 (item \# 16.72)
COQ6 (item \# 16.71)
COQ7 (item \# 16.73)
COQ9 (item \# 16.70)
COX6A2 (item \# 16.63)
DNA2 (item \# 16.34)
ECEL1 (item \# 16.18)
FBXL4 (item \# 16.52)
FDX2 (item \# 16.74)
FXR1 (item \# 3.56)
KIF26B (item \# 12.85)
LRP12 (item \# 5.18)

$M B$ (item \# 5.34)

MAPT (item \# 12.87)

$M E T$ (item \# 16.23)

MGME1 (item \# 16.49)

MPV17 (item \# 14.75)

MRPS25 (item \# 16.65)

MSTO1 (item \# 2.49, \# 16.66)

MYH14 (item \# 12.86)

MYL1 (item \# 3.54)

NOTCH2NLC (item \#14.117)

NUP88 (item \# 16.28)

PAX7 (item \# 3.57)

SPTAN1 (item \# 12.38)

SUCLG1 (item \# 16.48)

TBK1 (item \# 12.74)

TIMM22 (item \# 16.67)

TOP3A (item \# 16.39)

TYMP (item \# 16.40)

38 additional phenotypic variants caused by mutation in a gene already listed in the gene table

ACTN2 (item \# 3.54)

ASCC1 (item \#16.24)

BICD2 (item \# 12.34 and item \# 16.22)

CAPN3 (item \# 1.16)

COL6A1 (item \# 1.17 and item \# 1.46)

COL6A2 (item \# 1.18 and item \# 1.47)

COL6A3 (item \# 1.19 and item \# 1.48)

DGUOK (item \# 16.45)

HINT1 (item \# 12.15)

HSPB8 (item \# 4.21)

KBTBD13 (item \# 1.60)

KIF5A (item \# 12.67)

LAMA2 (item \# 1.49)

MFN2 (item \# 14.68)

MYL2 (item \# 3.19)

OPA1 (item \# 16.56)

$P O L G$ (item \# 16.46 and item \# 16.47)

POMGNT2 (item \# 1.50)

PYROXD1 (item \# 1.59 and item \# 3.60)

RRM2B (item \# 16.48)

RYR1 (item \# 2.50 and item \# 16.30)

SACS (item \# 14.89)

SCN4A (item \# 3.59 and item \# 16.31)

SLC25A4 (item \# 16.53 and item \# 16.54)

STAC3 (item \# 3.53)

SYT2 (item \# 12.37)

TNPO3 (item \# 3.61)

TTN (item \# 3.32)

VRK1 (item \# 12.10)

1 change of causative gene for a previously identified locus

PNKP (item \#14.74)

87 new key references 


\section{Gene table of monogenic neuromuscular disorders (nuclear genome only) Vol. 29 No. 12, December 2019}

A computerized version of the table is freely accessible at http://www.musclegenetable.fr/

Shaded background indicates newly added items.

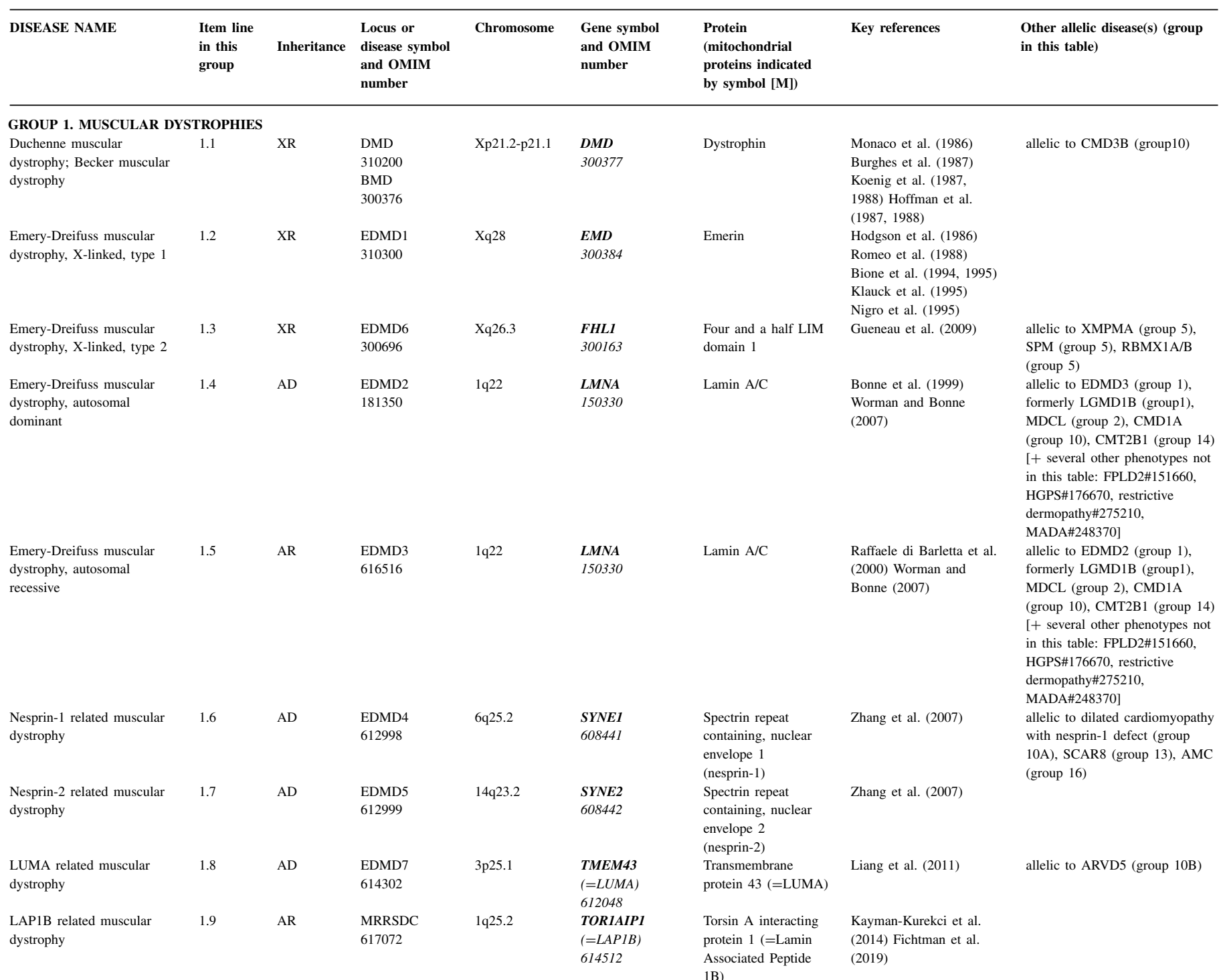




\begin{tabular}{|c|c|c|c|c|c|c|c|c|}
\hline DISEASE NAME & $\begin{array}{l}\text { Item line } \\
\text { in this } \\
\text { group }\end{array}$ & Inheritance & $\begin{array}{l}\text { Locus or } \\
\text { disease symbol } \\
\text { and OMIM } \\
\text { number }\end{array}$ & Chromosome & $\begin{array}{l}\text { Gene symbol } \\
\text { and OMIM } \\
\text { number }\end{array}$ & $\begin{array}{l}\text { Protein } \\
\text { (mitochondrial } \\
\text { proteins indicated } \\
\text { by symbol }[\mathrm{M}] \text { ) }\end{array}$ & Key references & $\begin{array}{l}\text { Other allelic disease(s) (group } \\
\text { in this table) }\end{array}$ \\
\hline $\begin{array}{l}\text { Facio-scapulo-humeral } \\
\text { muscular dystrophy, type } 1\end{array}$ & 1.10 & $\mathrm{AD}$ & $\begin{array}{l}\text { FSHD1 } \\
158900\end{array}$ & $4 q 35$ & $\begin{array}{l}\text { DUX } 4^{*} \\
606009 \\
\left({ }^{*} \text { inappropriate }\right. \\
\text { reactivation })\end{array}$ & Double homeobox 4 & $\begin{array}{l}\text { Wijmenga et al. } \\
\text { (1990-1993) Upadhyaya } \\
\text { et al. (1990, 1992) } \\
\text { Wright et al. (1993) van } \\
\text { Deutekom et al. (1993) } \\
\text { Gabellini et al. (2002) } \\
\text { Van der Maarel et al. } \\
\text { (2005) Gabellini et al. } \\
\text { (2006) Petrov et al. } \\
\text { (2006) Lemmers et al. } \\
\text { (2010) }\end{array}$ & \\
\hline $\begin{array}{l}\text { Facio-scapulo-humeral } \\
\text { muscular dystrophy, type } 2\end{array}$ & 1.11 & $\mathrm{AD}$ & $\begin{array}{l}\text { FSHD2 } \\
158901\end{array}$ & $18 \mathrm{p} 11.32$ & $\begin{array}{l}\text { SMCHDI* } \\
614982 \\
\left({ }^{*} \text { causing }\right. \\
\text { inappropriate } \\
\text { reactivation of } \\
\text { DUX4* } \\
606009)\end{array}$ & $\begin{array}{l}\text { Structural } \\
\text { maintenance of } \\
\text { chromosomes flexible } \\
\text { hinge domain } \\
\text { containing } 1\end{array}$ & $\begin{array}{l}\text { de Greef et al. (2010) } \\
\text { Sacconi et al. (2012) } \\
\text { Lemmers et al. (2012) } \\
\text { Sacconi et al. (2013) }\end{array}$ & $\begin{array}{l}\text { allelic to Bosma Arhinia } \\
\text { Microphthalmia Syndrome; } \\
\text { BAMS (\#603457) }\end{array}$ \\
\hline $\begin{array}{l}\text { Muscular dystrophy with } \\
\text { generalized lipodystrophy }\end{array}$ & 1.12 & $\mathrm{AD}$ & & $17 \mathrm{q} 21.2$ & $\begin{array}{l}\text { CAVIN1 } \\
603198\end{array}$ & $\begin{array}{l}\text { Caveolae-associated } \\
\text { protein1, Cavin-1, } \\
\text { (Polymerase I and } \\
\text { transcript release } \\
\text { factor) }\end{array}$ & Hayashi et al. (2009) & \\
\hline \multicolumn{9}{|c|}{ Limb girdle muscular dystrophies, dominant } \\
\hline $\begin{array}{l}\text { LGMDD1 (formerly } \\
\text { LGDM1E) }\end{array}$ & 1.13 & $\mathrm{AD}$ & $\begin{array}{l}\text { LGMDD1 } \\
\text { (LGMD1E) } \\
603511\end{array}$ & $7 \mathrm{q} 36.3$ & $\begin{array}{l}\text { DNAJB6 } \\
611332\end{array}$ & $\begin{array}{l}\text { Hsp40 homologue, } \\
\text { subfamily B, number } \\
6\end{array}$ & $\begin{array}{l}\text { Speer et al. (1999), } \\
\text { Sarparanta e al (2012) } \\
\text { Harms et al. (2012) }\end{array}$ & $\begin{array}{l}\text { allelic to distal myopathy } \\
\text { (group } 4 \text { ) }\end{array}$ \\
\hline $\begin{array}{l}\text { LGMDD2 (Formerly } \\
\text { LGMD1F) }\end{array}$ & 1.14 & $\mathrm{AD}$ & $\begin{array}{l}\text { LGMDD2 } \\
\text { (LGMD1F) } \\
608423\end{array}$ & $7 \mathrm{q} 32.1$ & $\begin{array}{l}\text { TNPO3 } \\
610032\end{array}$ & Transportin 3 & $\begin{array}{l}\text { Palenzuela et al. (2003) } \\
\text { Melià et al. (2013) } \\
\text { Torella et al. (2013) }\end{array}$ & $\begin{array}{l}\text { allelic to Congenital Myopathy } \\
\text { related to TNPO3 (group 3) }\end{array}$ \\
\hline $\begin{array}{l}\text { LGMDD3 (Formerly } \\
\text { LGMD1G) }\end{array}$ & 1.15 & $\mathrm{AD}$ & $\begin{array}{l}\text { LGMDD3 } \\
\text { (LGMD1G) } \\
609115\end{array}$ & $4 \mathrm{q} 21.22$ & $\begin{array}{l}\text { HNRNPDL } \\
607137\end{array}$ & $\begin{array}{l}\text { Heterogeneous } \\
\text { nuclear } \\
\text { ribonucleoprotein } \\
\text { D-like }\end{array}$ & $\begin{array}{l}\text { Starling et al. (2005) } \\
\text { Vieira et al. (2014) }\end{array}$ & \\
\hline LGMDD4 & 1.16 & $\mathrm{AD}$ & $\begin{array}{l}\text { LGMDD4 } \\
\text { (LGMD1I) } \\
618129\end{array}$ & $15 q 15.1$ & $\begin{array}{l}\text { CAPN3 } \\
114240\end{array}$ & Calpain-3 & $\begin{array}{l}\text { Vissing et al. (2016) } \\
\text { Martinez-Thompson } \\
\text { et al. (2018) }\end{array}$ & allelic to LGMDR1 (group 1) \\
\hline LGMDD5 & 1.17 & $\mathrm{AD}$ & $\begin{array}{l}\text { LGMDD5 } \\
\text { (BTHLM1) } \\
158810\end{array}$ & $21 \mathrm{q} 22.3$ & $\begin{array}{l}\text { COL6A1 } \\
120220\end{array}$ & $\begin{array}{l}\text { Collagen type VI } \\
\text { subunit alpha } 1\end{array}$ & Jöbsis et al. (1996) & $\begin{array}{l}\text { allelic to UCMD and BTHLM1 } \\
\text { (group 2) }\end{array}$ \\
\hline LGMDD5 & 1.18 & $\mathrm{AD}$ & $\begin{array}{l}\text { LGMDD5 } \\
\text { (BTHLM1) } \\
158810\end{array}$ & $21 \mathrm{q} 22.3$ & $\begin{array}{l}\text { COL6A2 } \\
120240\end{array}$ & $\begin{array}{l}\text { Collagen type VI } \\
\text { subunit alpha } 2\end{array}$ & Jöbsis et al. (1996) & $\begin{array}{l}\text { allelic to UCMD, BTHLM1 } \\
\text { and myosclerosis (group 2) }\end{array}$ \\
\hline LGMDD5 & 1.19 & $\mathrm{AD}$ & $\begin{array}{l}\text { LGMDD5 } \\
\text { (BTHLM1) } \\
158810\end{array}$ & $2 \mathrm{q} 37.3$ & $\begin{array}{l}\text { COL6A3 } \\
120250\end{array}$ & $\begin{array}{l}\text { Collagen type VI } \\
\text { subunit alpha } 3\end{array}$ & $\begin{array}{l}\text { Speer et al. (1996) } \\
\text { Bertini et al. (1998) Pan } \\
\text { et al. (1998) }\end{array}$ & $\begin{array}{l}\text { allelic to UCMD and } \\
\text { BTHLM1 (group 2) }\end{array}$ \\
\hline $\begin{array}{l}\text { Myofibrillar myopathy } 3 \\
\text { (Formerly LGMD1A) }\end{array}$ & 1.20 & $\mathrm{AD}$ & $\begin{array}{l}\text { MFM3 } \\
609200 \\
\text { (LGMD1A } \\
159,000)\end{array}$ & $5 q 31$ & $\begin{array}{l}\text { MYOT } \\
604103\end{array}$ & $\begin{array}{l}\text { Myotilin (titin } \\
\text { immunoglobulin } \\
\text { domain protein) }\end{array}$ & $\begin{array}{l}\text { Speer et al. (1992) } \\
\text { Hauser et al. (2000) }\end{array}$ & $\begin{array}{l}\text { allelic to distal myotilinopathy } \\
\text { (group 4), MFM (group 5), } \\
\text { spheroid body myopathy (group } \\
\text { 5) }\end{array}$ \\
\hline $\begin{array}{l}\text { Emery-Dreifuss muscular } \\
\text { dystrophy } 2 \text { (Formerly } \\
\text { LGMD1B) }\end{array}$ & 1.21 & $\mathrm{AD}$ & $\begin{array}{l}\text { EDMD2 } \\
181350 \\
\text { (LGMD1B } \\
159001)\end{array}$ & $1 \mathrm{q} 22$ & $\begin{array}{l}\text { LMNA } \\
150330\end{array}$ & Lamin $\mathrm{A} / \mathrm{C}$ & $\begin{array}{l}\text { van der Kooi et al. } \\
\text { (1997) Muchir et al. } \\
\text { (2000) Worman and } \\
\text { Bonne (2007) }\end{array}$ & $\begin{array}{l}\text { allelic to EDMD2 and EDMD3 } \\
\text { (group 1), MDCL (group 2), } \\
\text { CMD1A (group 10), CMT2B1 } \\
\text { (group 14) [+ several other } \\
\text { phenotypes not in this table: } \\
\text { FPLD2 \#151660, HGPS \#176670, } \\
\text { restrictive dermopathy \#275210, } \\
\text { MADA \#248370] }\end{array}$ \\
\hline $\begin{array}{l}\text { Rippling muscle disease } 2 \\
\text { (Formerly LGMD1C) }\end{array}$ & 1.22 & $\mathrm{AD}$ & $\begin{array}{l}\text { RMD } \\
606072 \\
\text { (LGMD1C } \\
607801)\end{array}$ & $3 \mathrm{p} 25.3$ & $\begin{array}{l}\text { CAV3 } \\
601253\end{array}$ & Caveolin-3 & $\begin{array}{l}\text { Minetti et al. (1998) } \\
\text { McNally et al. (1998) }\end{array}$ & $\begin{array}{l}\text { allelic to MPDT (group 4), hyper } \\
\text { CKemia (group 5), RMD2 (group } \\
\text { 6), CMH (group 10A), LQT9 } \\
\text { (group 10B) }\end{array}$ \\
\hline $\begin{array}{l}\text { Myofibrillar myopathy } 1 \\
\text { (Formerly LGMD1 related } \\
\text { to } D E S \text { ) }\end{array}$ & 1.23 & $\mathrm{AD}$ & $\begin{array}{l}\text { MFM1 } \\
601419\end{array}$ & $2 q 35$ & $\begin{array}{l}\text { DES } \\
125660\end{array}$ & Desmin & $\begin{array}{l}\text { Messina et al. (1997) } \\
\text { Greenberg et al. (2012) } \\
\text { Hedberg et al. (2012) }\end{array}$ & $\begin{array}{l}\text { allelic to formerly LGMD2R } \\
\text { (group 1), MFM1 and (group 5), } \\
\text { CMD1I (group 10A), ARVC7 } \\
\text { (group } 5 \text { and 10B) }\end{array}$ \\
\hline LGMD1H & 1.24 & $\mathrm{AD}$ & $\begin{array}{l}\text { LGMD1H } \\
613530\end{array}$ & $3 \mathrm{p} 25.1-\mathrm{p} 23$ & $?$ & & Bisceglia et al. (2010) & \\
\hline \multicolumn{9}{|c|}{ Limb girdle muscular dystrophies, recessive } \\
\hline $\begin{array}{l}\text { LGMDR1 (Formerly } \\
\text { LGMD2A) }\end{array}$ & 1.25 & $\mathrm{AR}$ & $\begin{array}{l}\text { LGMDR1 } \\
\text { (LGMD2A) } \\
253600\end{array}$ & $15 q 15.1$ & $\begin{array}{l}\text { CAPN3 } \\
114240\end{array}$ & Calpain-3 & $\begin{array}{l}\text { Beckmann et al. (1991) } \\
\text { Young et al. (1992), } \\
\text { Richard et al. (1995, } \\
\text { 1997) }\end{array}$ & allelic to LGMDD4 (group 1) \\
\hline $\begin{array}{l}\text { LGMDR2 (Formerly } \\
\text { LGMD2B) }\end{array}$ & 1.26 & $\mathrm{AR}$ & $\begin{array}{l}\text { LGMDR2 } \\
\text { (LGMD2B) } \\
253601\end{array}$ & $2 \mathrm{p} 13.2$ & $\begin{array}{l}\text { DYSF } \\
603009\end{array}$ & Dysferlin & $\begin{array}{l}\text { Bashir et al. (1994) } \\
\text { Bashir et al. (1998) Liu } \\
\text { et al. (1998) }\end{array}$ & allelic to MMD1 (group 4) \\
\hline
\end{tabular}




\begin{tabular}{|c|c|c|c|c|c|c|c|c|}
\hline DISEASE NAME & $\begin{array}{l}\text { Item line } \\
\text { in this } \\
\text { group }\end{array}$ & Inheritance & $\begin{array}{l}\text { Locus or } \\
\text { disease symbol } \\
\text { and OMIM } \\
\text { number }\end{array}$ & Chromosome & $\begin{array}{l}\text { Gene symbol } \\
\text { and OMIM } \\
\text { number }\end{array}$ & $\begin{array}{l}\text { Protein } \\
\text { (mitochondrial } \\
\text { proteins indicated } \\
\text { by symbol }[\mathrm{M}] \text { ) }\end{array}$ & Key references & $\begin{array}{l}\text { Other allelic disease(s) (group } \\
\text { in this table) }\end{array}$ \\
\hline $\begin{array}{l}\text { LGMDR3 (Formerly } \\
\text { LGMD2D) }\end{array}$ & 1.27 & $\mathrm{AR}$ & $\begin{array}{l}\text { LGMDR3 } \\
\text { (LGMD2D) } \\
608099\end{array}$ & $17 q 21.33$ & $\begin{array}{l}\text { SGCA } \\
600119\end{array}$ & Alpha-sarcoglycan & $\begin{array}{l}\text { Roberds et al. (1994) } \\
\text { Piccolo et al. (1995) } \\
\text { Passos-Bueno et al. } \\
\text { (1995) Ljunggren et al. } \\
\text { (1995) Carrié et al. } \\
\text { (1997) }\end{array}$ & \\
\hline $\begin{array}{l}\text { LGMDR4 (Formerly } \\
\text { LGMD2E) }\end{array}$ & 1.28 & $\mathrm{AR}$ & $\begin{array}{l}\text { LGMDR4 } \\
\text { (LGMD2E) } \\
604286\end{array}$ & $4 q 12$ & $\begin{array}{l}S G C B \\
600900\end{array}$ & Beta-sarcoglycan & $\begin{array}{l}\text { Lim et al. (1995) } \\
\text { Bönnemann et al. (1995) } \\
\text { Bönnemann et al. (1996) }\end{array}$ & \\
\hline $\begin{array}{l}\text { LGMDR5 (Formerly } \\
\text { LGMD2C) }\end{array}$ & 1.29 & $\mathrm{AR}$ & $\begin{array}{l}\text { LGMDR5 } \\
(\text { LGMD2C) } \\
253700\end{array}$ & $13 \mathrm{q} 12.12$ & $\begin{array}{l}\text { SGCG } \\
608896\end{array}$ & Gamma-sarcoglycan & $\begin{array}{l}\text { Ben Othmane et al. } \\
\text { (1992) Azibi et al. (1993) } \\
\text { Noguchi et al. (1995) } \\
\text { McNally et al. (1996) } \\
\text { Piccolo et al. (1996) }\end{array}$ & \\
\hline $\begin{array}{l}\text { LGMDR6 (Formerly } \\
\text { LGMD2F) }\end{array}$ & 1.30 & $\mathrm{AR}$ & $\begin{array}{l}\text { LGMDR6 } \\
\text { (LGMD2F) } \\
601287\end{array}$ & $5 q 33.3-q 33.3$ & $\begin{array}{l}S G C D \\
601411\end{array}$ & Delta-sarcoglycan & $\begin{array}{l}\text { Passos-Bueno et al. } \\
\text { (1996) Nigro et al. } \\
\text { (1996) }\end{array}$ & allelic to CMD1L (group 10A) \\
\hline $\begin{array}{l}\text { LGMDR7 (Formerly } \\
\text { LGMD2G }\end{array}$ & 1.31 & $\mathrm{AR}$ & $\begin{array}{l}\text { LGMDR7 } \\
\text { (LGMD2G) } \\
601954\end{array}$ & $17 \mathrm{q} 12$ & $\begin{array}{l}\text { TCAP } \\
604488\end{array}$ & Titin-cap (telethonin) & $\begin{array}{l}\text { Moreira et al. (1997) } \\
\text { Moreira et al. (2000) }\end{array}$ & $\begin{array}{l}\text { allelic to CMD related to } \\
\text { telethonin (group 2), CMH25 } \\
\text { (group 10A), CMD1N (group } \\
\text { 10A) }\end{array}$ \\
\hline $\begin{array}{l}\text { LGMDR8 (Formerly } \\
\text { LGMD2H }\end{array}$ & 1.32 & $\mathrm{AR}$ & $\begin{array}{l}\text { LGMDR8 } \\
\text { (LGMD2H) } \\
254110\end{array}$ & $9 \mathrm{q} 33.1$ & $\begin{array}{l}\text { TRIM32 } \\
602290\end{array}$ & $\begin{array}{l}\text { Tripartite } \\
\text { motif-containing } 32\end{array}$ & $\begin{array}{l}\text { Weiler et al. (1998) } \\
\text { Frosk et al. (2002) }\end{array}$ & $\begin{array}{l}\text { allelic to sarcotubular myopathy } \\
\text { (group 3) }\end{array}$ \\
\hline $\begin{array}{l}\text { LGMDR9 (Formerly } \\
\text { LGMD2I }\end{array}$ & 1.33 & $\mathrm{AR}$ & $\begin{array}{l}\text { LGMDR9 } \\
\text { (MDDGC5) } \\
607155\end{array}$ & $19 \mathrm{q} 13.32$ & $\begin{array}{l}\text { FKRP } \\
606596\end{array}$ & $\begin{array}{l}\text { Fukutin related } \\
\text { protein }\end{array}$ & $\begin{array}{l}\text { Driss et al. (2000) } \\
\text { Brockington et al. } \\
\text { (2001a) }\end{array}$ & $\begin{array}{l}\text { allelic to MDDGB5/MDC1C } \\
\text { (group 2), MDDGA5/WWS } \\
\text { (group 2), MEB (group 2) }\end{array}$ \\
\hline $\begin{array}{l}\text { LGMDR10 (Formerly } \\
\text { LGMD2J) }\end{array}$ & 1.34 & $\mathrm{AR}$ & $\begin{array}{l}\text { LGMDR10 } \\
(\text { LGMD2J) } \\
608807\end{array}$ & $2 \mathrm{q} 31.2$ & $\begin{array}{l}\text { TTN } \\
188840\end{array}$ & Titin & Hackman et al. (2003) & $\begin{array}{l}\text { allelic to CNM related to } T T N \\
\text { (group 3), MmD related to TTN } \\
\text { (group 3), SALMY (group 3), } \\
\text { TMD (group 4), HMERF (group } \\
\text { 5), CMH9 (group 10), CMD1G } \\
\text { (group 10) }\end{array}$ \\
\hline $\begin{array}{l}\text { LGMDR11 (Formerly } \\
\text { LGMD2K) }\end{array}$ & 1.35 & $\mathrm{AR}$ & $\begin{array}{l}\text { LGMDR11 } \\
\text { (MDDGC1) } \\
609308\end{array}$ & $9 \mathrm{q} 34.13$ & $\begin{array}{l}\text { POMT1 } \\
607423\end{array}$ & $\begin{array}{l}\text { Protein } 0 \text {-manno } \\
\text { syltransferase } 1\end{array}$ & $\begin{array}{l}\text { Balci et al. (2005) } \\
\text { D'Amico et al. (2006) }\end{array}$ & $\begin{array}{l}\text { allelic to WWS/MDDGA1 } \\
\text { (group 2) }\end{array}$ \\
\hline $\begin{array}{l}\text { LGMDR } 12 \text { (Formerly } \\
\text { LGMD2L) }\end{array}$ & 1.36 & $\mathrm{AR}$ & $\begin{array}{l}\text { LGMDR12 } \\
\text { (LGMD2L) } \\
611307\end{array}$ & $11 \mathrm{p} 14.3$ & $\begin{array}{l}\text { ANO5 } \\
(T M E M 16 E) \\
608662\end{array}$ & Anoctamin 5 & $\begin{array}{l}\text { Jarry et al. (2007), } \\
\text { Bolduc et al. (2008, } \\
\text { 2010), Hicks et al. } \\
(2011)\end{array}$ & $\begin{array}{l}\text { allelic to early onset calf distal } \\
\text { myopathy (group } 4 \text { ) }\end{array}$ \\
\hline $\begin{array}{l}\text { LGMDR13 (Formerly } \\
\text { LGMD2M) }\end{array}$ & 1.37 & $\mathrm{AR}$ & $\begin{array}{l}\text { LGMDR13 } \\
\text { (MDDGC4) } \\
611588\end{array}$ & $9 \mathrm{q} 31.2$ & $\begin{array}{l}\text { FKTN } \\
607440\end{array}$ & Fukutin & $\begin{array}{l}\text { Murakami et al. (2006) } \\
\text { Godfrey et al. (2006) }\end{array}$ & $\begin{array}{l}\text { allelic to FCMD (group 2), } \\
\text { WWS/MDDGB4 (group 2), } \\
\text { CMD1X (group 10) }\end{array}$ \\
\hline $\begin{array}{l}\text { LGMDR } 14 \text { (Formerly } \\
\text { LGMD2N) }\end{array}$ & 1.38 & AR & $\begin{array}{l}\text { LGMDR14 } \\
\text { (MDDGC2) } \\
613158\end{array}$ & $14 \mathrm{q} 24.3$ & $\begin{array}{l}\text { РОМТ2 } \\
607439\end{array}$ & $\begin{array}{l}\text { Protein O-mannosyl } \\
\text { transferase } 2\end{array}$ & Biancheri et al. (2007) & $\begin{array}{l}\text { allelic to WWS (group 2) and to } \\
\text { MEB (group 2) }\end{array}$ \\
\hline $\begin{array}{l}\text { LGMDR15 (Formerly } \\
\text { LGMD2O) }\end{array}$ & 1.39 & $\mathrm{AR}$ & $\begin{array}{l}\text { LGMDR15 } \\
\text { (MDDGC3) } \\
613157\end{array}$ & $1 \mathrm{p} 34.1$ & $\begin{array}{l}\text { POMGNT1 } \\
606822\end{array}$ & $\begin{array}{l}\text { Protein O-linked } \\
\text { mannose } \\
\text { beta1,2-N-acetyl } \\
\text { glucosaminyl } \\
\text { transferase } 1\end{array}$ & $\begin{array}{l}\text { Godfrey et al. (2007) } \\
\text { Clement et al. (2008) } \\
\text { Raducu et al. (2012) }\end{array}$ & $\begin{array}{l}\text { allelic to WWS (group 2) and to } \\
\text { MEB (group 2) }\end{array}$ \\
\hline $\begin{array}{l}\text { LGMDR } 16 \text { (Formerly } \\
\text { LGMD2P) }\end{array}$ & 1.40 & $\mathrm{AR}$ & $\begin{array}{l}\text { LGMDR16 } \\
\text { (MDDGC9) } \\
613818\end{array}$ & $3 \mathrm{p} 21.31$ & $\begin{array}{l}\text { DAG1 } \\
128239\end{array}$ & $\begin{array}{l}\text { Dystrophin-associated } \\
\text { glycoprotein } 1 \\
\text { (alpha-dystroglycan) }\end{array}$ & Hara et al. (2011) & allelic to MDDGA9 (group 2) \\
\hline $\begin{array}{l}\text { LGMDR17 (Formerly } \\
\text { LGMD2Q) }\end{array}$ & 1.41 & $\mathrm{AR}$ & $\begin{array}{l}\text { LGMDR17 } \\
\text { (LGMD2Q) } \\
613723\end{array}$ & $8 \mathrm{q} 24.3$ & $\begin{array}{l}\text { PLEC } \\
601282\end{array}$ & Plectin & Gundesli et al. (2010) & $\begin{array}{l}\text { allellic to LGMD with } \\
\text { ophthalmoplegia (group 1), } \\
\text { EBSMD (group 5), and } \\
\text { Myasthenic syndrome with plectin } \\
\text { defect (group 11) }\end{array}$ \\
\hline $\begin{array}{l}\text { LGMDR18 (Formerly } \\
\text { LGMD2S) }\end{array}$ & 1.42 & $\mathrm{AR}$ & $\begin{array}{l}\text { LGMDR18 } \\
(\text { LGMD2S) } \\
615356\end{array}$ & $4 \mathrm{q} 35.1$ & $\begin{array}{l}\text { TRAPPC11 } \\
614138\end{array}$ & $\begin{array}{l}\text { Trafficking protein } \\
\text { particle complex } 11\end{array}$ & $\begin{array}{l}\text { Bögershausen et al. } \\
\text { (2013) }\end{array}$ & $\begin{array}{l}\text { allelic to CMD related to } \\
\text { TRAPPC11 (group 2) }\end{array}$ \\
\hline $\begin{array}{l}\text { LGMDR19 (Formerly } \\
\text { LGMD2T) }\end{array}$ & 1.43 & $\mathrm{AR}$ & $\begin{array}{l}\text { LGMDR19 } \\
\text { (MDDGC14) } \\
615352\end{array}$ & $3 \mathrm{p} 21.31$ & $\begin{array}{l}\text { GMPPB } \\
615320\end{array}$ & $\begin{array}{l}\text { GDP-mannose } \\
\text { pyrophos } \\
\text { phorylase B }\end{array}$ & $\begin{array}{l}\text { Carss et al. (2013) } \\
\text { Cabrera-Serrano et al. } \\
\text { (2015) }\end{array}$ & $\begin{array}{l}\text { allelic to MEB/MDDGA14, } \\
\text { MDDGB14 (group 2) and } \\
\text { congenital myyasthenic syndrome } \\
\text { (group 11) }\end{array}$ \\
\hline $\begin{array}{l}\text { LGMDR20 (Formerly } \\
\text { LGMD2U) }\end{array}$ & 1.44 & $\mathrm{AR}$ & $\begin{array}{l}\text { LGMDR20 } \\
(\text { MDDGC7) } \\
616052\end{array}$ & $7 \mathrm{p} 21.2-\mathrm{p} 21.1$ & $\begin{array}{l}\text { ISPD } \\
614631\end{array}$ & $\begin{array}{l}\text { Isoprenoid synthase } \\
\text { domain containing } \\
\text { protein }\end{array}$ & Tasca et al. (2013) & $\begin{array}{l}\text { allelic to WWS/ MDDGA7 } \\
\text { (group 2) }\end{array}$ \\
\hline $\begin{array}{l}\text { LGMDR21 (Formerly } \\
\text { LGMD2Z) }\end{array}$ & 1.45 & AR & $\begin{array}{l}\text { LGMDR21 } \\
\text { (LGMD2Z) }\end{array}$ & $3 q 13.33$ & $\begin{array}{l}\text { POGLUT1 } \\
615618\end{array}$ & $\begin{array}{l}\text { Protein O-Glucosyl } \\
\text { transferase } 1\end{array}$ & $\begin{array}{l}\text { Servian-Morilla et al. } \\
\text { (2016) }\end{array}$ & \\
\hline
\end{tabular}




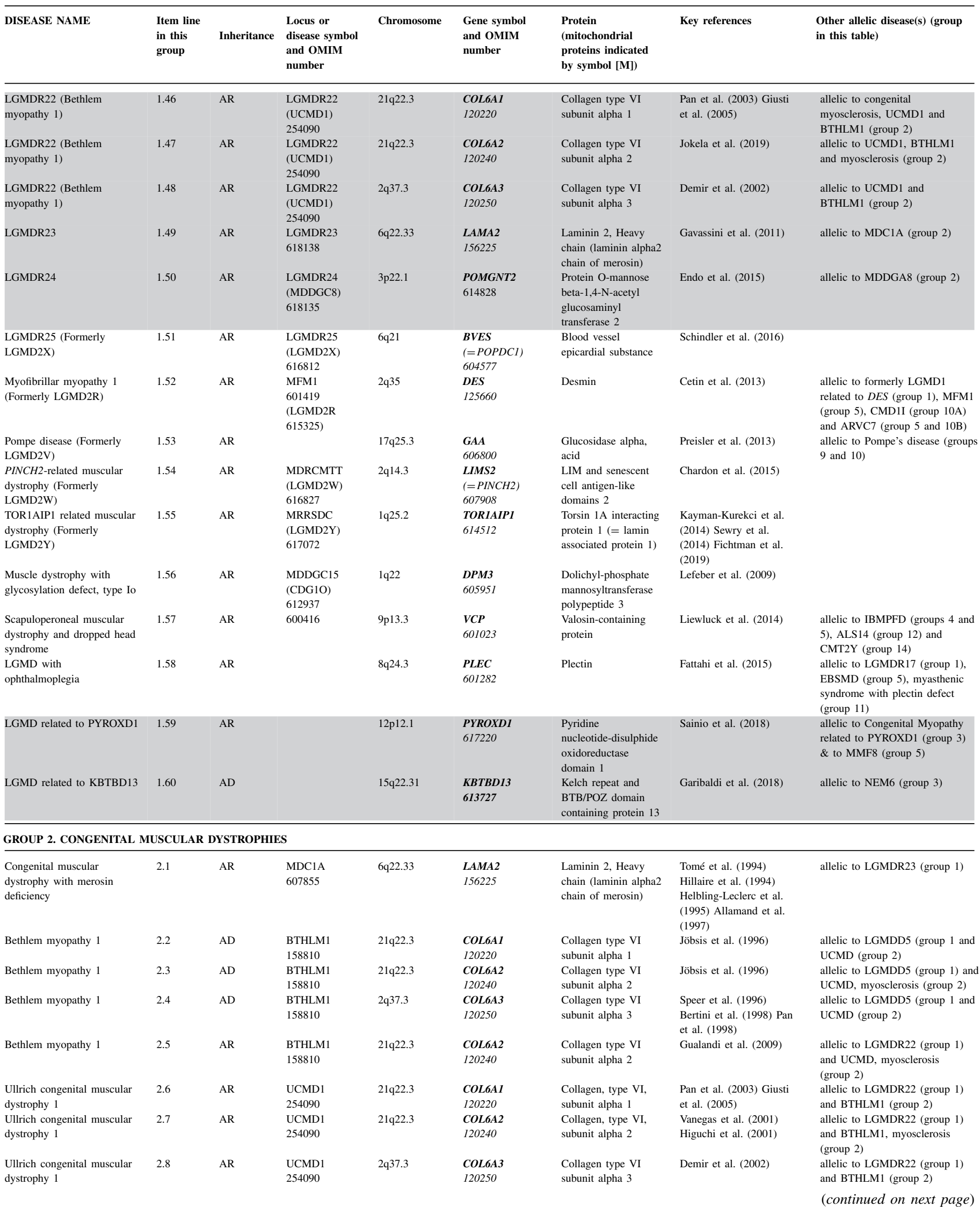




\begin{tabular}{|c|c|c|c|c|c|c|c|c|}
\hline DISEASE NAME & $\begin{array}{l}\text { Item line } \\
\text { in this } \\
\text { group }\end{array}$ & Inheritance & $\begin{array}{l}\text { Locus or } \\
\text { disease symbol } \\
\text { and OMIM } \\
\text { number }\end{array}$ & Chromosome & $\begin{array}{l}\text { Gene symbol } \\
\text { and OMIM } \\
\text { number }\end{array}$ & $\begin{array}{l}\text { Protein } \\
\text { (mitochondrial } \\
\text { proteins indicated } \\
\text { by symbol }[\mathrm{M}] \text { ) }\end{array}$ & Key references & $\begin{array}{l}\text { Other allelic disease(s) (group } \\
\text { in this table) }\end{array}$ \\
\hline $\begin{array}{l}\text { Ullrich congenital muscular } \\
\text { dystrophy } 2\end{array}$ & 2.9 & AR & $\begin{array}{l}\text { UCMD2 } \\
616470\end{array}$ & $6 q 13-q 14$ & $\begin{array}{l}\text { COL12A1 } \\
120320\end{array}$ & $\begin{array}{l}\text { Collagen type XII } \\
\text { alpha } 1 \text { chain }\end{array}$ & Zou et al. (2014) & $\begin{array}{l}\text { Allelic to BTHLM2 (group 2), } \\
\text { CMD related to COL12A1 } \\
\text { (group 2) }\end{array}$ \\
\hline Bethlem myopathy 2 & 2.10 & $\mathrm{AD}$ & $\begin{array}{l}\text { BTHLM2 } \\
616471\end{array}$ & $6 q 13-q 14$ & $\begin{array}{l}\text { COL12A1 } \\
120320\end{array}$ & $\begin{array}{l}\text { Collagen type XII } \\
\text { alpha } 1 \text { chain }\end{array}$ & Zou et al. (2014) & $\begin{array}{l}\text { Allelic to UCMD2 (group 2), } \\
\text { CMD related to COL12A1 } \\
\text { (group 2) }\end{array}$ \\
\hline $\begin{array}{l}\text { COL12Al-related congenital } \\
\text { muscular dystrophy }\end{array}$ & 2.11 & $\mathrm{AD}$ & & 6q13-q14 & $\begin{array}{l}\text { COL12AI } \\
120320\end{array}$ & $\begin{array}{l}\text { Collagen type XII } \\
\text { alpha } 1 \text { chain }\end{array}$ & Punetha et al. (2016) & $\begin{array}{l}\text { Allelic to UCMD2 (group 2), } \\
\text { BTHLM2 (group 2) }\end{array}$ \\
\hline Myosclerosis, congenital & 2.12 & AR & 255600 & $21 \mathrm{q} 22.3$ & $\begin{array}{l}\text { COL6A2 } \\
120240\end{array}$ & $\begin{array}{l}\text { Collagen type VI } \\
\text { subunit alpha } 2\end{array}$ & Merlini et al. (2008) & $\begin{array}{l}\text { allelic to LGMDR22 (group 1) } \\
\text { UCMD and BTHLM1 (group 2) }\end{array}$ \\
\hline Rigid spine syndrome 1 & 2.13 & $\mathrm{AR}$ & $\begin{array}{l}\text { RSMD1 } \\
602771\end{array}$ & $1 \mathrm{p} 36.11$ & $\begin{array}{l}\text { SELENON } \\
\text { (formerly } \\
\text { SEPN1) } \\
606210\end{array}$ & Selenoprotein $\mathrm{N}$ & $\begin{array}{l}\text { Moghadaszadeh et al. } \\
(1998,2001) \text { Ferreiro } \\
\text { et al. }(2002,2004)\end{array}$ & $\begin{array}{l}\text { allelic to CFTD (group 3), } \\
\text { multiminicore disease (group 3), } \\
\text { and desmin-related myopathy } \\
\text { with Mallory bodies (group 5) }\end{array}$ \\
\hline $\begin{array}{l}\text { Congenital muscular } \\
\text { dystrophy due to ITGA7 } \\
\text { deficiency }\end{array}$ & 2.14 & $\mathrm{AR}$ & 613204 & $12 \mathrm{q} 13.2$ & $\begin{array}{l}\text { ITGA7 } \\
600536\end{array}$ & Integrin alpha7 & Hayashi et al. (1998) & \\
\hline $\begin{array}{l}\text { Congenital muscular } \\
\text { dystrophy related to } \\
\text { dynamin } 2\end{array}$ & 2.15 & $\mathrm{AD}$ & & $19 \mathrm{p} 13.2$ & $\begin{array}{l}\text { DNM2 } \\
602378\end{array}$ & Dynamin 2 & Susman et al. (2008) & $\begin{array}{l}\text { allelic to CNM1 (group } 3 \text { and 4) } \\
\text { and CMTDIB (group 14) }\end{array}$ \\
\hline $\begin{array}{l}\text { Congenital musuclar } \\
\text { dystrophy related to } \\
\text { telethonin }\end{array}$ & 2.16 & $\mathrm{AR}$ & & $17 \mathrm{q} 12$ & $\begin{array}{l}\text { TCAP } \\
604488\end{array}$ & Titin-cap (telethonin) & Ferreiro et al. (2011) & $\begin{array}{l}\text { allelic to LGMDR7 (group 1), } \\
\text { CMH25 (group 10A), CMD1N } \\
\text { (group 10A) }\end{array}$ \\
\hline $\begin{array}{l}\text { Congenital m3:19uscular } \\
\text { dystrophy related to LMNA }\end{array}$ & 2.17 & $\mathrm{AD}$ & $\begin{array}{l}\text { MDCL } \\
613205\end{array}$ & $1 \mathrm{q} 22$ & $\begin{array}{l}\text { LMNA } \\
150330\end{array}$ & Lamin $\mathrm{A} / \mathrm{C}$ & Quijano-Roy et al. (2008) & $\begin{array}{l}\text { allelic to EDMD2, EDMD3 and } \\
\text { formerly LGMD1B (group 1), } \\
\text { CMD1A (group 10A), CMT2B1 } \\
\text { (group 14) [+ several other } \\
\text { phenotypes not in this table: } \\
\text { FPLD2 \#151660, HGPS \#176670, } \\
\text { restrictive dermopathy \#275210, } \\
\text { MADA \#248370] }\end{array}$ \\
\hline \multicolumn{9}{|l|}{ CMD-Dystroglycanopathies } \\
\hline $\begin{array}{l}\text { Fukuyama congenital } \\
\text { muscular dystrophy (FCMD) }\end{array}$ & 2.18 & $\mathrm{AR}$ & $\begin{array}{l}\text { MDDGA4 } \\
253800\end{array}$ & $9 \mathrm{q} 31.2$ & $\begin{array}{l}\text { FKTN } \\
607440\end{array}$ & Fukutin & $\begin{array}{l}\text { Toda et al. (1993) } \\
\text { Kobayashi et al. (1998) }\end{array}$ & $\begin{array}{l}\text { allelic to LGMDR13 (group 1), } \\
\text { WWS/MDDGB4 (group 2), } \\
\text { CMD1X (group 10A) }\end{array}$ \\
\hline $\begin{array}{l}\text { Walker-Warburg syndrome } \\
\text { (WWS) }\end{array}$ & 2.19 & AR & $\begin{array}{l}\text { MDDGB4 } \\
613152\end{array}$ & $9 \mathrm{q} 31.2$ & $\begin{array}{l}\text { FKTN } \\
607440\end{array}$ & Fukutin & $\begin{array}{l}\text { Beltran-Valero de } \\
\text { Bernabe (2003) Mercuri } \\
\text { et al. (2009) }\end{array}$ & $\begin{array}{l}\text { allelic to LGMDR13 (group 1) } \\
\text { and FCMD (group 2) and } \\
\text { CMD1X (group 10A) }\end{array}$ \\
\hline $\begin{array}{l}\text { Walker-Warburg syndrome } \\
\text { (WWS) }\end{array}$ & 2.20 & $\mathrm{AR}$ & $\begin{array}{l}\text { MDDGA1 } \\
236670 \\
\text { MDDGB1 } \\
607423\end{array}$ & $9 q 34.13$ & $\begin{array}{l}\text { POMT1 } \\
607423\end{array}$ & $\begin{array}{l}\text { Protein-O-mannosyl } \\
\text { transferase } 1\end{array}$ & $\begin{array}{l}\text { Beltran-Valero De } \\
\text { Bernabe et al. (2002) van } \\
\text { Reeuwijk et al. (2006) } \\
\text { Mercuri et al. (2009) }\end{array}$ & allelic to LGMDR11 (group 1) \\
\hline $\begin{array}{l}\text { Walker-Warburg syndrome } \\
\text { (WWS) }\end{array}$ & 2.21 & $\mathrm{AR}$ & $\begin{array}{l}\text { MDDGA2 } \\
613150 \\
\text { MDDGB2 } \\
613156\end{array}$ & $14 \mathrm{q} 24.3$ & $\begin{array}{l}\text { РОМT2 } \\
607439\end{array}$ & $\begin{array}{l}\text { Protein O-mannosyl } \\
\text { transferase } 2\end{array}$ & $\begin{array}{l}\text { van Reeuwijk et al. } \\
\text { (2005) Mercuri et al. } \\
\text { (2009) }\end{array}$ & $\begin{array}{l}\text { allelic to LGMDR14 (group 1) } \\
\text { and MEB (group 2) }\end{array}$ \\
\hline $\begin{array}{l}\text { Walker-Warburg syndrome } \\
\text { (WWS) }\end{array}$ & 2.22 & AR & $\begin{array}{l}\text { MDDGA5 } \\
613153\end{array}$ & $19 \mathrm{q} 13.32$ & $\begin{array}{l}\text { FKRP } \\
606596\end{array}$ & $\begin{array}{l}\text { Fukutin related } \\
\text { protein }\end{array}$ & $\begin{array}{l}\text { Beltran-Valero De } \\
\text { Bernabe et al. (2004) }\end{array}$ & $\begin{array}{l}\text { allelic to LGMDR9 (group 1), } \\
\text { MDDGB5/MDC1C (group 2), } \\
\text { MEB (group 2) }\end{array}$ \\
\hline $\begin{array}{l}\text { Walker-Warburg syndrome } \\
\text { (WWS) }\end{array}$ & 2.23 & $\mathrm{AR}$ & $\begin{array}{l}\text { MDDGA3 } \\
253280 \\
\text { MDDGB3 } \\
613151\end{array}$ & $1 \mathrm{p} 34.1$ & $\begin{array}{l}\text { POMGNTI } \\
606822\end{array}$ & $\begin{array}{l}\text { Protein O-mannose } \\
\text { beta1,2- N-acetyl } \\
\text { glucosaminyl } \\
\text { transferase }\end{array}$ & $\begin{array}{l}\text { Taniguchi et al. (2003) } \\
\text { Mercuri et al. (2009) }\end{array}$ & $\begin{array}{l}\text { allelic to LGMDR15 (group 1) } \\
\text { and MEB (group 2) }\end{array}$ \\
\hline $\begin{array}{l}\text { Walker-Warburg syndrome } \\
\text { (WWS) }\end{array}$ & 2.24 & $\mathrm{AR}$ & $\begin{array}{l}\text { MDDGA7 } \\
614643\end{array}$ & $7 \mathrm{p} 21.2$ & $\begin{array}{l}\text { ISPD } \\
614631\end{array}$ & $\begin{array}{l}\text { Isoprenoid synthase } \\
\text { domain containing }\end{array}$ & $\begin{array}{l}\text { Roscioli et al. (2012) } \\
\text { Willer et al. (2012) }\end{array}$ & Alletic to LGMDR20 (group 1) \\
\hline $\begin{array}{l}\text { Walker-Warburg syndrome } \\
\text { (WWS) }\end{array}$ & 2.25 & AR & $\begin{array}{l}\text { MDDGA8 } \\
614830\end{array}$ & $3 \mathrm{p} 22.1$ & $\begin{array}{l}\text { POMGNT2 } \\
614828\end{array}$ & $\begin{array}{l}\text { Protein O-mannose } \\
\text { beta-1,4-N-acetyl } \\
\text { glucosaminyl } \\
\text { transferase } 2\end{array}$ & Manzini et al. (2012) & allelic to LGMDR24 (group 1) \\
\hline $\begin{array}{l}\text { Walker-Warburg syndrome } \\
\text { (WWS) }\end{array}$ & 2.26 & $\mathrm{AR}$ & $\begin{array}{l}\text { MDDGA13 } \\
615287\end{array}$ & $11 \mathrm{q} 13.2$ & $\begin{array}{l}\text { B4GATI } \\
605517\end{array}$ & $\begin{array}{l}\text { Beta-1,4-glucuronyl } \\
\text { transferase } 1 \\
\text { (Beta-1,3-N-acetyl } \\
\text { glucosaminyl } \\
\text { transferase 1) }\end{array}$ & $\begin{array}{l}\text { Buysse et al. (2013) } \\
\text { Shaheen et al. (2013) }\end{array}$ & \\
\hline $\begin{array}{l}\text { Muscle-eye-brain disease } \\
\text { (MEB) }\end{array}$ & 2.27 & $\mathrm{AR}$ & $\begin{array}{l}\text { MDDGA3 } \\
253280\end{array}$ & $1 \mathrm{p} 34.1$ & $\begin{array}{l}\text { POMGNT1 } \\
606822\end{array}$ & $\begin{array}{l}\text { Protein O-mannose } \\
\text { beta1,2- } \mathrm{N} \text {-acetyl } \\
\text { glucosaminyl } \\
\text { transferase }\end{array}$ & $\begin{array}{l}\text { Yoshida et al. (2001) } \\
\text { Taniguchi et al. (2003) }\end{array}$ & $\begin{array}{l}\text { allelic to LGMDR15 (group 1) } \\
\text { and WWS (group 2) }\end{array}$ \\
\hline $\begin{array}{l}\text { Muscle-eye-brain disease } \\
\text { (MEB) }\end{array}$ & 2.28 & $\mathrm{AR}$ & $\begin{array}{l}\text { MDDGA5 } \\
613153\end{array}$ & $19 \mathrm{q} 13.32$ & $\begin{array}{l}\text { FKRP } \\
606596\end{array}$ & $\begin{array}{l}\text { Fukutin related } \\
\text { protein }\end{array}$ & $\begin{array}{l}\text { Beltran-Valero De } \\
\text { Bernabe et al. (2004) }\end{array}$ & $\begin{array}{l}\text { allelic to LGMDR9 (group 1), } \\
\text { MDDGB5/MDC1C (group 2), } \\
\text { MDDGA5/WWS (group 2) }\end{array}$ \\
\hline $\begin{array}{l}\text { Muscle-eye-brain disease } \\
\text { (MEB) }\end{array}$ & 2.29 & AR & $\begin{array}{l}\text { MDDGA2 } \\
613150 \\
\text { MDDGB2 } \\
613156\end{array}$ & $14 \mathrm{q} 24.3$ & $\begin{array}{l}\text { POMT2 } \\
607439\end{array}$ & $\begin{array}{l}\text { Protein O-mannosyl } \\
\text { transferase } 2\end{array}$ & Mercuri et al. (2006) & $\begin{array}{l}\text { allelic to LGMDR14 (group 1) } \\
\text { and WWS (group 2) }\end{array}$ \\
\hline
\end{tabular}




\begin{tabular}{|c|c|c|c|c|c|c|c|c|}
\hline DISEASE NAME & $\begin{array}{l}\text { Item line } \\
\text { in this } \\
\text { group }\end{array}$ & Inheritance & $\begin{array}{l}\text { Locus or } \\
\text { disease symbol } \\
\text { and OMIM } \\
\text { number }\end{array}$ & Chromosome & $\begin{array}{l}\text { Gene symbol } \\
\text { and OMIM } \\
\text { number }\end{array}$ & $\begin{array}{l}\text { Protein } \\
\text { (mitochondrial } \\
\text { proteins indicated } \\
\text { by symbol }[\mathrm{M}] \text { ) }\end{array}$ & Key references & $\begin{array}{l}\text { Other allelic disease(s) (group } \\
\text { in this table) }\end{array}$ \\
\hline $\begin{array}{l}\text { Muscle-eye-brain disease } \\
\text { (MEB) }\end{array}$ & 2.30 & $\mathrm{AR}$ & $\begin{array}{l}\text { MDDGA14 } \\
615350\end{array}$ & $3 \mathrm{p} 21.31$ & $\begin{array}{l}\text { GMPPB } \\
615320\end{array}$ & $\begin{array}{l}\text { GDP-mannose } \\
\text { pyrophos } \\
\text { phorylase B }\end{array}$ & de Carss et al. (2013) & $\begin{array}{l}\text { allelic to LGMDR19 (group 1), } \\
\text { MDDGB14 (group 2), congenital } \\
\text { myasthenic syndrome (group 11) }\end{array}$ \\
\hline $\begin{array}{l}\text { Muscular dystrophy- } \\
\text { dystroglycanopathy, } \\
\text { congenital with or without } \\
\text { mental retardation (formerly } \\
\text { MDC1C) }\end{array}$ & 2.31 & $\mathrm{AR}$ & $\begin{array}{l}\text { MDDGB5 } \\
606612\end{array}$ & $19 \mathrm{q} 13.32$ & $\begin{array}{l}\text { FKRP } \\
606596\end{array}$ & $\begin{array}{l}\text { Fukutin related } \\
\text { protein }\end{array}$ & $\begin{array}{l}\text { Brockington et al. } \\
\text { (2001b) Topaloglu et al. } \\
\text { (2003) Mercuri et al. } \\
\text { (2009) }\end{array}$ & $\begin{array}{l}\text { allelic to LGMDR9 (group 1), } \\
\text { MDDGA5/WWS (group 2), MEB } \\
\text { (group 2) }\end{array}$ \\
\hline $\begin{array}{l}\text { Congenital muscular } \\
\text { dystrophy with } \\
\text { hypoglycosylation of } \\
\text { dystroglycan }\end{array}$ & 2.32 & $\mathrm{AR}$ & $\begin{array}{l}\text { MDDGA6 } \\
613154 \\
\text { MDDGB6 } \\
608,840\end{array}$ & $22 q 12.3$ & $\begin{array}{l}\text { LARGEI } \\
603590\end{array}$ & $\begin{array}{l}\text { Acetyl } \\
\text { glucosaminyl- } \\
\text { transferase-like } \\
\text { protein (like-glycosyl } \\
\text { transferase) }\end{array}$ & $\begin{array}{l}\text { Longman et al. (2003) } \\
\text { Mercuri et al. (2009) }\end{array}$ & \\
\hline $\begin{array}{l}\text { Congenital muscular } \\
\text { dystrophy with } \\
\text { hypoglycosylation of } \\
\text { dystroglycan }\end{array}$ & 2.33 & $\mathrm{AR}$ & $\begin{array}{l}\text { CDG1E } \\
608799\end{array}$ & $20 \mathrm{q} 13.13$ & $\begin{array}{l}\text { DPM1 } \\
603503\end{array}$ & $\begin{array}{l}\text { Dolichyl-phosphate } \\
\text { mannosyl } \\
\text { transferase } 1 \\
\text { catalytic subunit }\end{array}$ & Yang et al. (2013) & \\
\hline $\begin{array}{l}\text { Congenital muscular } \\
\text { dystrophy with } \\
\text { hypoglycosylation of } \\
\text { dystroglycan and severe } \\
\text { epilepsy }\end{array}$ & 2.34 & $\mathrm{AR}$ & $\begin{array}{l}\text { CDG1U } \\
615042\end{array}$ & $9 \mathrm{q} 34.11$ & $\begin{array}{l}\text { DPM2 } \\
603564\end{array}$ & $\begin{array}{l}\text { Dolichyl-phosphate } \\
\text { mannosyl } \\
\text { transferase } \\
\text { polypeptide } 2 \text {, } \\
\text { regulatory subunit }\end{array}$ & Barone et al. (2012) & \\
\hline $\begin{array}{l}\text { Congenital muscular } \\
\text { dystrophy with } \\
\text { hypoglycosylation of } \\
\text { dystroglycan }\end{array}$ & 2.35 & $\mathrm{AR}$ & $\begin{array}{l}\text { MDDGA9 } \\
616538\end{array}$ & $3 \mathrm{p} 21.31$ & $\begin{array}{l}\text { DAG1 } \\
128239\end{array}$ & $\begin{array}{l}\text { Dystrophin- } \\
\text { Associated } \\
\text { Glycoprotein } 1\end{array}$ & Geis et al. (2013) & allelic to LGMDR16 (group 1) \\
\hline $\begin{array}{l}\text { Congenital muscular } \\
\text { dystrophy with } \\
\text { hypoglycosylation of } \\
\text { dystroglycan type A10 }\end{array}$ & 2.36 & $\mathrm{AR}$ & $\begin{array}{l}\text { MDGGA10 } \\
615041\end{array}$ & $12 \mathrm{q} 14.2$ & $\begin{array}{l}\text { RXYLT1 } \\
605862\end{array}$ & $\begin{array}{l}\text { Ribitol xylosyl } \\
\text { transferase } 1 \\
\text { (transmembrane } \\
\text { protein 5) }\end{array}$ & $\begin{array}{l}\text { Vuillaumier-Barrot et al. } \\
\text { (2013) }\end{array}$ & \\
\hline $\begin{array}{l}\text { Congenital muscular } \\
\text { dystrophy with } \\
\text { hypoglycosylation of } \\
\text { dystroglycan WWWS/MEB } \\
\text { like }\end{array}$ & 2.37 & $\mathrm{AR}$ & $\begin{array}{l}\text { MDDGA11 } \\
615181\end{array}$ & $1 \mathrm{q} 42.3$ & $\begin{array}{l}\text { B3GALNT2 } \\
610194\end{array}$ & $\begin{array}{l}\text { Beta-1,3-N-acetyl } \\
\text { galactosaminyl } \\
\text { transferase } 2\end{array}$ & Stevens et al. (2013) & \\
\hline $\begin{array}{l}\text { Congenital muscular } \\
\text { dystrophy with } \\
\text { hypoglycosylation of } \\
\text { dystroglycan }\end{array}$ & 2.38 & $\mathrm{AR}$ & $\begin{array}{l}\text { MDDGA12 } \\
615249\end{array}$ & $8 \mathrm{p} 11.21$ & $\begin{array}{l}\text { POMK } \\
615247\end{array}$ & $\begin{array}{l}\text { Protein-O-mannose } \\
\text { kinase }\end{array}$ & Jae et al. (2013) & \\
\hline $\begin{array}{l}\text { Congenital muscular } \\
\text { dystrophy with } \\
\text { hypoglycosylation of } \\
\text { dystroglycan and mental } \\
\text { retardation }\end{array}$ & 2.39 & $\mathrm{AR}$ & $\begin{array}{l}\text { MDDGB14 } \\
615351\end{array}$ & $3 \mathrm{p} 21.31$ & $\begin{array}{l}\text { GMPPB } \\
615320\end{array}$ & $\begin{array}{l}\text { GDP-mannose } \\
\text { pyropho } \\
\text { sphorylase B }\end{array}$ & Carss et al. (2013) & $\begin{array}{l}\text { allelic to LGMDR19 (group 1), } \\
\text { MEB/MDDGA14 (group 2) and } \\
\text { congenital myasthenic syndrome } \\
\text { (group 11) }\end{array}$ \\
\hline $\begin{array}{l}\text { Congenital muscular } \\
\text { dystrophy with fatty liver } \\
\text { and infantile-onset cataract } \\
\text { caused by } \\
\text { TRAPPC11mutations }\end{array}$ & 2.40 & $\mathrm{AR}$ & & $4 \mathrm{q} 35.1$ & $\begin{array}{l}\text { TRAPPC11 } \\
614138\end{array}$ & $\begin{array}{l}\text { Trafficking protein } \\
\text { particle complex } 11\end{array}$ & $\begin{array}{l}\text { Liang et al. (2015) } \\
\text { Larson et al. (2018) }\end{array}$ & allelic to LGMDR18 (group 1) \\
\hline $\begin{array}{l}\text { Congenital muscular } \\
\text { dystrophy with } \\
\text { hypoglycosylation of } \\
\text { dystroglycan and epilepsy } \\
\text { Other congenital muscular dy }\end{array}$ & rophies & $\mathrm{AR}$ & & $17 q 21.32$ & $\begin{array}{l}\text { GOSR2 } \\
604027\end{array}$ & $\begin{array}{l}\text { Golgi SNAP receptor } \\
\text { complex member } 2\end{array}$ & Larson et al. (2018) & \\
\hline $\begin{array}{l}\text { Congenital muscle dystrophy } \\
\text { with joint hyperlaxity }\end{array}$ & 2.42 & $\mathrm{AR}$ & & $3 \mathrm{p} 23-21$ & $?$ & & Tetreault et al. (2006) & \\
\hline $\begin{array}{l}\text { Congenital muscle dystrophy } \\
\text { with mitochondrial structural } \\
\text { abnormalities (megaconial } \\
\text { type) }\end{array}$ & 2.43 & $\mathrm{AR}$ & $\begin{array}{l}\text { MDCMC } \\
602541\end{array}$ & $22 \mathrm{q} 13.33$ & $\begin{array}{l}\text { CHKB } \\
612395\end{array}$ & Choline kinase beta & Mitsuhashi et al. (2011) & \\
\hline $\begin{array}{l}\text { Congenital muscular } \\
\text { dystrophy }\end{array}$ & 2.44 & $\mathrm{AR}$ & $\begin{array}{l}\text { MDC1B } \\
604801\end{array}$ & $1 \mathrm{q} 42$ & $?$ & & Brockington et al. (2000) & \\
\hline $\begin{array}{l}\text { Congenital muscular } \\
\text { dystrophy with rigid spine } \\
\text { related to } A C T A I\end{array}$ & 2.45 & $\mathrm{AR}$ & $\begin{array}{l}\text { Possibly } \\
\text { identical to } \\
\text { MDC1B } \\
604801\end{array}$ & $1 \mathrm{q} 42.13$ & $\begin{array}{l}\text { ACTA1 } \\
102610\end{array}$ & $\begin{array}{l}\text { Alpha actin, skeletal } \\
\text { muscle }\end{array}$ & O'Grady et al. (2014) & $\begin{array}{l}\text { allelic to NEM3, CFTD, Cap } \\
\text { myopathy related to ACTA1 } \\
\text { (group 3) }\end{array}$ \\
\hline $\begin{array}{l}\text { GOLGA2-related congenital } \\
\text { muscle dystrophy with brain } \\
\text { involvement }\end{array}$ & 2.46 & $\mathrm{AR}$ & & $9 \mathrm{q} 34.11$ & $\begin{array}{l}\text { GOLGA2 } \\
602580\end{array}$ & Golgin A2 & Shamseldin et al. (2016) & \\
\hline $\begin{array}{l}\text { Muscular dystrophy, } \\
\text { congenital } \\
\text { Davignon-Chauveau type }\end{array}$ & 2.47 & $\mathrm{AR}$ & $\begin{array}{l}\text { MDCDC } \\
617066\end{array}$ & $15 q 22.31$ & $\begin{array}{l}\text { TRIP4 } \\
604501\end{array}$ & $\begin{array}{l}\text { Thyroid hormone } \\
\text { receptor interactor } 4\end{array}$ & Davignon et al. (2016) & allelic to SMABF1 (group 12) \\
\hline $\begin{array}{l}\text { Muscular dystrophy, } \\
\text { congenital, with cataracts } \\
\text { and intellectual disability }\end{array}$ & 2.48 & $\mathrm{AR}$ & $\begin{array}{l}\text { MDCCAID } \\
617404\end{array}$ & $17 \mathrm{p} 13.3$ & $\begin{array}{l}\text { INPP5K } \\
607875\end{array}$ & $\begin{array}{l}\text { Inositol } \\
\text { Polyphosphate-5- } \\
\text { Phosphatase K }\end{array}$ & $\begin{array}{l}\text { Osborn et al. (2017) } \\
\text { Wiessner et al. (2017) }\end{array}$ & \\
\hline
\end{tabular}




\begin{tabular}{|c|c|c|c|c|c|c|c|c|}
\hline DISEASE NAME & $\begin{array}{l}\text { Item line } \\
\text { in this } \\
\text { group }\end{array}$ & Inheritance & $\begin{array}{l}\text { Locus or } \\
\text { disease symbol } \\
\text { and OMIM } \\
\text { number }\end{array}$ & Chromosome & $\begin{array}{l}\text { Gene symbol } \\
\text { and OMIM } \\
\text { number }\end{array}$ & $\begin{array}{l}\text { Protein } \\
\text { (mitochondrial } \\
\text { proteins indicated } \\
\text { by symbol }[\mathrm{M}] \text { ) }\end{array}$ & Key references & $\begin{array}{l}\text { Other allelic disease(s) (group } \\
\text { in this table) }\end{array}$ \\
\hline $\begin{array}{l}\text { Congenital muscular } \\
\text { dystrophy related to MSTO1 } \\
\text { (also listed in group } 13 \text { \& } \\
\text { 16) }\end{array}$ & 2.49 & AR & & $1 \mathrm{q} 22$ & $\begin{array}{l}\text { MSTO1 } \\
617619\end{array}$ & $\begin{array}{l}\text { Misato } 1 \text {, } \\
\text { mitochondrial } \\
\text { distribution and } \\
\text { morphology regulator } \\
\text { (M) }\end{array}$ & $\begin{array}{l}\text { Nasca et al. (2017) } \\
\text { Ardicli et al. (2019) } \\
\text { Donkervoort et al. (2019) }\end{array}$ & \\
\hline $\begin{array}{l}\text { Congenital muscular } \\
\text { dystrophy related to RYR1 }\end{array}$ & 2.50 & & & $19 \mathrm{q} 13.2$ & $\begin{array}{l}\text { RYRI } \\
180901\end{array}$ & Ryanodine receptor & Helbling et al. (2019) & $\begin{array}{l}\text { allelic to CFTD, CNM related to } \\
\text { RYR1, CCD, CNMDU1 (group } \\
\text { 3), minicore myopathy with } \\
\text { external ophthalmoplegia (group } \\
\text { 3), Late onset axial myopathy } \\
\text { (group 5), MHS1 (group 8) }\end{array}$ \\
\hline
\end{tabular}

\section{GROUP 3. CONGENITAL MYOPATHIES}

\section{Nemaline myopathies}

Nemalin myopathy 1

$3.1 \quad \mathrm{AD}$

$\mathrm{AD}$

NEM1

609284

Nemalin myopathy 2

3.2

AR

NEM2

Nemalin myopathy

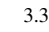

AD

NEM3

161800
Nemalin myopathy 4

Nemalin myopathy 5

Nemalin myopathy 6

Nemalin myopathy 7

Nemalin myopathy 8

Nemalin myopathy 9

Nemalin myopathy 10

Nemalin myopathy 11

Klippel-Feil syndrome with

Nemalin myopathy and

facial dysmorphism

Myopathy with nemaline

bodies

Other congenital myopathies

Myopathy, congenital, with

fiber-type disproportion 1

Myopathy, congenital, with fiber-type disproportion

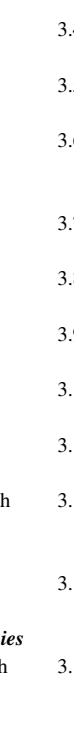

$3.4 \quad \mathrm{AD}$

NEM

NEM5

60555

NEM6

609273

NEM7

610687

NEM8

615,348

NEM9

615731

NEM 10

616165

NEM11

617336

KFS4

616549

$13 \quad$ AR

.14

$\mathrm{AD}, \mathrm{AR}$

CFTD

255310

$\mathrm{AD}, \mathrm{AR} \quad \mathrm{CFTD}$

255310

Myopathy, congenital, with $\quad 3.16$

fiber-type disproportion

Myopathy, congenital, with

fiber-type disproportion $\begin{array}{lll}3.16 & \text { AD, AR } & \text { CFTD } \\ & & 255310 \\ 3.17 & \text { AR } & \text { CFTD }\end{array}$

255310
$2 q 23.3$

NEB
161650

ACTAI

$1 \mathrm{q} 21.3$

TPM3
191030

102610

9p13.3

19q13.42

$15 \mathrm{q} 22.31$

$14 q 13.1$

$3 \mathrm{p} 22.1$

2q 31.1

3p14.1

$10 \mathrm{q} 21.3$

22q12.1

15q13-q14

$1 \mathrm{q} 42.13$

$1 \mathrm{p} 36.11$

.

$19 \mathrm{q} 13.2$

19.

180901

MYPN

608517

607295

RYR3

180903

ACTA1

SEPN1)

606210

TPM3

191030

RYRI

80901
Tropomyosin 3

(n)

Nebulin

Actin, alpha 1 ,

skeletal muscle

Tropomyosin 2 (beta)

Troponin T type 1

(skeletal, slow)

Kelch repeat and

BTB/POZ domain

containing protein 13

Cofilin 2 (muscle)

Kelch-like family

member 40

Kelch-like family

member 41

Myopalladin

MYO18B

SELENON

(formerly

Myosin XVIIIB

Actin, alpha 1,

Selenoprotein N

Tropomysosin 3

Ryanodine receptor
Leiomodin 3

Laing et al. (1992) Laing

et al. (1995b) Tan et al.

(1999)

Wattanasirichaigoon

et al. (2002)

Wallgren-Pettersson et al.

(1995, 2002) Pelin et al.

(1999) Lehtokari et al.

(2006)

Nowak et al. (1999)

Donner et al. (2002)

Monnier et al. (2009)

Johnston et al. (2000

Gommans et al. (2003)

Samburghin et al. (2010)

Agrawal et al. (2007)

Ravenscroft et al. (2013)

Gupta et al. (2013)

Yuen et al. (2014)

Miyatake et al. (2016)

Lornage et al. (2017)

Malfatti et al. (2015)

Ryanodine receptor 3 Nilipour et al. (2018)

Laing et al. (2004)

Clarke et al. (2006)

Clarke et al. (2008)

Clarke et al. (2010) skeletal muscle

allelic to CFTD, CAPM1

(group 3)

allelic to distal myopathy

(group 4)

allelic to CMD with rigid spine (group 2), CFTD and cap myopathy (group 3) allelic to CAPM2 (group 3), DA2B and DA1A (group 16)

allelic to LGMD related to

KBTBD13 (group 1)

allelic to CMD1KK, CMD22 and RCM 4 (group 10A)

allelic to CMD with rigid spine (group 2), NEM3 and cap myopathy (group 3 )

allelic to Rigid spine syndrome (group 2), CFTD (group 3), multminicore disease (group 3), desmin-related myopathy with

Mallory bodies (group 5) allelic to NEM1, CAPM1 (group 3)

allelic to CMD related to RYR1 (group 2), CNM related to RYR1, CCD, CNMDU1 (group 3), minicore myopathy with external ophthalmoplegia (group 3), Late onset axial myopathy (group 5), MHS1 (group 8)

allelic to MSMA and MSMB

(group 3), MPD1 (group 4),

CMH1, CMD1S and LVNC5 (group 10A)

7, cardiac muscle,

beta

\begin{tabular}{|c|c|c|c|c|c|c|c|c|}
\hline $\begin{array}{l}\text { Myopathy congenital, with } \\
\text { fiber-type disproportion }\end{array}$ & 3.19 & AR & $\begin{array}{l}\text { CFTD } \\
255310\end{array}$ & $12 \mathrm{q} 24.11$ & $\begin{array}{l}\text { MYL2 } \\
160781\end{array}$ & $\begin{array}{l}\text { Myosin regulatory } \\
\text { light chain } 2\end{array}$ & Waterman et al. (2013) & Allelic to CMH10 (group 10A) \\
\hline $\begin{array}{l}\text { Myopathy congenital, with } \\
\text { fiber-type disproportion }\end{array}$ & 3.20 & AR & $\begin{array}{l}\text { CNM6 } \\
617760\end{array}$ & $2 \mathrm{q} 31.1$ & $\begin{array}{l}\text { ZAK } \\
609479\end{array}$ & $\begin{array}{l}\text { Leucine zipper and } \\
\text { sterile alpha motif- } \\
\text { containing kinase }\end{array}$ & Vasli et al. (2017) & \\
\hline
\end{tabular}




\begin{tabular}{|c|c|c|c|c|c|c|c|c|}
\hline DISEASE NAME & $\begin{array}{l}\text { Item line } \\
\text { in this } \\
\text { group }\end{array}$ & Inheritance & $\begin{array}{l}\text { Locus or } \\
\text { disease symbol } \\
\text { and OMIM } \\
\text { number }\end{array}$ & Chromosome & $\begin{array}{l}\text { Gene symbol } \\
\text { and OMIM } \\
\text { number }\end{array}$ & $\begin{array}{l}\text { Protein } \\
\text { (mitochondrial } \\
\text { proteins indicated } \\
\text { by symbol }[\mathrm{M}] \text { ) }\end{array}$ & Key references & $\begin{array}{l}\text { Other allelic disease(s) (group } \\
\text { in this table) }\end{array}$ \\
\hline $\begin{array}{l}\text { Myotubular myopathy, } \\
\text { X-linked }\end{array}$ & 3.21 & $\mathrm{XR}$ & $\begin{array}{l}\text { CNMX } \\
310400\end{array}$ & $\mathrm{Xq} 28$ & $\begin{array}{l}\text { MTMI } \\
300415\end{array}$ & Myotubularin 1 & $\begin{array}{l}\text { Thomas et al. (1987) } \\
\text { Laporte (1996, 1997, } \\
\text { 2000) }\end{array}$ & \\
\hline Centronuclear myopathy 1 & 3.22 & $\mathrm{AD}$ & $\begin{array}{l}\text { CNM1 } \\
160150\end{array}$ & $19 \mathrm{p} 13.2$ & $\begin{array}{l}\text { DNM2 } \\
602378\end{array}$ & Dynamin 2 & Bitoun et al. (2005) & $\begin{array}{l}\text { allelic to CMD related to DNM2 } \\
\text { (group 2), CNM1 (group 4) and } \\
\text { CMTDIB (group 14) }\end{array}$ \\
\hline Centronuclear myopathy 2 & 3.23 & $\mathrm{AR}, \mathrm{AD}$ & $\begin{array}{l}\text { CNM2 } \\
255200\end{array}$ & $2 \mathrm{q} 14.3$ & $\begin{array}{l}\text { BINI } \\
601248\end{array}$ & $\begin{array}{l}\text { Bridging integrator } 1 \\
\text { (Amphiphysin) }\end{array}$ & $\begin{array}{l}\text { Nicot et al. (2007) Böhm } \\
\text { et al. (2014) }\end{array}$ & \\
\hline $\begin{array}{l}\text { Centronuclear myopathy } \\
\text { related to } R Y R I\end{array}$ & 3.24 & $\mathrm{AR}$ & & $19 \mathrm{q} 13.2$ & $\begin{array}{l}\text { RYRI } \\
180901\end{array}$ & Ryanodine receptor & Wilmshurst et al. (2010) & $\begin{array}{l}\text { allelic to CMD related to RYR1 } \\
\text { (group 2), CFTD, CCD, minicore } \\
\text { myopathy with external } \\
\text { ophthalmoplegia, CNMDU1 } \\
\text { (group 3), late onset axial } \\
\text { myopathy (group 5), MHS1 } \\
\text { (group 8) }\end{array}$ \\
\hline $\begin{array}{l}\text { Centronuclear myopathy } \\
\text { (CNM) related to } T T N\end{array}$ & 3.25 & $\mathrm{AR}$ & & $2 \mathrm{q} 31.2$ & $\begin{array}{l}\text { TTN } \\
188840\end{array}$ & Titin & $\begin{array}{l}\text { Ceyhan-Birsoy et al. } \\
\text { (2013) }\end{array}$ & $\begin{array}{l}\text { allelic to LGMDR10 (group 1), } \\
\text { MmD related to TTN (group 3), } \\
\text { SALMY (group 3), TMD (group } \\
\text { 4) HMERF (group 5), CMH9 } \\
\text { (group 10A), CMD1G (group } \\
\text { 10A) }\end{array}$ \\
\hline Centronuclear myopathy 5 & 3.26 & $\mathrm{AR}$ & $\begin{array}{l}\text { CNM5 } \\
615959\end{array}$ & $2 q 35$ & $\begin{array}{l}\text { SPEG } \\
615950\end{array}$ & SPEG complex locus & Agrawal et al. (2014) & \\
\hline Centronuclear myopathy 4 & 3.27 & $\mathrm{AD}$ & $\begin{array}{l}\text { CNM4 } \\
614807\end{array}$ & $16 \mathrm{p} 13.3$ & $\begin{array}{l}\text { CCDC78 } \\
614666\end{array}$ & $\begin{array}{l}\text { Coiled-coil } \\
\text { domain-containing } \\
\text { protein } 78\end{array}$ & Majczenko et al. (2012) & \\
\hline $\begin{array}{l}\text { Central core disease, } \\
\text { dominant }\end{array}$ & 3.28 & $\mathrm{AD}$ & $\begin{array}{l}\text { CCD } \\
117000\end{array}$ & $19 \mathrm{q} 13.2$ & $\begin{array}{l}\text { RYRI } \\
180901\end{array}$ & Ryanodine receptor & $\begin{array}{l}\text { Kausch et al. (1991) } \\
\text { Zhang et al. (1993) } \\
\text { Quane et al. (1993) } \\
\text { Robinson et al. (2002) }\end{array}$ & $\begin{array}{l}\text { allelic to CMD related to RYR1 } \\
\text { (group 2), CFTD, CNM related to } \\
\text { RYR1, minicore myopathy with } \\
\text { external ophthalmoplegia, } \\
\text { CNMDU1 (group 3), late onset } \\
\text { axial myopathy (group 5), MHS1 } \\
\text { (group 8) }\end{array}$ \\
\hline $\begin{array}{l}\text { Central core disease, } \\
\text { recessive (transient } \\
\text { multiminicore myopathy) }\end{array}$ & 3.29 & $\mathrm{AR}$ & $\begin{array}{l}\text { CCD } \\
117000\end{array}$ & $19 \mathrm{q} 13.2$ & $\begin{array}{l}\text { RYR1 } \\
180901\end{array}$ & Ryanodine receptor & $\begin{array}{l}\text { Ferreiro et al. (2002a) } \\
\text { Jungbluth et al. (2002) }\end{array}$ & $\begin{array}{l}\text { allelic to CMD related to RYR1 } \\
\text { (group 2), CFTD, CNM related to } \\
\text { RYR1, minicore myopathy with } \\
\text { external ophthalmoplegia, } \\
\text { CNMDU1 (group 3), late onset } \\
\text { axial myopathy (group 5), MHS1 } \\
\text { (group 8) }\end{array}$ \\
\hline $\begin{array}{l}\text { Minicore myopathy with } \\
\text { external ophthalmoplegia }\end{array}$ & 3.30 & $\mathrm{AR}$ & 255320 & $19 \mathrm{q} 13.2$ & $\begin{array}{l}\text { RYRI } \\
180901\end{array}$ & Ryanodine receptor & $\begin{array}{l}\text { Monnier et al. (2003) } \\
\text { Jungbluth et al. (2005) }\end{array}$ & $\begin{array}{l}\text { allelic to CMD related to RYR1 } \\
\text { (group 2), CFTD, CNM related to } \\
\text { RYR1, CCD, CNMDU1 (group } \\
\text { 3), late onset axial myopathy } \\
\text { (group 5), MHS1 (group 8) }\end{array}$ \\
\hline $\begin{array}{l}\text { Multiminicore disease, } \\
\text { classical form }\end{array}$ & 3.31 & AR & 255320 & $1 \mathrm{p} 36.11$ & $\begin{array}{l}\text { SELENON } \\
\text { (formerly } \\
\text { SEPN1) } 606210\end{array}$ & Selenoprotein N & $\begin{array}{l}\text { Ferreiro et al. (2002) } \\
\text { Ferreiro et al. (2004) }\end{array}$ & $\begin{array}{l}\text { allelic to Rigid spine syndrome } \\
\text { (group 2), CFTD (group 3), } \\
\text { desmin related myopathy with } \\
\text { Mallory bodies (group 5) }\end{array}$ \\
\hline $\begin{array}{l}\text { Multiminicore disease } \\
\text { (MmD) related to } T T N\end{array}$ & 3.32 & AR & & $2 \mathrm{q} 31.2$ & $\begin{array}{l}\text { TTN } \\
188840\end{array}$ & Titin & Ge et al. (2019) & $\begin{array}{l}\text { allelic to LGMDR10 (group 1), } \\
\text { CNM related to TTN (group 3), } \\
\text { SALMY (group 3), TMD } \\
\text { (group 4) HMERF (group 5), } \\
\text { CMH9 (group 10A), CMD1G } \\
\text { (group 10A) }\end{array}$ \\
\hline $\begin{array}{l}\text { Early onset myopathy, } \\
\text { areflexia, respiratory distress } \\
\text { and dysphagia }\end{array}$ & 3.33 & $\mathrm{AR}$ & $\begin{array}{l}\text { EMARDD } \\
614399\end{array}$ & $5 q 23.2$ & $\begin{array}{l}\text { MEGF10 } \\
612453\end{array}$ & $\begin{array}{l}\text { Multiple } \\
\text { EGF-like-domains } 10\end{array}$ & Logan et al. (2011) & $\begin{array}{l}\text { Allelic to recessive congenital } \\
\text { myopathy with minicores (group } \\
\text { 3) }\end{array}$ \\
\hline $\begin{array}{l}\text { Recessive congenital } \\
\text { myopathy with minicores }\end{array}$ & 3.34 & $\mathrm{AR}$ & $\begin{array}{l}\text { EMARDD } \\
614399\end{array}$ & $5 \mathrm{q} 23.2$ & $\begin{array}{l}\text { MEGF10 } \\
612453\end{array}$ & $\begin{array}{l}\text { Multiple } \\
\text { EGF-like-domains } 10\end{array}$ & Boyden et al. (2012) & Allelic to EMARDD (group 3) \\
\hline $\begin{array}{l}\text { Myopathy, myosin storage, } \\
\text { autosomal dominant }\end{array}$ & 3.35 & $\mathrm{AD}$ & $\begin{array}{l}\text { MSMA } \\
608358\end{array}$ & $14 \mathrm{q} 11.2$ & $\begin{array}{l}\text { МYH7 } \\
160760\end{array}$ & $\begin{array}{l}\text { Myosin, heavy chain } \\
7 \text {, cardiac muscle, } \\
\text { beta }\end{array}$ & $\begin{array}{l}\text { Tajsharghi et al. (2003) } \\
\text { Bohlega et al. (2004) } \\
\text { Laing et al. (2005) }\end{array}$ & $\begin{array}{l}\text { allelic to CFTD and MSMB } \\
\text { (group 3), MPD1 (group 4), } \\
\text { CMH1, CMD1S and LVNC5 } \\
\text { (group 10A) }\end{array}$ \\
\hline $\begin{array}{l}\text { Myopathy, myosin storage, } \\
\text { autosomal recessive }\end{array}$ & 3.36 & $\mathrm{AR}$ & $\begin{array}{l}\text { MSMB } \\
255160\end{array}$ & $14 \mathrm{q} 11.2$ & $\begin{array}{l}\text { МYH7 } \\
160780\end{array}$ & $\begin{array}{l}\text { Myosin, heavy chain } \\
7 \text {, cardiac muscle, } \\
\text { beta }\end{array}$ & $\begin{array}{l}\text { Onengut et al. (2004) } \\
\text { Tajsharghi et al. (2007) } \\
\text { Yuceyar et al. (2015) }\end{array}$ & $\begin{array}{l}\text { allelic to CFTD and MSMA } \\
\text { (group 3), MPD1 (group 4), } \\
\text { CMH1, CMD1S and LVNC5 } \\
\text { (group 10A) }\end{array}$ \\
\hline $\begin{array}{l}\text { Myopathy, proximal, and } \\
\text { ophthalmoplegia (inclusion } \\
\text { body myopathy 3) }\end{array}$ & 3.37 & $\mathrm{AD}, \mathrm{AR}$ & $\begin{array}{l}\text { MYPOP } \\
605637\end{array}$ & $17 \mathrm{p} 13.1$ & $\begin{array}{l}\text { MYH2 } \\
160740\end{array}$ & $\begin{array}{l}\text { Myosin, heavy chain } \\
2 \text {, skeletal muscle, } \\
\text { adult }\end{array}$ & $\begin{array}{l}\text { Martinsson et al. (1999, } \\
\text { 2000) Tajsharghi et al. } \\
\text { (2010) }\end{array}$ & \\
\hline $\begin{array}{l}\text { Isolated inclusion body } \\
\text { myopathy }\end{array}$ & 3.38 & $\mathrm{AD}$ & $\begin{array}{l}\text { IBMPFD3 } \\
615424\end{array}$ & $12 \mathrm{q} 13.13$ & $\begin{array}{l}\text { HNRNPAI } \\
164017\end{array}$ & $\begin{array}{l}\text { Heterogeneous } \\
\text { nuclear } \\
\text { ribonucleoprotein A1 }\end{array}$ & Izumi et al. (2015) & allelic to ALS20 (group 12) \\
\hline
\end{tabular}




\begin{tabular}{|c|c|c|c|c|c|c|c|c|}
\hline DISEASE NAME & $\begin{array}{l}\text { Item line } \\
\text { in this } \\
\text { group }\end{array}$ & Inheritance & $\begin{array}{l}\text { Locus or } \\
\text { disease symbol } \\
\text { and OMIM } \\
\text { number }\end{array}$ & Chromosome & $\begin{array}{l}\text { Gene symbol } \\
\text { and OMIM } \\
\text { number }\end{array}$ & $\begin{array}{l}\text { Protein } \\
\text { (mitochondrial } \\
\text { proteins indicated } \\
\text { by symbol }[\mathrm{M}] \text { ) }\end{array}$ & Key references & $\begin{array}{l}\text { Other allelic disease(s) (group } \\
\text { in this table) }\end{array}$ \\
\hline Cap myopathy CAPM1 & 3.39 & $\mathrm{AD}$ & $\begin{array}{l}\text { NEM1 } \\
609284\end{array}$ & $1 \mathrm{q} 21.3$ & $\begin{array}{l}\text { TPM3 } \\
191030\end{array}$ & Tropomysosin 3 & $\begin{array}{l}\text { De Paula et al. (2009) } \\
\text { Ohlsson et al. (2009) }\end{array}$ & allelic to NEM1, CFTD (group 3) \\
\hline Cap myopathy CAPM2 & 3.40 & $\mathrm{AD}$ & $\begin{array}{l}\text { NEM4 } \\
609285\end{array}$ & $9 \mathrm{p} 13.3$ & $\begin{array}{l}\text { TPM2 } \\
190990\end{array}$ & Tropomyosin 2, beta & $\begin{array}{l}\text { Tajsharghi et al. (2007) } \\
\text { Lehtokari et al. (2007) }\end{array}$ & $\begin{array}{l}\text { allelic to NEM4 (group 3), DA1A } \\
\text { and DA2B (group 16) }\end{array}$ \\
\hline Cap myopathy & 3.41 & $\mathrm{AD}$ & & $1 \mathrm{q} 42.13$ & $\begin{array}{l}\text { ACTAI } \\
102610\end{array}$ & $\begin{array}{l}\text { Actin, alpha 1, } \\
\text { skeletal muscle }\end{array}$ & Hung et al. (2010) & $\begin{array}{l}\text { allelic to CMD with rigid spine } \\
\text { (group 2), CFTD and NEM3 } \\
\text { (group 3) }\end{array}$ \\
\hline $\begin{array}{l}\text { Congenital neuromuscular } \\
\text { disease with uniform type } 1 \\
\text { fiber (CNMDU1) }\end{array}$ & 3.42 & $\mathrm{AR}, \mathrm{AD}$ & $\begin{array}{l}\mathrm{CCD} \\
117000\end{array}$ & $19 \mathrm{q} 13.2$ & $\begin{array}{l}\text { RYRI } \\
180901\end{array}$ & Ryanodine receptor I & Sato et al. (2007) & $\begin{array}{l}\text { allelic to CMD related to RYR1 } \\
\text { (group 2), CFTD, CNM related to } \\
\text { RYR1, CCD, minicore myopathy } \\
\text { with external ophthalmoplegia } \\
\text { (group 3), late onset axial } \\
\text { myopathy (group 5), MHS1 } \\
\text { (group 8) }\end{array}$ \\
\hline $\begin{array}{l}\text { Salih myopathy, (Congenital } \\
\text { myopathy with fatal } \\
\text { cardiomyopathy) }\end{array}$ & 3.43 & $\mathrm{AR}$ & $\begin{array}{l}\text { SALMY } \\
611705\end{array}$ & $2 \mathrm{q} 31.2$ & $\begin{array}{l}\text { TTN } \\
188840\end{array}$ & Titin & Carmignac et al. (2007) & $\begin{array}{l}\text { Allelic to LGMDR10 (group 1), } \\
\text { CNM related to TTN \& MmD } \\
\text { related to TTN (group 3), TMD } \\
\text { (group 4), HMERF (group 5), } \\
\text { CMH9 (group 10A), CMD1G } \\
\text { (group 10A) }\end{array}$ \\
\hline $\begin{array}{l}\text { Congenital skeletal } \\
\text { myopathy and fatal } \\
\text { cardiomyopathy }\end{array}$ & 3.44 & $\mathrm{AR}$ & & $11 \mathrm{p} 11.2$ & $\begin{array}{l}\text { MYBPC3 } \\
600958\end{array}$ & $\begin{array}{l}\text { Cardiac myosin } \\
\text { binding protein-C }\end{array}$ & Tajsharghi et al. (2010) & $\begin{array}{l}\text { allelic to CMH4, CMD1MM and } \\
\text { LVNC10 (group 10) }\end{array}$ \\
\hline $\begin{array}{l}\text { Congenital myopathy } \\
\text { Compton-North }\end{array}$ & 3.45 & $\mathrm{AR}$ & $\begin{array}{l}\text { MYPCN } \\
612540\end{array}$ & $12 \mathrm{q} 12$ & $\begin{array}{l}\text { CNTN1 } \\
600016\end{array}$ & Contactin-1 & Compton et al. (2008) & \\
\hline Sarcotubular myopathy & 3.46 & $\mathrm{AR}$ & & $9 \mathrm{q} 33.1$ & $\begin{array}{l}\text { TRIM32 } \\
602290\end{array}$ & $\begin{array}{l}\text { Tripartite motif } \\
\text { containing } 32\end{array}$ & Schoser et al. (2005) & allelic to LGMDR8 (group 1) \\
\hline $\begin{array}{l}\text { Congenital myopathy related } \\
\text { to PTPLA }\end{array}$ & 3.47 & $\mathrm{AR}$ & & $10 \mathrm{p} 12.33$ & $\begin{array}{l}\text { HACD1 } \\
(=P T P L A) \\
610467\end{array}$ & $\begin{array}{l}\text { 3-Hydroxyacyl-CoA } \\
\text { dehydratase (Protein } \\
\text { tyrosine } \\
\text { phosphatase-like) }\end{array}$ & Muhammad et al. (2013) & allelic to ARVD6 (group 10B) \\
\hline $\begin{array}{l}\text { Congenital myopathy with } \\
\text { ophthalmoplegia related to } \\
\text { CACNAIS }\end{array}$ & 3.48 & $\mathrm{AR}$ & & $1 \mathrm{q} 32.1$ & $\begin{array}{l}\text { CACNA1S } \\
114208\end{array}$ & $\begin{array}{l}\text { Calcium } \\
\text { channel,voltage- } \\
\text { dependent, L type, } \\
\text { alpha 1S subunit }\end{array}$ & Hunter et al. (2015) & $\begin{array}{l}\text { Allelic to HOKPP1 (group 7) } \\
\text { MHS5 (group 8) }\end{array}$ \\
\hline $\begin{array}{l}\text { Congenital myopathy with } \\
\text { neuropathy and deafness }\end{array}$ & 3.49 & $\mathrm{AR}$ & $\begin{array}{l}\text { NEDHND } \\
617519\end{array}$ & $19 \mathrm{q} 13.2$ & $\begin{array}{l}\text { SPTBN4 } \\
606214\end{array}$ & $\begin{array}{l}\text { Spectrin, beta, } \\
\text { nonerythrocytic, } 4\end{array}$ & Knierim et al. (2017) & \\
\hline $\begin{array}{l}\text { Myopathy, congenital, with } \\
\text { excess of muscle spindles }\end{array}$ & 3.50 & $\mathrm{AD}$ & $\begin{array}{l}\text { CMEMS } \\
218040\end{array}$ & $11 \mathrm{p} 15.5$ & $\begin{array}{l}\text { HRAS } \\
190020\end{array}$ & $\begin{array}{l}\text { V-Ha-RAS Harvey } \\
\text { rat sarcoma viral } \\
\text { oncogene homolog }\end{array}$ & Quélin et al. (2017) & \\
\hline $\begin{array}{l}\text { Carey-Fineman-Ziter } \\
\text { syndrome (formerly } \\
\text { congenital myopathy with } \\
\text { Moebius sequence and } \\
\text { Robin sequence) }\end{array}$ & 3.51 & $\mathrm{AR}$ & $\begin{array}{l}\text { CFZS } \\
254940\end{array}$ & $9 \mathrm{q} 34.2$ & $\begin{array}{l}\text { MYMK } \\
615345\end{array}$ & Myomaker & Di Gioia et al. (2017) & \\
\hline $\begin{array}{l}\text { Myopathy, congenital, } \\
\text { Baily-Bloch (Native } \\
\text { American myopathy) }\end{array}$ & 3.52 & $\mathrm{AR}$ & $\begin{array}{l}\text { MYPBB } \\
255995\end{array}$ & $12 \mathrm{q} 13.3$ & $\begin{array}{l}\text { STAC3 } \\
615521\end{array}$ & $\begin{array}{l}\text { SH3 and } \\
\text { cysteine-rich domains } \\
3\end{array}$ & Horstick et al. (2013) & $\begin{array}{l}\text { Allelic to Myopathy, congenital, } \\
\text { with malignant hyperthermia } \\
\text { susceptibility (group 3) }\end{array}$ \\
\hline $\begin{array}{l}\text { Myopathy, congenital, with } \\
\text { malignant hyperthermia } \\
\text { susceptibility }\end{array}$ & 3.53 & AR & & $12 \mathrm{q} 13.3$ & $\begin{array}{l}\text { STAC3 } \\
615521\end{array}$ & $\begin{array}{l}\text { SH3 and } \\
\text { cysteine-rich domains } \\
3\end{array}$ & Zaharieva et al. (2018) & Allelic to MYPBB (group 3) \\
\hline $\begin{array}{l}\text { Myopathy congenital related } \\
\text { to ACTN2 }\end{array}$ & 3.54 & $\mathrm{AD}$ & & $1 \mathrm{q} 43$ & $\begin{array}{l}A C T N 2 \\
102573\end{array}$ & Actinin, alpha 2 & Lornage et al. (2019) & $\begin{array}{l}\text { Allelic to } \mathrm{CMH} 23 \text { and } \\
\text { CMD1AA (group 10A) }\end{array}$ \\
\hline $\begin{array}{l}\text { Myopathy congenital with } \\
\text { fast twitch (type II) fiber } \\
\text { atrophy }\end{array}$ & 3.55 & $\mathrm{AR}$ & $\begin{array}{l}\text { MYOFTA } \\
618414\end{array}$ & $2 q 34$ & $\begin{array}{l}\text { MYLI } \\
160780\end{array}$ & $\begin{array}{l}\text { Myosin, light } \\
\text { polypeptide } 1 \text {, alkali, } \\
\text { skeletal fast }\end{array}$ & Ravenscroft et al. (2018) & \\
\hline Congenital amyotrophy & 3.56 & $\mathrm{AR}$ & & $16 \mathrm{p} 13.3$ & $\begin{array}{l}\text { CACNA1H } \\
607904\end{array}$ & $\begin{array}{l}\text { Calcium channel, } \\
\text { voltage-dependent, T } \\
\text { type, aplpha-1H } \\
\text { subunit }\end{array}$ & Carter et al. (2019) & \\
\hline $\begin{array}{l}\text { Congenital multi-minicore } \\
\text { myopathy }\end{array}$ & 3.57 & $\mathrm{AR}$ & & $3 q 26.33$ & $\begin{array}{l}\text { FXR1 } \\
600819\end{array}$ & $\begin{array}{l}\text { FMR1 autosomal } \\
\text { homolog }\end{array}$ & Estan et al. (2019) & \\
\hline $\begin{array}{l}\text { Congenital Myopathy related } \\
\text { to PAX7 }\end{array}$ & 3.58 & $\mathrm{AR}$ & & $1 \mathrm{p} 36.13$ & $\begin{array}{l}\text { PAX7 } \\
167410\end{array}$ & Paired Box gene 7 & Feichtinger et al. (2019) & \\
\hline $\begin{array}{l}\text { Congenital Myopathy related } \\
\text { to } S C N 4 A\end{array}$ & 3.59 & $\mathrm{AR}$ & & $17 \mathrm{q} 23.3$ & $\begin{array}{l}\text { SCN4A } \\
603967\end{array}$ & $\begin{array}{l}\text { Sodium channel, } \\
\text { voltage-gated, type } \\
\text { IV, alpha subunit }\end{array}$ & $\begin{array}{l}\text { Zaharieva et al. (2016) } \\
\text { Gonorazky et al. (2017) } \\
\text { Sloth et al. (2018) }\end{array}$ & $\begin{array}{l}\text { allelic to HYPP, HOKPP2, PMC } \\
\text { and K-aggravated myotonia } \\
\text { (group 7), CMS16 (group 11), } \\
\text { Severe foetal hypokinesia related } \\
\text { to } S C N 4 A \text { (group 16) }\end{array}$ \\
\hline $\begin{array}{l}\text { Congenital Myopathy related } \\
\text { to } P Y R O X D I\end{array}$ & 3.60 & $\mathrm{AR}$ & & $12 \mathrm{p} 12.1$ & $\begin{array}{l}\text { PYROXD1 } \\
617220\end{array}$ & $\begin{array}{l}\text { Pyridine } \\
\text { nucleotide-disulphide } \\
\text { oxidoreductase } \\
\text { domain } 1\end{array}$ & Lornage et al. (2019) & $\begin{array}{l}\text { allelic to LGMD related to } \\
\text { PYROXD1 (group 1) and } \\
\text { MMF8 (group 5) }\end{array}$ \\
\hline $\begin{array}{l}\text { Congenital Myopathy related } \\
\text { to } T N P O 3\end{array}$ & 3.61 & $\mathrm{AD}$ & & $7 q 32.1$ & $\begin{array}{l}\text { TNPO3 } \\
610032\end{array}$ & Transportin 3 & $\begin{array}{l}\text { Vihola et al. (2019) } \\
\text { Angelini et al. (2019) }\end{array}$ & allelic to LGMDD2 (group 1) \\
\hline
\end{tabular}




\begin{tabular}{|c|c|c|c|c|c|c|c|c|}
\hline DISEASE NAME & $\begin{array}{l}\text { Item line } \\
\text { in this } \\
\text { group }\end{array}$ & Inheritance & $\begin{array}{l}\text { Locus or } \\
\text { disease symbol } \\
\text { and OMIM } \\
\text { number }\end{array}$ & Chromosome & $\begin{array}{l}\text { Gene symbol } \\
\text { and OMIM } \\
\text { number }\end{array}$ & $\begin{array}{l}\text { Protein } \\
\text { (mitochondrial } \\
\text { proteins indicated } \\
\text { by symbol }[\mathrm{M}] \text { ) }\end{array}$ & Key references & $\begin{array}{l}\text { Other allelic disease(s) (group } \\
\text { in this table) }\end{array}$ \\
\hline \multicolumn{9}{|c|}{ GROUP 4. DISTAL MYOPATHIES } \\
\hline $\begin{array}{l}\text { Distal recessive myopathy } \\
\text { (Miyoshi) }\end{array}$ & 4.1 & $\mathrm{AR}$ & $\begin{array}{l}\text { MMD1 } \\
254130\end{array}$ & $2 \mathrm{p} 13.2$ & $\begin{array}{l}\text { DYSF } \\
603009\end{array}$ & Dysferlin & $\begin{array}{l}\text { Bejaoui et al. (1995) } \\
\text { Bashir et al. (1998) Liu } \\
\text { et al. (1998) }\end{array}$ & allelic to LGMDR2 (group 1) \\
\hline $\begin{array}{l}\text { Tibial muscular dystrophy } \\
\text { (Udd) }\end{array}$ & 4.2 & $\mathrm{AD}$ & $\begin{array}{l}\text { TMD } \\
600334\end{array}$ & $2 \mathrm{q} 31.2$ & $\begin{array}{l}\text { TTN } \\
188840\end{array}$ & Titin & $\begin{array}{l}\text { Haravuori et al. (1998, } \\
\text { 2001) Hackman et al. } \\
(2002)\end{array}$ & $\begin{array}{l}\text { allelic to LGMDR10 (group 1), } \\
\text { CNM related to } T T N \text { and } \\
\text { SALMY (group 3), HMERF } \\
\text { (group 5), CMH9 (group 10A), } \\
\text { CMD1G (group 10A) }\end{array}$ \\
\hline $\begin{array}{l}\text { Distal myopathy with } \\
\text { rimmed vacuoles (Nonaka) } \\
\text { and Hereditary inclusion } \\
\text { body myopathy }\end{array}$ & 4.3 & $\mathrm{AR}$ & $\begin{array}{l}\text { NM } \\
605820\end{array}$ & $9 \mathrm{p} 13.3$ & $\begin{array}{l}\text { GNE } \\
603824\end{array}$ & $\begin{array}{l}\text { Glucosamine } \\
\text { (UDP-N-acetyl)-2- } \\
\text { epimerase/N-acetyl } \\
\text { mannosamine kinase }\end{array}$ & $\begin{array}{l}\text { Mitrani-Rosenbaum et al. } \\
\text { (1996) Ikeuchi et al. } \\
\text { (1997) Eisenberg et al. } \\
\text { (2001) }\end{array}$ & \\
\hline Distal myopathy 1 (Laing) & 4.4 & $\mathrm{AD}$ & $\begin{array}{l}\text { MPD1 } \\
160500\end{array}$ & $14 \mathrm{q} 11.2$ & $\begin{array}{l}\text { MYH7 } \\
160760\end{array}$ & $\begin{array}{l}\text { Myosin, heavy chain } \\
7 \text {, cardiac muscle, } \\
\text { beta }\end{array}$ & $\begin{array}{l}\text { Laing et al. (1995) } \\
\text { Mastaglia et al. (2000) } \\
\text { Meredith et al. (2004) }\end{array}$ & $\begin{array}{l}\text { allelic to CFTD, MSMA and } \\
\text { MSMB (group 3), CMH1, } \\
\text { CMD1S and LVNC5 (group 10A) }\end{array}$ \\
\hline $\begin{array}{l}\text { Vocal cord and pharyngeal } \\
\text { distal myopathy }\end{array}$ & 4.5 & $\mathrm{AD}$ & $\begin{array}{l}\text { ALS21 } \\
606070\end{array}$ & $5 \mathrm{q} 31.2$ & $\begin{array}{l}\text { MATR3 } \\
164015\end{array}$ & Matrin 3 & $\begin{array}{l}\text { Feit et al. (1998) } \\
\text { Senderek et al. (2009) }\end{array}$ & Allelic to ALS21 (group 12) \\
\hline Myopathy distal 3 & 4.6 & $\mathrm{AD}$ & $\begin{array}{l}\text { MPD3 } \\
610099\end{array}$ & $8 \mathrm{p} 22-\mathrm{q} 11$ & $?$ & & Haravuori et al. (2004) & \\
\hline Welander distal myopathy & 4.7 & $\mathrm{AD}$ & $\begin{array}{l}\text { WDM } \\
604454\end{array}$ & $2 \mathrm{p} 13.3$ & $\begin{array}{l}\text { TIA1 } \\
603518\end{array}$ & $\begin{array}{l}\text { Cytotoxic } \\
\text { granule-associated } \\
\text { RNA binding protein }\end{array}$ & $\begin{array}{l}\text { Ahlberg et al. (1999) } \\
\text { Hackman et al. (2013) } \\
\text { Klar et al. (2013) }\end{array}$ & \\
\hline $\begin{array}{l}\text { Distal myopathy with pes } \\
\text { cavus and areflexia } \\
\text { (Vacuolar neuromyopathy) }\end{array}$ & 4.8 & $\mathrm{AD}$ & 601846 & $19 \mathrm{p} 13.3$ & $?$ & & Servidei et al. (1999) & \\
\hline $\begin{array}{l}\text { Distal myopathy with } \\
\text { myotilin defect }\end{array}$ & 4.9 & $\mathrm{AD}$ & & $5 \mathrm{q} 31.2$ & $\begin{array}{l}\text { MYOT } \\
604103\end{array}$ & Myotilin & $\begin{array}{l}\text { Penisson-Besnier et al. } \\
(1998,2006)\end{array}$ & $\begin{array}{l}\text { allelic to formerly LGMD1A } \\
\text { (group 1), MFM3 (group 5), } \\
\text { spheroid body myopathy } \\
\text { (group 5) }\end{array}$ \\
\hline $\begin{array}{l}\text { Distal myopathy with } \\
\text { nebulin defect }\end{array}$ & 4.10 & $\mathrm{AR}$ & & $2 \mathrm{q} 23.3$ & $\begin{array}{l}\text { NEB } \\
161650\end{array}$ & Nebulin & $\begin{array}{l}\text { Wallgren-Pettersson et al. } \\
\text { (2007) }\end{array}$ & allelic to NEM2 (group 3) \\
\hline $\begin{array}{l}\text { Distal myopathy, Tateyama } \\
\text { type }\end{array}$ & 4.11 & $\mathrm{AD}$ & $\begin{array}{l}\text { MPDT } \\
614321\end{array}$ & $3 \mathrm{p} 25.3$ & $\begin{array}{l}\text { CAV3 } \\
601253\end{array}$ & Caveolin-3 & $\begin{array}{l}\text { Tateyama et al. (2002) } \\
\text { Fulizio et al. (2005) }\end{array}$ & $\begin{array}{l}\text { allelic to formerly LGMD1C } \\
\text { (group 1), hyper CKemia (group } \\
\text { 5), RMD2 (group 6), CMH } \\
\text { (group 10A) and LQT9 (group } \\
\text { 10B) }\end{array}$ \\
\hline $\begin{array}{l}\text { Late onset distal myopathy } \\
\text { (Markesbery-Griggs) }\end{array}$ & 4.12 & $\mathrm{AD}$ & & $10 \mathrm{q} 23.2$ & $\begin{array}{l}\text { LDB3 } \\
605906\end{array}$ & $\begin{array}{l}\text { LIM domain } \\
\text { binding-3 }\end{array}$ & Griggs et al. (2007) & $\begin{array}{l}\text { allelic to MFM4 (group 5), } \\
\text { CMD1C, CMH24 and LVNC3 } \\
\text { (group 10A) }\end{array}$ \\
\hline $\begin{array}{l}\text { Miyoshi muscular dystrophy } \\
3\end{array}$ & 4.13 & $\mathrm{AR}$ & $\begin{array}{l}\text { MMD3 } \\
613319\end{array}$ & $11 \mathrm{p} 14.3$ & $\begin{array}{l}\text { AN05 } \\
608662\end{array}$ & Anoctamin 5 & Bolduc et al. (2010) & allelic to LGMDR12 (group 1) \\
\hline $\begin{array}{l}\text { Dynamin } 2 \text { related distal } \\
\text { myopathy }\end{array}$ & 4.14 & $\mathrm{AD}$ & $\begin{array}{l}\text { CNM1 } \\
160150\end{array}$ & $19 \mathrm{p} 13.2$ & $\begin{array}{l}\text { DNM2 } \\
602378\end{array}$ & Dynamin 2 & Fischer et al. (2006) & $\begin{array}{l}\text { allelic to CMD related to } \\
D N M 2 \text { (group 2), CNM1 (group 3) } \\
\text { and CMTDIB (group 14) }\end{array}$ \\
\hline $\begin{array}{l}\text { Early onset distal myopathy } \\
\text { with } K L H L 9 \text { defect }\end{array}$ & 4.15 & $\mathrm{AD}$ & & $9 \mathrm{p} 21.3$ & $\begin{array}{l}\text { KLHL9 } \\
611201\end{array}$ & Kelch-like 9 & Cirak et al. (2010) & \\
\hline Distal Myopathy 4 & 4.16 & $\mathrm{AD}$ & $\begin{array}{l}\text { MPD4 } \\
614065\end{array}$ & $7 \mathrm{q} 32.1$ & $\begin{array}{l}\boldsymbol{F L N C} \\
102565\end{array}$ & Filamin C (gamma) & Duff et al. (2011) & $\begin{array}{l}\text { allelic to MFM5 (group 5), } \\
\text { CMH26 and RCM4 (group 10A) }\end{array}$ \\
\hline $\begin{array}{l}\text { Inclusion body myopathy } \\
\text { with early-onset Paget } \\
\text { disease with or without } \\
\text { frontotemporal dementia } 1\end{array}$ & 4.17 & $\mathrm{AD}$ & $\begin{array}{l}\text { IBMPFD1 } \\
167320\end{array}$ & $9 \mathrm{p} 13.3$ & $\begin{array}{l}\boldsymbol{V C P} \\
601023\end{array}$ & $\begin{array}{l}\text { Valosin-containing } \\
\text { protein }\end{array}$ & Palmio et al. (2011) & $\begin{array}{l}\text { allelic to scapuloperoneal } \\
\text { myoathy (group 1), IBMBFD1 } \\
\text { (group 5), ALS14 (group 12) and } \\
\text { CMT2Y (group 14) }\end{array}$ \\
\hline Distal myopathy 5 & 4.18 & $\mathrm{AR}$ & $\begin{array}{l}\text { MPD5 } \\
617030\end{array}$ & $14 \mathrm{q} 32.33$ & $\begin{array}{l}\text { ADSSL1 } \\
612498\end{array}$ & $\begin{array}{l}\text { Adenylosuccinate } \\
\text { synthase-like }\end{array}$ & Park et al. (2016) & \\
\hline $\begin{array}{l}\text { Myopathy, distal, with } \\
\text { rimmed vacuoles }\end{array}$ & 4.19 & $\mathrm{AD}$ & $\begin{array}{l}\text { DMRV } \\
617158\end{array}$ & $5 q 35.3$ & $\begin{array}{l}\text { SQSTM1 } \\
601530\end{array}$ & Sequestosome 1 & Bucelli et al. (2015) & allelic to FTDALS3 (group 12) \\
\hline $\begin{array}{l}\text { Myopathy, distal, with } \\
\text { rimmed vacuoles }\end{array}$ & 4.20 & $\mathrm{AD}$ & & $7 \mathrm{q} 36.3$ & $\begin{array}{l}\text { DNAJB6 } \\
611332\end{array}$ & $\begin{array}{l}\text { Hsp40 homologue, } \\
\text { subfamily B, number } \\
6\end{array}$ & Ruggieri et al. (2015) & allelic to LGMDD1 (group 1) \\
\hline Rimmed vacuole myopathy & 4.21 & $\mathrm{AD}$ & & $12 q 24.23$ & $\begin{array}{l}\text { HSPB8 } \\
608014\end{array}$ & $\begin{array}{l}\text { Heat-shock } 22 \mathrm{kD} \\
\text { protein } 8\end{array}$ & Al-Tahan et al. (2019) & $\begin{array}{l}\text { Allelic to HMN2A (group 12) } \\
\text { and CMT2L (group 14) }\end{array}$ \\
\hline
\end{tabular}

\section{GROUP 5, OTHER MYOPATHIES}

Myofibrillar myopathies

Myofibrillar myopathy 1

$5.1 \quad \mathrm{AD}$

MFM1

$2 \mathrm{q} 35$

DES

125660

MFM2
608810
$11 \mathrm{q} 23.1$

CRYAB

123590
Myofibrillar myopathy 2
$\mathrm{AD}$
Goldfarb et al. (1998) Munoz-Marmol et al. (1998)
Desmin

Alpha-B crystallin

(1)

Vicart et al. (1998) Selcen et al. (2003) allelic to formerly LGMD1 related to $D E S$ and formerly LGM2R (group1), CMD1I (group $10 \mathrm{~A})$ and ARVC7 (group 5 and 10B)

allelic to CMD1II (group 10A)

(continued on next page) 


\begin{tabular}{|c|c|c|c|c|c|c|c|c|}
\hline DISEASE NAME & $\begin{array}{l}\text { Item line } \\
\text { in this } \\
\text { group }\end{array}$ & Inheritance & $\begin{array}{l}\text { Locus or } \\
\text { disease symbol } \\
\text { and OMIM } \\
\text { number }\end{array}$ & Chromosome & $\begin{array}{l}\text { Gene symbol } \\
\text { and OMIM } \\
\text { number }\end{array}$ & $\begin{array}{l}\text { Protein } \\
\text { (mitochondrial } \\
\text { proteins indicated } \\
\text { by symbol }[\mathrm{M}] \text { ) }\end{array}$ & Key references & $\begin{array}{l}\text { Other allelic disease(s) (group } \\
\text { in this table) }\end{array}$ \\
\hline Myofibrillar myopathy 3 & 5.3 & $\mathrm{AD}$ & $\begin{array}{l}\text { MFM3 } \\
609200\end{array}$ & $5 \mathrm{q} 31.2$ & $\begin{array}{l}\text { МYOT } \\
604103\end{array}$ & Myotilin & Selcen and Engel (2004) & $\begin{array}{l}\text { allelic to formerly LGMD1A } \\
\text { (group 1), distal myotilinopathy } \\
\text { (group 4), spheroid body } \\
\text { myopathy (group 5) }\end{array}$ \\
\hline Spheroid body myopathy & 5.4 & $\mathrm{AD}$ & 182920 & $5 \mathrm{q} 31.2$ & $\begin{array}{l}\text { МYOT } \\
604103\end{array}$ & Myotilin & Foroud et al. (2005) & $\begin{array}{l}\text { allelic to formerly LGMD1A } \\
\text { (group 1), distal myotilinopathy } \\
\text { (group 4), MFM3 (group 5) }\end{array}$ \\
\hline Myofibrillar myopathy 4 & 5.5 & $\mathrm{AD}$ & $\begin{array}{l}\text { MFM4 } \\
609452\end{array}$ & $10 \mathrm{q} 23.2$ & $\begin{array}{l}\text { LDB3 } \\
605906\end{array}$ & $\begin{array}{l}\text { LIM domain } \\
\text { binding-3 }\end{array}$ & Selcen and Engel (2005) & $\begin{array}{l}\text { (group 4), CMD1C, CMH24 and } \\
\text { LVNC3 (group 10A) }\end{array}$ \\
\hline Myofibrillar myopathy 5 & 5.6 & $\mathrm{AD}$ & $\begin{array}{l}\text { MFM5 } \\
609524\end{array}$ & $7 \mathrm{q} 32.1$ & $\begin{array}{l}\text { FLNC } \\
102565\end{array}$ & Filamin C (gamma) & Vorgerd et al. (2005) & $\begin{array}{l}\text { allelic to MPD4 (group 4), } \\
\text { CMH26 and RCM5 (group 10A) }\end{array}$ \\
\hline Myofibrillar myopathy 6 & 5.7 & $\mathrm{AD}$ & $\begin{array}{l}\text { MFM6 } \\
612954\end{array}$ & $10 \mathrm{q} 26.11$ & $\begin{array}{l}\text { BAG3 } \\
603883\end{array}$ & $\begin{array}{l}\text { BCL2-associated } \\
\text { athanogene } 3\end{array}$ & Selcen et al. (2009) & $\begin{array}{l}\text { allelic to CMD1HH (group 10A) } \\
\text { and CMT related to BAG3 } \\
\text { (group 14) }\end{array}$ \\
\hline Myofibrillar myopathy 7 & 5.8 & $\mathrm{AR}$ & $\begin{array}{l}\text { MFM7 } \\
617114\end{array}$ & $3 \mathrm{q} 22.2$ & $\begin{array}{l}\boldsymbol{K Y} \\
605739\end{array}$ & $\begin{array}{l}\text { Kyphoscoliosis } \\
\text { peptidase }\end{array}$ & $\begin{array}{l}\text { Hedberg-Oldfors et al. } \\
\text { (2016) Straussberg et al. } \\
\text { (2016) }\end{array}$ & \\
\hline Myofibrillar myopathy 8 & 5.9 & $\mathrm{AR}$ & $\begin{array}{l}\text { MFM8 } \\
617258\end{array}$ & $12 \mathrm{p} 12.1$ & $\begin{array}{l}\text { PYROXD1 } \\
617220\end{array}$ & $\begin{array}{l}\text { Pyridine } \\
\text { nucleotide-disulphide } \\
\text { oxidoreductase } \\
\text { domain } 1\end{array}$ & O'Grady et al. (2016) & $\begin{array}{l}\text { allelic to Congenital Myopathy } \\
\text { related to PYROXD1 (group 3) \& } \\
\text { LGMD related to PYROXD1 } \\
\text { (group 1) }\end{array}$ \\
\hline $\begin{array}{l}\text { Myofibrillar myopathy } 9 \\
\text { with early respiratory failure }\end{array}$ & 5.10 & $\mathrm{AD}$ & $\begin{array}{l}\text { MFM9 } \\
\text { (HMERF) } \\
603689\end{array}$ & $2 \mathrm{q} 31.2$ & $\begin{array}{l}\text { TTN } \\
188840\end{array}$ & Titin & $\begin{array}{l}\text { Nicolao et al. (1999) } \\
\text { Lange et al. (2005) }\end{array}$ & $\begin{array}{l}\text { allelic to LGMDR10 (group 1), } \\
\text { CMN related to TTN (group3), } \\
\text { MmD related to TTN (group 3), } \\
\text { SALMY (group 3), TMD (group } \\
\text { 4), CMH9 (group 10A), CMD1G } \\
\text { (group 10A) }\end{array}$ \\
\hline $\begin{array}{l}\text { Desmin-related myopathy } \\
\text { with Mallory bodies }\end{array}$ & 5.11 & $\mathrm{AD}$ & $\begin{array}{l}\text { RSMD1 } \\
602771\end{array}$ & $1 \mathrm{p} 36.11$ & $\begin{array}{l}\text { SELENON } \\
\text { (formerly } \\
\text { SEPN1) } \\
606210\end{array}$ & Selenoprotein N & Ferreiro et al. (2004) & $\begin{array}{l}\text { allelic to Rigid spine syndrome } \\
\text { (group 2), CFTD (group 3) } \\
\text { multiminicore disease (group 3) }\end{array}$ \\
\hline $\begin{array}{l}\text { Cardiac and skeletal } \\
\text { aggregate myopathy }\end{array}$ & 5.12 & Digenic & & $\begin{array}{l}1 \mathrm{p} 36.11 \\
2 \mathrm{p} .23 .3\end{array}$ & $\begin{array}{l}\text { TRIM63 } \\
06131+ \\
\text { TRIM54 } \\
606474\end{array}$ & $\begin{array}{l}\text { Tripartite motif } \\
\text { containing } 63 \\
\text { (MURF1) + Ring } \\
\text { finger protein } 30 \\
\text { (MURF3) }\end{array}$ & Olivé et al. (2015) & \\
\hline $\begin{array}{l}\text { Myofibrillar myopathy with } \\
\text { arrhythmogenic right } \\
\text { ventricular cardiomyopathy } \\
\text { (ARCV7) also listed in } \\
\text { group 10B }\end{array}$ & 5.13 & $\mathrm{AD}$ & $\begin{array}{l}\text { MFM1 } \\
601419\end{array}$ & $10 \mathrm{q} 22>2 \mathrm{q} 35$ & $\begin{array}{l}\text { DES } \\
125660\end{array}$ & Desmin & $\begin{array}{l}\text { Melberg et al. (1999) } \\
\text { Kuhl et al. (2008) } \\
\text { Hedberg et al. (2012) }\end{array}$ & $\begin{array}{l}\text { allelic to formerly LGMD1 } \\
\text { related to } D E S \text { and formerly } \\
\text { LGM2R (group 1), MFM1 (group } \\
\text { 5), CMD1I (group 10A) and } \\
\text { ARVC7 (group 10B) }\end{array}$ \\
\hline \multicolumn{9}{|l|}{ Miscellaneous } \\
\hline Danon disease & 5.14 & $\mathrm{XD}$ & $\begin{array}{l}\text { GSD2B } \\
300257\end{array}$ & $\mathrm{Xq} 24$ & $\begin{array}{l}\text { LAMP2 } \\
309060\end{array}$ & $\begin{array}{l}\text { Lysosomal-associated } \\
\text { membrane protein } 2\end{array}$ & $\begin{array}{l}\text { Nishino et al. (2000) } \\
\text { Musumeci et al. (2005) }\end{array}$ & \\
\hline $\begin{array}{l}\text { Myopathy with excessive } \\
\text { autophagy }\end{array}$ & 5.15 & XR & $\begin{array}{l}\text { MEAX } \\
310440\end{array}$ & $\mathrm{Xq} 28$ & $\begin{array}{l}\text { VMA21 } \\
300913\end{array}$ & $\begin{array}{l}\text { S. Cerevisiae } \\
\text { homolog of VMA21 }\end{array}$ & $\begin{array}{l}\text { Saviranta et al. (1988) } \\
\text { Villard et al. (2000) } \\
\text { Minassian et al. (2002) } \\
\text { Munteanu et al. (2008) } \\
\text { Ramachandran et al. } \\
\text { (2013) Crockett et al. } \\
\text { (2014) }\end{array}$ & \\
\hline $\begin{array}{l}\text { Autophagic vacuolar } \\
\text { myopathy }\end{array}$ & 5.16 & $\mathrm{AR}$ & $\begin{array}{l}\text { CLN3 } \\
204200\end{array}$ & $16 \mathrm{p} 12.1$ & $\begin{array}{l}\text { CLN3 } \\
607042\end{array}$ & $\begin{array}{l}\text { Ceroid-lipofuscinosis, } \\
\text { neuronal } 3(= \\
\text { Battenin) }\end{array}$ & Cortese et al. (2014) & \\
\hline $\begin{array}{l}\text { Oculopharyngeal muscular } \\
\text { dystrophy }\end{array}$ & 5.17 & $\mathrm{AD}$ & $\begin{array}{l}\text { OPMD } \\
164300\end{array}$ & $14 q 11.2$ & $\begin{array}{l}\text { PABPN1 } \\
602279\end{array}$ & $\begin{array}{l}\text { Polyadenylate- } \\
\text { binding protein, } \\
\text { nuclear } 1\end{array}$ & $\begin{array}{l}\text { Brais et al. }(1995,1998) \\
\text { Robinson et al. }(2005)\end{array}$ & \\
\hline $\begin{array}{l}\text { Oculopharyngodistal } \\
\text { myopathy }\end{array}$ & 5.18 & $\mathrm{AD}$ & $\begin{array}{l}\text { OPDM } \\
164310\end{array}$ & $8 \mathrm{q} 22.3$ & $\begin{array}{l}\text { LRP12 } \\
618299\end{array}$ & $\begin{array}{l}\text { Low density } \\
\text { lipoprotein } \\
\text { receptor-related } \\
\text { protein } 12\end{array}$ & Ishiura et al. (2019) & \\
\hline $\begin{array}{l}\text { Epidermolysis bullosa } \\
\text { simplex associated with } \\
\text { muscular dystrophy }\end{array}$ & 5.19 & AR & $\begin{array}{l}\text { EBSMD } \\
226670\end{array}$ & $8 \mathrm{q} 24.3$ & $\begin{array}{l}\text { PLEC } \\
601282\end{array}$ & Plectin & $\begin{array}{l}\text { Gache et al. (1996) } \\
\text { Smith et al. (1996) } \\
\text { Wuyts et al. (1996) }\end{array}$ & $\begin{array}{l}\text { allelic to LGMDR17 (group 1), } \\
\text { myasthenic syndrome with plectin } \\
\text { defect (group 11) }\end{array}$ \\
\hline Muscle hypertrophy & 5.20 & $\mathrm{AR}$ & $\begin{array}{l}\text { MSLHP } \\
614160\end{array}$ & $2 \mathrm{q} 32.2$ & $\begin{array}{l}\text { MSTN } \\
601788\end{array}$ & Myostatin & Schuelke et al. (2004) & \\
\hline $\begin{array}{l}\text { Fibrodysplasia ossificans } \\
\text { progressiva }\end{array}$ & 5.21 & $\mathrm{AD}$ & $\begin{array}{l}\text { FOP } \\
135100\end{array}$ & $2 \mathrm{q} 24.1$ & $\begin{array}{l}\text { ACVRI } \\
102576\end{array}$ & $\begin{array}{l}\text { Activin A receptor, } \\
\text { type } 1\end{array}$ & Shore et al. (2006) & \\
\hline $\begin{array}{l}\text { Creatine phosphokinase, } \\
\text { elevated serum (formerly } \\
\text { HyperCKemia, iodiopathic) }\end{array}$ & 5.22 & $\mathrm{AD}$ & 123320 & $3 \mathrm{p} 25.3$ & $\begin{array}{l}\text { CAV3 } \\
601253\end{array}$ & Caveolin-3 & Carbone et al. (2000) & $\begin{array}{l}\text { allelic to formerly LGMD1C } \\
\text { (group 1), MPDT (group 4), } \\
\text { RMD2 (group 6), CMH and } \\
\text { LQT9 (group 10) }\end{array}$ \\
\hline $\begin{array}{l}\text { X-linked myopathy with } \\
\text { postural muscle atrophy }\end{array}$ & 5.23 & $\mathrm{XR}$ & $\begin{array}{l}\text { XMPMA } \\
300696\end{array}$ & $\mathrm{Xq} 26.3$ & $\begin{array}{l}\text { FHLI } \\
300163\end{array}$ & $\begin{array}{l}\text { Four-and-a-half LIM } \\
\text { domains } 1\end{array}$ & $\begin{array}{l}\text { Windpassinger et al., } \\
2008\end{array}$ & $\begin{array}{l}\text { allelic to EDMD6 (group 1), } \\
\text { RBMX1A/B (group 5), SPM } \\
\text { (group 5) }\end{array}$ \\
\hline
\end{tabular}




\begin{tabular}{|c|c|c|c|c|c|c|c|c|}
\hline DISEASE NAME & $\begin{array}{l}\text { Item line } \\
\text { in this } \\
\text { group }\end{array}$ & Inheritance & $\begin{array}{l}\text { Locus or } \\
\text { disease symbol } \\
\text { and OMIM } \\
\text { number }\end{array}$ & Chromosome & $\begin{array}{l}\text { Gene symbol } \\
\text { and OMIM } \\
\text { number }\end{array}$ & $\begin{array}{l}\text { Protein } \\
\text { (mitochondrial } \\
\text { proteins indicated } \\
\text { by symbol }[\mathrm{M}] \text { ) }\end{array}$ & Key references & $\begin{array}{l}\text { Other allelic disease(s) (group } \\
\text { in this table) }\end{array}$ \\
\hline Scapuloperoneal myopathy & 5.24 & $\mathrm{XD}$ & $\begin{array}{l}\text { SPM } \\
300695\end{array}$ & $\mathrm{Xq} 26.3$ & $\begin{array}{l}\text { FHL1 } \\
300163\end{array}$ & $\begin{array}{l}\text { Four-and-a-half LIM } \\
\text { domains } 1\end{array}$ & Quinzii et al. (2008) & $\begin{array}{l}\text { allelic to EDMD6 (group 1), } \\
\text { RBMX1A/B (group 5), XMPMA } \\
\text { (group 5) }\end{array}$ \\
\hline $\begin{array}{l}\text { Reducing body myopathy } \\
\text { (1A and } 1 \mathrm{~B})\end{array}$ & 5.25 & $\mathrm{XD}$ & $\begin{array}{l}\text { RBMX1A } \\
300717 \\
\text { RBMX1B } \\
300718\end{array}$ & $\mathrm{Xq} 26.3$ & $\begin{array}{l}\text { FHL1 } \\
300163\end{array}$ & $\begin{array}{l}\text { Four-and-a-half LIM } \\
\text { domains } 1\end{array}$ & $\begin{array}{l}\text { Schessl et al. (2008), } \\
\text { Shalaby et al. (2009) }\end{array}$ & $\begin{array}{l}\text { allelic to EDMD6 (group 1), } \\
\text { XPMA (group 5), SPM (group 5) }\end{array}$ \\
\hline $\begin{array}{l}\text { Episodic muscle weakness, } \\
\text { X-linked }\end{array}$ & 5.26 & $\mathrm{XR}$ & $\begin{array}{l}\text { EMWX } \\
300211\end{array}$ & $\mathrm{Xp} 22.3$ & $?$ & & Ryan et al. (1999) & \\
\hline $\begin{array}{l}\text { Inclusion body myopathy } \\
\text { associated with Paget } \\
\text { disease of bone and } \\
\text { frontotemporal dementia } 1\end{array}$ & 5.27 & $\mathrm{AD}$ & $\begin{array}{l}\text { IBMPFD1 } \\
167320\end{array}$ & $9 \mathrm{p} 13.3$ & $\begin{array}{l}\boldsymbol{V C P} \\
601023\end{array}$ & $\begin{array}{l}\text { Valosin-containing } \\
\text { protein }\end{array}$ & $\begin{array}{l}\text { Watts et al. (2004) } \\
\text { Haubenberger et al. } \\
\text { (2005) }\end{array}$ & $\begin{array}{l}\text { allelic to scapuloperoneal } \\
\text { myopathy (group 1), IBMPFD1 } \\
\text { (group 4), ALS14 (group 12) and } \\
\text { CMT2Y (group 14) }\end{array}$ \\
\hline $\begin{array}{l}\text { Inclusion body myopathy } \\
\text { with early-onset Paget } \\
\text { disease with or without } \\
\text { frontotemporal dementia } 2\end{array}$ & 5.28 & & $\begin{array}{l}\text { IBMPFD2 } \\
615422\end{array}$ & $7 \mathrm{p} 15.2$ & $\begin{array}{l}\text { HNRNPA2B1 } \\
600124\end{array}$ & $\begin{array}{l}\text { Heterogeneous } \\
\text { nuclear } \\
\text { ribonucleoprotein } \\
\text { A2/B1 }\end{array}$ & Kim et al. (2013) & \\
\hline $\begin{array}{l}\text { Myopathy with lactic } \\
\text { acidosis, hereditary }\end{array}$ & 5.29 & $\mathrm{AR}$ & $\begin{array}{l}\text { HML } \\
255125\end{array}$ & $12 \mathrm{q} 23.3$ & $\begin{array}{l}\text { ISCU } \\
611911\end{array}$ & $\begin{array}{l}\text { Iron-sulfur cluster } \\
\text { scaffold homolog (E. } \\
\text { coli) }\end{array}$ & Mochel et al. (2008) & \\
\hline $\begin{array}{l}\text { Late onset axial myopathy } \\
\text { related to RYR1 }\end{array}$ & 5.30 & $\mathrm{AD}$ & & $19 \mathrm{q} 13.2$ & $\begin{array}{l}\text { RYRI } \\
180901\end{array}$ & $\begin{array}{l}\text { Ryanodine receptor } 1 \\
\text { (skeletal) }\end{array}$ & Løseth et al. (2013) & $\begin{array}{l}\text { allelic to CFTD, CNM related to } \\
\text { RYR1, CCD (group 3), minicore } \\
\text { myopathy with external } \\
\text { ophthalmoplegia (group 3), } \\
\text { CNMDU1 (group 3), MHS1 } \\
\text { (group 8) }\end{array}$ \\
\hline $\begin{array}{l}\text { Tubular aggregate myopathy } \\
1\end{array}$ & 5.31 & $\mathrm{AD}$ & $\begin{array}{l}\text { TAM1 } \\
160565\end{array}$ & $11 \mathrm{p} 15.4$ & $\begin{array}{l}\text { STIMI } \\
605921\end{array}$ & $\begin{array}{l}\text { Stromal interaction } \\
\text { molecule } 1\end{array}$ & $\begin{array}{l}\text { Bohm et al. (2013) } \\
\text { Hedberg et al. (2014) } \\
\text { Nesin et al. (2014) }\end{array}$ & \\
\hline $\begin{array}{l}\text { Tubular aggregate myopathy } \\
2\end{array}$ & 5.32 & $\mathrm{AD}$ & $\begin{array}{l}\text { TAM2 } \\
615883\end{array}$ & $12 \mathrm{q} 24.31$ & $\begin{array}{l}\text { ORAII } \\
610277\end{array}$ & $\begin{array}{l}\text { ORAI calcium } \\
\text { release-activated } \\
\text { calcium modulator } 1\end{array}$ & Nesin et al. (2014) & \\
\hline $\begin{array}{l}\text { Vacuolar myopathy with } \\
\text { CASQ1 aggregates }\end{array}$ & 5.33 & $\mathrm{AD}$ & $\begin{array}{l}\text { VMCQA } \\
616231\end{array}$ & $1 \mathrm{q} 23.2$ & $\begin{array}{l}\text { CASQ1 } \\
114250\end{array}$ & Calsequestrin 1 & Rossi et al. (2014) & \\
\hline $\begin{array}{l}\text { Myopathy with characteristic } \\
\text { sarcoplasmic inclusions }\end{array}$ & 5.34 & $\mathrm{AD}$ & & $22 \mathrm{q} 12.3$ & $\begin{array}{l}M B \\
160000\end{array}$ & Myoglobin & Olivé et al. (2019) & \\
\hline \multicolumn{9}{|c|}{ GROUP 6. MYOTONIC SYNDROMES } \\
\hline $\begin{array}{l}\text { Myotonic dystrophy } 1 \\
\text { (Steinert) }\end{array}$ & 6.1 & $\mathrm{AD}$ & $\begin{array}{l}\text { DM1 } \\
160900\end{array}$ & $19 \mathrm{q} 13.32$ & $\begin{array}{l}\text { DMPK } \\
605377\end{array}$ & $\begin{array}{l}\text { Dystrophia } \\
\text { myotonica protein } \\
\text { kinase }\end{array}$ & $\begin{array}{l}\text { Renwick et al. (1971) } \\
\text { Friedrich et al. (1987) } \\
\text { Harley et al. (1992) } \\
\text { Buxton et al. (1992) } \\
\text { Aslanidis et al. (1992) } \\
\text { Mahadevan et al. (1992) } \\
\text { Fu et al. (1992) Brook } \\
\text { et al. (1992) }\end{array}$ & \\
\hline $\begin{array}{l}\text { Myotonic dystrophy type } 2 \\
\text { (proximal myotonic } \\
\text { myopathy) }\end{array}$ & 6.2 & $\mathrm{AD}$ & $\begin{array}{l}\text { DM2 } \\
\text { (PROMM) } \\
602668\end{array}$ & $3 q 21.3$ & $\begin{array}{l}\text { CNBP } \\
\text { (formerly ZNF9) } \\
116955\end{array}$ & $\begin{array}{l}\text { CCHC-type Zinc } \\
\text { finger nucleic } \\
\text { acid-binding protein } \\
\text { (Zinc finger protein } \\
\text { 9) }\end{array}$ & $\begin{array}{l}\text { Ranum et al. (1998) } \\
\text { Liquori et al. (2001) }\end{array}$ & \\
\hline $\begin{array}{l}\text { Myotonia, dominant } \\
\text { (Thomsen) }\end{array}$ & 6.3 & $\mathrm{AD}$ & \multicolumn{3}{|c|}{ see under Ion channel muscle diseases (group 7) } & & & \\
\hline Myotonia, recessive (Becker) & 6.4 & $\mathrm{AR}$ & \multicolumn{3}{|c|}{ see under Ion channel muscle diseases (group 7) } & & & \\
\hline $\begin{array}{l}\text { Rippling muscle disease, } \\
\text { dominant }\end{array}$ & 6.5 & $\mathrm{AD}$ & $\begin{array}{l}\text { RMD1 } \\
600332\end{array}$ & $1 \mathrm{q} 41$ & $?$ & & Stephan et al. (1994) & \\
\hline $\begin{array}{l}\text { Rippling muscle disease, } \\
\text { dominant }\end{array}$ & 6.6 & $\mathrm{AD}$ & $\begin{array}{l}\text { RMD2 } \\
606072\end{array}$ & $3 \mathrm{p} 25.3$ & $\begin{array}{l}\text { CAV3 } \\
601253\end{array}$ & Caveolin-3 & Betz et al. (2001) & $\begin{array}{l}\text { allelic to formerly LGMD1C } \\
\text { (group 1), MPDT (group 4), } \\
\text { hyper CKemia (group 5), CMH1 } \\
\text { (group 10A) and LQT9 (group } \\
\text { 10B) }\end{array}$ \\
\hline $\begin{array}{l}\text { Rippling muscle disease, } \\
\text { recessive }\end{array}$ & 6.7 & AR & $\begin{array}{l}\text { RMD2 } \\
606072\end{array}$ & $3 \mathrm{p} 25.3$ & $\begin{array}{l}\text { CAV3 } \\
601253\end{array}$ & Caveolin-3 & $\begin{array}{l}\text { Kubisch et al. (2003, } \\
\text { 2005) }\end{array}$ & $\begin{array}{l}\text { allelic to formerly LGMD1C } \\
\text { (group 1), MPDT (group 4), } \\
\text { hyper CKemia (group 5), CMH1 } \\
\text { (group 10A) and LQT9 (group } \\
\text { 10B) }\end{array}$ \\
\hline Schwartz-Jampel syndrome & 6.8 & AR & $\begin{array}{l}\text { SJS1 } \\
255800\end{array}$ & $1 \mathrm{p} 36.12$ & $\begin{array}{l}\text { HSPG2 } \\
14246\end{array}$ & $\begin{array}{l}\text { Heparan sulfate } \\
\text { proteoglycan of } \\
\text { basement membrane } \\
\text { (perlecan) }\end{array}$ & $\begin{array}{l}\text { Nicole et al. (1995, } \\
\text { 2000) }\end{array}$ & \\
\hline Brody disease & 6.9 & $\mathrm{AR}$ & 601003 & $16 \mathrm{p} 11.2$ & $\begin{array}{l}\text { ATP2A1 } \\
\text { (formerly } \\
\text { SERCA1) } \\
108730\end{array}$ & $\begin{array}{l}\text { ATPase, } \mathrm{Ca}^{++} \\
\text {transporting, fast } \\
\text { twitch } 1\end{array}$ & Odermatt et al. (1996) & \\
\hline
\end{tabular}




\begin{tabular}{|c|c|c|c|c|c|c|c|c|}
\hline DISEASE NAME & $\begin{array}{l}\text { Item line } \\
\text { in this } \\
\text { group }\end{array}$ & Inheritance & $\begin{array}{l}\text { Locus or } \\
\text { disease symbol } \\
\text { and OMIM } \\
\text { number }\end{array}$ & Chromosome & $\begin{array}{l}\text { Gene symbol } \\
\text { and OMIM } \\
\text { number }\end{array}$ & $\begin{array}{l}\text { Protein } \\
\text { (mitochondrial } \\
\text { proteins indicated } \\
\text { by symbol }[\mathrm{M}] \text { ) }\end{array}$ & Key references & $\begin{array}{l}\text { Other allelic disease(s) (group } \\
\text { in this table) }\end{array}$ \\
\hline
\end{tabular}

Group 7. ION CHANNEL MUSCLE DISEASES

\section{Chloride channel}

Myotonia congenit

dominant (Thomsen)

Myotonia, recessive (Becker) 7

Sodium channel

Hyperkalaemic periodic

paralysis

number

. 


\begin{tabular}{|c|c|c|c|c|c|c|c|c|}
\hline DISEASE NAME & $\begin{array}{l}\text { Item line } \\
\text { in this } \\
\text { group }\end{array}$ & Inheritance & $\begin{array}{l}\text { Locus or } \\
\text { disease symbol } \\
\text { and OMIM } \\
\text { number }\end{array}$ & Chromosome & $\begin{array}{l}\text { Gene symbol } \\
\text { and OMIM } \\
\text { number }\end{array}$ & $\begin{array}{l}\text { Protein } \\
\text { (mitochondrial } \\
\text { proteins indicated } \\
\text { by symbol }[\mathrm{M}] \text { ) }\end{array}$ & Key references & $\begin{array}{l}\text { Other allelic disease(s) (group } \\
\text { in this table) }\end{array}$ \\
\hline Malignant hyperthermia & 8.2 & $\mathrm{AD}$ & $\begin{array}{l}\text { MHS2 } \\
154275\end{array}$ & $17 q 11.2-q 24$ & $?$ & & $\begin{array}{l}\text { Levitt et al. (1992) } \\
\text { Moslehi et al. (1998) }\end{array}$ & \\
\hline Malignant hyperthermia & 8.3 & $\mathrm{AD}$ & $\begin{array}{l}\text { MHS3 } \\
154276\end{array}$ & $7 \mathrm{q} 21-\mathrm{q} 22$ & $?$ & & Iles et al. (1994) & \\
\hline Malignant hyperthermia & 8.4 & $\mathrm{AD}$ & $\begin{array}{l}\text { MHS4 } \\
600467\end{array}$ & $3 q 13.1$ & $?$ & & Sudbrak et al. (1995) & \\
\hline Malignant hyperthermia & 8.5 & $\mathrm{AD}$ & $\begin{array}{l}\text { MHS5 } \\
601887\end{array}$ & $1 \mathrm{q} 32.1$ & $\begin{array}{l}\text { CACNA1S } \\
114208\end{array}$ & $\begin{array}{l}\text { Calcium channel, } \\
\text { voltage-dependent, L } \\
\text { type, alpha 1S } \\
\text { subunit }\end{array}$ & Monnier et al. (1997) & $\begin{array}{l}\text { allelic to congenital myopathy } \\
\text { with ophthalmoplegia (group 3), } \\
\text { HOKPP1 (group 7) }\end{array}$ \\
\hline Malignant hyperthermia & 8.6 & $\mathrm{AD}$ & $\begin{array}{l}\text { MHS6 } \\
601888\end{array}$ & $5 p$ & $?$ & & Robinson et al. (1997) & \\
\hline \multicolumn{9}{|c|}{ GROUP 9. METABOLIC MYOPATHIES } \\
\hline \multicolumn{9}{|l|}{ Glycogen storage diseases } \\
\hline $\begin{array}{l}\text { Glycogen storage disease } \\
\text { type II, Pompe disease (also } \\
\text { listed in group 10A) }\end{array}$ & 9.1 & AR & $\begin{array}{l}\text { GSD2 } \\
232300\end{array}$ & $17 \mathrm{q} 25.3$ & $\begin{array}{l}\text { GAA } \\
606800\end{array}$ & $\begin{array}{l}\text { Glucosidase, alpha } \\
\text { acid }\end{array}$ & $\begin{array}{l}\text { Hers et al. (1963) } \\
\text { Martiniuk et al. (1990) } \\
\text { Wokke et al. (1995) }\end{array}$ & $\begin{array}{l}\text { Allelic to formerly LMGD2V } \\
\text { (group 1) and Pompe's disease } \\
\text { (group 10A) }\end{array}$ \\
\hline $\begin{array}{l}\text { Glycogen storage disease } \\
\text { type III }\end{array}$ & 9.2 & AR & $\begin{array}{l}\text { GSD3 } \\
232400\end{array}$ & $1 \mathrm{p} 21.2$ & $\begin{array}{l}A G L \\
610860\end{array}$ & $\begin{array}{l}\text { Amylo-1, } \\
\text { 6-glucosidase, } \\
\text { 4-alpha-glucano } \\
\text { transferase (glycogen } \\
\text { debrancher enzyme) }\end{array}$ & Sheng et al. (1996) & \\
\hline $\begin{array}{l}\text { Glycogen storage disease } \\
\text { type IV }\end{array}$ & 9.3 & AR & $\begin{array}{l}\text { GSD4 } \\
232500\end{array}$ & $3 \mathrm{p} 12.2$ & $\begin{array}{l}\text { GBE1 } \\
607839\end{array}$ & $\begin{array}{l}\text { Glycogen branching } \\
\text { enzyme (1,4- } \alpha \text {-glucan } \\
\text { branching enzyme) }\end{array}$ & $\begin{array}{l}\text { Brown et al. (1966) Bao } \\
\text { et al. (1996) Bruno et al. } \\
\text { (2004) }\end{array}$ & \\
\hline $\begin{array}{l}\text { Glycogen storage disease } \\
\text { type V (McArdle) }\end{array}$ & 9.4 & AR & $\begin{array}{l}\text { GSD5 } \\
232600\end{array}$ & $11 \mathrm{q} 13.1$ & $\begin{array}{l}\text { PYGM } \\
608455\end{array}$ & $\begin{array}{l}\text { Glycogen } \\
\text { phosphorylase, } \\
\text { muscle }\end{array}$ & $\begin{array}{l}\text { Mommaerts et al. (1959) } \\
\text { Schmidt et al. (1959) } \\
\text { Lebo et al. (1984) } \\
\text { Tsujino et al. (1993) }\end{array}$ & \\
\hline $\begin{array}{l}\text { Glycogen storage type VII } \\
\text { (Tarui) }\end{array}$ & 9.5 & AR & $\begin{array}{l}\text { GSD7 } \\
232800\end{array}$ & $12 \mathrm{q} 13.11$ & $\begin{array}{l}\text { PFKM } \\
610681\end{array}$ & $\begin{array}{l}\text { Phosphofructo } \\
\text { kinase, muscle type }\end{array}$ & $\begin{array}{l}\text { Tarui et al. (1965) } \\
\text { Nakajima et al. (1991) } \\
\text { Howard et al. (1996) }\end{array}$ & \\
\hline $\begin{array}{l}\text { Glycogen storage disease } \\
\text { type IXd (ex type VIII) }\end{array}$ & 9.6 & $\mathrm{XR}$ & $\begin{array}{l}\text { GSD9D } \\
300559\end{array}$ & $\mathrm{Xq} 13.1$ & $\begin{array}{l}\text { PHKA1 } \\
311870\end{array}$ & $\begin{array}{l}\text { Phosphorylase kinase, } \\
\text { alpha-1 subunit }\end{array}$ & $\begin{array}{l}\text { Wehner et al. (1994) } \\
\text { Burwinkel et al. (2004) }\end{array}$ & \\
\hline $\begin{array}{l}\text { Glycogen storage disease } \\
\text { type XIV (Congenital } \\
\text { disorder of glycosylation, } \\
\text { type It) }\end{array}$ & 9.7 & AR & $\begin{array}{l}\text { CDG1T } \\
614921\end{array}$ & $1 \mathrm{p} 31.3$ & $\begin{array}{l}\text { PGM1 } \\
171900\end{array}$ & $\begin{array}{l}\text { Phospho } \\
\text { glucomutase } 1\end{array}$ & Stojkovic et al. (2009) & \\
\hline $\begin{array}{l}\text { Glycogen storage disease } \\
\text { type } \mathrm{XV}\end{array}$ & 9.8 & AR & $\begin{array}{l}\text { GSD15 } \\
613507\end{array}$ & $3 q 24$ & $\begin{array}{l}\text { GYG1 } \\
603942\end{array}$ & Glycogenin 1 & Moslemi et al. (2010) & allelic to PGBM2 (group 9) \\
\hline $\begin{array}{l}\text { Glycogen storage disease } \\
\text { type } 0\end{array}$ & 9.9 & AR & $\begin{array}{l}\text { GSD0B } \\
611556\end{array}$ & $9 \mathrm{q} 13.33$ & $\begin{array}{l}\text { GYS1 } \\
138570\end{array}$ & Glycogen synthase 1 & Kolberg et al. (2007) & \\
\hline $\begin{array}{l}\text { Glycogen storage disease of } \\
\text { heart, lethal congenital }\end{array}$ & 9.10 & $\mathrm{AD}$ & 261740 & $7 \mathrm{q} 36.1$ & $\begin{array}{l}\text { PRKAG2 } \\
602743\end{array}$ & $\begin{array}{l}\text { Protein kinase, } \\
\text { AMP-activated, non } \\
\text { catalytic } \\
\text { (AMPK-gamma-2) }\end{array}$ & Burwinkel et al. (2005) & allelic to CMH6 (group 10A) \\
\hline $\begin{array}{l}\text { Polyglucosan Body } \\
\text { Myopathy } 1 \text { with or without } \\
\text { immunodeficiency }\end{array}$ & 9.11 & $\mathrm{AR}$ & $\begin{array}{l}\text { PGBM1 } \\
615895\end{array}$ & $20 \mathrm{p} 13$ & $\begin{array}{l}\text { RBCK1 } \\
610924\end{array}$ & $\begin{array}{l}\text { RanBP-type and } \\
\text { C3HC4-type zinc } \\
\text { finger containing } 1\end{array}$ & Nilsson et al. (2013) & \\
\hline $\begin{array}{l}\text { Polyglucosan Body } \\
\text { Myopathy } 2\end{array}$ & 9.12 & AR & $\begin{array}{l}\text { PGBM2 } \\
616199\end{array}$ & $3 q 24$ & $\begin{array}{l}\text { GYG1 } \\
603942\end{array}$ & Glycogenin 1 & Malfatti et al. (2014) & allelic to GSD15 (group 9) \\
\hline \multicolumn{9}{|l|}{ Glycolytic pathway } \\
\hline $\begin{array}{l}\text { Posphoglycerate kinase } 1 \\
\text { deficiency }\end{array}$ & 9.13 & $\mathrm{XR}$ & 300653 & $\mathrm{Xq} 21.1$ & $\begin{array}{l}\text { PGK1 } \\
311800\end{array}$ & $\begin{array}{l}\text { Phospho } \\
\text { glycerate kinase } 1\end{array}$ & $\begin{array}{l}\text { DiMauro et al. (1981, } \\
\text { 1983) Rosa et al. (1982) }\end{array}$ & \\
\hline $\begin{array}{l}\text { Glycogen storage disease } \\
\text { type X }\end{array}$ & 9.14 & AR & $\begin{array}{l}\text { GSD10 } \\
261670\end{array}$ & $7 \mathrm{p} 13$ & $\begin{array}{l}\text { PGAM2 } \\
612931\end{array}$ & $\begin{array}{l}\text { Phospho } \\
\text { glycerate mutase } 2\end{array}$ & $\begin{array}{l}\text { DiMauro et al. (1981) } \\
\text { Edwards et al. (1989) } \\
\text { Castella-Escola et al. } \\
\text { (1990) Tsujino et al. } \\
\text { (1993) }\end{array}$ & \\
\hline $\begin{array}{l}\text { Glycogen storage disease } \\
\text { type XI }\end{array}$ & 9.15 & AR & $\begin{array}{l}\text { GSD11 } \\
612933\end{array}$ & $11 \mathrm{p} 15.1$ & $\begin{array}{l}\text { LDHA } \\
150000\end{array}$ & $\begin{array}{l}\text { Lactate } \\
\text { dehydrogenase A }\end{array}$ & $\begin{array}{l}\text { Kanno et al. (1980) } \\
\text { Scrable et al. (1990) }\end{array}$ & \\
\hline $\begin{array}{l}\text { Glycogen storage disease } \\
\text { type XIII }\end{array}$ & 9.16 & $\mathrm{AD}$ & $\begin{array}{l}\text { GSD13 } \\
612932\end{array}$ & $17 \mathrm{p} 13.2$ & $\begin{array}{l}\text { ENO3 } \\
131370\end{array}$ & Enolase 3 & Comi et al. (2001) & \\
\hline $\begin{array}{l}\text { Erythrocyte lactate } \\
\text { transporter defect (Myopathy } \\
\text { due to actate transporter } \\
\text { defect) }\end{array}$ & 9.17 & $\mathrm{AD}$ & 245340 & $1 \mathrm{p} 13.2$ & $\begin{array}{l}\text { SLC16A1 } \\
600682\end{array}$ & $\begin{array}{l}\text { Solute carrier family } \\
16 \text { (monocar } \\
\text { boxylic acid } \\
\text { transporter), member } \\
1\end{array}$ & $\begin{array}{l}\text { Merezhinskaya et al. } \\
(2000)\end{array}$ & \\
\hline \multicolumn{9}{|l|}{ Disorders of lipid metabolism } \\
\hline $\begin{array}{l}\text { Carnitine } \\
\text { palmitoyl-transferase II } \\
\text { deficiency, myopathic, stress } \\
\text { induced }\end{array}$ & 9.18 & AR & 255110 & $1 \mathrm{p} 32.3$ & $\begin{array}{l}\text { CPT2 } \\
600650\end{array}$ & $\begin{array}{l}\text { Carnitine palmitoyl } \\
\text { transferase II }\end{array}$ & $\begin{array}{l}\text { DiMauro et al. (1973) } \\
\text { Finocchiaro et al. (1991) } \\
\text { Taroni et al. (1993) } \\
\text { Gellera et al. (1994) }\end{array}$ & \\
\hline
\end{tabular}




\begin{tabular}{|c|c|c|c|c|c|c|c|c|}
\hline DISEASE NAME & $\begin{array}{l}\text { Item line } \\
\text { in this } \\
\text { group }\end{array}$ & Inheritance & $\begin{array}{l}\text { Locus or } \\
\text { disease symbol } \\
\text { and OMIM } \\
\text { number }\end{array}$ & Chromosome & $\begin{array}{l}\text { Gene symbol } \\
\text { and OMIM } \\
\text { number }\end{array}$ & $\begin{array}{l}\text { Protein } \\
\text { (mitochondrial } \\
\text { proteins indicated } \\
\text { by symbol }[\mathrm{M}] \text { ) }\end{array}$ & Key references & $\begin{array}{l}\text { Other allelic disease(s) (group } \\
\text { in this table) }\end{array}$ \\
\hline $\begin{array}{l}\text { Primary systemic carnitine } \\
\text { deficiency }\end{array}$ & 9.19 & $\mathrm{AR}$ & $\begin{array}{l}\text { CDSP } \\
212140\end{array}$ & $5 \mathrm{q} 31.1$ & $\begin{array}{l}\text { SLC22A5 } \\
603377\end{array}$ & $\begin{array}{l}\text { Solute carrier family } \\
22 \text { (organic cation } \\
\text { transporter), member } \\
5\end{array}$ & Nezu et al. (1999) & \\
\hline $\begin{array}{l}\text { Carnitine/acyl-carnitine } \\
\text { translocase deficiency }\end{array}$ & 9.20 & $\mathrm{AR}$ & $\begin{array}{l}\text { CACTD } \\
212138\end{array}$ & $3 \mathrm{p} 21.31$ & $\begin{array}{l}\text { SLC25A20 } \\
613698\end{array}$ & $\begin{array}{l}\text { Solute carrier family } \\
25 \text { (carnitine/ } \\
\text { acylcarnitine } \\
\text { translocase), member } \\
20\end{array}$ & $\begin{array}{l}\text { Huizing et al. (1997) } \\
\text { Ogawa et al. (2000) }\end{array}$ & \\
\hline $\begin{array}{l}\text { Multiple acyl-CoA } \\
\text { dehydrogenase deficiency } \\
\text { (Glutaric aciduria type IIA) }\end{array}$ & 9.21 & $\mathrm{AR}$ & $\begin{array}{l}\text { MADD } \\
231680\end{array}$ & $15 \mathrm{q} 24.2-\mathrm{q} 24.3$ & $\begin{array}{l}\text { ETFA } \\
608053\end{array}$ & $\begin{array}{l}\text { Electron-transfer- } \\
\text { flavoprotein, alpha } \\
\text { polypeptide }\end{array}$ & $\begin{array}{l}\text { Indo et al. (1991) } \\
\text { Freneaux et al. (1992) }\end{array}$ & $\begin{array}{l}\text { allelic to MADD-GaIIB and } \\
\text { GaIIC (group 9) }\end{array}$ \\
\hline $\begin{array}{l}\text { Multiple acyl-CoA } \\
\text { dehydrogenase deficiency } \\
\text { (Glutaric aciduria type IIB) }\end{array}$ & 9.22 & $\mathrm{AR}$ & $\begin{array}{l}\text { MADD } \\
231680\end{array}$ & $19 \mathrm{q} 13.41$ & $\begin{array}{l}\boldsymbol{E T F B} \\
130410\end{array}$ & $\begin{array}{l}\text { Electron-transfer- } \\
\text { flavoprotein, beta } \\
\text { polypeptide }\end{array}$ & Colombo et al. (1994) & $\begin{array}{l}\text { allelic to MADD-GaIIA and } \\
\text { GaIIC (group 9) }\end{array}$ \\
\hline $\begin{array}{l}\text { Multiple acyl-CoA } \\
\text { dehydrogenase deficiency } \\
\text { (Glutaric aciduria type IIC, } \\
\text { riboflavin responsive) }\end{array}$ & 9.23 & $\mathrm{AR}$ & $\begin{array}{l}\text { MADD } \\
231680\end{array}$ & $4 \mathrm{q} 32.1$ & $\begin{array}{l}\text { ETFDH } \\
231675\end{array}$ & $\begin{array}{l}\text { Electron-transfer- } \\
\text { flavoprotein } \\
\text { dehydrogenase }\end{array}$ & Beard et al. (1993) & $\begin{array}{l}\text { allelic to MADD-GaIIA and } \\
\text { GaIIB (group 9) }\end{array}$ \\
\hline $\begin{array}{l}\text { Acyl-CoA dehydrogenase } \\
\text { (very long chain) deficiency } \\
\text { (VLCAD deficiency) }\end{array}$ & 9.24 & $\mathrm{AR}$ & $\begin{array}{l}\text { ACADVLD } \\
201475\end{array}$ & $17 \mathrm{p} 13.1$ & $\begin{array}{l}\text { ACADVL } \\
609575\end{array}$ & $\begin{array}{l}\text { Acyl-Coenzyme A } \\
\text { dehydrogenase, very } \\
\text { long chain }\end{array}$ & $\begin{array}{l}\text { Aoyama }(1993,1995) \\
\text { Strauss et al. (1995) } \\
\text { Mathur et al. 1999) }\end{array}$ & \\
\hline $\begin{array}{l}\text { Mitochondrial complex I } \\
\text { deficiency due to ACAD9 } \\
\text { deficiency }\end{array}$ & 9.25 & AR & 611126 & $3 q 21.3$ & $\begin{array}{l}A C A D 9 \\
611103\end{array}$ & $\begin{array}{l}\text { Acyl-CoA } \\
\text { dehydrogenase family } \\
\text { member } 9 \text { (M) }\end{array}$ & Fragaki etal (2016) & \\
\hline $\begin{array}{l}\text { Triglyceride storage disease } \\
\text { with ichthyosis } \\
\text { (Chanarin-Dorfman } \\
\text { syndrome) }\end{array}$ & 9.26 & $\mathrm{AR}$ & $\begin{array}{l}\text { CDS } \\
275630\end{array}$ & $3 \mathrm{p} 21.33$ & $\begin{array}{l}\text { ABHD5 } \\
604780\end{array}$ & $\begin{array}{l}\text { Abhydrolase domain } \\
\text { containing } 5\end{array}$ & Lefevre et al. (2001) & \\
\hline $\begin{array}{l}\text { Neutral lipid storage disease } \\
\text { with myopathy without } \\
\text { ichthyosis }\end{array}$ & 9.27 & $\mathrm{AR}$ & $\begin{array}{l}\text { NLSDM } \\
610717\end{array}$ & $11 \mathrm{p} 15.5$ & $\begin{array}{l}\text { PNPLA2 } \\
609059\end{array}$ & $\begin{array}{l}\text { Patatin-like } \\
\text { phosphorylase } \\
\text { domain-containing } \\
\text { protein } 2 \text { (Adipose } \\
\text { triglyceride lipase) }\end{array}$ & Fischer et al. (2007) & \\
\hline $\begin{array}{l}\text { Acute Recurrent } \\
\text { myoglobinuria }\end{array}$ & 9.28 & $\mathrm{AR}$ & 268200 & $2 \mathrm{p} 25.1$ & $\begin{array}{l}\text { LPIN1 } \\
605518\end{array}$ & $\begin{array}{l}\text { lipin } 1 \text { (phsosphatidic } \\
\text { acid phosphatase 1) }\end{array}$ & Zeharia et al. (2008) & \\
\hline $\begin{array}{l}\text { Mitochondrial myopathy } \\
\text { with lactic acidosis }\end{array}$ & 9.29 & $\mathrm{AR}$ & $\begin{array}{l}\text { MMLA } \\
251950\end{array}$ & $7 \mathrm{q} 31.1$ & $\begin{array}{l}\text { PNPLA8 } \\
612123\end{array}$ & $\begin{array}{l}\text { Patatin-like } \\
\text { phospholipase } \\
\text { domain containing } 8 \\
\text { (M) }\end{array}$ & Saunders et al. (2015) & \\
\hline $\begin{array}{l}\text { Lipid storage myopathy due } \\
\text { to Flavin adenine } \\
\text { dinucleotide synthetase } \\
\text { deficiency }\end{array}$ & 9.30 & $\mathrm{AR}$ & $\begin{array}{l}\text { LSMFLAD } \\
255100\end{array}$ & $1 \mathrm{q} 21.3$ & $\begin{array}{l}\text { FLAD1 } \\
610595\end{array}$ & $\begin{array}{l}\text { Flavin adenine } \\
\text { dinucleotide } \\
\text { synthetase, S. } \\
\text { Cerevisiae, homolog } \\
\text { of }(\mathbf{M})\end{array}$ & Taylor et al. (2014) & \\
\hline
\end{tabular}

GROUP 10A. HEREDITARY CARDIOMYOPATHIES non arrhythmogenic

\section{Hypertrophic cardiomyopathies}

Familial hypertrophic

cardiomyopathy, 1

$0.1-\mathrm{AD}$

$\mathrm{AD} \quad \mathrm{CMH} 1$

CMH1
192600

$14 \mathrm{q} 11.2$

MYH7

160760

Familial hypertrophic

cardiomyopathy, 2

Familial hypertrophic

cardiomyopathy, 3

Familial hypertrophic

cardiomyopathy, 4

$\begin{array}{lll}10.2 & \text { AD } & \text { CMH2 } \\ & & 115195 \\ 10.3 & \text { AD } & \text { CMH3 } \\ & & 115196 \\ 10.4 & \text { AD } & \text { CMH4 } \\ & & 115197\end{array}$

$1 \mathrm{q} 32.1$

$15 \mathrm{q} 22.2$

$11 \mathrm{p} 11.2$

Familial hypertrophic

cardiomyopathy, 6

Familial hypertrophic

cardiomyopathy, 7

Familial hypertrophic

cardiomyopathy, 8
$10.5 \quad \mathrm{AD} \quad \mathrm{CMH}$

600858

$7 \mathrm{q} 36.1$

PRKAG2

602743

10

10.7

AD

CMH7

613690

CMH8

608751

191044
MYL3
160790

$\begin{array}{ll}3 \mathrm{p} 21.31 & \text { MYL3 } \\ & 160790\end{array}$

TNNT2

191045

TPM1
191010

МYBPC3

600958
Myosin heavy chain Jarcho et al. (1989)

7 (beta), cardiac

muscle

Cardiac troponin $\mathrm{T}$

Tropomyosin-1

Cardiac myosin binding protein-C

Protein kinase,

AMP-activated, non

catalytic

(AMPK-gamma-2)

Cardiac troponin I

Myosin, light chain

3, alkali; ventricular,

skeletal, slow

Geisterfer-Lowrance

et al. (1990)

Carrier et al. (1993)

Bonne et al. (1995)

Watkins et al. (1995)

Blair et al. (2001)

Kimura et al. (1997)

Poetter et al. (1996)
Solomon et al. (1990)

Tanigawa et al. (1990)

Watkins et al. (1993)

Thierfelder et al. (1994)

Thierfelder et al. (1994) allelic to CFTD, MSMA and MSMB (group 3), MPD1 (group 4), CMD1S and LVNC5 (group 10A)

allelic to CMD1D, RCM3 and LVNC6 (group 10A)

allelic to CMD1Y and LVNC9 (group 10A)

allelic to congenital skeletal myopathy and fatal

cardiomyopathy (group 3), CMD1MM and LVNC10 (group 10A)

allelic to glycogen storage disease of heart, lethal congenital (group 9)

allelic to RCM1, CMD1FF and CMD2A (group 10A)

(continued on next page) 


\begin{tabular}{|c|c|c|c|c|c|c|c|c|}
\hline DISEASE NAME & $\begin{array}{l}\text { Item line } \\
\text { in this } \\
\text { group }\end{array}$ & Inheritance & $\begin{array}{l}\text { Locus or } \\
\text { disease symbol } \\
\text { and OMIM } \\
\text { number }\end{array}$ & Chromosome & $\begin{array}{l}\text { Gene symbol } \\
\text { and OMIM } \\
\text { number }\end{array}$ & $\begin{array}{l}\text { Protein } \\
\text { (mitochondrial } \\
\text { proteins indicated } \\
\text { by symbol }[\mathrm{M}] \text { ) }\end{array}$ & Key references & $\begin{array}{l}\text { Other allelic disease(s) (group } \\
\text { in this table) }\end{array}$ \\
\hline $\begin{array}{l}\text { Familial hypertrophic } \\
\text { cardiomyopathy, } 9\end{array}$ & 10.8 & $\mathrm{AD}$ & $\begin{array}{l}\text { CMH9 } \\
613765\end{array}$ & $2 \mathrm{q} 31.2$ & $\begin{array}{l}\text { TTN } \\
188840\end{array}$ & Titin & Satoh et al. (1999) & $\begin{array}{l}\text { allelic to LGMDR10 (group 1), } \\
\text { CNM related to TTN (group3), } \\
\text { MmD related to TTN (group 3), } \\
\text { SALMY (group 3), TMD (group } \\
\text { 4), HMERF (group 5), CMD1G } \\
\text { (group 10A) }\end{array}$ \\
\hline $\begin{array}{l}\text { Familial hypertrophic } \\
\text { cardiomyopathy, } 10\end{array}$ & 10.9 & $\mathrm{AD}$ & $\begin{array}{l}\text { CMH10 } \\
608758\end{array}$ & $12 \mathrm{q} 24.11$ & $\begin{array}{l}\text { MYL2 } \\
160781\end{array}$ & $\begin{array}{l}\text { Myosin, light chain } \\
2 \text {, regulatory, cardiac, } \\
\text { slow }\end{array}$ & Poetter et al. (1996) & Allelic to CFTD (group 3) \\
\hline $\begin{array}{l}\text { Familial hypertrophic } \\
\text { cardiomyopathy, } 11\end{array}$ & 10.10 & $\mathrm{AD}$ & $\begin{array}{l}\text { CMH11 } \\
612098\end{array}$ & $15 q 14$ & $\begin{array}{l}\text { ACTC1 } \\
102540\end{array}$ & $\begin{array}{l}\text { Actin, alpha, cardiac } \\
\text { muscle }\end{array}$ & Mogensen et al. (1999) & $\begin{array}{l}\text { allelic to CMD1R, LVNC4 } \\
\text { (group 10A) }\end{array}$ \\
\hline $\begin{array}{l}\text { Familial hypertrophic } \\
\text { cardiomyopathy, } 12\end{array}$ & 10.11 & $\mathrm{AD}$ & $\begin{array}{l}\text { CMH12 } \\
612124\end{array}$ & $11 \mathrm{p} 15.1$ & $\begin{array}{l}\text { CSRP3 } \\
600824\end{array}$ & $\begin{array}{l}\text { Cysteine and } \\
\text { glycine-rich protein } 3 \\
\text { (cardiac LIM protein) }\end{array}$ & Geier et al. (2008) & allelic to CMD1M (group 10A) \\
\hline $\begin{array}{l}\text { Familial hypertrophic } \\
\text { cardiomyopathy, } 13\end{array}$ & 10.12 & $\mathrm{AD}$ & $\begin{array}{l}\text { CMH13 } \\
613243\end{array}$ & $3 \mathrm{p} 21.1$ & $\begin{array}{l}\text { TNNC1 } \\
191040\end{array}$ & Slow troponin $\mathrm{C}$ & Landstrom et al. (2008) & allelic to CMD1Z (group 10A) \\
\hline $\begin{array}{l}\text { Familial hypertrophic } \\
\text { cardiomyopathy, } 14\end{array}$ & 10.13 & $\mathrm{AD}$ & $\begin{array}{l}\text { CMH14 } \\
613251\end{array}$ & $14 \mathrm{q} 11.2$ & $\begin{array}{l}\text { MYH6 } \\
160710\end{array}$ & $\begin{array}{l}\text { Myosin, heavy chain } \\
6 \text {, cardiac muscle, } \\
\text { alpha }\end{array}$ & Carniel et al. (2005) & $\begin{array}{l}\text { allelic to CMD1EE (group 10A) } \\
\text { and SSS3 (group 10B) }\end{array}$ \\
\hline $\begin{array}{l}\text { Hypertrophic } \\
\text { cardiomyopathy, } 15\end{array}$ & 10.14 & $\mathrm{AD}$ & $\begin{array}{l}\text { CMH15 } \\
613255\end{array}$ & $10 \mathrm{q} 22.2$ & $\begin{array}{l}V C L \\
193065\end{array}$ & Vinculin & Vasile et al. (2006) & allelic to CMD1W (group 10) \\
\hline $\begin{array}{l}\text { Familial hypertrophic } \\
\text { cardiomyopathy, } 1\end{array}$ & 10.15 & $\begin{array}{l}\mathrm{AD}, \\
\text { digenic }\end{array}$ & $\begin{array}{l}\text { CMH1 } \\
192600\end{array}$ & $20 \mathrm{q} 11.21$ & $\begin{array}{l}\text { MYLK2 } \\
606566\end{array}$ & $\begin{array}{l}\text { Myosin light chain } \\
\text { kinase } 2\end{array}$ & Davis et al. (2001) & \\
\hline $\begin{array}{l}\text { Familial hypertrophic } \\
\text { cardiomyopathy, } 1\end{array}$ & 10.16 & $\mathrm{AD}$ & $\begin{array}{l}\text { CMH1 } \\
192600\end{array}$ & $3 p 25.3$ & $\begin{array}{l}\text { CAV3 } \\
601253\end{array}$ & Caveolin-3 & $\begin{array}{l}\text { Hayashi et al. (2004) } \\
\text { Fulizio et al. (2005) }\end{array}$ & $\begin{array}{l}\text { allelic to formerly LGMD1C } \\
\text { (group 1), hyperCKemia (group } \\
\text { 5), MPDT (group 4), RMD2 } \\
\text { (group 6) and LQT9 (group 10B) }\end{array}$ \\
\hline $\begin{array}{l}\text { Hypertrophic } \\
\text { cardiomyopathy, } 16\end{array}$ & 10.17 & $\mathrm{AD}$ & $\begin{array}{l}\text { CMH16 } \\
613838\end{array}$ & $4 \mathrm{q} 26$ & $\begin{array}{l}\text { MYOZ2 } \\
605602\end{array}$ & $\begin{array}{l}\text { Myozenin 2 } \\
\text { (calsarcin 1) }\end{array}$ & Osio et al. (2007) & \\
\hline $\begin{array}{l}\text { Hypertrophic } \\
\text { cardiomyopathy, } 17\end{array}$ & 10.18 & $\mathrm{AD}$ & $\begin{array}{l}\text { CMH17 } \\
613873\end{array}$ & $20 \mathrm{q} 13.12$ & $\begin{array}{l}\text { JPH2 } \\
605267\end{array}$ & Junctophilin-2 & $\begin{array}{l}\text { Landstrom et al. (2007) } \\
\text { Matsuhita et al. (2007) }\end{array}$ & \\
\hline $\begin{array}{l}\text { Hypertrophic } \\
\text { cardiomyopathy, } 18\end{array}$ & 10.19 & $\mathrm{AD}$ & $\begin{array}{l}\text { CMH18 } \\
613874\end{array}$ & $6 \mathrm{q} 22.31$ & $\begin{array}{l}\text { PLN } \\
172405\end{array}$ & Phospholamban & $\begin{array}{l}\text { Minamisawa et al. (2003) } \\
\text { Landstrom et al. (2011) }\end{array}$ & allelic to CMD1P (group 10A) \\
\hline $\begin{array}{l}\text { Hypertrophic } \\
\text { cardiomyopathy, } 19\end{array}$ & 10.20 & $\mathrm{AD}$ & $\begin{array}{l}\text { CMH19 } \\
61387\end{array}$ & 19p13.11 & $\begin{array}{l}\text { CALR3 } \\
611414\end{array}$ & Calreticulin 3 & Chiu et al. (2007) & \\
\hline $\begin{array}{l}\text { Hypertrophic } \\
\text { cardiomyopathy, } 20\end{array}$ & 10.21 & $\mathrm{AD}$ & $\begin{array}{l}\text { CMH20 } \\
613876\end{array}$ & $1 \mathrm{p} 31.1$ & $\begin{array}{l}\text { NEXN } \\
613121\end{array}$ & $\begin{array}{l}\text { Nexilin F-actin } \\
\text { binding protein }\end{array}$ & Wang et al. (2010) & allelic to CMD1CC (group 10A) \\
\hline $\begin{array}{l}\text { Hypertrophic } \\
\text { cardiomyopathy related to } \\
\text { cardiac ankyrin repeat } \\
\text { domain protein }\end{array}$ & 10.22 & $\mathrm{AD}$ & & $10 \mathrm{q} 23.31$ & $\begin{array}{l}\text { ANKRDI } \\
609599\end{array}$ & $\begin{array}{l}\text { Ankyrin repeat } \\
\text { domain-protein } 1\end{array}$ & Arimura et al. (2009) & $\begin{array}{l}\text { allelic to dilated cardiomyopathy } \\
\text { (group 10A) }\end{array}$ \\
\hline $\begin{array}{l}\text { Hypertrophic } \\
\text { cardiomyopathy, } 22\end{array}$ & 10.23 & $\mathrm{AD}$ & $\begin{array}{l}\text { CMH22 } \\
615248\end{array}$ & $10 \mathrm{q} 21.3$ & $\begin{array}{l}\text { MYPN } \\
608517\end{array}$ & Myopalladin & Purevjav et al. (2012) & $\begin{array}{l}\text { allelic to CMD1KK (group 10A) } \\
\text { and NEM11 (group 3), RCM4 } \\
\text { (group 10A) }\end{array}$ \\
\hline $\begin{array}{l}\text { Hypertrophic } \\
\text { cardiomyopathy, } 23\end{array}$ & 10.24 & $\mathrm{AD}$ & $\begin{array}{l}\text { CMH23 } \\
612158\end{array}$ & $1 \mathrm{q} 43$ & $\begin{array}{l}\operatorname{ACTN2} \\
102573\end{array}$ & Actinin alpha-2 & Chiu C et al. (2010) & $\begin{array}{l}\text { allelic to Myopathy congenital } \\
\text { related to ACTN2 (group 3), } \\
\text { CMD1AA (group 10A) }\end{array}$ \\
\hline $\begin{array}{l}\text { Hypertrophic } \\
\text { cardiomyopathy, } 24\end{array}$ & 10.25 & $\mathrm{AD}$ & $\begin{array}{l}\text { CMH24 } \\
601493\end{array}$ & $10 \mathrm{q} 23.2$ & $\begin{array}{l}\text { LDB3 } \\
605906\end{array}$ & $\begin{array}{l}\text { LIM domain } \\
\text { binding-3 }\end{array}$ & Theis et al. (2006) & $\begin{array}{l}\text { allelic to Markesbery-Griggs } \\
\text { (group 4), MFM4 (group 5), } \\
\text { CMD1C and LVNC3 (group 10) }\end{array}$ \\
\hline $\begin{array}{l}\text { Hypertrophic } \\
\text { cardiomyopathy, } 25\end{array}$ & 10.26 & $\mathrm{AD}$ & $\begin{array}{l}\text { CMH25 } \\
607487\end{array}$ & $17 \mathrm{q} 12$ & $\begin{array}{l}\text { TCAP } \\
604488\end{array}$ & Titin-cap (telethonin) & Hayashi et al. (2004) & $\begin{array}{l}\text { allelic to LGMDR7 (group 1), } \\
\text { CMD related to telethonin } \\
\text { (group 2), CMD1N (group 10A) }\end{array}$ \\
\hline $\begin{array}{l}\text { Hypertrophic } \\
\text { cardiomyopathy, } 26\end{array}$ & 10.27 & $\mathrm{AD}$ & $\begin{array}{l}\text { CMH26 } \\
617047\end{array}$ & $7 \mathrm{q} 32.1$ & $\begin{array}{l}\text { FLNC } \\
102565\end{array}$ & Filamin C & Valdes-Mas et al. (2014) & $\begin{array}{l}\text { allelic to MFM5 (group 5) and } \\
\text { MPD4 (group 4) and RCM5 } \\
\text { (group 10A) }\end{array}$ \\
\hline $\begin{array}{l}\text { Hypertrophic } \\
\text { cardiomyopathy, } 27\end{array}$ & 10.28 & $\mathrm{AR}$ & $\begin{array}{l}\text { CMH27 } \\
618052\end{array}$ & $15 \mathrm{q} 25.3$ & $\begin{array}{l}\text { ALPK3 } \\
617608\end{array}$ & Alpha Kinase 3 & Almomani et al. (2016) & \\
\hline $\begin{array}{l}\text { Mitochondrial complex } 1 \\
\text { deficiency, nuclear type } 11\end{array}$ & 10.29 & $\mathrm{AR}$ & $\begin{array}{l}\text { MC1DN11 } \\
618234\end{array}$ & $15 \mathrm{q} 15.1$ & $\begin{array}{l}\text { NDUFAF1 } \\
606934\end{array}$ & $\begin{array}{l}\text { NADH } \\
\text { dehydrogenase } \\
\text { (ubiquinone) complex } \\
\text { I, Assembly factor } 1 \\
\text { (M) }\end{array}$ & Fassone et al. (2011) & \\
\hline $\begin{array}{l}\text { Combined oxydative } \\
\text { phosphorylation deficiency } 3\end{array}$ & 10.30 & $\mathrm{AR}$ & $\begin{array}{l}\text { COXPD3 } \\
610505\end{array}$ & $12 \mathrm{q} 14.1$ & $\begin{array}{l}\text { TSFM } \\
604723\end{array}$ & $\begin{array}{l}\text { Ts translation } \\
\text { elongation factor, } \\
\text { mitochondrial (M) }\end{array}$ & Smeitink et al.(2006) & \\
\hline $\begin{array}{l}\text { Combined oxydative } \\
\text { phosphorylation deficiency } 8\end{array}$ & 10.31 & $\mathrm{AR}$ & $\begin{array}{l}\text { COXPD8 } \\
614096\end{array}$ & $6 \mathrm{p} 21.1$ & $\begin{array}{l}\text { AARS2 } \\
612035\end{array}$ & $\begin{array}{l}\text { Alanyl-tRNA } \\
\text { synthetase 2, } \\
\text { mitochondrial }(\mathbf{M})\end{array}$ & Götz et al. (2011) & \\
\hline $\begin{array}{l}\text { Combined oxydative } \\
\text { phosphorylation deficiency } 9\end{array}$ & 10.32 & $\mathrm{AR}$ & $\begin{array}{l}\text { COXPD9 } \\
614582\end{array}$ & $3 \mathrm{q} 21.1$ & $\begin{array}{l}\text { MRPL3 } \\
607118\end{array}$ & $\begin{array}{l}\text { Mitochondrial } \\
\text { ribosomal protein L3 } \\
\text { (M) }\end{array}$ & Galmiche et al. (2011) & \\
\hline $\begin{array}{l}\text { Combined oxydative } \\
\text { phosphorylation deficiency } \\
10\end{array}$ & 10.33 & AR & $\begin{array}{l}\text { COXPD10 } \\
614702\end{array}$ & $6 \mathrm{q} 13$ & $\begin{array}{l}\text { MTO1 } \\
614667\end{array}$ & $\begin{array}{l}\text { Mitochondrial tRNA } \\
\text { translation } \\
\text { optimization } 1 \text { (M) }\end{array}$ & $\begin{array}{l}\text { Ghezzi et al. (2012) } \\
\text { Baruffini et al. (2013) }\end{array}$ & \\
\hline
\end{tabular}




\begin{tabular}{|c|c|c|c|c|c|c|c|c|}
\hline DISEASE NAME & $\begin{array}{l}\text { Item line } \\
\text { in this } \\
\text { group }\end{array}$ & Inheritance & $\begin{array}{l}\text { Locus or } \\
\text { disease symbol } \\
\text { and OMIM } \\
\text { number }\end{array}$ & Chromosome & $\begin{array}{l}\text { Gene symbol } \\
\text { and OMIM } \\
\text { number }\end{array}$ & $\begin{array}{l}\text { Protein } \\
\text { (mitochondrial } \\
\text { proteins indicated } \\
\text { by symbol }[\mathrm{M}] \text { ) }\end{array}$ & Key references & $\begin{array}{l}\text { Other allelic disease(s) (group } \\
\text { in this table) }\end{array}$ \\
\hline $\begin{array}{l}\text { Combined oxydative } \\
\text { phosphorylation deficiency } \\
16\end{array}$ & 10.34 & AR & $\begin{array}{l}\text { COXPD16 } \\
615395\end{array}$ & $2 \mathrm{q} 36.1$ & $\begin{array}{l}\text { MRPL44 } \\
611849\end{array}$ & $\begin{array}{l}\text { Mitochondrial } \\
\text { ribosomal protein } \\
\text { L44 (M) }\end{array}$ & Carroll et al. (2013) & \\
\hline $\begin{array}{l}\text { Cardio-encephalo-myopathy, } \\
\text { fatal infantile, due to } \\
\text { cytochrome C oxidase } \\
\text { deficiency } 1\end{array}$ & 10.35 & $\mathrm{AR}$ & $\begin{array}{l}\text { CEMCOX1 } \\
604377\end{array}$ & $22 \mathrm{q} 13.33$ & $\begin{array}{l}\mathrm{SCO} 2 \\
604272\end{array}$ & $\begin{array}{l}\text { Cytochrome c } \\
\text { oxidase assembly } \\
\text { protein }(\mathbf{M})\end{array}$ & $\begin{array}{l}\text { Papadopoulou et al. } \\
\text { (1999) }\end{array}$ & $\begin{array}{l}\text { allelic to CMT2 related to } \mathrm{SCO} 2 \\
\text { (group 14) }\end{array}$ \\
\hline $\begin{array}{l}\text { Cardio-encephalo-myopathy, } \\
\text { fatal infantile, due to } \\
\text { cytochrome C oxidase } \\
\text { deficiency } 2\end{array}$ & 10.36 & AR & $\begin{array}{l}\text { CEMCOX2 } \\
615119\end{array}$ & $10 \mathrm{q} 24.2$ & $\begin{array}{l}\text { COX15 } \\
603646\end{array}$ & $\begin{array}{l}\text { Cytochrome c } \\
\text { oxidase assembly } \\
\text { factor Cox15 (M) }\end{array}$ & Antonicka et al. (2003) & \\
\hline \multicolumn{9}{|l|}{ Dilated cardiomyopathies } \\
\hline Dilated cardiomyopathy, 1A & 10.37 & $\mathrm{AD}$ & $\begin{array}{l}\text { CMD1A } \\
115200\end{array}$ & $1 \mathrm{q} 22$ & $\begin{array}{l}\text { LMNA } \\
150330\end{array}$ & Lamin $\mathrm{A} / \mathrm{C}$ & Fatkin et al. (1999) & $\begin{array}{l}\text { allelic to EDMD2, EDMD3 and } \\
\text { formerly LGMD1B (group1), } \\
\text { MDCL (group 2), CMT2B1 } \\
\text { (group 14) [+ several other } \\
\text { phenotypes not in this table: } \\
\text { FPLD2 \#151660, HGPS \#176670, } \\
\text { restrictive dermopathy \#275210, } \\
\text { MADA \#248370] }\end{array}$ \\
\hline Dilated cardiomyopathy, 1B & 10.38 & $\mathrm{AD}$ & $\begin{array}{l}\text { CMD1B } \\
600884\end{array}$ & $9 \mathrm{q} 13$ & $?$ & & Krajinovic et al. (1995) & \\
\hline $\begin{array}{l}\text { Dilated cardiomyopathy, 1C, } \\
\text { with or without LVNC }\end{array}$ & 10.39 & $\mathrm{AD}$ & $\begin{array}{l}\text { CMD1C } \\
601493\end{array}$ & $10 \mathrm{q} 23.2$ & $\begin{array}{l}\text { LDB3 } \\
605906\end{array}$ & $\begin{array}{l}\text { LIM domain } \\
\text { binding-3 }\end{array}$ & $\begin{array}{l}\text { Bowles et al. (1996) } \\
\text { Vatta et al. (2003) } \\
\text { Arimura et al. (2004) }\end{array}$ & $\begin{array}{l}\text { allelic to Markesbery-Griggs } \\
\text { (group 4), MFM4 (group 5), } \\
\text { CMH24 and LVNC3 (group 10A) }\end{array}$ \\
\hline Dilated cardiomyopathy, 1D & 10.40 & $\mathrm{AD}$ & $\begin{array}{l}\text { CMD1D } \\
601494\end{array}$ & $1 \mathrm{q} 32.1$ & $\begin{array}{l}\text { TNNT2 } \\
191045\end{array}$ & $\begin{array}{l}\text { Troponin type } 2 \\
\text { (cardiac) }\end{array}$ & $\begin{array}{l}\text { Durand et al. (1995) } \\
\text { Kamisago et al. (2000) }\end{array}$ & $\begin{array}{l}\text { allelic to } \mathrm{CMH} 2 \text {, RSM3 and } \\
\text { LVNC6 (group 10) }\end{array}$ \\
\hline Dilated cardiomyopathy, $1 \mathrm{E}$ & 10.41 & $\mathrm{AD}$ & $\begin{array}{l}\text { CMD1E } \\
601154\end{array}$ & $3 \mathrm{p} 22.2$ & $\begin{array}{l}S C N 5 A \\
600163\end{array}$ & $\begin{array}{l}\text { Sodium channel, } \\
\text { voltage-gated, type V, } \\
\text { alpha }\end{array}$ & McNair et al. (2004) & $\begin{array}{l}\text { allelic to BRGDA1, LQT3, SSS1 } \\
\text { (group 10B) }\end{array}$ \\
\hline Dilated cardiomyopathy, 1G & 10.42 & $\mathrm{AD}$ & $\begin{array}{l}\text { CMD1G } \\
604145\end{array}$ & $2 \mathrm{q} 31.2$ & $\begin{array}{l}\text { TTN } \\
188840\end{array}$ & Titin & $\begin{array}{l}\text { Siu et al. (1999) Gerull } \\
\text { et al. (2002) Itoh-Satoh } \\
\text { et al. (2002) }\end{array}$ & $\begin{array}{l}\text { allelic to LGMDR10 (group 1), } \\
\text { CNM related to TTN (group 3), } \\
\text { MmD related to TTN (group 3), } \\
\text { SALMY (group 3), TMD } \\
\text { (group 4), HMERF (group 5), } \\
\text { CMH9 (group 10A) }\end{array}$ \\
\hline Dilated cardiomyopathy, $1 \mathrm{H}$ & 10.43 & $\mathrm{AD}$ & $\begin{array}{l}\text { CMD1H } \\
604288\end{array}$ & $2 q 14-q 22$ & $?$ & & Jung et al. (1999) & \\
\hline Dilated cardiomyopathy, 1I & 10.44 & $\mathrm{AD}$ & $\begin{array}{l}\text { CMD1I } \\
604765\end{array}$ & $2 \mathrm{q} 35$ & $\begin{array}{l}\text { DES } \\
125660\end{array}$ & Desmin & Li et al. (1999) & $\begin{array}{l}\text { allelic to formerly LGMD1 } \\
\text { related to DES and formerly } \\
\text { LGM2R (group 1), MFM1 (group } \\
\text { 5) and ARVC7 (group } 5 \text { and 10B) }\end{array}$ \\
\hline Dilated cardiomyopathy, 1J & 10.45 & $\mathrm{AD}$ & $\begin{array}{l}\text { CMD1J } \\
605362\end{array}$ & $6 \mathrm{q} 23.2$ & $\begin{array}{l}\text { EYA4 } \\
603550\end{array}$ & Eyes absent homolog & Schönberger et al. (2005) & \\
\hline Dilated cardiomyopathy, $1 \mathrm{~K}$ & 10.46 & $\mathrm{AD}$ & $\begin{array}{l}\text { CMD1K } \\
605582\end{array}$ & $6 q 12-q 16$ & $?$ & & Sylvius et al. (2001) & \\
\hline Dilated cardiomyopathy, 1L & 10.47 & $\mathrm{AD}$ & $\begin{array}{l}\text { CMD1L } \\
606685\end{array}$ & $5 q 33.2-q 33.3$ & $\begin{array}{l}S G C D \\
601411\end{array}$ & Sarcoglycan, delta & Tsubata et al. (2000) & allelic to LGMDR6 (group 1) \\
\hline Dilated cardiomyopathy, 1M & 10.48 & $\mathrm{AD}$ & $\begin{array}{l}\text { CMD1M } \\
607482\end{array}$ & $11 \mathrm{p} 15.1$ & $\begin{array}{l}\text { CSRP3 } \\
600824\end{array}$ & $\begin{array}{l}\text { Cysteine and } \\
\text { glycine-rich protein } 3 \\
\text { (cardiac LIM protein) }\end{array}$ & Knoll et al. (2002) & allelic to CMH12 (group 10A) \\
\hline Dilated cardiomyopathy, $1 \mathrm{~N}$ & 10.49 & $\mathrm{AD}$ & $\begin{array}{l}\text { CMD1N } \\
607487\end{array}$ & $17 \mathrm{q} 12$ & $\begin{array}{l}\text { TCAP } \\
604488\end{array}$ & Titin-cap (Telethonin) & Knoll et al. (2002) & $\begin{array}{l}\text { allelic to LGMDR7 (group 1), } \\
\text { CMD related to telethonin } \\
\text { (group 2), CMH25 (group 10) }\end{array}$ \\
\hline Dilated cardiomyopathy, 10 & 10.50 & $\mathrm{AD}$ & $\begin{array}{l}\text { CMD1O } \\
605569\end{array}$ & $12 \mathrm{p} 12.1$ & $\begin{array}{l}A B C C 9 \\
601439\end{array}$ & $\begin{array}{l}\text { ATP-binding cassette, } \\
\text { subfamily C, member } \\
9\end{array}$ & $\begin{array}{l}\text { Bienengraeber etal } \\
(2004)\end{array}$ & \\
\hline Dilated cardiomyopathy, $1 \mathrm{P}$ & 10.51 & $\mathrm{AD}$ & $\begin{array}{l}\text { CMD1P } \\
609909\end{array}$ & $6 \mathrm{q} 22.31$ & $\begin{array}{l}P L N \\
172405\end{array}$ & phospholamban & $\begin{array}{l}\text { Schmitt et al. (2003) } \\
\text { Haghighi et al. (2003, } \\
\text { 2006) }\end{array}$ & allelic to CMH18 (group 10A) \\
\hline Dilated cardiomyopathy, 1Q & 10.52 & $\mathrm{AD}$ & $\begin{array}{l}\text { CMD1Q } \\
609915\end{array}$ & $7 \mathrm{q} 22.3-\mathrm{q} 31.1$ & $?$ & & Schonberger et al. (2005) & \\
\hline Dilated cardiomyopathy, 1R & 10.53 & $\mathrm{AD}$ & $\begin{array}{l}\text { CMD1R } \\
613424\end{array}$ & $15 \mathrm{q} 14$ & $\begin{array}{r}\text { ACTC1 } \\
102540\end{array}$ & $\begin{array}{l}\text { actin, alpha, cardiac } \\
\text { muscle }\end{array}$ & $\begin{array}{l}\text { Olson et al. (1998) } \\
\text { Mogensen et al. (1999) }\end{array}$ & $\begin{array}{l}\text { allelic to CMH11, LVNC4 } \\
\text { (group 10A) }\end{array}$ \\
\hline Dilated cardiomyopathy, is & 10.54 & $\mathrm{AD}$ & $\begin{array}{l}\text { CMD1S } \\
613426\end{array}$ & $14 \mathrm{q} 11.2$ & $\begin{array}{l}\text { MYH7 } \\
160760\end{array}$ & $\begin{array}{l}\text { Myosin heavy chain } \\
7 \text { (beta), cardiac } \\
\text { muscle }\end{array}$ & Kamisago et al. (2000) & $\begin{array}{l}\text { allelic to CFTD, MSMA and } \\
\text { MSMB (group 3), MPD1 } \\
\text { (group 4), CMH1 and LVNC5 } \\
\text { (group 10A) }\end{array}$ \\
\hline Dilated cardiomyopathy, 1T & 10.55 & $\mathrm{AD}$ & CMD1T & $12 \mathrm{q} 23.1$ & $\begin{array}{l}\text { TMPO } \\
188380\end{array}$ & $\begin{array}{l}\text { Thymopoietin } \\
\text { (lamina-associated } \\
\text { polypeptide 2) }\end{array}$ & Taylor et al. (2005) & \\
\hline Dilated cardiomyopathy, $1 \mathrm{U}$ & 10.56 & $\mathrm{AD}$ & $\begin{array}{l}\text { CMD1U } \\
613694\end{array}$ & $14 \mathrm{q} 24.2$ & $\begin{array}{l}\text { PSEN1 } \\
104311\end{array}$ & Presenilin 1 & Li et al. (2006) & \\
\hline Dilated cardiomyopathy, 1V & 10.57 & $\mathrm{AD}$ & $\begin{array}{l}\text { CMD1V } \\
613697\end{array}$ & $1 \mathrm{q} 42.13$ & $\begin{array}{l}\text { PSEN2 } \\
600759\end{array}$ & Presenilin 2 & Li et al. (2006) & \\
\hline
\end{tabular}




\begin{tabular}{|c|c|c|c|c|c|c|c|c|}
\hline DISEASE NAME & $\begin{array}{l}\text { Item line } \\
\text { in this } \\
\text { group }\end{array}$ & Inheritance & $\begin{array}{l}\text { Locus or } \\
\text { disease symbol } \\
\text { and OMIM } \\
\text { number }\end{array}$ & Chromosome & $\begin{array}{l}\text { Gene symbol } \\
\text { and OMIM } \\
\text { number }\end{array}$ & $\begin{array}{l}\text { Protein } \\
\text { (mitochondrial } \\
\text { proteins indicated } \\
\text { by symbol }[\mathrm{M}] \text { ) }\end{array}$ & Key references & $\begin{array}{l}\text { Other allelic disease(s) (group } \\
\text { in this table) }\end{array}$ \\
\hline Dilated cardiomyopathy, $1 \mathrm{~W}$ & 10.58 & $\mathrm{AD}$ & $\begin{array}{l}\text { CMD1W } \\
611407\end{array}$ & $10 \mathrm{q} 22.2$ & $\begin{array}{l}\text { VCL } \\
193065\end{array}$ & Vinculin & $\begin{array}{l}\text { Olson et al. (2002) } \\
\text { Vasile et al. (2006) }\end{array}$ & allelic to CMH15 (group 10) \\
\hline $\begin{array}{l}\text { Dilated cardiomyopathy } \\
\text { related, } 1 \mathrm{X}\end{array}$ & 10.59 & $\mathrm{AR}$ & $\begin{array}{l}\text { CMD1 } \times \\
611615\end{array}$ & $9 \mathrm{q} 31.2$ & $\begin{array}{l}\text { FKTN } \\
607440\end{array}$ & Fukutin & Murakami et al. (2006) & $\begin{array}{l}\text { allelic to LGMDR13 (group 1), } \\
\text { FCMD and WWS/MDDGB4 } \\
\text { (group 2) }\end{array}$ \\
\hline Dilated cardiomyopathy, $1 \mathrm{Y}$ & 10.60 & $\mathrm{AD}$ & $\begin{array}{l}\text { CMD1Y } \\
611878\end{array}$ & $15 \mathrm{q} 22.2$ & $\begin{array}{l}\text { TPMI } \\
191010\end{array}$ & Tropomyosin-1 & Olson et al. (2010) & $\begin{array}{l}\text { allelic to CMH3 and LVNC9 } \\
\text { (group 10A) }\end{array}$ \\
\hline Dilated cardiomyopathy, $1 \mathrm{Z}$ & 10.61 & $\mathrm{AD}$ & $\begin{array}{l}\text { CMD1Z } \\
611879\end{array}$ & $3 \mathrm{p} 21.1$ & $\begin{array}{l}\text { TNNC1 } \\
191040\end{array}$ & Slow troponin $\mathrm{C}$ & Mogensen et al. (2004) & allelic to $\mathrm{CMH13}$ (group 10A) \\
\hline $\begin{array}{l}\text { Dilated cardiomyopathy, } \\
1 \mathrm{AA} \text {, with or without LVNC }\end{array}$ & 10.62 & $\mathrm{AD}$ & $\begin{array}{l}\text { CMD1AA } \\
612158\end{array}$ & $1 q 42-q 43$ & $\begin{array}{l}\operatorname{ACTN2} \\
102573\end{array}$ & Actinin alpha-2 & Mohapatra et al. (2003) & $\begin{array}{l}\text { allelic to Myopathy congenital } \\
\text { related to ACTN2 (group 3), } \\
\text { CMH23 (group 10A) }\end{array}$ \\
\hline $\begin{array}{l}\text { Dilated cardiomyopathy, } \\
\text { 1BB }\end{array}$ & 10.63 & $\mathrm{AD} / \mathrm{AR}$ & $\begin{array}{l}\text { CMD1BB } \\
612877\end{array}$ & $18 \mathrm{q} 12.1$ & $\begin{array}{l}\text { DSG2 } \\
125671\end{array}$ & Desmoglein 2 & Posch et al. (2008) & allelic to ARVD10 (group 10B) \\
\hline $\begin{array}{l}\text { Dilated cardiomyopathy, } \\
1 \mathrm{CC}\end{array}$ & 10.64 & $\mathrm{AD}$ & $\begin{array}{l}\text { CMD1CC } \\
613122\end{array}$ & $1 \mathrm{p} 31.1$ & $\begin{array}{l}\text { NEXN } \\
613121\end{array}$ & $\begin{array}{l}\text { Nexilin F-actin } \\
\text { binding protein }\end{array}$ & Hassel et al. (2009) & allelic to $\mathrm{CMH} 20$ (group 10A) \\
\hline $\begin{array}{l}\text { Dilated cardiomyopathy, } \\
\text { 1DD }\end{array}$ & 10.65 & $\mathrm{AD}$ & $\begin{array}{l}\text { CMD1DD } \\
613172\end{array}$ & $10 \mathrm{q} 25.2$ & $\begin{array}{l}\text { RBM20 } \\
613171\end{array}$ & $\begin{array}{l}\text { RNA-binding motif } \\
\text { protein } 20\end{array}$ & Brauch et al. (2009) & \\
\hline $\begin{array}{l}\text { Dilated cardiomyopathy, } \\
\text { 1EE }\end{array}$ & 10.66 & $\mathrm{AD}$ & $\begin{array}{l}\text { CMD1EE } \\
613252\end{array}$ & $14 q 11.2$ & $\begin{array}{l}\text { МYH6 } \\
160710\end{array}$ & $\begin{array}{l}\text { Myosin, heavy chain } \\
6 \text {, cardiac muscle, } \\
\text { alpha }\end{array}$ & Carniel et al. (2005) & $\begin{array}{l}\text { allelic to CMH14 (group 10A), } \\
\text { SSS3 (group 10B) }\end{array}$ \\
\hline Dilated cardiomyopathy, 1FF & 10.67 & $\mathrm{AD}$ & $\begin{array}{l}\text { CMD1FF } \\
613286\end{array}$ & $19 \mathrm{q} 13.42$ & TNNI3 191044 & Cardic troponin I & Carballo et al. (2009) & $\begin{array}{l}\text { allelic to } \mathrm{CMH} 7, \mathrm{CDM} 2 \mathrm{~A}, \mathrm{RCM} 1 \\
\text { (group 10A) }\end{array}$ \\
\hline $\begin{array}{l}\text { Dilated cardiomyopathy, } \\
\text { 1GG }\end{array}$ & 10.68 & AR & $\begin{array}{l}\text { CMD1GG } \\
613642\end{array}$ & $5 \mathrm{p} 15.33$ & $\begin{array}{l}\text { SDHA } \\
600857\end{array}$ & $\begin{array}{l}\text { Succinate } \\
\text { dehydrogenase } \\
\text { complex, subunit a, } \\
\text { flavoprotein }(\mathbf{M})\end{array}$ & Levitas et al. (2010) & \\
\hline $\begin{array}{l}\text { Dilated cardiomyopathy, } \\
1 \mathrm{HH}\end{array}$ & 10.69 & $\mathrm{AD}$ & $\begin{array}{l}\text { CMD1HH } \\
613881\end{array}$ & $10 \mathrm{q} 26.11$ & $\begin{array}{l}\text { BAG3 } \\
603883\end{array}$ & $\begin{array}{l}\text { Bcl2-associated } \\
\text { athanogene } 3\end{array}$ & Norton et al. (2011) & $\begin{array}{l}\text { allelic to MFM6 (group 5) and } \\
\text { CMT related to BAG3 (group 14) }\end{array}$ \\
\hline Dilated cardiomyopathy, 1II & 10.70 & $\mathrm{AD}$ & $\begin{array}{l}\text { CMD1II } \\
615184\end{array}$ & $11 \mathrm{q} 23.1$ & $\begin{array}{l}\text { CRYAB } \\
123590\end{array}$ & Alpha-B crystallin & Inagaki et al. (2006) & allelic to MFM2 (group 5) \\
\hline Dilated cardiomyopathy, 1JJ & 10.71 & $\mathrm{AD}$ & $\begin{array}{l}\text { CMD1JJ } \\
615235\end{array}$ & $6 \mathrm{q} 21$ & $\begin{array}{l}\text { LAMA4 } \\
600133\end{array}$ & Laminin, alpha-4 & Knöll et al. (2007) & \\
\hline $\begin{array}{l}\text { Dilated cardiomyopathy, } \\
1 \mathrm{KK}\end{array}$ & 10.72 & $\mathrm{AD}$ & $\begin{array}{l}\text { CMD1KK } \\
615248\end{array}$ & $10 \mathrm{q} 21.3$ & $\begin{array}{l}\text { MYPN } \\
608517\end{array}$ & Myopalladin & Duboscq-Bidot (2008) & $\begin{array}{l}\text { allelic to NEM11 (group 3) and } \\
\text { CMH22 (group 10A), RCM4 } \\
\text { (group 10A) }\end{array}$ \\
\hline $\begin{array}{l}\text { Dilated cardiomyopathy, } \\
\text { 1LL }\end{array}$ & 10.73 & $\mathrm{AD}$ & $\begin{array}{l}\text { CMD1LL } \\
615373\end{array}$ & $1 \mathrm{p} 36.32$ & $\begin{array}{l}\text { PRDM16 } \\
605557\end{array}$ & $\begin{array}{l}\mathrm{PR} \\
\text { domain-containing } \\
\text { protein } 16\end{array}$ & Arndt et al. (2013) & allelic to LVNC8 (group 10A) \\
\hline $\begin{array}{l}\text { Dilated cardiomyopathy, } \\
1 \mathrm{MM}\end{array}$ & 10.74 & $\mathrm{AD}$ & $\begin{array}{l}\text { CMD1MM } \\
615396\end{array}$ & $11 \mathrm{p} 11.2$ & $\begin{array}{l}\text { МYBPC3 } \\
600958\end{array}$ & $\begin{array}{l}\text { Myosin-binding } \\
\text { protein C, cardiac }\end{array}$ & Hershberger et al. (2010) & $\begin{array}{l}\text { allelic to congenital myopathy and } \\
\text { fatal cardiomyopathy (group 3), } \\
\text { CMH4 and LVNC10 (group 10) }\end{array}$ \\
\hline $\begin{array}{l}\text { Dilated cardiomyopathy, } \\
\text { 1NN }\end{array}$ & 10.75 & $\mathrm{AD}$ & $\begin{array}{l}\text { CMD1NN } \\
615916\end{array}$ & $3 \mathrm{p} 25.2$ & $\begin{array}{l}\text { RAF1 } \\
164760\end{array}$ & $\begin{array}{l}\text { V-Raf-1 murine } \\
\text { leukemia viral } \\
\text { oncogene homolog } 1\end{array}$ & Dhandapany et al. (2014) & \\
\hline $\begin{array}{l}\text { Dilated cardiomyopathy } \\
\text { related to integrin-linked } \\
\text { kinase }\end{array}$ & 10.76 & $\mathrm{AD}$ & & $11 \mathrm{p} 15.4$ & $\begin{array}{l}I L K \\
602366\end{array}$ & Integrin-linked kinase & Knöll et al. (2007) & \\
\hline $\begin{array}{l}\text { Dilated cardiomyopathy } \\
\text { related to cardiac ankyrin } \\
\text { repeat protein }\end{array}$ & 10.77 & $\mathrm{AD}$ & & $10 \mathrm{q} 23.31$ & $\begin{array}{l}\text { ANKRDI } \\
609599\end{array}$ & $\begin{array}{l}\text { Ankyrin repeat } \\
\text { domain } 1 \text { containing } \\
\text { protein } 1\end{array}$ & $\begin{array}{l}\text { Duboscq-Bidot et al. } \\
\text { (2009) Moulik et al. } \\
(2009)\end{array}$ & $\begin{array}{l}\text { Allelic to Hypertrophic } \\
\text { cardiomyopathy related to cardiac } \\
\text { ankyrin repeat domain protein } \\
\text { (group 10A) }\end{array}$ \\
\hline Dilated cardiomyopathy, 2A & 10.78 & AR & $\begin{array}{l}\text { CMD2A } \\
611880\end{array}$ & $19 \mathrm{q} 13.42$ & $\begin{array}{l}\text { TNNI3 } \\
191044\end{array}$ & Cardiac troponin I & Carballo et al. (2009) & $\begin{array}{l}\text { allelic to CMH7, CMD1FF, } \\
\text { RCM1 (group 10A) }\end{array}$ \\
\hline Dilated cardiomyopathy 2B & 10.79 & $\mathrm{AR}$ & $\begin{array}{l}\text { CMD2B } \\
614672\end{array}$ & $7 \mathrm{q} 21.2$ & $\begin{array}{l}\text { GATAD1 } \\
614518\end{array}$ & $\begin{array}{l}\text { GATA zinc finger } \\
\text { domain-containing } \\
\text { protein } 1\end{array}$ & Theis et al. (2011) & \\
\hline Dilated cardiomyopathy, 3A & 10.80 & XR & CMD3A & $\mathrm{Xq} 28$ & $\begin{array}{l}\text { TAZ } \\
300394\end{array}$ & Tafazzin & Gedeon et al. (1995) & allelic to BTHS (group 10A) \\
\hline Dilated cardiomyopathy, 3B & 10.81 & XR & $\begin{array}{l}\text { CMD3B } \\
302045\end{array}$ & $\mathrm{Xp} 21.2-\mathrm{p} 21.1$ & $\begin{array}{l}\text { DMD } \\
300377\end{array}$ & Dystrophin & $\begin{array}{l}\text { Muntoni et al. (1993) } \\
\text { Milasin et al. (1996) }\end{array}$ & allelic to DMD (group 1) \\
\hline $\begin{array}{l}\text { Dilated cardiomyopathy } \\
\text { related to nesprin-1 }\end{array}$ & 10.82 & $\mathrm{AD}$ & & $6 \mathrm{q} 25.2$ & $\begin{array}{l}\text { SYNE1 } \\
608441\end{array}$ & $\begin{array}{l}\text { Spectrin repeat } \\
\text { containing, nuclear } \\
\text { envelope protein } 1 \\
\text { (nesprin-1) }\end{array}$ & Puckelwartz et al. (2010) & $\begin{array}{l}\text { allelic to EDMD4 (group 1) } \\
\text { SCAR8 (group 13), AMC with } \\
\text { nesprin-1 defect (group 16) }\end{array}$ \\
\hline $\begin{array}{l}\text { Dilated cardiomyopathy } \\
\text { related to MURC }\end{array}$ & 10.83 & $\mathrm{AD}$ & & $9 \mathrm{q} 31.1$ & $\begin{array}{l}\text { CAVIN4 } \\
617714\end{array}$ & $\begin{array}{l}\text { Caveolae-associated } \\
\text { protein } 4 \text { (MURC) }\end{array}$ & Rodriguez et al. (2011) & \\
\hline $\begin{array}{l}\text { Dilated cardiomyopathy } \\
\text { related to DOLK }\end{array}$ & 10.84 & AR & $\begin{array}{l}\text { CDGM1 } \\
610768\end{array}$ & $9 \mathrm{q} 34.11$ & $\begin{array}{l}\text { DOLK } \\
610746\end{array}$ & Dolichol kinase & $\begin{array}{l}\text { Kranz et al. (2007) } \\
\text { Lefeber et al. (2011) }\end{array}$ & \\
\hline \multicolumn{9}{|l|}{ Restrictive cardiomyopathies } \\
\hline $\begin{array}{l}\text { Restrictive cardiomyopathy, } \\
1\end{array}$ & 10.85 & $\mathrm{AD}$ & $\begin{array}{l}\text { RCM1 } \\
115210\end{array}$ & $19 \mathrm{q} 13.42$ & $\begin{array}{l}\text { TNNI3 } \\
191044\end{array}$ & Cardiac troponin I & Mogensen et al. (2003) & $\begin{array}{l}\text { allelic to CMH7, CMD1FF, } \\
\text { CMD2A (group 10A) }\end{array}$ \\
\hline
\end{tabular}




\begin{tabular}{|c|c|c|c|c|c|c|c|c|}
\hline DISEASE NAME & $\begin{array}{l}\text { Item line } \\
\text { in this } \\
\text { group }\end{array}$ & Inheritance & $\begin{array}{l}\text { Locus or } \\
\text { disease symbol } \\
\text { and OMIM } \\
\text { number }\end{array}$ & Chromosome & $\begin{array}{l}\text { Gene symbol } \\
\text { and OMIM } \\
\text { number }\end{array}$ & $\begin{array}{l}\text { Protein } \\
\text { (mitochondrial } \\
\text { proteins indicated } \\
\text { by symbol }[\mathrm{M}] \text { ) }\end{array}$ & Key references & $\begin{array}{l}\text { Other allelic disease(s) (group } \\
\text { in this table) }\end{array}$ \\
\hline $\begin{array}{l}\text { Restrictive cardiomyopathy, } \\
2\end{array}$ & 10.86 & & $\begin{array}{l}\mathrm{RCM} 2 \\
609578\end{array}$ & $10 \mathrm{q} 23.3$ & $?$ & & Zhang et al. (2005) & \\
\hline $\begin{array}{l}\text { Restrictive cardiomyopathy, } \\
3\end{array}$ & 10.87 & $\mathrm{AD}$ & $\begin{array}{l}\text { RCM3 } \\
612422\end{array}$ & $1 \mathrm{q} 32.1$ & $\begin{array}{l}\text { TNNT2 } \\
191045\end{array}$ & Cardiac Troponin T & Peddy et al. (2006) & $\begin{array}{l}\text { allelic to CMH2, CMD1D and } \\
\text { LVNC6 (group 10) }\end{array}$ \\
\hline $\begin{array}{l}\text { Restrictive cardiomyopathy, } \\
4\end{array}$ & 10.88 & $\mathrm{AD}$ & $\begin{array}{l}\text { RCM4 } \\
615248\end{array}$ & $10 \mathrm{q} 21.3$ & $\begin{array}{l}\text { MYPN } \\
608517\end{array}$ & Myopalladin & Purevjav et al. (2012) & $\begin{array}{l}\text { allelic to CMH22 (group 10A), } \\
\text { CMD1KK (group 10A) and } \\
\text { NEM11 (group 3) }\end{array}$ \\
\hline $\begin{array}{l}\text { Restrictive cardiomyopathy, } \\
5\end{array}$ & 10.89 & $\mathrm{AD}$ & $\begin{array}{l}\text { RCM5 } \\
617047\end{array}$ & $7 \mathrm{q} 32.1$ & $\begin{array}{l}\boldsymbol{F L N C} \\
102565\end{array}$ & Filamin C & Brodehl et al. (2016) & $\begin{array}{l}\text { allelic to MFM5 (group 5), } \\
\text { MPD4 (group 4) and CMH26 } \\
\text { (group 10A) }\end{array}$ \\
\hline \multicolumn{9}{|c|}{ Other non arrhythmogenic hereditary cardiomyopathies } \\
\hline $\begin{array}{l}\text { Pompe disease, } \\
\text { Glycogenosis, generalized, } \\
\text { cardiac form (also listed in } \\
\text { group 9) }\end{array}$ & 10.90 & $\mathrm{AR}$ & $\begin{array}{l}\text { GSDII } \\
232300\end{array}$ & $17 \mathrm{q} 25.3$ & $\begin{array}{l}\text { GAA } \\
606800\end{array}$ & $\begin{array}{l}\text { Glucosidase, alpha; } \\
\text { acid }\end{array}$ & $\begin{array}{l}\text { Hers (1963) Martiniuk } \\
\text { et al. (1990) Wokke } \\
\text { et al. (1995) }\end{array}$ & $\begin{array}{l}\text { Allelic to formerly LGMD2V } \\
\text { (group 1) and Pompe's disease } \\
\text { (group 9) }\end{array}$ \\
\hline $\begin{array}{l}\text { Cardioskeletal myopathy } \\
\text { with neutropenia and } \\
\text { abnormal mitochondria } \\
\text { (Barth syndrome) }\end{array}$ & 10.91 & $\mathrm{XR}$ & $\begin{array}{l}\text { BTHS } \\
302060\end{array}$ & $\mathrm{Xq} 28$ & $\begin{array}{l}\text { TAZ } \\
300394\end{array}$ & Tafazzin & $\begin{array}{l}\text { Bolhuis et al. (1991) } \\
\text { Bione et al. (1996) }\end{array}$ & allelic to CMD3A (group 10A) \\
\hline $\begin{array}{l}\text { Left ventricular } \\
\text { noncompaction, } 1\end{array}$ & 10.92 & $\mathrm{AD}$ & $\begin{array}{l}\text { LVNC1 } \\
604169\end{array}$ & $18 \mathrm{q} 12.1$ & $\begin{array}{l}\text { DTNA } \\
601239\end{array}$ & Dystrobrevin, alpha & Ichida et al. (2001) & \\
\hline $\begin{array}{l}\text { Left ventricular } \\
\text { noncompaction, } 2\end{array}$ & 10.93 & & $\begin{array}{l}\text { LVNC2 } \\
609470\end{array}$ & $11 \mathrm{q} 15$ & $?$ & & $\begin{array}{l}\text { Sasse-Klaassen et al. } \\
\text { (2004) }\end{array}$ & \\
\hline $\begin{array}{l}\text { Left ventricular } \\
\text { noncompaction, } 3\end{array}$ & 10.94 & $\mathrm{AD}$ & $\begin{array}{l}\text { LVNC3 } \\
601493\end{array}$ & $10 \mathrm{q} 23.2$ & $\begin{array}{l}\text { LDB3 } \\
605906\end{array}$ & $\begin{array}{l}\text { LIM domain } \\
\text { binding-3 }\end{array}$ & Vatta et al. (2003) & $\begin{array}{l}\text { alllelic to Markesbery-Griggs } \\
\text { (group 4), MFM4 (group 5), } \\
\text { CMH24, CMD1C (group 10), }\end{array}$ \\
\hline $\begin{array}{l}\text { Left ventricular } \\
\text { noncompaction, } 4\end{array}$ & 10.95 & $\mathrm{AD}$ & $\begin{array}{l}\text { LVNC4 } \\
613424\end{array}$ & $15 \mathrm{q} 14$ & $\begin{array}{l}\text { ACTC1 } \\
102540\end{array}$ & Alpha-cardiac actin & Monserrat et al. (2007) & $\begin{array}{l}\text { allelic to CMH11, CMD1R } \\
\text { (group 10A) }\end{array}$ \\
\hline $\begin{array}{l}\text { Left ventricular } \\
\text { noncompaction, } 5\end{array}$ & 10.96 & $\mathrm{AD}$ & $\begin{array}{l}\text { LVNC5 } \\
613426\end{array}$ & $14 \mathrm{q} 11.2$ & $\begin{array}{l}\text { MYH7 } \\
160760\end{array}$ & $\begin{array}{l}\text { Myosin heavy chain } \\
7 \text { (beta), cardiac } \\
\text { muscle }\end{array}$ & Klaassen et al. (2008) & $\begin{array}{l}\text { allelic to CFTD and MSMA, } \\
\text { MSMB (group 3), MPD1 (group } \\
\text { 4), CMH1 and CMD1S (group } \\
\text { 10A) }\end{array}$ \\
\hline $\begin{array}{l}\text { Left ventricular } \\
\text { noncompaction, } 6\end{array}$ & 10.97 & $\mathrm{AD}$ & $\begin{array}{l}\text { LVNC6 } \\
601494\end{array}$ & $1 \mathrm{q} 32.1$ & $\begin{array}{l}\text { TNNT2 } \\
191045\end{array}$ & Cardiac Troponin $\mathrm{T}$ & Luedde et al. (2010) & $\begin{array}{l}\text { allelic to } \mathrm{CMH} 2, \mathrm{CMD} 1 \mathrm{D} \text { and } \\
\text { RCM3 (group 10A) }\end{array}$ \\
\hline $\begin{array}{l}\text { Left ventricular } \\
\text { noncompaction, } 7\end{array}$ & 10.98 & $\mathrm{AD}$ & $\begin{array}{l}\text { LVNC7 } \\
615092\end{array}$ & $18 \mathrm{q} 11.2$ & $\begin{array}{l}\text { MIB1 } \\
608677\end{array}$ & $\begin{array}{l}\text { Mindbomb, } \\
\text { drosophila, homolog } \\
\text { of }\end{array}$ & Luxan et al. (2013) & \\
\hline $\begin{array}{l}\text { Left ventricular } \\
\text { noncompaction, } 8\end{array}$ & 10.99 & $\mathrm{AD}$ & $\begin{array}{l}\text { LVNC8 } \\
615373\end{array}$ & $1 \mathrm{p} 36.32$ & $\begin{array}{l}\text { PRDM16 } \\
605557\end{array}$ & $\begin{array}{l}\text { PR } \\
\text { domain-containing } \\
\text { protein } 16\end{array}$ & Arndt et al. (2013) & allelic to CMD1LL (group 10A) \\
\hline $\begin{array}{l}\text { Left ventricular } \\
\text { noncompaction, } 9\end{array}$ & 10.100 & $\mathrm{AD}$ & $\begin{array}{l}\text { LVNC9 } \\
611878\end{array}$ & $15 q 22.2$ & $\begin{array}{l}\text { TPM1 } \\
191010\end{array}$ & Tropomyosin-1 & Probst et al. (2011) & $\begin{array}{l}\text { allelic to } \mathrm{CMH} 3 \text {, CMD1Y (group } \\
\text { 10A) }\end{array}$ \\
\hline $\begin{array}{l}\text { Left ventricular } \\
\text { noncompaction, } 10\end{array}$ & 10.101 & $\mathrm{AD}$ & $\begin{array}{l}\text { LVNC10 } \\
615396\end{array}$ & $11 \mathrm{p} 11.2$ & $\begin{array}{l}\text { МYBPC3 } \\
600958\end{array}$ & $\begin{array}{l}\text { Cardiac myosin } \\
\text { binding protein-C }\end{array}$ & Probst et al. (2011) & $\begin{array}{l}\text { allelic to congenital skeletal } \\
\text { myopathy and fatal } \\
\text { cardiomyopathy (group 3), CMH4 } \\
\text { and CMD1MM (group 10) }\end{array}$ \\
\hline $\begin{array}{l}\text { Cardiovalvular dysplasia, } \\
\text { X-linked (Myxomatous } \\
\text { valvular dystrophy) }\end{array}$ & 10.102 & $\mathrm{XR}$ & $\begin{array}{l}\text { CVD1 } \\
314400\end{array}$ & $\mathrm{Xq} 28$ & $\begin{array}{l}\text { FLNA } \\
300017\end{array}$ & $\begin{array}{l}\text { Filamin A, alpha } \\
\text { (actin binding protein } \\
280 \text { ) }\end{array}$ & $\begin{array}{l}\text { Kyndt et al. (1998) } \\
\text { Kyndt et al. (2007) }\end{array}$ & \\
\hline \multicolumn{9}{|c|}{ GROUP 11. CONGENITAL MYASTHENIC SYNDROMES } \\
\hline $\begin{array}{l}\text { Myasthenic syndrome, } \\
\text { congenital, 1A, } \\
\text { Slow-channel }\end{array}$ & 11.1 & $\mathrm{AD}$ & $\begin{array}{l}\text { CMS1A } \\
601462\end{array}$ & $2 \mathrm{q} 31.1$ & $\begin{array}{l}\text { CHRNAI } \\
100690\end{array}$ & $\begin{array}{l}\text { Cholinergic receptor, } \\
\text { nicotinic, alpha } 1\end{array}$ & $\begin{array}{l}\text { Sine et al. (1995) Engel } \\
\text { et al. (1996) Croxen } \\
\text { et al. (1997) }\end{array}$ & allelic to CMS1B (group 11) \\
\hline $\begin{array}{l}\text { Myasthenic syndrome, } \\
\text { congenital, 2A, } \\
\text { Slow-channel }\end{array}$ & 11.2 & $\mathrm{AD}$ & $\begin{array}{l}\text { CMS2A } \\
616313\end{array}$ & $17 \mathrm{p} 13.1$ & $\begin{array}{l}\text { CHRNB1 } \\
100710\end{array}$ & $\begin{array}{l}\text { Cholinergic receptor, } \\
\text { nicotinic, beta } 1\end{array}$ & $\begin{array}{l}\text { Engel et al. (1996b) } \\
\text { Gomez et al. (1996) }\end{array}$ & allelic to CMS2C (group 11) \\
\hline $\begin{array}{l}\text { Myasthenic syndrome, } \\
\text { congenital, 3A, } \\
\text { Slow-channel }\end{array}$ & 11.3 & $\mathrm{AD}$ & $\begin{array}{l}\text { CMS3A } \\
616321\end{array}$ & $2 \mathrm{q} 37.1$ & $\begin{array}{l}\text { CHRND } \\
100720\end{array}$ & $\begin{array}{l}\text { Cholinergic receptor, } \\
\text { Cicotinic, delta }\end{array}$ & Gomez et al. (2002) & $\begin{array}{l}\text { allelic to CMS3B, CMS3C } \\
\text { (group 11) }\end{array}$ \\
\hline $\begin{array}{l}\text { Myasthenic syndrome, } \\
\text { congenital, 4A, } \\
\text { Slow-channel }\end{array}$ & 11.4 & $\mathrm{AD}, \mathrm{AR}$ & $\begin{array}{l}\text { CMS4A } \\
605809\end{array}$ & $17 \mathrm{p} 13.2$ & $\begin{array}{l}\text { CHRNE } \\
100725\end{array}$ & $\begin{array}{l}\text { Cholinergic receptor, } \\
\text { nicotinic, epsilon }\end{array}$ & $\begin{array}{l}\text { Ohno et al. (1995) } \\
\text { Gomez et al. (1995) } \\
\text { Engel et al. (1996) } \\
\text { Croxen et al. (2002) }\end{array}$ & $\begin{array}{l}\text { allelic to CMS4B, CMS4C } \\
\text { (group 11) }\end{array}$ \\
\hline $\begin{array}{l}\text { Myasthenic syndrome, } \\
\text { congenital, 1B, Fast-channel }\end{array}$ & 11.5 & AR & $\begin{array}{l}\text { CMS1B } \\
608930\end{array}$ & $2 \mathrm{q} 31.1$ & $\begin{array}{l}\text { CHRNAI } \\
100690\end{array}$ & $\begin{array}{l}\text { Cholinergic receptor, } \\
\text { nicotinic, alpha } 1\end{array}$ & $\begin{array}{l}\text { Wang et al. (1999) Shen } \\
\text { et al. (2003) }\end{array}$ & allelic to CMS1A (group 11) \\
\hline $\begin{array}{l}\text { Myasthenic syndrome, } \\
\text { congenital, 3B, Fast-channel }\end{array}$ & 11.6 & $\mathrm{AR}$ & $\begin{array}{l}\text { CMS3B } \\
616322\end{array}$ & $2 \mathrm{q} 37.1$ & $\begin{array}{l}\text { CHRND } \\
100720\end{array}$ & $\begin{array}{l}\text { Cholinergic receptor, } \\
\text { nicotinic, delta }\end{array}$ & Brownlow et al. (2001) & $\begin{array}{l}\text { allelic to CMS3A, CMS3C } \\
\text { (group11) }\end{array}$ \\
\hline $\begin{array}{l}\text { Myasthenic syndrome, } \\
\text { congenital, 4B, Fast-channel }\end{array}$ & 11.7 & AR & $\begin{array}{l}\text { CMS4B } \\
616324\end{array}$ & $17 \mathrm{p} 13.2$ & $\begin{array}{l}\text { CHRNE } \\
100725\end{array}$ & $\begin{array}{l}\text { Cholinergic receptor, } \\
\text { nicotinic, epsilon }\end{array}$ & Ohno et al. (1996) & $\begin{array}{l}\text { allelic to CMS4A, CMS4C } \\
\text { (group 11) }\end{array}$ \\
\hline $\begin{array}{l}\text { Myasthenic syndrome, } \\
\text { congenital, } 2 \mathrm{C} \text {, associated }\end{array}$ & 11.8 & AR & $\begin{array}{l}\text { CMS2C } \\
616314\end{array}$ & $17 \mathrm{p} 13.1$ & $\begin{array}{l}\text { CHRNB1 } \\
100710\end{array}$ & $\begin{array}{l}\text { Cholinergic receptor, } \\
\text { nicotinic, beta } 1\end{array}$ & Quiram et al. (1999) & allelic to CMS2A (group 11) \\
\hline
\end{tabular}




\begin{tabular}{|c|c|c|c|c|c|c|c|c|}
\hline DISEASE NAME & $\begin{array}{l}\text { Item line } \\
\text { in this } \\
\text { group }\end{array}$ & Inheritance & $\begin{array}{l}\text { Locus or } \\
\text { disease symbol } \\
\text { and OMIM } \\
\text { number }\end{array}$ & Chromosome & $\begin{array}{l}\text { Gene symbol } \\
\text { and OMIM } \\
\text { number }\end{array}$ & $\begin{array}{l}\text { Protein } \\
\text { (mitochondrial } \\
\text { proteins indicated } \\
\text { by symbol }[M] \text { ) }\end{array}$ & Key references & $\begin{array}{l}\text { Other allelic disease(s) (group } \\
\text { in this table) }\end{array}$ \\
\hline $\begin{array}{l}\text { Myasthenic syndrome, } \\
\text { congenital, 3C, associated } \\
\text { with acetylcholine receptor } \\
\text { deficiency }\end{array}$ & 11.9 & AR & $\begin{array}{l}\text { CMS3C } \\
616323\end{array}$ & $2 \mathrm{q} 37.1$ & $\begin{array}{l}\text { CHRND } \\
100720\end{array}$ & $\begin{array}{l}\text { Cholinergic receptor, } \\
\text { nicotinic, delta }\end{array}$ & Shen et al. (2002) & $\begin{array}{l}\text { allelic to CMS3A, CMS3B } \\
\text { (group11) }\end{array}$ \\
\hline $\begin{array}{l}\text { Myasthenic syndrome, } \\
\text { congenital, } 4 \mathrm{C} \text {, associated } \\
\text { with acetylcholine receptor } \\
\text { deficiency }\end{array}$ & 11.10 & AR & $\begin{array}{l}\text { CMS4C } \\
608931\end{array}$ & $17 \mathrm{p} 13.2$ & $\begin{array}{l}\text { CHRNE } \\
100725\end{array}$ & $\begin{array}{l}\text { Ccholinergic receptor, } \\
\text { nicotinic, epsilon }\end{array}$ & $\begin{array}{l}\text { Engel et al. (1996) Ohno } \\
\text { et al. (1997) }\end{array}$ & $\begin{array}{l}\text { allelic to CMS4A, CMS4B } \\
\text { (group 11) }\end{array}$ \\
\hline $\begin{array}{l}\text { Myasthenic syndrome, } \\
\text { congenital, } 5\end{array}$ & 11.11 & AR & $\begin{array}{l}\text { CMS5 } \\
603034\end{array}$ & $3 \mathrm{p} 25.1$ & $\begin{array}{l}\text { COLQ } \\
603033\end{array}$ & $\begin{array}{l}\text { Collagenic tail of } \\
\text { endplate } \\
\text { acetylcholinesterase }\end{array}$ & $\begin{array}{l}\text { Donger et al. (1998) } \\
\text { Ohno et al. (1998-2000) }\end{array}$ & \\
\hline $\begin{array}{l}\text { Myasthenic syndrome, } \\
\text { congenital, } 6 \text {, presynaptic }\end{array}$ & 11.12 & AR & $\begin{array}{l}\text { CMS6 } \\
254210\end{array}$ & $10 \mathrm{q} 11.23$ & $\begin{array}{l}\text { CHAT } \\
118490\end{array}$ & $\begin{array}{l}\text { Choline } \\
\text { acetyltransferase }\end{array}$ & $\begin{array}{l}\text { Ohno et al. (2001) } \\
\text { Maselli et al. (2003) }\end{array}$ & \\
\hline $\begin{array}{l}\text { Myasthenic syndrome, } \\
\text { congenital, } 7 \text {, presynaptic }\end{array}$ & 11.13 & $\mathrm{AD}$ & $\begin{array}{l}\text { CMS7 } \\
616040\end{array}$ & $1 \mathrm{q} 32.1$ & $\begin{array}{l}\text { SYT2 } \\
600104\end{array}$ & Synaptotagmin 2 & Herrmann et al. (2014) & $\begin{array}{l}\text { Allelic to Distal motor neuropathy } \\
\text { related to SYT2 (group 12) }\end{array}$ \\
\hline $\begin{array}{l}\text { Myasthenic syndrome, } \\
\text { congenital, } 8 \text {, with pre- and } \\
\text { postsynaptic defects }\end{array}$ & 11.14 & AR & $\begin{array}{l}\text { CMS8 } \\
615120\end{array}$ & $1 \mathrm{p} 36.33$ & $\begin{array}{l}\text { AGRN } \\
103320\end{array}$ & Agrin & Huzé et al. (2009) & \\
\hline $\begin{array}{l}\text { Myasthenic syndrome, } \\
\text { congenital, } 9 \text {, associated } \\
\text { with acetylcholine receptor } \\
\text { deficiency }\end{array}$ & 11.15 & AR & $\begin{array}{l}\text { CMS9 } \\
616325\end{array}$ & $9 \mathrm{q} 31.3$ & $\begin{array}{l}\text { MUSK } \\
601296\end{array}$ & $\begin{array}{l}\text { Muscle-specific } \\
\text { receptor tyrosine } \\
\text { kinase }\end{array}$ & Chevessier et al. (2004) & allelic to FADS (group 16) \\
\hline $\begin{array}{l}\text { Myasthenic syndrome, } \\
\text { congenital, } 10\end{array}$ & 11.16 & AR & $\begin{array}{l}\text { CMS10 } \\
254300\end{array}$ & $4 \mathrm{p} 16.3$ & $\begin{array}{l}\text { DOK7 } \\
610285\end{array}$ & $\begin{array}{l}\text { Downstream of } \\
\text { tyrosin kinase } 7\end{array}$ & $\begin{array}{l}\text { Beeson et al. (2006) } \\
\text { Selcen et al. (2008) }\end{array}$ & allelic to FADS (group 16) \\
\hline $\begin{array}{l}\text { Myasthenic syndrome, } \\
\text { congenital, } 11 \text {, associated } \\
\text { with acetylcholine receptor } \\
\text { deficiency }\end{array}$ & 11.17 & AR & $\begin{array}{l}\text { CMS11 } \\
616326\end{array}$ & $11 \mathrm{p} 11.2$ & $\begin{array}{l}\text { RAPSN } \\
601592\end{array}$ & $\begin{array}{l}\text { Receptor-associated } \\
\text { protein of the } \\
\text { synapse, } 43 \mathrm{kD} \\
\text { (Rapsyn) }\end{array}$ & $\begin{array}{l}\text { Ohno et al. (2002) Ohno } \\
\text { et al. (2003) Dunne et al. } \\
\text { (2003) }\end{array}$ & allelic to FADS (group 16) \\
\hline $\begin{array}{l}\text { Myasthenia, congenital, } 12 \text {, } \\
\text { with tubular aggregates }\end{array}$ & 11.18 & AR & $\begin{array}{l}\text { CMS12 } \\
610542\end{array}$ & $2 \mathrm{p} 13.3$ & $\begin{array}{l}\text { GFPT1 } \\
138292\end{array}$ & $\begin{array}{l}\text { Glutamine:fructose-6- } \\
\text { phosphate amido } \\
\text { transtransferase } 1\end{array}$ & Senderek et al. (2011) & \\
\hline $\begin{array}{l}\text { Myasthenic syndrome, } \\
\text { congenital, 13, with tubular } \\
\text { aggregates }\end{array}$ & 11.19 & AR & $\begin{array}{l}\text { CMS13 } \\
614750\end{array}$ & $11 \mathrm{q} 23.3$ & $\begin{array}{l}\text { DPAGTI } \\
191350\end{array}$ & $\begin{array}{l}\text { Dolichyl-phosphate } \\
\text { N-acetylglucosamine } \\
\text { phosphotransferase } 1\end{array}$ & Belaya et al. (2012) & \\
\hline $\begin{array}{l}\text { Myasthenic syndrome, } \\
\text { congenital, 14, with tubular } \\
\text { aggregates }\end{array}$ & 11.20 & AR & $\begin{array}{l}\text { CMS14 } \\
616228\end{array}$ & $9 \mathrm{q} 22.33$ & $\begin{array}{l}\text { ALG2 } \\
607905\end{array}$ & $\begin{array}{l}\text { S. Cerevisae homolog } \\
\text { of ALG2 (alpha- } \\
1,3 / 1,6-\text { mannosyl } \\
\text { transferase) }\end{array}$ & Cossins et al. (2013) & \\
\hline $\begin{array}{l}\text { Myasthenic syndrome, } \\
\text { congenital, } 15 \text {, without } \\
\text { tubular aggregates }\end{array}$ & 11.21 & AR & $\begin{array}{l}\text { CMS15 } \\
607227\end{array}$ & $1 \mathrm{p} 21.3$ & $\begin{array}{l}\text { ALG14 } \\
612866\end{array}$ & $\begin{array}{l}\text { S. Cerevisae homolog } \\
\text { of ALG14 (UDP-N- } \\
\text { acetylglucosami- } \\
\text { nyltransferase } \\
\text { subunit) }\end{array}$ & Cossins et al. (2013) & \\
\hline $\begin{array}{l}\text { Myasthenic syndrome, } \\
\text { congenital, } 16\end{array}$ & 11.22 & AR & $\begin{array}{l}\text { CMS16 } \\
614198\end{array}$ & $17 \mathrm{q} 23.3$ & $\begin{array}{l}\text { SCN4A } \\
603967\end{array}$ & $\begin{array}{l}\text { Sodium channel, } \\
\text { voltage-gated, type } \\
\text { IV, alpha subnit }\end{array}$ & Tsujino et al. (2003) & $\begin{array}{l}\text { allelic to Congenital Myopathy } \\
\text { related to } S C N 4 A \text { (group 3), } \\
\text { HOKPP2, HYPP, PMC and } \\
\text { K-aggravated myotonia (group 7), } \\
\text { Severe foetal hypokinesia related } \\
\text { to } S C N 4 A \text { (group 16) }\end{array}$ \\
\hline $\begin{array}{l}\text { Myasthenic syndrome, } \\
\text { congenital, } 17\end{array}$ & 11.23 & AR & $\begin{array}{l}\text { CMS17 } \\
616304\end{array}$ & $11 \mathrm{p} 11.2$ & $\begin{array}{l}\text { LRP4 } \\
604270\end{array}$ & $\begin{array}{l}\text { LDL receptor-related } \\
\text { protein } 4\end{array}$ & Ohkawara et al. (2014) & \\
\hline $\begin{array}{l}\text { Myasthenic syndrome, } \\
\text { congenital, } 18\end{array}$ & 11.24 & $\mathrm{AD}$ & $\begin{array}{l}\text { CMS18 } \\
616330\end{array}$ & $20 \mathrm{p} 12.2$ & $\begin{array}{l}\text { SNAP25 } \\
600322\end{array}$ & $\begin{array}{l}\text { Synaptosomal } \\
\text { associated protein } 25\end{array}$ & Shen et al. (2014) & \\
\hline $\begin{array}{l}\text { Myasthenic syndrome, } \\
\text { congenital, } 19\end{array}$ & 11.25 & AR & $\begin{array}{l}\text { CMS } 19 \\
616720\end{array}$ & $10 \mathrm{q} 22.1$ & $\begin{array}{l}\text { COLI3AI } \\
120350\end{array}$ & $\begin{array}{l}\text { Collagen type XIII } \\
\text { alpha } 1 \text { chain }\end{array}$ & Logan et al. (2015) & \\
\hline $\begin{array}{l}\text { Myasthenic syndrome, } \\
\text { congenital, 20, presynaptic }\end{array}$ & 11.26 & AR & $\begin{array}{l}\text { CMS20 } \\
617143\end{array}$ & $2 q 12.3$ & $\begin{array}{l}\text { SLC5A7 } \\
608761\end{array}$ & $\begin{array}{l}\text { Solute carrier family } \\
5 \text { (choline } \\
\text { transporter) member } \\
7\end{array}$ & Bauche et al. (2016) & allelic to HMN7A (group 12) \\
\hline $\begin{array}{l}\text { Myasthenic syndrome, } \\
\text { congenital, 21, presynaptic }\end{array}$ & 11.27 & AR & $\begin{array}{l}\text { CMS21 } \\
617239\end{array}$ & $10 \mathrm{q} 11.23$ & $\begin{array}{l}\text { SLC18A3 } \\
600336\end{array}$ & $\begin{array}{l}\text { Solute carrier family } \\
18 \text { (vesicular } \\
\text { acetylcholine), } \\
\text { member } 3\end{array}$ & O'Grady et al. (2016) & \\
\hline $\begin{array}{l}\text { Myasthenic syndrome, } \\
\text { congenital, } 22\end{array}$ & 11.28 & AR & $\begin{array}{l}\text { CMS22 } \\
616224\end{array}$ & $2 \mathrm{p} 21$ & $\begin{array}{l}\text { PREPL } \\
609557\end{array}$ & $\begin{array}{l}\text { Prolyl } \\
\text { endopeptidase-like }\end{array}$ & Regal et al. (2014) & \\
\hline $\begin{array}{l}\text { Presynaptic congenital } \\
\text { myasthenic syndrome } 23\end{array}$ & 11.29 & AR & $\begin{array}{l}\text { CMS23 } \\
618197\end{array}$ & $22 q 11.21$ & $\begin{array}{l}\text { SLC25AI } \\
190315\end{array}$ & $\begin{array}{l}\text { Solute carrier family } \\
25 \text { (mitochondrial } \\
\text { carrier, citrate } \\
\text { transporter), member } \\
1\end{array}$ & Chaouch et al. 2014) & \\
\hline $\begin{array}{l}\text { Presynaptic congenital } \\
\text { myasthenic syndrome } 24\end{array}$ & 11.30 & AR & $\begin{array}{l}\text { CMS24 } \\
618198\end{array}$ & $15 \mathrm{q} 23$ & $\begin{array}{l}\text { MYO9A } \\
604875\end{array}$ & Myosin IXA & O'Connor et al. (2016) & \\
\hline $\begin{array}{l}\text { Presynaptic congenital } \\
\text { myasthenic syndrome } 25\end{array}$ & 11.31 & AR & $\begin{array}{l}\text { CMS25 } \\
618323\end{array}$ & $12 p 13.31$ & $\begin{array}{l}\text { VAMPI } \\
185880\end{array}$ & $\begin{array}{l}\text { Vesicle-associated } \\
\text { membrane protein } 1\end{array}$ & $\begin{array}{l}\text { Shen et al. (2017) } \\
\text { Salpieto et al. (2017) }\end{array}$ & allelic to SPAX1 (group 15) \\
\hline
\end{tabular}




\begin{tabular}{|c|c|c|c|c|c|c|c|c|}
\hline DISEASE NAME & $\begin{array}{l}\text { Item line } \\
\text { in this } \\
\text { group }\end{array}$ & Inheritance & $\begin{array}{l}\text { Locus or } \\
\text { disease symbol } \\
\text { and OMIM } \\
\text { number }\end{array}$ & Chromosome & $\begin{array}{l}\text { Gene symbol } \\
\text { and OMIM } \\
\text { number }\end{array}$ & $\begin{array}{l}\text { Protein } \\
\text { (mitochondrial } \\
\text { proteins indicated } \\
\text { by symbol }[\mathrm{M}] \text { ) }\end{array}$ & Key references & $\begin{array}{l}\text { Other allelic disease(s) (group } \\
\text { in this table) }\end{array}$ \\
\hline $\begin{array}{l}\text { Congenital myasthenic } \\
\text { syndrome with nephrotic } \\
\text { syndrome }\end{array}$ & 11.32 & $\mathrm{AR}$ & $\begin{array}{l}\text { NPHS5 } \\
614199\end{array}$ & $3 \mathrm{p} 21.31$ & $\begin{array}{l}\text { LAMB2 } \\
150325\end{array}$ & Laminin-beta 2 & Maselli et al. (2009) & \\
\hline $\begin{array}{l}\text { Escobar syndrome (multiple } \\
\text { pterygium syndrome) }\end{array}$ & 11.33 & $\mathrm{AR}$ & $\begin{array}{l}\text { EVMPS } \\
265000\end{array}$ & $2 \mathrm{q} 37.1$ & $\begin{array}{l}\text { CHRNG } \\
100730\end{array}$ & $\begin{array}{l}\text { Cholinergic receptor, } \\
\text { nicotinic, gamma }\end{array}$ & $\begin{array}{l}\text { Hoffman et al. (2006) } \\
\text { Morgan et al. (2006) }\end{array}$ & \\
\hline $\begin{array}{l}\text { Myasthenic syndrome, with } \\
\text { plectin defect }\end{array}$ & 11.34 & $\mathrm{AR}$ & & $8 \mathrm{q} 24.3$ & $\begin{array}{l}\text { PLEC } \\
601282\end{array}$ & Plectin & $\begin{array}{l}\text { Banwell et al. (1999) } \\
\text { Forrest et al. (2010) } \\
\text { Selcen et al. (2011) }\end{array}$ & $\begin{array}{l}\text { Allelic to LGMDR17 (group 1), } \\
\text { EBSMD (group 5) }\end{array}$ \\
\hline $\begin{array}{l}\text { Congenital myasthenic } \\
\text { syndrome related to } G M P P B\end{array}$ & 11.35 & $\mathrm{AR}$ & & $3 \mathrm{q} 21.31$ & $\begin{array}{l}\text { GMPPB } \\
615320\end{array}$ & $\begin{array}{l}\text { GDP-mannose } \\
\text { pyrophosphorylase B }\end{array}$ & Belaya et al. (2015) & $\begin{array}{l}\text { allelic to LGMDR19 (group 1); } \\
\text { MEB/MDDGA14 and MDDGB14 } \\
\text { (group 2) }\end{array}$ \\
\hline $\begin{array}{l}\text { Presynaptic congenital } \\
\text { myasthenic syndrome }\end{array}$ & 11.36 & $\mathrm{AR}$ & & $20 \mathrm{q} 13.33$ & $\begin{array}{l}\text { LAMA5 } \\
601033\end{array}$ & Laminin, alpha-5 & Maselli et al. (2017) & \\
\hline $\begin{array}{l}\text { Presynaptic congenital } \\
\text { myasthenic syndrome related } \\
\text { to MUNC13-1 }\end{array}$ & 11.37 & $\mathrm{AR}$ & & $19 \mathrm{p} 13.11$ & $\begin{array}{l}\text { UNC13A } \\
609894\end{array}$ & $\begin{array}{l}\text { C. Elegans, homolog } \\
\text { of UNC13A } \\
\text { (MUNC13) }\end{array}$ & Engel et al. (2016) & \\
\hline $\begin{array}{l}\text { Congenital myasthenic } \\
\text { syndrome related to RPH3A, } \\
\text { presynaptic }\end{array}$ & 11.38 & $\mathrm{AR}$ & & $12 \mathrm{q} 24.13$ & $\begin{array}{l}\text { RPH3A } \\
612159\end{array}$ & Rabphilin 3A & Maselli et al. (2018) & \\
\hline
\end{tabular}

\section{GROUP 12. SPINAL MUSCULAR ATROPHIES MOTONEURON DISEASES}

Spinal muscular atrophy related to SMNI

Spinal muscular atrophy,

type I (Werdnig-Hoffman)
$12.1 \quad$ AR $\quad$ SMA1

253300
$5 \mathrm{q} 13.2$

600354
Survival of motor neuron 1

\begin{tabular}{|c|c|c|c|c|c|c|c|c|}
\hline \multirow[b]{2}{*}{$\begin{array}{l}\text { Spinal muscular atrophy, } \\
\text { type II (intermediate) }\end{array}$} & \multirow[b]{2}{*}{12.2} & \multirow[b]{2}{*}{$\mathrm{AR}$} & \multirow[b]{2}{*}{$\begin{array}{l}\text { SMA2 } \\
253550\end{array}$} & \multirow[b]{2}{*}{$5 \mathrm{q} 13.2$} & \multirow[b]{2}{*}{$\begin{array}{l}\text { SMN1 } \\
600354\end{array}$} & \multirow[b]{2}{*}{$\begin{array}{l}\text { Survival of motor } \\
\text { neuron } 1\end{array}$} & \multicolumn{2}{|l|}{ et al. (1997) } \\
\hline & & & & & & & $\begin{array}{l}\text { Matthijs et al. (1996) } \\
\text { Samilchuk (1996) }\end{array}$ & $\begin{array}{l}\text { allelic to SMA1, SMA3, SMA4 } \\
\text { (group 12) }\end{array}$ \\
\hline $\begin{array}{l}\text { Spinal muscular atrophy, } \\
\text { type III } \\
\text { (Kugelberg-Welander) }\end{array}$ & 12.3 & AR & $\begin{array}{l}\text { SMA3 } \\
253400\end{array}$ & $5 \mathrm{q} 13.2$ & $\begin{array}{l}\text { SMN1 } \\
600354\end{array}$ & $\begin{array}{l}\text { Survival of motor } \\
\text { neuron } 1\end{array}$ & $\begin{array}{l}\text { Brzustowicz et al. (1990) } \\
\text { Melki et al. (1990b) } \\
\text { Lefebvre et al. (1995) }\end{array}$ & $\begin{array}{l}\text { allelic to SMA2, SMA1, SMA4 } \\
\text { (group 12) }\end{array}$ \\
\hline $\begin{array}{l}\text { Spinal muscular atrophy, } \\
\text { type IV, adult form }\end{array}$ & 12.4 & $\mathrm{AR}$ & $\begin{array}{l}\text { SMA4 } \\
271150\end{array}$ & $5 \mathrm{q} 13.2$ & $\begin{array}{l}\text { SMN1 } \\
600354\end{array}$ & $\begin{array}{l}\text { Survival of motor } \\
\text { neuron } 1\end{array}$ & $\begin{array}{l}\text { Brahe et al. (1995) } \\
\text { Clermont et al. (1995) }\end{array}$ & $\begin{array}{l}\text { allelic to SMA2, SMA3, SMA1 } \\
\text { (group 12) }\end{array}$ \\
\hline \multicolumn{9}{|c|}{ Distal spinal muscular atrophy, recessive } \\
\hline $\begin{array}{l}\text { Spinal muscular atrophy, } \\
\text { distal, autosomal recessive } 1 \\
\text { (with respiratory distress) }\end{array}$ & 12.5 & AR & $\begin{array}{l}\text { DSMA1 } \\
604320\end{array}$ & $11 \mathrm{q} 13.3$ & $\begin{array}{l}\text { IGHMBP2 } \\
600502\end{array}$ & $\begin{array}{l}\text { Immunoglobulin } \\
\text { Mu-binding protein } 2\end{array}$ & $\begin{array}{l}\text { Grohmann et al. (1999, } \\
\text { 2001) }\end{array}$ & allelic to CMT2S (group 14) \\
\hline $\begin{array}{l}\text { Spinal muscular atrophy, } \\
\text { distal autosomal recessive } 2\end{array}$ & 12.6 & AR & $\begin{array}{l}\text { DSMA2 } \\
605726\end{array}$ & $9 \mathrm{p} 13.3$ & $\begin{array}{l}\text { SIGMARI } \\
601978\end{array}$ & $\begin{array}{l}\text { Sigma non-opioid } \\
\text { intracellular receptor } \\
1\end{array}$ & $\begin{array}{l}\text { Christodoulou et al. } \\
\text { (2000) Li et al. (2015) }\end{array}$ & allelic to ALS16 (group 12) \\
\hline $\begin{array}{l}\text { Spinal muscular atrophy, } \\
\text { distal autosomal recessive } 3\end{array}$ & 12.7 & AR & $\begin{array}{l}\text { DSMA3 } \\
607088\end{array}$ & $11 \mathrm{q} 13$ & $?$ & & Viollet et al. (2004) & \\
\hline $\begin{array}{l}\text { Spinal muscular atrophy, } \\
\text { distal autosomal recessive } 4\end{array}$ & 12.8 & $\mathrm{AR}$ & $\begin{array}{l}\text { DSMA4 } \\
611067\end{array}$ & $1 \mathrm{p} 36.31$ & $\begin{array}{l}\text { PLEKHG5 } \\
611101\end{array}$ & $\begin{array}{l}\text { Pleckstrin homology } \\
\text { domain and RhoGEF } \\
\text { domai-containing } \\
\text { protein G5 }\end{array}$ & $\begin{array}{l}\text { Maystadt et al. (2006, } \\
\text { 2007) }\end{array}$ & allelic to CMTRIC (group 14) \\
\hline $\begin{array}{l}\text { Spinal muscular atrophy, } \\
\text { distal, autosomal recessive, } 5\end{array}$ & 12.9 & AR & $\begin{array}{l}\text { DSMA5 } \\
614881\end{array}$ & $2 q 35$ & $\begin{array}{l}\text { DNAJB2 } \\
604139\end{array}$ & $\begin{array}{l}\text { DnaJ/Hsp } 40 \\
\text { homolog, subfamily } \\
\text { B, member } 2\end{array}$ & Blumen et al. (2012) & $\begin{array}{l}\text { Allelic to CMT related to } \\
\text { DNAJB2 (group 14) }\end{array}$ \\
\hline $\begin{array}{l}\text { Spinal muscular atrophy, } \\
\text { distal, autosomal recessive }\end{array}$ & 12.10 & AR & & $14 \mathrm{q} 32.2$ & $\begin{array}{l}\text { VRK1 } \\
602168\end{array}$ & $\begin{array}{l}\text { Vaccinia related } \\
\text { kinase } 1\end{array}$ & $\begin{array}{l}\text { Stoll et al. (2016) Li } \\
\text { et al. (2019) }\end{array}$ & $\begin{array}{l}\text { Allelic to PCH1 (group 12), } \\
\text { Complex motor and sensory } \\
\text { axonal neuropathy plus } \\
\text { microcephaly and cerebral } \\
\text { dysgenesis (group 14) }\end{array}$ \\
\hline $\begin{array}{l}\text { Spinal muscular atrophy } \\
\text { with congenital bone } \\
\text { fractures } 1\end{array}$ & 12.11 & AR & $\begin{array}{l}\text { SMABF1 } \\
616866\end{array}$ & $15 \mathrm{q} 22.31$ & $\begin{array}{l}\text { TRIP4 } \\
604501\end{array}$ & $\begin{array}{l}\text { Thyroid hormone } \\
\text { receptor interactor } 4\end{array}$ & Knierim et al. (2016) & allelic to MDCDC (group 2) \\
\hline $\begin{array}{l}\text { Spinal muscular atrophy } \\
\text { with congenital bone } \\
\text { fractures } 2\end{array}$ & 12.12 & AR & $\begin{array}{l}\text { SMABF2 } \\
616867\end{array}$ & 10q22.1 & $\begin{array}{r}\text { ASCC1 } \\
614215\end{array}$ & $\begin{array}{l}\text { Activating signal } \\
\text { cointegrator } 1 \\
\text { complex subunit } 1\end{array}$ & Knierim et al. (2016) & $\begin{array}{l}\text { allelic to Arthrogryposis related } \\
\text { to } A S C C I \text { (group 16) }\end{array}$ \\
\hline $\begin{array}{l}\text { Spinal muscular atrophy } \\
\text { with progressive myoclonic } \\
\text { epilepsy }\end{array}$ & 12.13 & AR & $\begin{array}{l}\text { SMAPME } \\
159950\end{array}$ & $8 \mathrm{p} 22$ & $\begin{array}{l}\text { ASAH1 } \\
613468\end{array}$ & $\begin{array}{l}\mathrm{N} \text {-acylsphingosine } \\
\text { amidohydrolase } 1\end{array}$ & Zhou et al. (2012) & allelic to FRBRL ( $\# 228000)$ \\
\hline $\begin{array}{l}\text { Spinal muscular atrophy and } \\
\text { cerebellar hypoplasia }\end{array}$ & 12.14 & AR & $\begin{array}{l}\text { PCH1C } \\
616081\end{array}$ & $13 q 13.3$ & $\begin{array}{l}\text { EXOSC8 } \\
606019\end{array}$ & $\begin{array}{l}\text { Exosome component } \\
8\end{array}$ & Boczonadi et al. (2014) & \\
\hline $\begin{array}{l}\text { Distal hereditary motor } \\
\text { neuronopathy }\end{array}$ & 12.15 & AR & & $5 q 23.3$ & $\begin{array}{l}\text { HINT1 } \\
601314\end{array}$ & $\begin{array}{l}\text { Histidine triad } \\
\text { nucleotide-binding } \\
\text { protein }\end{array}$ & Zhao et al. (2014) & Allelic to NMAN (group 14) \\
\hline \multicolumn{9}{|c|}{ Distal spinal muscular atrophy, dominant } \\
\hline $\begin{array}{l}\text { Neuronopathy, distal } \\
\text { hereditary motor, type I }\end{array}$ & 12.16 & $\mathrm{AD}$ & $\begin{array}{l}\text { HMN1 } \\
182960\end{array}$ & $7 q 34-q 36$ & $?$ & & Gopinath et al. (2007) & \\
\hline
\end{tabular}

Gilliam et al. (1990) allelic to SMA2, SMA3, SMA4 Melki et al. $(1990,1994) \quad$ (group 12)

Lefebvre et al. (1995)

Bussaglia et al. (1995)

Rodrigues et al. (1995)

Roy et al. (1995) Hahnen et al. (1997)

Brzustowicz et al. (1990)

lki et al. (1990b)

Brahe et al. (1995)

Clermont et al. (1995)

Grohmann et al. (1999, 


\begin{tabular}{|c|c|c|c|c|c|c|c|c|}
\hline DISEASE NAME & $\begin{array}{l}\text { Item line } \\
\text { in this } \\
\text { group }\end{array}$ & Inheritance & $\begin{array}{l}\text { Locus or } \\
\text { disease symbol } \\
\text { and OMIM } \\
\text { number }\end{array}$ & Chromosome & $\begin{array}{l}\text { Gene symbol } \\
\text { and OMIM } \\
\text { number }\end{array}$ & $\begin{array}{l}\text { Protein } \\
\text { (mitochondrial } \\
\text { proteins indicated } \\
\text { by symbol }[\mathrm{M}] \text { ) }\end{array}$ & Key references & $\begin{array}{l}\text { Other allelic disease(s) (group } \\
\text { in this table) }\end{array}$ \\
\hline $\begin{array}{l}\text { Neuronopathy, distal } \\
\text { hereditary motor, type IIA }\end{array}$ & 12.17 & $\mathrm{AD}$ & $\begin{array}{l}\text { HMN2A } \\
158590\end{array}$ & $12 \mathrm{q} 24.23$ & $\begin{array}{l}\text { HSPB8 } \\
608014\end{array}$ & $\begin{array}{l}\text { Heat-shock 22-kD } \\
\text { protein } 8\end{array}$ & $\begin{array}{l}\text { Timmerman et al. (1992) } \\
\text { Irobi et al. (2004) }\end{array}$ & $\begin{array}{l}\text { allelic to Myopathy with rimmed } \\
\text { vacuoles (group 4) and CMT2L } \\
\text { (group 14) }\end{array}$ \\
\hline $\begin{array}{l}\text { Neuronopathy, distal } \\
\text { hereditary motor, type IIB }\end{array}$ & 12.18 & $\mathrm{AD}$ & $\begin{array}{l}\text { HMN2B } \\
608634\end{array}$ & $7 \mathrm{q} 11.23$ & $\begin{array}{l}\text { HSPB1 } \\
602195\end{array}$ & $\begin{array}{l}\text { Heat-shock } 27-\mathrm{kD} \\
\text { protein } 1\end{array}$ & Evgrafov et al. (2004) & allelic to CMT2F (group 14) \\
\hline $\begin{array}{l}\text { Neuronopathy, distal } \\
\text { hereditary motor, type IIC }\end{array}$ & 12.19 & $\mathrm{AD}$ & $\begin{array}{l}\text { HMN2C } \\
613376\end{array}$ & $5 q 11.2$ & $\begin{array}{l}\text { HSPB3 } \\
604624\end{array}$ & $\begin{array}{l}\text { Heat shock } 27-\mathrm{kD} \\
\text { protein } 3\end{array}$ & Kolb et al. (2010) & \\
\hline $\begin{array}{l}\text { Neuronopathy, distal } \\
\text { hereditary motor, type IID }\end{array}$ & 12.20 & $\mathrm{AD}$ & $\begin{array}{l}\text { HMN2D } \\
615575\end{array}$ & $5 q 32$ & $\begin{array}{l}\text { FВXO38 } \\
608533\end{array}$ & $\begin{array}{l}\text { F-box only protein } \\
38\end{array}$ & Sumner et al. (2013) & \\
\hline $\begin{array}{l}\text { Distal spinal muscular } \\
\text { atrophy, distal with upper } \\
\text { limb predominance (type V) }\end{array}$ & 12.21 & $\mathrm{AD}$ & $\begin{array}{l}\text { HMN5A } \\
600794\end{array}$ & $7 \mathrm{p} 14.3$ & $\begin{array}{l}\text { GARS } \\
600287\end{array}$ & $\begin{array}{l}\text { Glycyl-tRNA } \\
\text { synthetase }\end{array}$ & $\begin{array}{l}\text { Christodoulou et al. } \\
\text { (1995) Antonellis et al. } \\
\text { (2003) }\end{array}$ & allelic to CMT2D (group 14) \\
\hline $\begin{array}{l}\text { Distal spinal muscular } \\
\text { atrophy type VA }\end{array}$ & 12.22 & $\mathrm{AD}$ & $\begin{array}{l}\text { HMN5A } \\
600794\end{array}$ & $11 \mathrm{q} 12.3$ & $\begin{array}{l}B S C L 2 \\
606158\end{array}$ & Seipin & $\begin{array}{l}\text { Windpassinger et al. } \\
\text { (2004) }\end{array}$ & allelic to SPG17 (group 15) \\
\hline $\begin{array}{l}\text { Distal spinal muscular } \\
\text { atrophy, type VB }\end{array}$ & 12.23 & $\mathrm{AD}$ & $\begin{array}{l}\text { HMNS5B } \\
614751\end{array}$ & $2 \mathrm{p} 11.2$ & $\begin{array}{l}\text { REEP1 } \\
609139\end{array}$ & $\begin{array}{l}\text { Receptor } \\
\text { expression-enhancing } \\
\text { protein } 1\end{array}$ & Beetz et al. (2012) & allelic to SPG31 (group 15) \\
\hline $\begin{array}{l}\text { Dominant distal hereditary } \\
\text { motor neuropathy }\end{array}$ & 12.24 & $\mathrm{AD}$ & dHMN & $16 \mathrm{q} 22.1$ & $\begin{array}{l}\text { AARS } \\
601065\end{array}$ & $\begin{array}{l}\text { Alanyl-tRNA } \\
\text { synthetase }\end{array}$ & Zhao et al. (2012) & allelic to CMT2N (group 14) \\
\hline $\begin{array}{l}\text { Neuronopathy, distal } \\
\text { hereditary motor, type IX }\end{array}$ & 12.25 & $\mathrm{AD}$ & $\begin{array}{l}\text { HMN9 } \\
61772\end{array}$ & $14 \mathrm{q} 32.2$ & $\begin{array}{l}\text { WARS } \\
191050\end{array}$ & $\begin{array}{l}\text { Tryptophanyl-tRNA } \\
\text { synthetase }\end{array}$ & Tsai et al. (2017) & \\
\hline $\begin{array}{l}\text { Spinal muscular atrophy, } \\
\text { distal, with vocal cord } \\
\text { paralysis (Harper-Young) }\end{array}$ & 12.26 & $\mathrm{AD}$ & $\begin{array}{l}\text { HMN7A } \\
158580\end{array}$ & $2 q 12.3$ & $\begin{array}{l}\text { SLC5A7 } \\
608761\end{array}$ & $\begin{array}{l}\text { Solute carrier family } \\
5 \text { (choline } \\
\text { cotransporter), } \\
\text { member } 7\end{array}$ & $\begin{array}{l}\text { McEntagart et al. (2001) } \\
\text { Barwick et al. (2012) }\end{array}$ & allelic to CMS20 (group 11) \\
\hline $\begin{array}{l}\text { Distal hereditary motor } \\
\text { neuronopathy type VIIB }\end{array}$ & 12.27 & $\mathrm{AD}$ & $\begin{array}{l}\text { HMN7B } \\
607641\end{array}$ & $2 \mathrm{p} 13.1$ & $\begin{array}{l}\text { DCTN1 } \\
601143\end{array}$ & Dynactin 1 & Puls et al. (2003) & $\begin{array}{l}\text { allelic to ALS related to DCTN1 } \\
\text { (group 12) }\end{array}$ \\
\hline $\begin{array}{l}\text { Hereditary motor and } \\
\text { sensory neuropathy } \mathrm{V}\end{array}$ & 12.28 & $\mathrm{AD}$ & $\begin{array}{l}\text { HMSN5 } \\
600361\end{array}$ & $4 q 34.3-\mathrm{q} 35.2$ & $?$ & & Muglia et al. (2008) & \\
\hline $\begin{array}{l}\text { Spinal muscular atrophy, } \\
\text { distal, congenital non } \\
\text { progressive }\end{array}$ & 12.29 & $\mathrm{AD}$ & $\begin{array}{l}\text { HMN8 } \\
600175\end{array}$ & $12 \mathrm{q} 24.11$ & $\begin{array}{l}\text { TRPV4 } \\
605427\end{array}$ & $\begin{array}{l}\text { Transient receptor } \\
\text { potential cation } \\
\text { channel, subfamily V, } \\
\text { member } 4\end{array}$ & $\begin{array}{l}\text { van der Vleuten et al. } \\
\text { (1998) Auer-Grumbach } \\
\text { et al. (2010) Deng et al. } \\
(2010)\end{array}$ & $\begin{array}{l}\text { allelic to SPSMA (group 12), } \\
\text { HSMN2C (group 14) }\end{array}$ \\
\hline $\begin{array}{l}\text { Scapuloperoneal spinal } \\
\text { muscular atrophy }\end{array}$ & 12.30 & $\mathrm{AD}$ & $\begin{array}{l}\text { SPSMA } \\
181405\end{array}$ & $12 q .24$ & $\begin{array}{l}\text { TRPV4 } \\
605427\end{array}$ & $\begin{array}{l}\text { Transient receptor } \\
\text { potential cation } \\
\text { channel, subfamily V, } \\
\text { member } 4\end{array}$ & $\begin{array}{l}\text { Isozumi et al. (1996) } \\
\text { Deng et al. (2010) }\end{array}$ & $\begin{array}{l}\text { allelic to HMN8 (group 12), } \\
\text { HSMN2C (group 14) }\end{array}$ \\
\hline Spinal motor neuropathy & 12.31 & & & $11 \mathrm{q} 23.2$ & $\begin{array}{l}\text { RBM7 } \\
612413\end{array}$ & $\begin{array}{l}\text { RNA-binding motif } \\
\text { protein } 7\end{array}$ & Giunta et al. (2016) & \\
\hline $\begin{array}{l}\text { Spinal muscular atrophy, } \\
\text { lower } \\
\text { extremity-predominant, } \\
\text { autosomal dominant } 1\end{array}$ & 12.32 & $\mathrm{AD}$ & $\begin{array}{l}\text { SMALED1 } \\
158600\end{array}$ & $14 \mathrm{q} 32.31$ & $\begin{array}{l}\text { DYNC1H1 } \\
600112\end{array}$ & $\begin{array}{l}\text { Dynein, cytoplasmic } \\
1 \text {, heavy chain } 1\end{array}$ & $\begin{array}{l}\text { Harms et al. (2010, } \\
\text { 2012) }\end{array}$ & allelic to CMT2O (group 14) \\
\hline $\begin{array}{l}\text { Spinal muscular atrophy, } \\
\text { lower } \\
\text { extremity-predominant, } \\
\text { autosomal dominant } 2 \mathrm{~A}\end{array}$ & 12.33 & $\mathrm{AD}$ & $\begin{array}{l}\text { SMALED2A } \\
615290\end{array}$ & $9 \mathrm{q} 22.31$ & $\begin{array}{l}\text { BICD2 } \\
609797\end{array}$ & $\begin{array}{l}\text { Bicaudal D homolog } \\
2 \text { (Drosophila) }\end{array}$ & $\begin{array}{l}\text { Neveling et al. (2013) } \\
\text { Oates et al. (2013) } \\
\text { Peeters et al. (2013) }\end{array}$ & $\begin{array}{l}\text { Allelic to SMALED2B (group } \\
\text { 12) and Arthrogryposis and } \\
\text { BICD2-related neuromuscular } \\
\text { disease (group 16) }\end{array}$ \\
\hline $\begin{array}{l}\text { Spinal muscular atrophy, } \\
\text { lower } \\
\text { extremity-predominant, } \\
\text { autosomal dominant } 2 \text { B }\end{array}$ & 12.34 & $\mathrm{AD}$ & $\begin{array}{l}\text { SMALED2B } \\
618291\end{array}$ & $9 \mathrm{q} 22.31$ & $\begin{array}{l}\text { BICD2 } \\
609797\end{array}$ & $\begin{array}{l}\text { Bicaudal D homolog } \\
2 \text { (Drosophila) }\end{array}$ & Ravenscroft et al. (2016) & $\begin{array}{l}\text { Allelic to SMALED2A (group } \\
\text { 12) and Arthrogryposis and } \\
\text { BICD2-related neuromuscular } \\
\text { disease (group 16) }\end{array}$ \\
\hline $\begin{array}{l}\text { Spinal muscular atrophy, } \\
\text { late-onset, Finkel type }\end{array}$ & 12.35 & $\mathrm{AD}$ & $\begin{array}{l}\text { SMAFK } \\
182980\end{array}$ & $20 \mathrm{q} 13.32$ & $\begin{array}{l}\text { VAPB } \\
605704\end{array}$ & $\begin{array}{l}\text { Vesicle-associated } \\
\text { membrane } \\
\text { protein-associated } \\
\text { protein B }\end{array}$ & Nishimura et al. (2004) & allelic to ALS8 (group 12) \\
\hline $\begin{array}{l}\text { Spinal muscular atrophy, } \\
\text { Jokela type }\end{array}$ & 12.36 & $\mathrm{AD}$ & $\begin{array}{l}\text { SMAJ } \\
615048\end{array}$ & $22 \mathrm{q} 11.23$ & $\begin{array}{l}\text { CHCHD10 } \\
615903\end{array}$ & $\begin{array}{l}\text { Coiled-coil-helix- } \\
\text { coiled-coil-helix } \\
\text { domain containing } 10 \\
\text { (M) }\end{array}$ & $\begin{array}{l}\text { Muller et al. (2014) } \\
\text { Penttilä et al. (2012, } \\
\text { 2015) }\end{array}$ & $\begin{array}{l}\text { allelic to FTDALS2 (group 12), } \\
\text { IMMD (group 16) }\end{array}$ \\
\hline $\begin{array}{l}\text { Distal motor neuropathy } \\
\text { related to SYT2 }\end{array}$ & 12.37 & $\mathrm{AD}$ & & $1 \mathrm{q} 32.1$ & $\begin{array}{l}S Y T 2 \\
600104\end{array}$ & Synaptotagmin 2 & $\begin{array}{l}\text { Montes-Chinea et al. } \\
\text { (2018) }\end{array}$ & Allelic to CMS7 (group 11) \\
\hline Distal motor neuropathy & 12.38 & $\mathrm{AD}$ & & $9 \mathrm{q} 34.11$ & $\begin{array}{l}\text { SPTAN1 } \\
182810\end{array}$ & $\begin{array}{l}\text { Spectrin, alpha, } \\
\text { nonerythrocytic } 1\end{array}$ & Beijer et al. (2019) & \\
\hline \multicolumn{9}{|c|}{ Distal spinal muscular atrophy, $X$-linked } \\
\hline $\begin{array}{l}\text { Spinal and bulbar muscular } \\
\text { atrophy, X-linked, } 1 \\
\text { (Kennedy disease) }\end{array}$ & 12.39 & $\mathrm{XR}$ & $\begin{array}{l}\text { SBMX1 } \\
313200\end{array}$ & $\mathrm{Xq} 12$ & $\begin{array}{l}\boldsymbol{A R} \\
313700\end{array}$ & Androgen receptor & $\begin{array}{l}\text { Fishbeck et al. (1986) La } \\
\text { Spada et al. (1991) }\end{array}$ & \\
\hline $\begin{array}{l}\text { Spinal muscular atrophy, } \\
\text { distal, X-linked } 2\end{array}$ & 12.40 & $\mathrm{XR}$ & $\begin{array}{l}\text { SMAX2 } \\
301830\end{array}$ & Xp11.3 & $\begin{array}{l}\text { UBAI } \\
314370\end{array}$ & $\begin{array}{l}\text { Ubiquitin-like } \\
\text { modifyer-activating } \\
\text { enzyme } 1\end{array}$ & $\begin{array}{l}\text { Ramser et al. (2013) } \\
\text { Diamini et al. (2013) }\end{array}$ & \\
\hline $\begin{array}{l}\text { Spinal muscular atrophy, } \\
\text { distal, X-linked, } 3\end{array}$ & 12.41 & $\mathrm{XR}$ & $\begin{array}{l}\text { SMAX3 } \\
300489\end{array}$ & $\mathrm{Xq} 21.1$ & $\begin{array}{l}\text { ATP7A } \\
300011\end{array}$ & $\begin{array}{l}\text { ATPase, } \\
\mathrm{Cu}^{++} \text {transporting, } \\
\text { alpha polypeptide }\end{array}$ & $\begin{array}{l}\text { Takata et al. (2004) } \\
\text { Kennerson et al. (2010) }\end{array}$ & \\
\hline \multicolumn{9}{|c|}{ Amyotrophic lateral sclerosis (ALS) } \\
\hline $\begin{array}{l}\text { Amyotrophic lateral sclerosis } \\
1 \text { (dominant) }\end{array}$ & 12.42 & $\mathrm{AD}$ & $\begin{array}{l}\text { ALS1 } \\
105400\end{array}$ & $21 \mathrm{q} 22.11$ & $\begin{array}{l}\text { SOD1 } \\
147450\end{array}$ & $\begin{array}{l}\mathrm{Cu} / \mathrm{Zn} \text { superoxide } \\
\text { dismutase }\end{array}$ & $\begin{array}{l}\text { Siddique et al. (1991, } \\
\text { 1996) Rosen et al. (1993) }\end{array}$ & \\
\hline
\end{tabular}




\begin{tabular}{|c|c|c|c|c|c|c|c|c|}
\hline DISEASE NAME & $\begin{array}{l}\text { Item line } \\
\text { in this } \\
\text { group }\end{array}$ & Inheritance & $\begin{array}{l}\text { Locus or } \\
\text { disease symbol } \\
\text { and OMIM } \\
\text { number }\end{array}$ & Chromosome & $\begin{array}{l}\text { Gene symbol } \\
\text { and OMIM } \\
\text { number }\end{array}$ & $\begin{array}{l}\text { Protein } \\
\text { (mitochondrial } \\
\text { proteins indicated } \\
\text { by symbol }[\mathrm{M}] \text { ) }\end{array}$ & Key references & $\begin{array}{l}\text { Other allelic disease(s) (group } \\
\text { in this table) }\end{array}$ \\
\hline $\begin{array}{l}\text { Amyotrophic lateral sclerosis } \\
1 \text { (recessive) }\end{array}$ & 12.43 & $\mathrm{AR}$ & $\begin{array}{l}\text { ALS1 } \\
105400\end{array}$ & $21 \mathrm{q} 22.11$ & $\begin{array}{l}\text { SOD1 } \\
147450\end{array}$ & $\begin{array}{l}\mathrm{Cu} / \mathrm{Zn} \text { superoxide } \\
\text { dismutase }\end{array}$ & Andersen et al. (1995) & \\
\hline $\begin{array}{l}\text { Amyotrophic lateral sclerosis } \\
2 \text {, juvenile }\end{array}$ & 12.44 & AR & $\begin{array}{l}\text { ALS2 } \\
205100\end{array}$ & $2 \mathrm{q} 33.1$ & $\begin{array}{l}\boldsymbol{A L S 2} 2 \\
606352\end{array}$ & Alsin & $\begin{array}{l}\text { Hentati et al. (1994) } \\
\text { Yang et al. (2001) } \\
\text { Hadano et al. (2001) }\end{array}$ & allelic to IAHSP (group 15) \\
\hline $\begin{array}{l}\text { Amyotrophic lateral sclerosis } \\
3\end{array}$ & 12.45 & $\mathrm{AD}$ & $\begin{array}{l}\text { ALS3 } \\
606640\end{array}$ & $18 \mathrm{q} 21$ & $?$ & & Hand et al. (2002) & \\
\hline $\begin{array}{l}\text { Amyotrophic lateral sclerosis } \\
4 \text {, juvenile }\end{array}$ & 12.46 & $\mathrm{AD}$ & $\begin{array}{l}\text { ALS4 } \\
602433\end{array}$ & $9 \mathrm{q} 34.13$ & $\begin{array}{l}\text { SETX } \\
608465\end{array}$ & Senataxin & $\begin{array}{l}\text { Chance et al. (1998) } \\
\text { Chen et al. (2004) } \\
\text { Moreira et al. (2004) }\end{array}$ & allelic to SCAR1 (group 13) \\
\hline $\begin{array}{l}\text { Amyotrophic lateral sclerosis } \\
5 \text {, juvenile }\end{array}$ & 12.47 & $\mathrm{AR}$ & $\begin{array}{l}\text { ALS5 } \\
602099\end{array}$ & $15 \mathrm{q} 21.1$ & $\begin{array}{l}\text { SPG11 } \\
610844\end{array}$ & Spatacsin & $\begin{array}{l}\text { Hentati et al. (1998) } \\
\text { Orlacchio et al. (2010) }\end{array}$ & allelic to CMT2X (group 14) \\
\hline $\begin{array}{l}\text { Amyotrophic lateral sclerosis } \\
6 \text {, with or without } \\
\text { frontotemporal dementia }\end{array}$ & 12.48 & $\mathrm{AD}$ & $\begin{array}{l}\text { ALS6 } \\
608030\end{array}$ & $16 \mathrm{p} 11.2$ & $\begin{array}{l}\text { FUS } \\
137070\end{array}$ & Fused in sarcoma & $\begin{array}{l}\text { Sapp et al. (2003) } \\
\text { Abalkhail et al. (2003) } \\
\text { Kwiatkowski et al. } \\
\text { (2009) Vance et al. } \\
\text { (2009) }\end{array}$ & \\
\hline $\begin{array}{l}\text { Amyotrophic lateral sclerosis } \\
7\end{array}$ & 12.49 & $\mathrm{AD}$ & $\begin{array}{l}\text { ALS7 } \\
608031\end{array}$ & $20 \mathrm{p} 13$ & $?$ & & Sapp et al. (2003) & \\
\hline $\begin{array}{l}\text { Amyotrophic lateral sclerosis } \\
8\end{array}$ & 12.50 & $\mathrm{AD}$ & $\begin{array}{l}\text { ALS8 } \\
608627\end{array}$ & $20 \mathrm{q} 13.32$ & $\begin{array}{l}\text { VAPB } \\
605704\end{array}$ & $\begin{array}{l}\text { Vesicle-associated } \\
\text { membrane } \\
\text { protein-associated } \\
\text { protein B and C }\end{array}$ & Nishimura et al. (2004) & allelic to SMAFK (group 12) \\
\hline $\begin{array}{l}\text { Amyotrophic lateral sclerosis } \\
9\end{array}$ & 12.51 & $\mathrm{AD}$ & $\begin{array}{l}\text { ALS9 } \\
611895\end{array}$ & $14 \mathrm{q} 11.2$ & $\begin{array}{l}A N G \\
105850\end{array}$ & Angiogenin & $\begin{array}{l}\text { Greenway et al. (2006) } \\
\text { Wu et al. (2007) }\end{array}$ & \\
\hline $\begin{array}{l}\text { Amyotrophic lateral sclerosis } \\
10 \text {, with or without } \\
\text { frontotemporal dementia }\end{array}$ & 12.52 & $\mathrm{AD}$ & $\begin{array}{l}\text { ALS10 } \\
612069\end{array}$ & $1 \mathrm{p} 36.22$ & $\begin{array}{l}\text { TARDBP } \\
605078\end{array}$ & $\begin{array}{l}\text { TAR DNA-binding } \\
\text { protein }\end{array}$ & Sreedharan et al. (2008) & \\
\hline $\begin{array}{l}\text { Amyotrophic lateral sclerosis } \\
11\end{array}$ & 12.53 & $\mathrm{AD}$ & $\begin{array}{l}\text { ALS11 } \\
612577\end{array}$ & $6 \mathrm{q} 21$ & $\begin{array}{l}\text { FIG4 } \\
609390\end{array}$ & $\begin{array}{l}\text { FIG4, S. Cerevisiae, } \\
\text { homolog of }\end{array}$ & Chow et al. (2009) & allelic to CMT4J (group 14) \\
\hline $\begin{array}{l}\text { Amyotrophic lateral sclerosis } \\
12\end{array}$ & 12.54 & $\mathrm{AD}, \mathrm{AR}$ & $\begin{array}{l}\text { ALS12 } \\
613435\end{array}$ & $10 \mathrm{p} 13$ & $\begin{array}{l}\text { OPTN } \\
602432\end{array}$ & Optineurin & Maruyama et al. (2010) & \\
\hline $\begin{array}{l}\text { Amyotrophic lateral sclerosis } \\
13\end{array}$ & 12.55 & $\mathrm{AD}$ & $\begin{array}{l}\text { ALS13 } \\
183090\end{array}$ & $12 \mathrm{q} 24.12$ & $\begin{array}{l}\boldsymbol{A T X N 2} \\
601517\end{array}$ & Ataxin 2 & $\begin{array}{l}\text { Elden et al. (2010) } \\
\text { Daoud et al. (2011) Van } \\
\text { Damme et al. (2011) }\end{array}$ & allelic to SCA2 (group 13) \\
\hline $\begin{array}{l}\text { Amyotrophic lateral sclerosis } \\
14 \text {, with or without } \\
\text { frontotemporal dementia }\end{array}$ & 12.56 & $\mathrm{AD}$ & $\begin{array}{l}\text { ALS14 } \\
613954\end{array}$ & $9 \mathrm{p} 13.3$ & $\begin{array}{l}\boldsymbol{V C P} \\
601023\end{array}$ & $\begin{array}{l}\text { Valosin-containing } \\
\text { protein }\end{array}$ & Johnson et al. (2011) & $\begin{array}{l}\text { allelic to scapuloperoreal MD } \\
\text { (group 1), IBMPFD1 (groups } 4 \\
\text { and 5), CMT2Y (group 14) }\end{array}$ \\
\hline $\begin{array}{l}\text { Amyotrophic lateral sclerosis } \\
15 \text {, with or without } \\
\text { frontotemporal dementia }\end{array}$ & 12.57 & $\mathrm{XD}$ & $\begin{array}{l}\text { ALS15 } \\
300857\end{array}$ & Xp11.21 & $\begin{array}{l}\text { UBQLN2 } \\
300264\end{array}$ & Ubiquilin 2 & Deng et al. (2011) & \\
\hline $\begin{array}{l}\text { Amyotrophic lateral sclerosis } \\
16 \text {, juvenile }\end{array}$ & 12.58 & $\mathrm{AR}$ & $\begin{array}{l}\text { ALS16 } \\
614373\end{array}$ & $9 \mathrm{p} 13.3$ & $\begin{array}{l}\text { SIGMARI } \\
601978\end{array}$ & $\begin{array}{l}\text { Sigma non-opioid } \\
\text { intracellular receptor } \\
1\end{array}$ & Al-Saif et al. (2011) & allelic to DSMA2 (group 12) \\
\hline $\begin{array}{l}\text { Amyotrophic lateral sclerosis } \\
17\end{array}$ & 12.59 & $\mathrm{AD}$ & $\begin{array}{l}\text { ALS17 } \\
614696\end{array}$ & $3 \mathrm{p} 11.2$ & $\begin{array}{l}\text { СНMР2B } \\
609512\end{array}$ & $\begin{array}{l}\text { Charged } \\
\text { multivesicular body } \\
\text { protein 2B }\end{array}$ & $\begin{array}{l}\text { Parkinson et al. (2006) } \\
\text { Cox et al. (2010) }\end{array}$ & \\
\hline $\begin{array}{l}\text { Amyotrophic lateral sclerosis } \\
18\end{array}$ & 12.60 & $\mathrm{AD}$ & $\begin{array}{l}\text { ALS18 } \\
614808\end{array}$ & $17 \mathrm{p} 13.2$ & $\begin{array}{l}\text { PFN1 } \\
176610\end{array}$ & Profilin 1 & Wu et al. (2012) & \\
\hline $\begin{array}{l}\text { Amyotrophic lateral sclerosis } \\
19\end{array}$ & 12.61 & $\mathrm{AD}$ & $\begin{array}{l}\text { ALS19 } \\
615515\end{array}$ & $2 q 34$ & $\begin{array}{l}\text { ERBB4 } \\
600543\end{array}$ & $\begin{array}{l}\text { V-ERB-B2 avian } \\
\text { erythroblastic } \\
\text { leukemia viral } \\
\text { oncogene homolog } 4\end{array}$ & Takahashi et al. (2013) & \\
\hline $\begin{array}{l}\text { Amyotrophic lateral sclerosis } \\
20\end{array}$ & 12.62 & $\mathrm{AD}$ & $\begin{array}{l}\text { ALS20 } \\
615426\end{array}$ & $12 \mathrm{q} 13.13$ & $\begin{array}{l}\text { HNRNPA1 } \\
164017\end{array}$ & $\begin{array}{l}\text { Heterogeneous } \\
\text { nuclear } \\
\text { ribonucleoprotein A1 }\end{array}$ & Kim et al. (2013) & allelic to IBMPFD3 (group 3) \\
\hline $\begin{array}{l}\text { Amyotrophic lateral sclerosis } \\
21\end{array}$ & 12.63 & $\mathrm{AD}$ & $\begin{array}{l}\text { ALS21 } \\
606070\end{array}$ & $5 \mathrm{q} 31.2$ & $\begin{array}{l}\text { MATR3 } \\
164015\end{array}$ & Matrin 3 & Johnson et al. (2014) & allelic to VCPDM (group 4) \\
\hline $\begin{array}{l}\text { Amyotrophic lateral sclerosis } \\
22 \text {, with or without } \\
\text { frontotemporal dementia }\end{array}$ & 12.64 & $\mathrm{AD}$ & $\begin{array}{l}\text { ALS22 } \\
616208\end{array}$ & $2 q 35$ & $\begin{array}{l}\text { TUBA4A } \\
191110\end{array}$ & Tubulin, alpha-4A & Smith et al. (2014) & \\
\hline $\begin{array}{l}\text { Amyotrophic lateral sclerosis } \\
23\end{array}$ & 12.65 & $\mathrm{AD}$ & $\begin{array}{l}\text { ALS23 } \\
617839\end{array}$ & $10 \mathrm{q} 22.3$ & $\begin{array}{l}\text { ANXA11 } \\
602572\end{array}$ & Annexin A11 & Smith et al. (2017) & \\
\hline $\begin{array}{l}\text { Amyotrophic lateral sclerosis } \\
24 \text {, suseptibility to }\end{array}$ & 12.66 & & $\begin{array}{l}\text { ALS24 } \\
617892\end{array}$ & $4 q 33$ & $\begin{array}{l}\text { NEK1 } \\
604588\end{array}$ & $\begin{array}{l}\text { Never in mitosis gene } \\
\text { A-related kinase } 1\end{array}$ & $\begin{array}{l}\text { Brenner et al. (2016) } \\
\text { Kenna et al. (2016) }\end{array}$ & \\
\hline $\begin{array}{l}\text { Amyotrophic lateral sclerosis } \\
25 \text {, susceptibility to }\end{array}$ & 12.67 & $\mathrm{AD}$ & $\begin{array}{l}\text { ALS25 } \\
617921\end{array}$ & $12 q 13.3$ & $\begin{array}{l}\text { KIF5A } \\
60282 I\end{array}$ & $\begin{array}{l}\text { Kinesin family } \\
\text { member } 5 \mathrm{~A}\end{array}$ & Nicolas et al. (2018) & $\begin{array}{l}\text { Allelic to CMT2 related to } \\
\text { KIF5A (group 14) and SPG10 } \\
\text { (group 15) }\end{array}$ \\
\hline $\begin{array}{l}\text { Amyotrophic lateral sclerosis } \\
\text { related to NEFH, } \\
\text { susceptibility to }\end{array}$ & 12.68 & $\mathrm{AD}, \mathrm{AR}$ & $\begin{array}{l}\text { ALS1 } \\
105400\end{array}$ & $22 q 12.2$ & $\begin{array}{l}\text { NEFH } \\
162230\end{array}$ & $\begin{array}{l}\text { Neurofilament, heavy } \\
\text { polypeptide }\end{array}$ & Al-Chalabie et al. (1999) & allelic to CMT2CC (group 14) \\
\hline $\begin{array}{l}\text { Amyotrophic lateral sclerosis } \\
\text { related to peripherin, } \\
\text { susceptibility to }\end{array}$ & 12.69 & $\mathrm{AD}$ & $\begin{array}{l}\text { ALS1 } \\
105400\end{array}$ & $12 \mathrm{q} 13.12$ & $\begin{array}{l}\text { PRPH } \\
170710\end{array}$ & Peripherin & $\begin{array}{l}\text { Gros-Louis et al. (2004) } \\
\text { Leung et al. (2004) }\end{array}$ & \\
\hline $\begin{array}{l}\text { Amyotrophic lateral sclerosis } \\
\text { related to dynactin } 1 \text {, }\end{array}$ & 12.70 & $\mathrm{AD}$ & $\begin{array}{l}\text { ALS1 } \\
105400\end{array}$ & $2 \mathrm{p} 13.1$ & $\begin{array}{l}\text { DCTN1 } \\
601143\end{array}$ & Dynactin 1 & Munch et al. (2005) & allelic to HMN7B (group 12) \\
\hline
\end{tabular}




\begin{tabular}{|c|c|c|c|c|c|c|c|c|}
\hline DISEASE NAME & $\begin{array}{l}\text { Item line } \\
\text { in this } \\
\text { group }\end{array}$ & Inheritance & $\begin{array}{l}\text { Locus or } \\
\text { disease symbol } \\
\text { and OMIM } \\
\text { number }\end{array}$ & Chromosome & $\begin{array}{l}\text { Gene symbol } \\
\text { and OMIM } \\
\text { number }\end{array}$ & $\begin{array}{l}\text { Protein } \\
\text { (mitochondrial } \\
\text { proteins indicated } \\
\text { by symbol }[\mathrm{M}] \text { ) }\end{array}$ & Key references & $\begin{array}{l}\text { Other allelic disease(s) (group } \\
\text { in this table) }\end{array}$ \\
\hline $\begin{array}{l}\text { Amyotrophic lateral sclerosis } \\
\text { and/or frontotemporal } \\
\text { dementia }\end{array}$ & 12.71 & $\mathrm{AD}$ & $\begin{array}{l}\text { FTDALS1 } \\
105550\end{array}$ & $9 \mathrm{p} 21.2$ & $\begin{array}{l}\text { C9orf72 } \\
614260\end{array}$ & $\begin{array}{l}\text { Chromosome } 9 \text { open } \\
\text { reading frame } 72\end{array}$ & $\begin{array}{l}\text { Morita et al. (2006) } \\
\text { DeJesus-Hernandez } \\
\text { (2011) }\end{array}$ & \\
\hline $\begin{array}{l}\text { Amyotrophic lateral sclerosis } \\
\text { and/or frontotemporal } \\
\text { dementia }\end{array}$ & 12.72 & $\mathrm{AD}$ & $\begin{array}{l}\text { FTDALS2 } \\
615911\end{array}$ & $22 q 11.23$ & $\begin{array}{l}\text { CHCHD10 } \\
615903\end{array}$ & $\begin{array}{l}\text { Coiled-coil-helix- } \\
\text { coiled-coil-helix } \\
\text { domain containing } 10 \\
\text { (M) }\end{array}$ & Bannwarth et al. (2014) & $\begin{array}{l}\text { allelic to SMAJ (group 12), } \\
\text { IMMD (group 16) }\end{array}$ \\
\hline $\begin{array}{l}\text { Amyotrophic lateral sclerosis } \\
\text { and/or frontotemporal } \\
\text { dementia }\end{array}$ & 12.73 & $\mathrm{AD}$ & $\begin{array}{l}\text { FTDALS3 } \\
66437\end{array}$ & $5 q 35.3$ & $\begin{array}{l}\text { SQSTM1 } \\
601530\end{array}$ & Sequestosome 1 & Fecto et al. (2011) & allelic to DMRV (group 4) \\
\hline $\begin{array}{l}\text { Amyotrophic lateral sclerosis } \\
\text { and/or frontotemporal } \\
\text { dementia }\end{array}$ & 12.74 & $\mathrm{AD}$ & $\begin{array}{l}\text { FTDALS4 } \\
616439\end{array}$ & $12 q 14.2$ & $\begin{array}{l}\text { TBK1 } \\
604834\end{array}$ & $\begin{array}{l}\text { Tank-binding kinase } \\
1\end{array}$ & $\begin{array}{l}\text { Cirulli et al. (2015) } \\
\text { Freischmidt et al. (2015) }\end{array}$ & \\
\hline \multicolumn{9}{|l|}{ Others } \\
\hline $\begin{array}{l}\text { Lethal Congenital } \\
\text { Contracture Syndrome } 1\end{array}$ & 12.75 & $\mathrm{AR}$ & $\begin{array}{l}\text { LCCS1 } \\
253310\end{array}$ & $9 \mathrm{q} 34.11$ & $\begin{array}{l}\text { GLE1 } \\
603371\end{array}$ & $\begin{array}{l}\text { GLE1, RNA export } \\
\text { mediator }\end{array}$ & $\begin{array}{l}\text { Makela-Bengs et al. } \\
\text { (1998) Nousiainen et al. } \\
(2008)\end{array}$ & \\
\hline $\begin{array}{l}\text { Lethal Congenital } \\
\text { Contracture Syndrome } 2\end{array}$ & 12.76 & $\mathrm{AR}$ & $\begin{array}{l}\text { LCCS2 } \\
607598\end{array}$ & $12 \mathrm{q} 13.2$ & $\begin{array}{l}\text { ERBB3 } \\
190151\end{array}$ & $\begin{array}{l}\text { V-ERB-B2 avian } \\
\text { erythroblastic } \\
\text { leukemia viral } \\
\text { oncogene homolog } 3\end{array}$ & Narkis et al. (2007) & \\
\hline $\begin{array}{l}\text { Lethal Congenital } \\
\text { Contracture Syndrome } 3\end{array}$ & 12.77 & $\mathrm{AR}$ & $\begin{array}{l}\text { LCCS3 } \\
611359\end{array}$ & 19p13.3 & $\begin{array}{l}\text { PIP5K1C } \\
606102\end{array}$ & $\begin{array}{l}\text { Phosphatidylinositol- } \\
\text { 4-phosphate 5-kinase, } \\
\text { type I, gamma }\end{array}$ & Narkis et al. (2007) & \\
\hline $\begin{array}{l}\text { Spinal muscular atrophy } \\
\text { with pontocerebellar } \\
\text { hypoplasia, type } 1 \mathrm{~b}\end{array}$ & 12.78 & $\mathrm{AR}$ & $\begin{array}{l}\text { PCH1B } \\
614678\end{array}$ & $9 \mathrm{p} 13.2$ & $\begin{array}{l}\text { EXOSC3 } \\
606489\end{array}$ & $\begin{array}{l}\text { Exosome component } \\
3\end{array}$ & $\begin{array}{l}\text { Rudnik-Schöneborn et al. } \\
\text { (2013) }\end{array}$ & \\
\hline $\begin{array}{l}\text { Spinal muscular atrophy } \\
\text { with or without } \\
\text { pontocerebellar hypoplasia }\end{array}$ & 12.79 & $\mathrm{AR}$ & $\begin{array}{l}\text { PCH1 } \\
607596\end{array}$ & $14 \mathrm{q} 32.2$ & $\begin{array}{l}\text { VRK1 } \\
602168\end{array}$ & $\begin{array}{l}\text { Vaccinia related } \\
\text { kinase } 1\end{array}$ & $\begin{array}{l}\text { Renbaum et al. (2009) } \\
\text { Stoll et al. (2016) }\end{array}$ & $\begin{array}{l}\text { Allelic to DSMA (group 12), } \\
\text { Complex motor and sensory } \\
\text { axonal neuropathy plus } \\
\text { microcephaly and cerebral } \\
\text { dysgenesis (group 14) }\end{array}$ \\
\hline $\begin{array}{l}\text { Pontocerebellar hypoplasia } \\
\text { with spinal muscular atrophy }\end{array}$ & 12.80 & $\mathrm{AR}$ & $\begin{array}{l}\text { HSMN6B } \\
616505\end{array}$ & $5 q 22.1$ & $\begin{array}{l}\text { SLC25A46 } \\
610826\end{array}$ & $\begin{array}{l}\text { Solute Carrier Family } \\
25 \text {, Member } 46\end{array}$ & van Dijk et al. (2017) & \\
\hline $\begin{array}{l}\text { Brown-Vialetto-van Laere } \\
\text { syndrome } 1\end{array}$ & 12.81 & $\mathrm{AR}$ & $\begin{array}{l}\text { BVVLS1 } \\
211530\end{array}$ & $20 \mathrm{p} 13$ & $\begin{array}{l}\text { SLC52A3 } \\
613350\end{array}$ & $\begin{array}{l}\text { Solute carrier family } \\
52 \text { (riboflavin } \\
\text { transporter) member } \\
3\end{array}$ & $\begin{array}{l}\text { Green et al. (2010) } \\
\text { Bosch et al. (2011) } \\
\text { Johnson et al. (2010) }\end{array}$ & \\
\hline $\begin{array}{l}\text { Brown-Vialetto-van Laere } \\
\text { syndrome } 2\end{array}$ & 12.82 & $\mathrm{AR}$ & $\begin{array}{l}\text { BVVLS2 } \\
614707\end{array}$ & $8 \mathrm{q} 24.3$ & $\begin{array}{l}\text { SLC52A2 } \\
607882\end{array}$ & $\begin{array}{l}\text { Solute carrier family } \\
52 \text { (riboflavin } \\
\text { transporter) member } \\
2\end{array}$ & $\begin{array}{l}\text { Green et al. (2010) } \\
\text { Bosch et al. (2011) } \\
\text { Johnson et al. (2012) }\end{array}$ & \\
\hline $\begin{array}{l}\text { Late onset spinal muscular } \\
\text { atrophy related to } H E X B\end{array}$ & 12.83 & $\mathrm{AR}$ & & $5 q 13.3$ & $\begin{array}{l}\text { HEXB } \\
606873\end{array}$ & Hexosaminidase B & Rattay et al. (2013) & $\begin{array}{l}\text { allelic to Sandhoff disease, adult } \\
\text { type (OMIM \#268800) }\end{array}$ \\
\hline $\begin{array}{l}\text { Spinal muscular atrophy, } \\
\text { related to PRUNE1 }\end{array}$ & 12.84 & $\mathrm{AR}$ & & $1 \mathrm{q} 21.3$ & $\begin{array}{l}\text { PRUNE1 } \\
617413\end{array}$ & $\begin{array}{l}\text { Prune } \\
\text { exopolyphosphatase } 1\end{array}$ & Iacomino et al. (2017) & \\
\hline $\begin{array}{l}\text { Spinal muscular atrophy } \\
\text { with pontocerebellar } \\
\text { hypoplasia related to } \\
\text { KIF26B }\end{array}$ & 12.85 & $\mathrm{AD}$ & & $1 q 44$ & $\begin{array}{l}\text { KIF26B } \\
614026\end{array}$ & $\begin{array}{l}\text { Kinesin family } \\
\text { member } 26 B\end{array}$ & Wojcik et al. (2018) & \\
\hline $\begin{array}{l}\text { Peripheral neuropathy, } \\
\text { myopathy, hoarseness and } \\
\text { hearing loss }\end{array}$ & 12.86 & $\mathrm{AD}$ & $\begin{array}{l}\text { PNMHH } \\
614369\end{array}$ & $19 \mathrm{q} 13.33$ & $\begin{array}{l}\text { MYH14 } \\
608568\end{array}$ & $\begin{array}{l}\text { Myosin, heavy chain } \\
14, \text { non muscle }\end{array}$ & Choi et al. (2011) & \\
\hline $\begin{array}{l}\text { Lower motor neuron disease } \\
\text { with respiratory failure } \\
\text { related to MAPT }\end{array}$ & 12.87 & $\mathrm{AD}$ & & $17 \mathrm{q} 21.31$ & $\begin{array}{l}\text { MAPT } \\
157140\end{array}$ & $\begin{array}{l}\text { Microtubule } \\
\text { associated protein } \\
\text { Tau }\end{array}$ & Di Fonso et al. (2014) & $\begin{array}{l}\text { allelic to Frontotemporal } \\
\text { dementia (OMIM \#600274) }\end{array}$ \\
\hline
\end{tabular}

GROUP 14. HEREDITARY MOTOR SENSORY NEUROPATHIES (HMSN)

A. Charcot-Marie-Tooth neuropathy, type 1 (demyelinating)

Autosomal dominant (AD-CMTI)

Charcot-Marie-Tooth

disease, type $1 \mathrm{~A}$

AD CMT1A

118220

PMP22

601097

$\begin{array}{lcclcc}\begin{array}{l}\text { Charcot-Marie-Tooth } \\ \text { disease, type 1B }\end{array} & 14.2 & \text { AD } & \begin{array}{l}\text { CMT1B } \\ 118200\end{array} & 1 \mathrm{q} 23.3 & \begin{array}{l}\text { MPZ } \\ 159440\end{array} \\ \begin{array}{l}\text { Charcot-Marie-Tooth } \\ \text { disease, type 1C }\end{array} & 14.3 & \text { AD } & \begin{array}{l}\text { CMT1C } \\ 601098\end{array} & 16 \mathrm{p} 13.13 & \text { LITAF } \\ & & & & & 603795 \\ \begin{array}{l}\text { Charcot-Marie-Tooth } \\ \text { disease, type 1D }\end{array} & 14.4 & \text { AD } & \begin{array}{l}\text { CMT1D } \\ \text { 607678 }\end{array} & 10 \mathrm{q} 21.3 & \begin{array}{l}\text { EGR2 } \\ \text { I29010 }\end{array}\end{array}$

Peripheral myelin

protein 22

Myelin protein zero

Lipopolysaccharideinduced TNF-alpha

factor

Early growth

response 2 (Krox-20

homolog)
Vance et al. (1989) Patel et al. (1992) Matsunami et al. (1992) Timmerman et al. $(1990,1992)$ Valentijn et al. (1992)

Roa et al. (1993) Bird et al. (1982) Guiloff et al. (1982) Hayasaka et al. (1993) Kulkens et al. (1993) Street et al. $(2002,2003)$

Warner et al. (1998) Street et al. (2003) allelic to CMT1E, HNPP and DSS (group 14)

allelic to CMTDID, CMT2I, CMT2J, DSS and CHN (group14)

allelic to CHN and DSS (group 14)

(continued on next page) 


\begin{tabular}{|c|c|c|c|c|c|c|c|c|}
\hline DISEASE NAME & $\begin{array}{l}\text { Item line } \\
\text { in this } \\
\text { group }\end{array}$ & Inheritance & $\begin{array}{l}\text { Locus or } \\
\text { disease symbol } \\
\text { and OMIM } \\
\text { number }\end{array}$ & Chromosome & $\begin{array}{l}\text { Gene symbol } \\
\text { and OMIM } \\
\text { number }\end{array}$ & $\begin{array}{l}\text { Protein } \\
\text { (mitochondrial } \\
\text { proteins indicated } \\
\text { by symbol }[\mathrm{M}] \text { ) }\end{array}$ & Key references & $\begin{array}{l}\text { Other allelic disease(s) (group } \\
\text { in this table) }\end{array}$ \\
\hline $\begin{array}{l}\text { Charcot-Marie-Tooth } \\
\text { disease, type } 1 \mathrm{E} \text {, with } \\
\text { deafness }\end{array}$ & 14.5 & $\mathrm{AD}$ & $\begin{array}{l}\text { CMT1E } \\
118300\end{array}$ & $17 \mathrm{p} 12$ & $\begin{array}{l}\text { PMP22 } \\
601097\end{array}$ & $\begin{array}{l}\text { Peripheral myelin } \\
\text { protein } 22\end{array}$ & $\begin{array}{l}\text { Kovach et al. (1999) } \\
\text { Boerkoel et al. (2002) }\end{array}$ & $\begin{array}{l}\text { allelic to CMT1A, HNPP and } \\
\text { DSS (group14), }\end{array}$ \\
\hline $\begin{array}{l}\text { Hereditary neuropathy with } \\
\text { liability to pressure palsies }\end{array}$ & 14.6 & $\mathrm{AD}$ & $\begin{array}{l}\text { HNPP } \\
162500\end{array}$ & $17 \mathrm{p} 12$ & $\begin{array}{l}\text { PMP22 } \\
601097\end{array}$ & $\begin{array}{l}\text { Peripheral myelin } \\
\text { protein P22 }\end{array}$ & $\begin{array}{l}\text { Chance et al. (1993) } \\
\text { Nicholson et al. (1994) } \\
\text { Mariman et al. (1994) }\end{array}$ & $\begin{array}{l}\text { allelic to CMT1A, CMT1E and } \\
\text { DSS (group 14) }\end{array}$ \\
\hline $\begin{array}{l}\text { Charcot-Marie-Tooth } \\
\text { disease, type } 1 \mathrm{~F}\end{array}$ & 14.7 & $\mathrm{AD}$ & $\begin{array}{l}\text { CMT1F } \\
607734\end{array}$ & $8 \mathrm{p} 21.2$ & $\begin{array}{l}\text { NEFL } \\
162280\end{array}$ & $\begin{array}{l}\text { Neurofilament, light } \\
\text { polypeptide } 68 \mathrm{kDa}\end{array}$ & Jordanova et al. (2003) & $\begin{array}{l}\text { allelic to CMTDIG and CMT2E } \\
\text { (group 14) }\end{array}$ \\
\hline $\begin{array}{l}\text { Charcot-Marie Tooth } \\
\text { disease, demyelinating type } \\
\text { 1G }\end{array}$ & 14.8 & $\mathrm{AD}$ & $\begin{array}{l}\text { CMT1G } \\
618279\end{array}$ & $8 \mathrm{q} 21.13$ & $\begin{array}{l}\text { PMP2 } \\
170715\end{array}$ & $\begin{array}{l}\text { Peripheral myelin } \\
\text { protein } 2\end{array}$ & Hong et al. (2016) & \\
\hline $\begin{array}{l}\text { CMT with congenital } \\
\text { vertical talus }\end{array}$ & 14.9 & $\mathrm{AD}$ & $\begin{array}{l}\text { CVT } \\
192950\end{array}$ & $2 \mathrm{q} 31.1$ & $\begin{array}{l}\text { HOXD10 } \\
142984\end{array}$ & Homeobox D10 & Shrimpton et al. (2004) & \\
\hline $\begin{array}{l}\text { Slowed nerve conduction } \\
\text { velocity }\end{array}$ & 14.10 & $\mathrm{AD}$ & $\begin{array}{l}\text { SNCV } \\
608236\end{array}$ & $8 \mathrm{p} 23.3$ & $\begin{array}{l}\text { ARHGEF10 } \\
608136\end{array}$ & $\begin{array}{l}\text { Rho } \\
\text { guanine-nucleotide } \\
\text { exchange factor-10 }\end{array}$ & $\begin{array}{l}\text { De Jonghe et al. (1999) } \\
\text { Verhoeven et al. (2003) }\end{array}$ & \\
\hline $\begin{array}{l}\text { Neuropathy, hereditary, with } \\
\text { or without age-related } \\
\text { macular degeneration }\end{array}$ & 14.11 & $\mathrm{AD}$ & $\begin{array}{l}\text { HNARMD } \\
608895\end{array}$ & $14 \mathrm{q} 32.12$ & $\begin{array}{l}\text { FBLN5 } \\
604580\end{array}$ & Fibulin 5 & $\begin{array}{l}\text { Auer-Grumbach et al. } \\
\text { (2011) }\end{array}$ & \\
\hline \multicolumn{9}{|c|}{ Dominant intermediate (CMTDI) } \\
\hline $\begin{array}{l}\text { Charcot-Marie-Tooth } \\
\text { disease, dominant } \\
\text { intermediate A }\end{array}$ & 14.12 & $\mathrm{AD}$ & $\begin{array}{l}\text { CMTDIA } \\
606483\end{array}$ & $10 \mathrm{q} 24.1-\mathrm{q} 25.1$ & $?$ & & Verhoeven et al. (2001) & \\
\hline $\begin{array}{l}\text { Charcot-Marie-Tooth } \\
\text { disease, dominant } \\
\text { intermediate B }\end{array}$ & 14.13 & $\mathrm{AD}$ & $\begin{array}{l}\text { CMTDIB } \\
606482\end{array}$ & $19 \mathrm{p} 13.2$ & $\begin{array}{l}\text { DNM2 } \\
602378\end{array}$ & Dynamin 2 & Zuchner et al. (2005) & $\begin{array}{l}\text { allelic to CNM1 (group } 3 \text { and } 4 \text { ) } \\
\text { and CMD related to DNM2 } \\
\text { (group 2) }\end{array}$ \\
\hline $\begin{array}{l}\text { Charcot-Marie-Tooth } \\
\text { disease, dominant } \\
\text { intermediate C }\end{array}$ & 14.14 & $\mathrm{AD}$ & $\begin{array}{l}\text { CMTDIC } \\
608323\end{array}$ & $1 \mathrm{p} 35.1$ & $\begin{array}{l}\text { YARS } \\
603623\end{array}$ & $\begin{array}{l}\text { Tyrosyl-tRNA } \\
\text { synthetase }\end{array}$ & $\begin{array}{l}\text { Jordanova et al. (2003, } \\
\text { 2006) }\end{array}$ & Allelic to MLASA2 (group 16) \\
\hline $\begin{array}{l}\text { Charcot-Marie-Tooth } \\
\text { disease, dominant } \\
\text { intermediate D }\end{array}$ & 14.15 & $\mathrm{AD}$ & $\begin{array}{l}\text { CMTDID } \\
607791\end{array}$ & $1 \mathrm{q} 23.3$ & $\begin{array}{l}\text { MPZ } \\
159440\end{array}$ & Myelin protein zero & Mastaglia et al. (1999) & $\begin{array}{l}\text { allelic to CMT1B, CMT2I, } \\
\text { CMT2J, DSS and CHN (group14) }\end{array}$ \\
\hline $\begin{array}{l}\text { Charcot-Marie-Tooth } \\
\text { disease, dominant } \\
\text { intermediate E }\end{array}$ & 14.16 & $\mathrm{AD}$ & $\begin{array}{l}\text { CMTDIE } \\
614455\end{array}$ & $14 \mathrm{q} 32.33$ & $\begin{array}{l}\text { INF2 } \\
610982\end{array}$ & Inverted formin 2 & Boyer et al. (2011) & \\
\hline $\begin{array}{l}\text { Charcot-Marie-Tooth } \\
\text { disease, dominant } \\
\text { intermediate F }\end{array}$ & 14.17 & $\mathrm{AD}$ & $\begin{array}{l}\text { CMTDIF } \\
615185\end{array}$ & $3 \mathrm{q} 28.33$ & $\begin{array}{l}\text { GNB4 } \\
610863\end{array}$ & $\begin{array}{l}\text { Guanine } \\
\text { nucleotide-binding } \\
\text { protein, beta- } 4\end{array}$ & Soong et al. (2013) & \\
\hline $\begin{array}{l}\text { Charcot-Marie-Tooth } \\
\text { disease, dominant } \\
\text { intermediate G }\end{array}$ & 14.18 & $\mathrm{AD}$ & $\begin{array}{l}\text { CMTDIG } \\
617882\end{array}$ & $8 \mathrm{p} 21.2$ & $\begin{array}{l}\text { NEFL } \\
162280\end{array}$ & $\begin{array}{l}\text { Neurofilament, light } \\
\text { polypeptide } 68 \mathrm{kDa}\end{array}$ & Berciano et al. (2015) & $\begin{array}{l}\text { allelic to CMT1F and CMT2E } \\
\text { (group 14) }\end{array}$ \\
\hline $\begin{array}{l}\text { Charcot-Marie Tooth } \\
\text { disease, intermediate }\end{array}$ & 14.19 & $\mathrm{AD}$ & & $1 \mathrm{p} 21.2-\mathrm{p} 13.3$ & C1orf194 & $\begin{array}{l}\text { Chromosome } 1 \text { open } \\
\text { reading frame } 194\end{array}$ & Sun et al. (2019) & \\
\hline \multicolumn{9}{|c|}{ Autosomal recessive (AR-CMT1 or CMT4) } \\
\hline $\begin{array}{l}\text { Charcot-Marie-Tooth } \\
\text { disease, type } 4 \mathrm{~A}\end{array}$ & 14.20 & AR & $\begin{array}{l}\text { CMT4A } \\
214400\end{array}$ & $8 \mathrm{q} 21.11$ & $\begin{array}{l}\text { GDAPI } \\
606598\end{array}$ & $\begin{array}{l}\text { Ganglioside-induced } \\
\text { differentiation } \\
\text { associated protein } 1\end{array}$ & $\begin{array}{l}\text { Ben Othmane et al. } \\
\text { (1993) Baxter et al. } \\
\text { (2002) Cuesta et al. } \\
\text { (2002) Nelis et al. (2002) }\end{array}$ & $\begin{array}{l}\text { allelic to CMT2K and CMTRIA } \\
\text { (group 14) }\end{array}$ \\
\hline $\begin{array}{l}\text { Charcot-Marie-Tooth } \\
\text { disease, type 4B1 }\end{array}$ & 14.21 & AR & $\begin{array}{l}\text { CMT4B1 } \\
601382\end{array}$ & $11 \mathrm{q} 21$ & $\begin{array}{l}\text { MTMR2 } \\
603557\end{array}$ & $\begin{array}{l}\text { Myotubularin-related } \\
\text { protein-2 }\end{array}$ & $\begin{array}{l}\text { Bolino et al. (1996, } \\
\text { 2000) Previtali et al. } \\
\text { (2003) }\end{array}$ & \\
\hline $\begin{array}{l}\text { Charcot-Marie-Tooth } \\
\text { disease, type 4B2 }\end{array}$ & 14.22 & AR & $\begin{array}{l}\text { CMT4B2 } \\
604563\end{array}$ & $11 \mathrm{p} 15.4$ & $\begin{array}{l}S B F 2 \\
607697\end{array}$ & SET-binding factor 2 & $\begin{array}{l}\text { Azzedine et al. (2003) } \\
\text { Senderek et al. (2004) }\end{array}$ & \\
\hline $\begin{array}{l}\text { Charcot-Marie-Tooth } \\
\text { disease, type 4B3 }\end{array}$ & 14.23 & $\mathrm{AR}$ & $\begin{array}{l}\text { CMT4B3 } \\
615284\end{array}$ & $22 q 13.33$ & $\begin{array}{l}S B F 1 \\
603560\end{array}$ & SET-binding factor 1 & Nakhro et al. (2013) & \\
\hline $\begin{array}{l}\text { Charcot-Marie-Tooth } \\
\text { disease, type } 4 \mathrm{C}\end{array}$ & 14.24 & AR & $\begin{array}{l}\text { CMT4C } \\
601596\end{array}$ & $5 \mathrm{q} 32$ & $\begin{array}{l}\text { SH3TC2 } \\
608206\end{array}$ & $\begin{array}{l}\text { SH3 domain and } \\
\text { tetratricopeptide } \\
\text { repeats domain } 2\end{array}$ & $\begin{array}{l}\text { LeGuern et al. (1996) } \\
\text { Senderek et al. (2003) }\end{array}$ & \\
\hline $\begin{array}{l}\text { Charcot-Marie-Tooth } \\
\text { disease, type } 4 \mathrm{D}\end{array}$ & 14.25 & $\mathrm{AR}$ & $\begin{array}{l}\text { CMT4D } \\
601455\end{array}$ & $8 \mathrm{q} 24.22$ & $\begin{array}{l}\text { NDRG1 } \\
605262\end{array}$ & $\begin{array}{l}\mathrm{N}-m y c \text { downstream } \\
\text { regulated gene } 1\end{array}$ & $\begin{array}{l}\text { Kalaydjieva et al. (1996, } \\
\text { 2000) Hunter et al. } \\
(2003)\end{array}$ & \\
\hline $\begin{array}{l}\text { Neuropathy, congenital } \\
\text { hypomyelinating, } 1\end{array}$ & 14.26 & AR & $\begin{array}{l}\text { CHN } \\
605253\end{array}$ & $10 \mathrm{q} 21.3$ & $\begin{array}{l}\text { EGR2 } \\
129010\end{array}$ & $\begin{array}{l}\text { Early growth } \\
\text { response } 2\end{array}$ & Warner et al. (1998) & $\begin{array}{l}\text { allelic to CMT1D and DSS } \\
\text { (group 14) }\end{array}$ \\
\hline $\begin{array}{l}\text { Neuropathy, congenital } \\
\text { hypomyelinating, } 1\end{array}$ & 14.27 & $\mathrm{AR}$ & $\begin{array}{l}\text { CHN } \\
605253\end{array}$ & $1 \mathrm{q} 23.3$ & $\begin{array}{l}\text { MPZ } \\
159440\end{array}$ & Myelin protein zero & Warner et al. (1996) & $\begin{array}{l}\text { allelic to CMT1B, CMTDID, } \\
\text { CMT2I, CMT2J, DSS } \\
\text { (group 14) }\end{array}$ \\
\hline $\begin{array}{l}\text { Charcot-Marie-Tooth } \\
\text { disease, type } 4 \mathrm{~F}\end{array}$ & 14.28 & AR & $\begin{array}{l}\text { CMT4F } \\
614895\end{array}$ & $19 \mathrm{q} 13.2$ & $\begin{array}{l}\boldsymbol{P R X} \\
605725\end{array}$ & Periaxin & $\begin{array}{l}\text { Delague et al. (2000) } \\
\text { Guilbot et al. (2001) }\end{array}$ & allelic to DSS (group14) \\
\hline $\begin{array}{l}\text { Neuropathy, hereditary } \\
\text { motor and sensory, Russe } \\
\text { type }\end{array}$ & 14.29 & AR & $\begin{array}{l}\text { HMSNR } \\
605285\end{array}$ & $10 \mathrm{q} 22.1$ & $\begin{array}{l}\text { HKI } \\
142600\end{array}$ & Hexokinase 1 & $\begin{array}{l}\text { Rogers et al. (2000) } \\
\text { Thomas et al. (2001) } \\
\text { Hantke et al. (2009) } \\
\text { Sevilla et al. (2013) }\end{array}$ & \\
\hline $\begin{array}{l}\text { Charcot-Marie-Tooth } \\
\text { disease, type } 4 \mathrm{H}\end{array}$ & 14.30 & AR & $\begin{array}{l}\text { CMT4H } \\
609311\end{array}$ & $12 \mathrm{p} 11.21$ & $\begin{array}{l}\text { FGD4 } \\
611104\end{array}$ & $\begin{array}{l}\text { Fyve, RhoGEF and } \\
\text { Phdomain-containing } \\
\text { protein } 4 \text { (Frabin) }\end{array}$ & $\begin{array}{l}\text { De Sandre-Giovannoli } \\
\text { et al. (2005) Delague } \\
\text { et al. (2007) Stendel } \\
\text { et al. (2007) }\end{array}$ & \\
\hline
\end{tabular}




\begin{tabular}{|c|c|c|c|c|c|c|c|c|}
\hline DISEASE NAME & $\begin{array}{l}\text { Item line } \\
\text { in this } \\
\text { group }\end{array}$ & Inheritance & $\begin{array}{l}\text { Locus or } \\
\text { disease symbol } \\
\text { and OMIM } \\
\text { number }\end{array}$ & Chromosome & $\begin{array}{l}\text { Gene symbol } \\
\text { and OMIM } \\
\text { number }\end{array}$ & $\begin{array}{l}\text { Protein } \\
\text { (mitochondrial } \\
\text { proteins indicated } \\
\text { by symbol }[\mathrm{M}] \text { ) }\end{array}$ & Key references & $\begin{array}{l}\text { Other allelic disease(s) (group } \\
\text { in this table) }\end{array}$ \\
\hline $\begin{array}{l}\text { Charcot-Marie-Tooth } \\
\text { disease, type } 4 \mathrm{~J}\end{array}$ & 14.31 & $\mathrm{AR}$ & $\begin{array}{l}\text { CMT4J } \\
611228\end{array}$ & $6 \mathrm{q} 21$ & $\begin{array}{l}\text { FIG4 } \\
609390\end{array}$ & $\begin{array}{l}\text { FIG4, S. Cerevisiae, } \\
\text { homolog of }\end{array}$ & Chow et al. (2007) & allelic to ALS11 (group 12) \\
\hline $\begin{array}{l}\text { Charcot-Marie-Tooth } \\
\text { disease, type } 4 \mathrm{~K}\end{array}$ & 14.32 & $\mathrm{AR}$ & $\begin{array}{l}\text { CMT4K } \\
616684\end{array}$ & $9 \mathrm{q} 34.2$ & $\begin{array}{l}\text { SURF1 } \\
185620\end{array}$ & Surfeit $1(\mathbf{M})$ & $\begin{array}{l}\text { Echaniz-Laguna et al. } \\
\text { (2013) }\end{array}$ & \\
\hline Charcot-Marie Tooth disease & 14.33 & $\mathrm{AR}$ & & $14 q 32$ & $\begin{array}{l}\text { AHNAK2 } \\
608570\end{array}$ & $\begin{array}{l}\text { Ahnak nucleoprotein } \\
2\end{array}$ & Tey et al. (2019) & \\
\hline \multicolumn{9}{|l|}{$X$-linked CMTI } \\
\hline $\begin{array}{l}\text { Charcot-Marie-Tooth } \\
\text { neuropathy, X-linked } \\
\text { dominant, } 1\end{array}$ & 14.34 & $\mathrm{XD}$ & $\begin{array}{l}\text { CMTX1 } \\
302800\end{array}$ & $\mathrm{Xq} 13.1$ & $\begin{array}{l}\text { GJB1 } \\
304040\end{array}$ & $\begin{array}{l}\text { Gap junction protein, } \\
\text { beta } 1\end{array}$ & $\begin{array}{l}\text { Bergoffen et al. (1993) } \\
\text { Bone et al. (1995) }\end{array}$ & allelic to DSS (group 14) \\
\hline $\begin{array}{l}\text { Charcot-Marie-Tooth } \\
\text { neuropathy, X-linked } \\
\text { recessive, } 2\end{array}$ & 14.35 & $\mathrm{XR}$ & $\begin{array}{l}\text { CMTX2 } \\
302801\end{array}$ & $\mathrm{Xp} 22.2$ & $?$ & & Ionasecu et al. (1992) & \\
\hline $\begin{array}{l}\text { Charcot-Marie-Tooth } \\
\text { neuropathy, X-linked } \\
\text { recessive, } 3\end{array}$ & 14.36 & $\mathrm{XR}$ & $\begin{array}{l}\text { CMTX3 } \\
302802\end{array}$ & $\mathrm{Xq} 26$ & $\begin{array}{l}78 \mathrm{~kb} \text { Chro8 } \\
\text { insertion }\end{array}$ & $\begin{array}{l}78 \mathrm{~kb} \\
\text { inter-chromosomal } \\
\text { insertion (from chro } \\
8 \mathrm{q} 24.3 \text { ) }\end{array}$ & $\begin{array}{l}\text { Ionasecu et al. (1992) } \\
\text { Huttner et al. (2006) } \\
\text { Brewer et al. (2016) }\end{array}$ & \\
\hline $\begin{array}{l}\text { Charcot-Marie-Tooth } \\
\text { disease, X-linked } 4 \\
\text { (Cowchock syndrome) }\end{array}$ & 14.37 & $\mathrm{XR}$ & $\begin{array}{l}\text { COWCK } \\
310490\end{array}$ & $\mathrm{Xq} 26.1$ & $\begin{array}{l}\text { AIFMI } \\
300169\end{array}$ & $\begin{array}{l}\text { Apoptosis-inducing } \\
\text { factor, mitochondria- } \\
\text { associated, } 1 \\
\text { (M) }\end{array}$ & $\begin{array}{l}\text { Priest et al. (1995) } \\
\text { Rinaldi et al. (2012) }\end{array}$ & Allelic to COXPD6 (group 16) \\
\hline $\begin{array}{l}\text { Charcot-Marie-Tooth } \\
\text { disease, X-linked recessive, } \\
5\end{array}$ & 14.38 & $\mathrm{XR}$ & $\begin{array}{l}\text { CMTX5 } \\
311070\end{array}$ & $\mathrm{Xq} 22.3$ & $\begin{array}{l}\text { PRPS1 } \\
311850\end{array}$ & $\begin{array}{l}\text { Phosphoribosyl } \\
\text { pyrophosphate } \\
\text { synthetase } 1\end{array}$ & Kim at al (2007) & \\
\hline $\begin{array}{l}\text { Charcot-Marie-Tooth } \\
\text { disease, X-linked dominant, } \\
6\end{array}$ & 14.39 & $\mathrm{XD}$ & $\begin{array}{l}\text { CMTX6 } \\
300905\end{array}$ & $\mathrm{Xp} 22.11$ & $\begin{array}{l}\text { PDK3 } \\
300906\end{array}$ & $\begin{array}{l}\text { Pyruvate } \\
\text { dehydrogenase } \\
\text { kinase, isoenzyme } 3\end{array}$ & Kennerson et al. (2013) & \\
\hline \multicolumn{9}{|c|}{ Déjerine-Sottas syndrome (DSS or CMT3) } \\
\hline $\begin{array}{l}\text { Déjerine-Sottas hypertrophic } \\
\text { neuropathy, dominant }\end{array}$ & 14.40 & $\mathrm{AD}$ & $\begin{array}{l}\text { DSS } \\
145900\end{array}$ & $17 \mathrm{p} 12$ & $\begin{array}{l}P M P 22 \\
601097\end{array}$ & $\begin{array}{l}\text { Peripheral myelin } \\
\text { protein } 22\end{array}$ & Roa et al. (1993) & $\begin{array}{l}\text { allelic to CMT1A, CMT1E and } \\
\text { HNPP (group 14) }\end{array}$ \\
\hline $\begin{array}{l}\text { Déjerine-Sottas hypertrophic } \\
\text { neuropathy, dominant }\end{array}$ & 14.41 & $\mathrm{AD}$ & $\begin{array}{l}\text { DSS } \\
145900\end{array}$ & $1 \mathrm{q} 23.3$ & $\begin{array}{l}\text { MPZ } \\
159440\end{array}$ & Myelin protein zero & Hayasaka et al. (1993) & $\begin{array}{l}\text { allelic to CMT1B, CMTD2I, } \\
\text { CMT2J, CMT2I and CHN (group } \\
\text { 14) }\end{array}$ \\
\hline $\begin{array}{l}\text { Déjerine-Sottas hypertrophic } \\
\text { neuropathy, dominant }\end{array}$ & 14.42 & $\begin{array}{l}\mathrm{AD} \\
\text { (digenic) }\end{array}$ & $\begin{array}{l}\text { DSS } \\
145900\end{array}$ & $\begin{array}{l}10 \mathrm{q} 21.3 \text { and } \\
\mathrm{Xq} 13\end{array}$ & $\begin{array}{l}\boldsymbol{E G R 2} \\
129010 \text { and } \\
\boldsymbol{G J B 1} \\
304040\end{array}$ & $\begin{array}{l}\text { Early growth } \\
\text { response } 2 \text { and Gap } \\
\text { junction protein, beta } \\
1\end{array}$ & Chung et al. (2005) & $\begin{array}{l}\text { EGR2: allelic to CMT1D and } \\
\text { CHN (group 14) GJB1: allelic to } \\
\text { CMTX1 (group 14) }\end{array}$ \\
\hline $\begin{array}{l}\text { Déjerine-Sottas hypertrophic } \\
\text { neuropathy, recessive }\end{array}$ & 14.43 & $\mathrm{AR}$ & $\begin{array}{l}\text { DSS } \\
145900\end{array}$ & $19 \mathrm{q} 13.2$ & $\begin{array}{l}\text { PRX } \\
605725\end{array}$ & Periaxin & $\begin{array}{l}\text { Delague et al. (2000) } \\
\text { Boerkoel et al. (2001) }\end{array}$ & allelic to CMT4F (group 14) \\
\hline \multicolumn{9}{|c|}{$\begin{array}{l}\text { B. Charcot-Marie-Tooth neuropathy, type } 2(\text { axonal })=C M T 2 \\
\text { Autosomal dominant CMT2 }\end{array}$} \\
\hline $\begin{array}{l}\text { Charcot-Marie-Tooth } \\
\text { disease, type } 2 \mathrm{~A} 1\end{array}$ & 14.44 & $\mathrm{AD}$ & $\begin{array}{l}\text { CMT2A1 } \\
118210\end{array}$ & $1 \mathrm{p} 36.22$ & $\begin{array}{l}\text { KIFIB } \\
605995\end{array}$ & $\begin{array}{l}\text { Kinesin family } \\
\text { member 1B }\end{array}$ & Zhao et al. (2001) & \\
\hline $\begin{array}{l}\text { Charcot-Marie-Tooth } \\
\text { disease, axonal, type 2A2A }\end{array}$ & 14.45 & $\mathrm{AD}$ & $\begin{array}{l}\text { CMT2A2A } \\
609260\end{array}$ & $1 \mathrm{p} 36.22$ & $\begin{array}{l}\text { MFN2 } \\
608507\end{array}$ & Mitofusin 2 & $\begin{array}{l}\text { Ben Othmane et al. } \\
\text { (1993) Züchner et al. } \\
\text { (2004) }\end{array}$ & $\begin{array}{l}\text { allelic to CMT2A2B and } \\
\text { HMSN6A (group14) }\end{array}$ \\
\hline $\begin{array}{l}\text { Charcot-Marie-Tooth } \\
\text { disease, type 2B }\end{array}$ & 14.46 & $\mathrm{AD}$ & $\begin{array}{l}\text { CMT2B } \\
600882\end{array}$ & $3 q 21.3$ & $\begin{array}{l}\boldsymbol{R A B 7} \\
602298\end{array}$ & $\begin{array}{l}\text { RAS-associated } \\
\text { protein RAB7 }\end{array}$ & $\begin{array}{l}\text { Kwon et al. (1995) } \\
\text { Pericak-Vance et al. } \\
\text { (1997) Kok et al. (2003) }\end{array}$ & \\
\hline $\begin{array}{l}\text { Hereditary motor and } \\
\text { sensory neuropathy, type IIC }\end{array}$ & 14.47 & $\mathrm{AD}$ & $\begin{array}{l}\text { HMSN2C } \\
606071\end{array}$ & $12 \mathrm{q} 24.11$ & $\begin{array}{l}\text { TRPV4 } \\
605427\end{array}$ & $\begin{array}{l}\text { Transient receptor } \\
\text { potential cation } \\
\text { channel, subfamily V, } \\
\text { member } 4\end{array}$ & $\begin{array}{l}\text { Klein et al. (2003) } \\
\text { McEntagart et al. (2005) } \\
\text { Auer-Grumbach et al. } \\
\text { (2010) Deng et al. (2010) } \\
\text { Landoure et al. (2010) }\end{array}$ & $\begin{array}{l}\text { allelic to HMN8 and SPSMA } \\
\text { (group 12) }\end{array}$ \\
\hline $\begin{array}{l}\text { Charcot-Marie-Tooth } \\
\text { disease, type 2D }\end{array}$ & 14.48 & $\mathrm{AD}$ & $\begin{array}{l}\text { CMT2D } \\
601472\end{array}$ & $7 \mathrm{p} 14.3$ & $\begin{array}{l}\text { GARS } \\
600287\end{array}$ & $\begin{array}{l}\text { Glycyl-tRNA } \\
\text { synthetase }\end{array}$ & $\begin{array}{l}\text { Ionasescu et al. (1996) } \\
\text { Antonellis et al. (2003) }\end{array}$ & allelic to HMN5A (group12) \\
\hline $\begin{array}{l}\text { Charcot-Marie-Tooth } \\
\text { disease, type } 2 \mathrm{E}\end{array}$ & 14.49 & $\mathrm{AD}$ & $\begin{array}{l}\text { CMT2E } \\
607684\end{array}$ & $8 \mathrm{p} 21.2$ & $\begin{array}{l}\text { NEFL } \\
162280\end{array}$ & $\begin{array}{l}\text { Neurofilament, light } \\
\text { polypeptide }\end{array}$ & $\begin{array}{l}\text { Birouk et al. (2003) } \\
\text { Claramunt et al. (2005) }\end{array}$ & $\begin{array}{l}\text { allelic to CMT1F, CMTDIG } \\
\text { (group 14) }\end{array}$ \\
\hline $\begin{array}{l}\text { Charcot-Marie-Tooth } \\
\text { disease, type } 2 \mathrm{~F}\end{array}$ & 14.50 & $\mathrm{AD}$ & $\begin{array}{l}\text { CMT2F } \\
606595\end{array}$ & $7 \mathrm{q} 11.23$ & $\begin{array}{l}\text { HSPBI } \\
602195\end{array}$ & $\begin{array}{l}\text { Heat-shock } 27-\mathrm{kD} \\
\text { protein } 1\end{array}$ & $\begin{array}{l}\text { Ismailov et al. (2001) } \\
\text { Evgrafov et al. (2004) }\end{array}$ & allelic to HMN2B (group 14) \\
\hline $\begin{array}{l}\text { Charcot-Marie-Tooth } \\
\text { disease, type } 2 \mathrm{H}\end{array}$ & 14.51 & $\mathrm{AD}$ & $\begin{array}{l}\text { CMT2H } \\
607731\end{array}$ & $8 \mathrm{q} 13-\mathrm{q} 23$ & $?$ & $?$ & Barhoumi et al. (2001) & $\begin{array}{l}\text { maybe allelic to CMT4A } \\
\text { (group14) }\end{array}$ \\
\hline $\begin{array}{l}\text { Charcot-Marie-Tooth } \\
\text { disease, type 2I }\end{array}$ & 14.52 & $\mathrm{AD}$ & $\begin{array}{l}\text { CMT2I } \\
607677\end{array}$ & $1 \mathrm{q} 23.3$ & $\begin{array}{l}\text { MPZ } \\
159440\end{array}$ & Myelin protein zero & $\begin{array}{l}\text { Auer-Grumbach et al. } \\
\text { (2003) }\end{array}$ & $\begin{array}{l}\text { allelic to CMT1B, CMTDID, } \\
\text { CMT2J, DSS, CHN (group 14) }\end{array}$ \\
\hline $\begin{array}{l}\text { Charcot-Marie-Tooth } \\
\text { disease, type 2J }\end{array}$ & 14.53 & $\mathrm{AD}$ & $\begin{array}{l}\text { CMT2J } \\
607736\end{array}$ & $1 \mathrm{q} 23.3$ & $\begin{array}{l}M P Z \\
159440\end{array}$ & Myelin protein zero & $\begin{array}{l}\text { De Jonghe et al. (1999) } \\
\text { Chapon et al. (1999) }\end{array}$ & $\begin{array}{l}\text { allelic to CMT1B, CMTDID, } \\
\text { CMT2I, DSS, CHN (group 14) }\end{array}$ \\
\hline $\begin{array}{l}\text { Charcot-Marie-Tooth } \\
\text { disease, type } 2 \mathrm{~K}\end{array}$ & 14.54 & $\mathrm{AD}, \mathrm{AR}$ & $\begin{array}{l}\text { CMT2K } \\
607831\end{array}$ & $8 \mathrm{q} 21.11$ & $\begin{array}{l}\text { GDAP1 } \\
606598\end{array}$ & $\begin{array}{l}\text { Ganglioside-induced } \\
\text { differentiation- } \\
\text { associated } \\
\text { protein } 1\end{array}$ & $\begin{array}{l}\text { Nelis et al. (2002) } \\
\text { Birouk et al. (2003) } \\
\text { Claramunt et al. (2005) }\end{array}$ & $\begin{array}{l}\text { allelic to CMT4A and CMTRIA } \\
\text { (group 14) }\end{array}$ \\
\hline $\begin{array}{l}\text { Charcot-Marie-Tooth } \\
\text { disease, type } 2 \mathrm{~L}\end{array}$ & 14.55 & $\mathrm{AD}$ & $\begin{array}{l}\text { CMT2L } \\
608673\end{array}$ & $12 \mathrm{q} 24.23$ & $\begin{array}{l}\text { HSPB8 } \\
608014\end{array}$ & $\begin{array}{l}\text { Heat-shock 22-kD } \\
\text { protein } 8\end{array}$ & Tang et al. $(2004,2005)$ & $\begin{array}{l}\text { allelic to Myopathy with rimmed } \\
\text { vacuoles (group 4) and HMN2A } \\
\text { (group 12) }\end{array}$ \\
\hline $\begin{array}{l}\text { Charcot-Marie-Tooth } \\
\text { disease, type } 2 \mathrm{~N}\end{array}$ & 14.56 & $\mathrm{AD}$ & $\begin{array}{l}\text { CMT2N } \\
613287\end{array}$ & $16 \mathrm{q} 22.1$ & $\begin{array}{l}\text { AARS } \\
601065\end{array}$ & $\begin{array}{l}\text { Alanyl-tRNA } \\
\text { synthetase }\end{array}$ & Latour et al. (2010) & Allelic to dHMN (group 12) \\
\hline
\end{tabular}




\begin{tabular}{|c|c|c|c|c|c|c|c|c|}
\hline DISEASE NAME & $\begin{array}{l}\text { Item line } \\
\text { in this } \\
\text { group }\end{array}$ & Inheritance & $\begin{array}{l}\text { Locus or } \\
\text { disease symbol } \\
\text { and OMIM } \\
\text { number }\end{array}$ & Chromosome & $\begin{array}{l}\text { Gene symbol } \\
\text { and OMIM } \\
\text { number }\end{array}$ & $\begin{array}{l}\text { Protein } \\
\text { (mitochondrial } \\
\text { proteins indicated } \\
\text { by symbol }[\mathrm{M}] \text { ) }\end{array}$ & Key references & $\begin{array}{l}\text { Other allelic disease(s) (group } \\
\text { in this table) }\end{array}$ \\
\hline $\begin{array}{l}\text { Charcot-Marie-Tooth } \\
\text { disease, type } 20\end{array}$ & 14.57 & $\mathrm{AD}$ & $\begin{array}{l}\text { CMT2O } \\
614228\end{array}$ & $14 \mathrm{q} 32.31$ & $\begin{array}{l}\text { DYNC1H1 } \\
600112\end{array}$ & $\begin{array}{l}\text { Dynein, cytoplasmic } \\
1, \text { heavy chain } 1\end{array}$ & Weedon et al. (2011) & allelic to SMALED1 (group 12) \\
\hline $\begin{array}{l}\text { Charcot-Marie-Tooth } \\
\text { disease, type } 2 \mathrm{P}\end{array}$ & 14.58 & $\mathrm{AD}$ & $\begin{array}{l}\text { CMT2P } \\
614436\end{array}$ & $9 \mathrm{q} 33.3-\mathrm{q} 34.1$ & $\begin{array}{l}\text { LRSAM1 } \\
610933\end{array}$ & $\begin{array}{l}\text { Leucine rich repeat } \\
\text { and sterile alpha } \\
\text { motif containing } 1\end{array}$ & $\begin{array}{l}\text { Nelis et al. (2004) } \\
\text { Guernsey et al. (2010) } \\
\text { Weterman et al. (2012) }\end{array}$ & \\
\hline $\begin{array}{l}\text { Charcot-Marie-Tooth } \\
\text { disease, type } 2 \mathrm{Q}\end{array}$ & 14.59 & $\mathrm{AD}$ & $\begin{array}{l}\text { CMT2Q } \\
615025\end{array}$ & $10 \mathrm{p} 14$ & $\begin{array}{l}\text { DHTKDI } \\
614984\end{array}$ & $\begin{array}{l}\text { Dehydrogenase E1 } \\
\text { and transketolase } \\
\text { domain containing } 1\end{array}$ & Xu et al. (2012) & \\
\hline $\begin{array}{l}\text { Charcot-Marie-Tooth } \\
\text { disease, type } 2 U\end{array}$ & 14.60 & $\mathrm{AD}$ & $\begin{array}{l}\text { CMT2U } \\
616280\end{array}$ & $12 \mathrm{q} 13.3$ & $\begin{array}{l}\text { MARS } \\
156560\end{array}$ & $\begin{array}{l}\text { Methionyl-tRNA } \\
\text { synthetase }\end{array}$ & Gonzalez et al. (2013) & \\
\hline $\begin{array}{l}\text { Charcot-Marie-Tooth } \\
\text { disease, type } 2 \mathrm{~V}\end{array}$ & 14.61 & $\mathrm{AD}$ & $\begin{array}{l}\text { CMT2V } \\
616491\end{array}$ & $17 \mathrm{q} 21.2$ & $\begin{array}{l}\text { NAGLU } \\
609701\end{array}$ & $\begin{array}{l}\text { N-acetyl-alpha- } \\
\text { glucosaminidase }\end{array}$ & Tetreault et al. (2015) & \\
\hline $\begin{array}{l}\text { Charcot-Marie-Tooth } \\
\text { disease, type } 2 \mathrm{~W}\end{array}$ & 14.62 & $\mathrm{AD}$ & $\begin{array}{l}\text { CMT2W } \\
616625\end{array}$ & $5 q 31.3$ & $\begin{array}{l}\text { HARS } \\
142810\end{array}$ & $\begin{array}{l}\text { Histidyl-tRNA } \\
\text { synthetase }\end{array}$ & $\begin{array}{l}\text { Vester et al. (2013) } \\
\text { Safka-Brozkova et al. } \\
\text { (2015) }\end{array}$ & \\
\hline $\begin{array}{l}\text { Charcot-Marie-Tooth } \\
\text { disease, type } 2 \mathrm{Y}\end{array}$ & 14.63 & $\mathrm{AD}$ & $\begin{array}{l}\text { CMT2Y } \\
616687\end{array}$ & $9 \mathrm{p} 13.3$ & $\begin{array}{l}\boldsymbol{V C P} \\
601023\end{array}$ & $\begin{array}{l}\text { Valosin-containing } \\
\text { protein }\end{array}$ & Gonsalez et al. (2014) & $\begin{array}{l}\text { allelic to scapuloperoreal MD } \\
\text { (group 1), IBMPFD1 (groups } 4 \\
\text { and 5), ALS14 (group 12) }\end{array}$ \\
\hline $\begin{array}{l}\text { Charcot-Marie-Tooth } \\
\text { disease, type } 2 Z\end{array}$ & 14.64 & $\mathrm{AD}$ & $\begin{array}{l}\text { CMT2Z } \\
616688\end{array}$ & $22 \mathrm{q} 12.2$ & $\begin{array}{l}\text { MORC2 } \\
616661\end{array}$ & $\begin{array}{l}\text { MORC family } \\
\text { CW-type zinc finger } \\
2\end{array}$ & $\begin{array}{l}\text { Albulym et al. (2015) } \\
\text { Sevilla et al. (2016) }\end{array}$ & \\
\hline $\begin{array}{l}\text { Charcot-Marie-Tooth } \\
\text { disease, axonal, type } 2 \mathrm{CC}\end{array}$ & 14.65 & $\mathrm{AD}$ & $\begin{array}{l}\text { CMT2CC } \\
616924\end{array}$ & $22 \mathrm{q} 12.2$ & $\begin{array}{l}N E F H \\
162230\end{array}$ & $\begin{array}{l}\text { Neurofilament } \\
\text { Protein, Heavy } \\
\text { Polypeptide }\end{array}$ & Rebelo et al. (2016) & $\begin{array}{l}\text { allelic to ALS related to NEFH } \\
\text { (group 12) }\end{array}$ \\
\hline $\begin{array}{l}\text { Charcot-Marie-Tooth } \\
\text { disease, axonal, type 2DD }\end{array}$ & 14.66 & $\mathrm{AD}$ & $\begin{array}{l}\text { CMT2DD } \\
618036\end{array}$ & $1 \mathrm{p} 13.1$ & $\begin{array}{l}\text { ATP1A1 } \\
182310\end{array}$ & $\begin{array}{l}\text { ATPase, } \mathrm{Na}^{+} / K^{+} \\
\text {transporting, alpha-1 } \\
\text { polypeptide }\end{array}$ & Lassuthova et al. (2018) & \\
\hline $\begin{array}{l}\text { Hereditary motor and } \\
\text { sensory neuropathy, } \\
\text { Okinawa type }\end{array}$ & 14.67 & $\mathrm{AD}$ & $\begin{array}{l}\text { HMSNO } \\
604484\end{array}$ & $3 q 12.2$ & $\begin{array}{l}\boldsymbol{T F G} \\
602498\end{array}$ & TRK-fused gene & $\begin{array}{l}\text { Takeshima et al. (1997, } \\
\text { 1999) Maeda et al. } \\
\text { (2007) Ishiura et al. } \\
\text { (2012) }\end{array}$ & allelic to SPG57 (group 15) \\
\hline $\begin{array}{l}\text { Hereditary motor and } \\
\text { sensory neuropathy, type } \\
\text { VIA with optic atrophy }\end{array}$ & 14.68 & $\mathrm{AD}$ & $\begin{array}{l}\text { HMSN6A } \\
601152\end{array}$ & $1 \mathrm{p} 36.22$ & $\begin{array}{l}\text { MFN2 } \\
608507\end{array}$ & Mitofusin 2 & Zuchner et al. (2006) & $\begin{array}{l}\text { Allelic to CMT2A2A and } \\
\text { CMT2A2B (group 14) }\end{array}$ \\
\hline CMT2 related to KIF5A & 14.69 & $\mathrm{AD}$ & & $12 \mathrm{q} 13.3$ & $\begin{array}{l}\text { KIF5A } \\
602821\end{array}$ & $\begin{array}{l}\text { Kinesin family } \\
\text { member } 5 \mathrm{~A}\end{array}$ & Liu et al. (2014) & $\begin{array}{l}\text { allelic to ALS25 (group 12) and } \\
\text { SPG10 (group 15) }\end{array}$ \\
\hline $\begin{array}{l}\text { Early onset axonal } \\
\text { neuropathy with sensory } \\
\text { ataxia }\end{array}$ & 14.70 & $\mathrm{AD}$ & CMT2 & $1 \mathrm{q} 13.5$ & $\begin{array}{l}\text { DGAT2 } \\
606983\end{array}$ & $\begin{array}{l}\text { Diacylglycerol } \\
\text { O-acyltransferase } 2\end{array}$ & Hong et al. (2016) & \\
\hline $\begin{array}{l}\text { Charcot-Marie-Tooth } \\
\text { disease, axonal, related to } \\
\text { BAG3 }\end{array}$ & 14.71 & $\mathrm{AD}$ & & $10 \mathrm{q} 26.11$ & $\begin{array}{l}\text { BAG3 } \\
603883\end{array}$ & $\begin{array}{l}\text { BCL2-associated } \\
\text { athanogene } 3\end{array}$ & Noury et al. (2017) & $\begin{array}{l}\text { allelic to MFM6 (group 5) and to } \\
\text { CMH1HH (group 10A) }\end{array}$ \\
\hline \multicolumn{9}{|l|}{ Autosomal recessive CMT2 } \\
\hline $\begin{array}{l}\text { Charcot-Marie-Tooth } \\
\text { disease, axonal, type 2A2B }\end{array}$ & 14.72 & $\mathrm{AR}$ & $\begin{array}{l}\text { CMT2A2B } \\
617087\end{array}$ & $1 \mathrm{p} 36.22$ & $\begin{array}{l}\text { MFN2 } \\
608507\end{array}$ & Mitofusin 2 & Polke et al. (2011) & $\begin{array}{l}\text { allelic to CMT2A2A and } \\
\text { HMSN6A (group14) }\end{array}$ \\
\hline $\begin{array}{l}\text { Charcot-Marie-Tooth } \\
\text { disease, axonal, type 2B1 }\end{array}$ & 14.73 & $\mathrm{AR}$ & $\begin{array}{l}\text { CMT2B1 } \\
605588\end{array}$ & $1 \mathrm{q} 22$ & $\begin{array}{l}\text { LMNA } \\
150330\end{array}$ & Lamin $\mathrm{A} / \mathrm{C}$ & $\begin{array}{l}\text { Bouhouch et al. (1999) } \\
\text { De Sandre et al. (2002) } \\
\text { Worman and Bonne } \\
\text { (2007) }\end{array}$ & $\begin{array}{l}\text { allelic to EDMD2, EDMD3, } \\
\text { formerly LGMD1B (group1), } \\
\text { MDCL (group 2), CMD1A } \\
\text { (group 10) [+ several other } \\
\text { phenotypes not in this table: } \\
\text { FPLD2 \#151660, HGPS \#176670, } \\
\text { restrictive dermopathy \#275210, } \\
\text { MADA \#248370] }\end{array}$ \\
\hline $\begin{array}{l}\text { Charcot-Marie-Tooth } \\
\text { disease, axonal, type 2B2 }\end{array}$ & 14.74 & AR & $\begin{array}{l}\text { CMT2B2 } \\
605589\end{array}$ & $19 \mathrm{q} 13.33$ & $\begin{array}{l}\text { PNKP } \\
605610\end{array}$ & $\begin{array}{l}\text { Polynucleotide kinase } \\
\text { 3-prime phosphatase }\end{array}$ & $\begin{array}{l}\text { Leal et al. (2009) Leal } \\
\text { et al. (2018) }\end{array}$ & Allelic to AOA4 (group 14) \\
\hline $\begin{array}{l}\text { Charcot-Marie-Tooth } \\
\text { disease, axonal, type 2EE }\end{array}$ & 14.75 & $\mathrm{AR}$ & $\begin{array}{l}\text { CMT2EE } \\
618400\end{array}$ & $2 \mathrm{p} 23.3$ & $\begin{array}{l}\text { MPV17 } \\
137960\end{array}$ & $\begin{array}{l}\text { MPV17, mouse, } \\
\text { homolog of }(\mathbf{M})\end{array}$ & $\begin{array}{l}\text { Choi et al. (2015) } \\
\text { Baumannn et al. (2019) }\end{array}$ & \\
\hline $\begin{array}{l}\text { Charcot-Marie-Tooth } \\
\text { disease, axonal, related to } \\
D N A J B 2\end{array}$ & 14.76 & AR & $\begin{array}{l}\text { DSM5 } \\
614881\end{array}$ & $2 q 35$ & $\begin{array}{l}\text { DNAJB2 } \\
604139\end{array}$ & $\begin{array}{l}\text { DnaJ/Hsp } 40 \\
\text { homolog, subfamily } \\
\text { B, member } 2\end{array}$ & Gess et al. (2014) & allelic to DSMA5 (group 12) \\
\hline $\begin{array}{l}\text { Neuromyotonia and axonal } \\
\text { neuropathy, autosomal } \\
\text { recessive }\end{array}$ & 14.77 & $\mathrm{AR}$ & $\begin{array}{l}\text { NMAN } \\
137200\end{array}$ & $5 \mathrm{q} 23.3$ & $\begin{array}{l}\text { HINTI } \\
601314\end{array}$ & $\begin{array}{l}\text { Histidine triad } \\
\text { nucleotide binding } \\
\text { protein } 1\end{array}$ & Zimon et al. (2012) & $\begin{array}{l}\text { Allelic to Distal hereditary motor } \\
\text { neuronopathy (group 12) }\end{array}$ \\
\hline $\begin{array}{l}\text { Charcot-Marie-Tooth } \\
\text { disease, recessive } \\
\text { intermediate, A }\end{array}$ & 14.78 & AR & $\begin{array}{l}\text { CMTRIA } \\
608340\end{array}$ & $8 \mathrm{q} 21.11$ & $\begin{array}{l}\text { GDAP1 } \\
606598\end{array}$ & $\begin{array}{l}\text { Ganglioside-induced } \\
\text { differentiation- } \\
\text { associated protein } \\
1\end{array}$ & Nelis et al. (2002) & $\begin{array}{l}\text { allelic to CMT4A and CMT2K } \\
\text { (group 14) }\end{array}$ \\
\hline $\begin{array}{l}\text { Charcot-Marie-Tooth } \\
\text { disease, recessive } \\
\text { intermediate, B }\end{array}$ & 14.79 & AR & $\begin{array}{l}\text { CMTRIB } \\
613641\end{array}$ & $16 \mathrm{q} 23.1$ & $\begin{array}{l}\text { KARS } \\
601421\end{array}$ & $\begin{array}{l}\text { Lysyl-tRNA } \\
\text { synthetase }\end{array}$ & McLaughlin et al. (2010) & \\
\hline $\begin{array}{l}\text { Charcot-Marie-Tooth } \\
\text { disease, recessive } \\
\text { intermediate, } \mathrm{C}\end{array}$ & 14.80 & $\mathrm{AR}$ & $\begin{array}{l}\text { CMTRIC } \\
615376\end{array}$ & $1 \mathrm{p} 36.31$ & $\begin{array}{l}\text { PLEKHG5 } \\
611101\end{array}$ & $\begin{array}{l}\text { Pleckstrin homology } \\
\text { domain- and } \\
\text { RhoGEF } \\
\text { domain-containing, } \\
\text { family G5 }\end{array}$ & $\begin{array}{l}\text { Azzedine et al. (2013) } \\
\text { Kim et al. (2013) }\end{array}$ & allelic to DSMA4 (group 12) \\
\hline
\end{tabular}




\begin{tabular}{|c|c|c|c|c|c|c|c|c|}
\hline DISEASE NAME & $\begin{array}{l}\text { Item line } \\
\text { in this } \\
\text { group }\end{array}$ & Inheritance & $\begin{array}{l}\text { Locus or } \\
\text { disease symbol } \\
\text { and OMIM } \\
\text { number }\end{array}$ & Chromosome & $\begin{array}{l}\text { Gene symbol } \\
\text { and OMIM } \\
\text { number }\end{array}$ & $\begin{array}{l}\text { Protein } \\
\text { (mitochondrial } \\
\text { proteins indicated } \\
\text { by symbol }[\mathrm{M}] \text { ) }\end{array}$ & Key references & $\begin{array}{l}\text { Other allelic disease(s) (group } \\
\text { in this table) }\end{array}$ \\
\hline $\begin{array}{l}\text { Charcot-Marie-Tooth } \\
\text { disease, recessive } \\
\text { intermediate, D }\end{array}$ & 14.81 & $\mathrm{AR}$ & $\begin{array}{l}\text { CMTRID } \\
616039\end{array}$ & $12 \mathrm{q} 24.31$ & $\begin{array}{l}\text { СОХ6А1 } \\
602072\end{array}$ & $\begin{array}{l}\text { Cytochrome c } \\
\text { oxidase subunit } 6 \mathrm{a} 1 \\
\text { (M) }\end{array}$ & Tamiya et al. (2014) & \\
\hline $\begin{array}{l}\text { Charcot-Marie-Tooth } \\
\text { disease, type } 2 \mathrm{R}\end{array}$ & 14.82 & $\mathrm{AR}$ & $\begin{array}{l}\text { CMT2R } \\
615490\end{array}$ & $4 \mathrm{q} 31.3$ & $\begin{array}{l}\text { TRIM2 } \\
614141\end{array}$ & $\begin{array}{l}\text { Tripartite } \\
\text { motif-containing } \\
\text { protein } 2\end{array}$ & $\begin{array}{l}\text { Ylikallio et al. (2013) } \\
\text { Pehlivan et al. (2015) }\end{array}$ & \\
\hline $\begin{array}{l}\text { Charcot-Marie-Tooth } \\
\text { disease, type } 2 S\end{array}$ & 14.83 & $\mathrm{AR}$ & $\begin{array}{l}\text { CMT2S } \\
616155\end{array}$ & $11 \mathrm{q} 13.3$ & $\begin{array}{l}\text { IGHMBP2 } \\
600502\end{array}$ & $\begin{array}{l}\text { Immunoglobulin mu- } \\
\text { binding protein } 2\end{array}$ & $\begin{array}{l}\text { Cottenie et al. (2014) } \\
\text { Schottmann et al. (2015) }\end{array}$ & allelic to DSMA1 (group 12) \\
\hline $\begin{array}{l}\text { Charcot-Marie-Tooth } \\
\text { disease, type } 2 \mathrm{~T}\end{array}$ & 14.84 & $\mathrm{AR}$ & $\begin{array}{l}\text { CMT2T } \\
617017\end{array}$ & $3 q 25.2$ & $\begin{array}{l}\text { MME } \\
120520\end{array}$ & $\begin{array}{l}\text { Membrane } \\
\text { metalloendopeptidase }\end{array}$ & Higuchi et al. (2016) & allelic to SCA43 (group 15) \\
\hline $\begin{array}{l}\text { Charcot-Marie-Tooth } \\
\text { disease, type } 2 \mathrm{X}\end{array}$ & 14.85 & $\mathrm{AR}$ & $\begin{array}{l}\text { CMT2 } \\
\times 616668\end{array}$ & $15 \mathrm{q} 21.1$ & $\begin{array}{l}S P G 11 \\
610844\end{array}$ & $\begin{array}{l}\text { SPG11 gene } \\
\text { (Spatacsin) }\end{array}$ & $\begin{array}{l}\text { Montecchiani et al. } \\
\text { (2015) }\end{array}$ & allelic to ALS5 (group 12), \\
\hline $\begin{array}{l}\text { Early-onset axonal } \\
\text { Charcot-Marie-Tooth with } \\
\text { ataxia }\end{array}$ & 14.86 & $\mathrm{AR}$ & $\begin{array}{l}\text { AOA4 } \\
616267\end{array}$ & $19 \mathrm{q} 13.33$ & $\begin{array}{l}\text { PNKP } \\
605610\end{array}$ & $\begin{array}{l}\text { Polynucleotide kinase } \\
3^{\prime} \text {-phosphatase }\end{array}$ & Pedroso et al. (2015) & Allelic to CMT2B2 (group 14) \\
\hline $\begin{array}{l}\text { Charcot-Marie-Tooth } \\
\text { disease, axonal }\end{array}$ & 14.87 & $\mathrm{AR}$ & & $10 \mathrm{q} 22.1$ & $\begin{array}{l}\text { SGPL1 } \\
603729\end{array}$ & $\begin{array}{l}\text { Sphingosine-1 } \\
\text { phosphate lyase } 1\end{array}$ & Atkinson et al. (2017) & $\begin{array}{l}\text { allelic to Nephrotic Syndrome } 14 \\
\text { (\# 617575) }\end{array}$ \\
\hline $\begin{array}{l}\text { Charcot-Marie-Tooth } \\
\text { disease, axonal; related to } \\
\text { SCO2 }\end{array}$ & 14.88 & $\mathrm{AR}$ & & $22 \mathrm{q} 13.33$ & $\begin{array}{l}\mathrm{SCO} 2 \\
604272\end{array}$ & $\begin{array}{l}\text { Cytochrome c } \\
\text { oxidase assembly } \\
\text { protein }\end{array}$ & Rebelo et al. (2018) & allelic to CEMCOX1 (group 10A) \\
\hline $\begin{array}{l}\text { Charcot-Marie-Tooth } \\
\text { disease, axonal; related to } \\
\text { SACS }\end{array}$ & 14.89 & $\mathrm{AR}$ & & $13 q 12.12$ & $\begin{array}{l}\text { SACS } \\
604490\end{array}$ & Sacsin & Souza et al. (2018) & $\begin{array}{l}\text { Allelic to SACS (group 13) } \\
\text { and SPAX6 (group 15) }\end{array}$ \\
\hline
\end{tabular}

C. CMT Distal=Distal hereditary motor neuropathies $($ dHMN) $=$ spinal CMT or distal spinal muscular atrophy (DSMA) See under MOTOR NEURONE DISEASES (Group 12)

D. Other Hereditary sensory and autonomic neuropathy (HSAN)

\begin{tabular}{|c|c|c|c|c|c|}
\hline $\begin{array}{l}\text { Hereditary sensory and } \\
\text { autonomic neuropathy, type } \\
\text { IA }\end{array}$ & 14.90 & $\mathrm{AD}$ & $\begin{array}{l}\text { HSAN1A } \\
162400\end{array}$ & $9 \mathrm{q} 22.31$ & $\begin{array}{l}\text { SPTLC1 } \\
605712\end{array}$ \\
\hline $\begin{array}{l}\text { Hereditary sensory and } \\
\text { autonomic neuropathy, type } \\
\text { IB with cough and } \\
\text { gastroesophageal reflux }\end{array}$ & 14.91 & $\mathrm{AD}$ & $\begin{array}{l}\text { HSAN1B } \\
608088\end{array}$ & $3 \mathrm{p} 24-\mathrm{p} 22$ & $?$ \\
\hline $\begin{array}{l}\text { Hereditary sensory and } \\
\text { autonomic neuropathy, type } \\
\text { IC }\end{array}$ & 14.92 & $\mathrm{AD}$ & $\begin{array}{l}\text { HSAN1C } \\
613640\end{array}$ & $14 \mathrm{q} 24.3$ & $\begin{array}{l}\text { SPTLC2 } \\
605713\end{array}$ \\
\hline $\begin{array}{l}\text { Hereditary sensory and } \\
\text { autonomic neuropathy, type } \\
\text { IIA }\end{array}$ & 14.93 & AR & $\begin{array}{l}\text { HSAN2A } \\
201300\end{array}$ & 12 p. 13.33 & $\begin{array}{l}\text { WNK1 } \\
605232\end{array}$ \\
\hline $\begin{array}{l}\text { Hereditary sensory and } \\
\text { autonomic neuropath, type } \\
\text { IIB }\end{array}$ & 14.94 & AR & $\begin{array}{l}\text { HSAN2B } \\
613115\end{array}$ & $5 \mathrm{p} 15.1$ & $\begin{array}{l}\text { RETREGI } \\
613114\end{array}$ \\
\hline $\begin{array}{l}\text { Hereditary sensory and } \\
\text { autonomic neuropathy, type } \\
\text { IID }\end{array}$ & 14.95 & AR & $\begin{array}{l}\text { CIP } \\
24300\end{array}$ & $2 \mathrm{q} 24.3$ & $\begin{array}{l}\text { SCN9A } \\
603415\end{array}$ \\
\hline $\begin{array}{l}\text { Hereditary sensory and } \\
\text { autonomic neuropathy type } \\
\text { III }\end{array}$ & 14.96 & AR & $\begin{array}{l}\text { HSAN3 } \\
223900\end{array}$ & $9 \mathrm{q} 31.3$ & $\begin{array}{l}\text { ELP1 } \\
603722\end{array}$ \\
\hline
\end{tabular}

Hereditary sensory and autonomic neuropathy type IV

Hereditary sensory and autonomic neuropathy type $\mathrm{V}$

Hereditary sensory and autonomic neuropathy type VI

Neuropathy, hereditary sensory and autonomic, type VII

Hereditary sensory and autonomic neuropathy type VIII

Hereditary sensory neuropathy, type ID Hereditary sensory neuropathy, type IE Neuropathy, hereditary sensory, type IF Hereditary sensory neuropathy, type IIC

\begin{tabular}{|c|c|c|c|c|}
\hline 14.97 & $\mathrm{AR}$ & $\begin{array}{l}\text { CIPA } \\
256800\end{array}$ & $1 \mathrm{q} 23.1$ & $\begin{array}{l}\text { NTRK1 } \\
191315\end{array}$ \\
\hline 14.98 & $\mathrm{AR}$ & $\begin{array}{l}\text { HSAN5 } \\
608654\end{array}$ & $1 \mathrm{p} 13.1$ & $\begin{array}{l}\text { NGF } \\
162030\end{array}$ \\
\hline 14.99 & $\mathrm{AR}$ & $\begin{array}{l}\text { HSAN6 } \\
614653\end{array}$ & $6 \mathrm{p} 12.1$ & $\begin{array}{l}\text { DST } \\
113810\end{array}$ \\
\hline 14.100 & $\mathrm{AD}$ & $\begin{array}{l}\text { HSAN7 } \\
615548\end{array}$ & $3 \mathrm{p} 22.2$ & $\begin{array}{l}\text { SCN11A } \\
604385\end{array}$ \\
\hline 14.101 & $\mathrm{AR}$ & $\begin{array}{l}\text { HSAN8 } \\
616488\end{array}$ & $9 \mathrm{q} 34.12$ & $\begin{array}{l}\text { PRDM12 } \\
616458\end{array}$ \\
\hline 14.102 & $\mathrm{AD}$ & $\begin{array}{l}\text { HSN1D } \\
613708\end{array}$ & $14 q 22.1$ & $\begin{array}{l}\text { ATL1 } \\
606439\end{array}$ \\
\hline 14.103 & $\mathrm{AD}$ & $\begin{array}{l}\text { HSN1E } \\
614116\end{array}$ & $19 \mathrm{p} 13.2$ & $\begin{array}{l}\text { DNMT1 } \\
126375\end{array}$ \\
\hline 14.104 & $\mathrm{AD}$ & $\begin{array}{l}\text { HSN1F } \\
615632\end{array}$ & $11 \mathrm{q} 13.1$ & $\begin{array}{l}A T L 3 \\
609369\end{array}$ \\
\hline 14.105 & $\mathrm{AR}$ & $\begin{array}{l}\text { HSN2C } \\
614213\end{array}$ & $2 \mathrm{q} 37.3$ & $\begin{array}{l}\text { KIFIA } \\
601255\end{array}$ \\
\hline
\end{tabular}

Serine palmitoyl
transferase long-chain
base subunit 1

Nicholson et al. (1996)

Bejaoui et al. (2001)

Dawkins et al. (2001) Kok et al. (2004)

\author{
Serine palmitoyl \\ transferase long-chain \\ base subunit 2 \\ Protein kinase, lysine Lafreniere et al. (2004) \\ deficient 1 \\ Shekarabi et al. (2008) \\ Family with sequence Kurth et al. (2009) \\ similarity 134 \\ member B \\ Sodium channel, \\ voltage-gated alpha \\ Yuan et al. (2013)
}

subunit

Inhibitor of kappa

light polypeptide

gene enhanccer in B cells, kinase complex associated protein (IKBKAP)

Neurotrophic tyrosine kinase, receptor, type

Nerve growth factor (beta polypeptide)

Dystonin

Blumenfeld et al. (1993) Anderson et al. (2001)

allelic to familial Dysautonomia

Einarsdottir et al. (2004)

Sodium channel,

voltage-gated alpha

subunit

PR/SET domain 12

(positive regulatory

domain zinc finger

protein 12)

Atlastin GTPase 1

allelic to SPG3A (group 15)

DNA

methyltransferase 1

Atlastin GTPase 3

Kinesin family member $1 \mathrm{~A}$
Slaugenhaupt et al.

(2001)

Indo et al. (1996)

Edvardson et al. (2012)

Guelly et al. (2011)

Klein et al. (2011)

Kornak et al. (2014)

(group 16)

Riviere et al. (2011) allelic to SPG30 (group 15)

(continued on next page) 


\begin{tabular}{|c|c|c|c|c|c|c|c|c|}
\hline DISEASE NAME & $\begin{array}{l}\text { Item line } \\
\text { in this } \\
\text { group }\end{array}$ & Inheritance & $\begin{array}{l}\text { Locus or } \\
\text { disease symbol } \\
\text { and OMIM } \\
\text { number }\end{array}$ & Chromosome & $\begin{array}{l}\text { Gene symbol } \\
\text { and OMIM } \\
\text { number }\end{array}$ & $\begin{array}{l}\text { Protein } \\
\text { (mitochondrial } \\
\text { proteins indicated } \\
\text { by symbol }[\mathrm{M}] \text { ) }\end{array}$ & Key references & $\begin{array}{l}\text { Other allelic disease(s) (group } \\
\text { in this table) }\end{array}$ \\
\hline $\begin{array}{l}\text { Ataxia, posterior column, } \\
\text { with retinitis pigmentosa } \\
\text { (PCARP) }\end{array}$ & 14.106 & AR & $\begin{array}{l}\text { AXPC1 } \\
609033\end{array}$ & $1 \mathrm{q} 32.3$ & $\begin{array}{l}\text { FLVCRI } \\
609144\end{array}$ & $\begin{array}{l}\text { Feline leukemia } \\
\text { subgroup C receptor } \\
1\end{array}$ & $\begin{array}{l}\text { Rajadhyaksha et al. } \\
\text { (2010) }\end{array}$ & \\
\hline Absence of pain, Congenital & 14.107 & AR & & $22 \mathrm{q} 11.21$ & $\begin{array}{l}\text { CLTCL1 } \\
601273\end{array}$ & $\begin{array}{l}\text { Clathrin, heavy } \\
\text { polypepdide-like } 1\end{array}$ & Nahorski et al. (2015) & \\
\hline $\begin{array}{l}\text { Marsili syndrome } \\
\text { (insensitivity to pain, } \\
\text { congenital, AD) }\end{array}$ & 14.108 & $\mathrm{AD}$ & $\begin{array}{l}\text { MARSIS } \\
147430\end{array}$ & $14 q 11.2$ & $\begin{array}{l}\text { ZFHX2 } \\
617828\end{array}$ & $\begin{array}{l}\text { Zinc finger } \\
\text { homeobox } 2\end{array}$ & Habib et al. (2018) & \\
\hline \multicolumn{9}{|c|}{ E. Other complex neuropathy syndromes } \\
\hline $\begin{array}{l}\text { Peripheral neuropathy and } \\
\text { agenesis of the corpus } \\
\text { callosum (Charlevoix } \\
\text { disease) }\end{array}$ & 14.109 & $\mathrm{AR}$ & $\begin{array}{l}\text { ACCPN } \\
218000\end{array}$ & $15 \mathrm{q} 14$ & $\begin{array}{l}\text { SLC12A6 } \\
\text { (KCC3) } \\
604878\end{array}$ & $\begin{array}{l}\text { Solute carrier family } \\
12 \text { (potassium/ } \\
\text { chloride transporter), } \\
\text { member } 6\end{array}$ & $\begin{array}{l}\text { Casaubon et al. (1996) } \\
\text { Howard et al. (2002) }\end{array}$ & \\
\hline $\begin{array}{l}\text { Peripheral neuropathy and } \\
\text { deafness, autosomal } \\
\text { dominant }\end{array}$ & 14.110 & $\mathrm{AD}$ & & $1 \mathrm{p} 34.3$ & $\begin{array}{l}\text { GJB3 } \\
603324\end{array}$ & $\begin{array}{l}\text { Gap junction protein, } \\
\text { beta } 3\end{array}$ & Lopez-Bigas et al. (2001) & \\
\hline $\begin{array}{l}\text { Hereditary neuralgic } \\
\text { amyotrophy (familial } \\
\text { brachial plexus neuropathy) }\end{array}$ & 14.111 & $\mathrm{AD}$ & $\begin{array}{l}\text { HNA } \\
162100\end{array}$ & $17 \mathrm{q} 25.3$ & $\begin{array}{l}\text { SEPT9 } \\
604061\end{array}$ & Septin 9 & $\begin{array}{l}\text { Pellegrino et al. (1996) } \\
\text { Kuhlenbaumer et al. } \\
(2005)\end{array}$ & \\
\hline Giant axonal neuropathy-1 & 14.112 & AR & $\begin{array}{l}\text { GAN1 } \\
256850\end{array}$ & $16 \mathrm{q} 23.2$ & $\begin{array}{l}\text { GAN1 } \\
605379\end{array}$ & Gigaxonin & $\begin{array}{l}\text { Ben Hamida et al. (1997) } \\
\text { Bomont et al. (2000) }\end{array}$ & \\
\hline Giant axonal neuropathy-2 & 14.113 & $\mathrm{AD}$ & $\begin{array}{l}\text { GAN2 } \\
610100\end{array}$ & $1 \mathrm{q} 23.2$ & $\begin{array}{l}\text { DCAF8 } \\
615820\end{array}$ & $\begin{array}{l}\text { DDB1- and } \\
\text { CUL4-associated } \\
\text { factor } 8\end{array}$ & Klein et al. (2014) & \\
\hline $\begin{array}{l}\text { Congenital cataracts, facial } \\
\text { dysmorphism and } \\
\text { neuropathy }\end{array}$ & 14.114 & $\mathrm{AR}$ & $\begin{array}{l}\text { CCFDN } \\
604168\end{array}$ & $18 \mathrm{p} 23$ & $\begin{array}{l}\text { CTDP1 } \\
604927\end{array}$ & $\begin{array}{l}\text { C-terminal domain of } \\
\text { RNA polymerase II } \\
\text { subunit A, } \\
\text { phosphatase of, } \\
\text { subunit } 1\end{array}$ & Varon et al. (2003) & \\
\hline $\begin{array}{l}\text { Complex motor and sensory } \\
\text { axonal neuropathy plus } \\
\text { microcephaly and cerebral } \\
\text { dysgenesis }\end{array}$ & 14.115 & $\mathrm{AR}$ & & $14 \mathrm{q} 32.2$ & $\begin{array}{l}\text { VRK1 } \\
602168\end{array}$ & $\begin{array}{l}\text { Vaccinia related } \\
\text { kinase } 1\end{array}$ & $\begin{array}{l}\text { Gonzaga-Jauregui et al. } \\
\text { (2013) }\end{array}$ & $\begin{array}{l}\text { Allelic to DSMA and PCH1 } \\
\text { (group 12) }\end{array}$ \\
\hline $\begin{array}{l}\text { Neuropathy, hereditary } \\
\text { sensory, with spastic } \\
\text { paraplegia }\end{array}$ & 14.116 & $\mathrm{AR}$ & 256840 & $5 \mathrm{p} 15.2$ & $\begin{array}{l}\text { CCT5 } \\
610150\end{array}$ & $\begin{array}{l}\text { Chaperonin } \\
\text { containing T-complex } \\
\text { polypeptide1, subunit } \\
5\end{array}$ & Bouhouche et al. (2006) & \\
\hline $\begin{array}{l}\text { Neuronal intranuclear } \\
\text { inclusion diseases }\end{array}$ & 14.117 & $\mathrm{AD}$ & 603472 & $1 \mathrm{q} 21.2$ & $\begin{array}{l}\text { NOTCH2NLC } \\
(\text { NBPF19) } \\
618025 \\
\end{array}$ & $\begin{array}{l}\text { Notch2 } \\
\text { N-terminal-like } \\
\text { protein }\end{array}$ & $\begin{array}{l}\text { Tian et al. (2019) Sone } \\
\text { et al. (2019) Ishiura } \\
\text { et al. (2019) }\end{array}$ & \\
\hline \multicolumn{9}{|c|}{ Group 16. OTHER NEUROMUSCULAR DISORDERS } \\
\hline $\begin{array}{l}\text { Torsion dystonia } 1 \text {, } \\
\text { early onset }\end{array}$ & 16.1 & $\mathrm{AD}$ & $\begin{array}{l}\text { DYT1 } \\
128100\end{array}$ & $9 \mathrm{q} 34.11$ & $\begin{array}{l}\text { TORIA } \\
605204\end{array}$ & Torsin $1 \mathrm{~A}$ & $\begin{array}{l}\text { Ozelius et al. (1997) } \\
\text { Ikeuchi et al. (1999) }\end{array}$ & \\
\hline Myoclonic dystonia 11 & 16.2 & $\mathrm{AD}$ & $\begin{array}{l}\text { DYT11 } \\
159900\end{array}$ & $7 \mathrm{q} 21.3$ & $\begin{array}{l}S G C E \\
604149\end{array}$ & Sarcoglycan, Epsilon & $\begin{array}{l}\text { Klein et al. (2000) } \\
\text { Zimprich et al. (2001) } \\
\text { Tezenas du Montcel } \\
\text { et al. (2006) }\end{array}$ & \\
\hline $\begin{array}{l}\text { Hereditary neuropathy, } \\
\text { sensory and autonomic } \\
\text { (Riley-Day syndrome) }\end{array}$ & 16.3 & $\mathrm{AR}$ & $\begin{array}{l}\text { HSAN3 } \\
223900\end{array}$ & $9 \mathrm{q} 31.3$ & $\begin{array}{l}\boldsymbol{E L P 1} \\
603722\end{array}$ & $\begin{array}{l}\text { Inhibitor of kappa } \\
\text { Light polypeptide } \\
\text { gene enhaner in B } \\
\text { cells, kinase complex } \\
\text { associated protein }\end{array}$ & $\begin{array}{l}\text { Blumenfeld et al. (1993) } \\
\text { Anderson et al. (2001) } \\
\text { Slaugenhaupt et al. } \\
\text { (2001) }\end{array}$ & allelic to HSNA3 (group 14) \\
\hline $\begin{array}{l}\text { Hereditary amyloidosis } \\
\text { transthyretin-related }\end{array}$ & 16.4 & $\mathrm{AD}$ & 105210 & $18 \mathrm{q} 12.1$ & $\begin{array}{l}\text { TTR } \\
176300\end{array}$ & Transthyretin & $\begin{array}{l}\text { Costa et al. (1978) } \\
\text { Tawara et al. (1983) } \\
\text { Saraiva et al. (1995) }\end{array}$ & \\
\hline $\begin{array}{l}\text { Fibrosis of extraocular } \\
\text { muscles, congenital, } 1\end{array}$ & 16.5 & $\mathrm{AD}$ & $\begin{array}{l}\text { CFEOM1 } \\
\text { CFEOM3B } \\
135700\end{array}$ & $12 \mathrm{q} 12$ & $\begin{array}{l}\text { KIF21A } \\
608283\end{array}$ & $\begin{array}{l}\text { Kinesin family } \\
\text { member } 21 \mathrm{~A}\end{array}$ & $\begin{array}{l}\text { Engle et al. (1994) } \\
\text { Yamada et al. (2003) } \\
\text { Tiab et al. (2004) }\end{array}$ & \\
\hline $\begin{array}{l}\text { Fibrosis of extraocular } \\
\text { muscles, congenital, } 2\end{array}$ & 16.6 & $\mathrm{AD}$ & $\begin{array}{l}\text { CFEOM2 } \\
602078\end{array}$ & $11 \mathrm{q} 13.4$ & $\begin{array}{l}\text { РHOX2A } \\
602753\end{array}$ & $\begin{array}{l}\text { Aristaless homeobox, } \\
\text { drosophila, homolg } \\
\text { of, (ARIX) }\end{array}$ & $\begin{array}{l}\text { Wang et al. (1998) } \\
\text { Nakano et al. (2001) }\end{array}$ & \\
\hline $\begin{array}{l}\text { Fibrosis of extraocular } \\
\text { muscles, congenital, } 3 \mathrm{~A} \text {, } \\
\text { with or without extraocular } \\
\text { involvement }\end{array}$ & 16.7 & $\mathrm{AD}$ & $\begin{array}{l}\text { CFEOM3A } \\
600638\end{array}$ & $16 \mathrm{q} 24.3$ & $\begin{array}{l}\text { TUBB3 } \\
602661\end{array}$ & Tubulin, beta-3 & $\begin{array}{l}\text { Doherty et al. (1999) } \\
\text { Tischfield et al. (2010) }\end{array}$ & \\
\hline $\begin{array}{l}\text { Fibrosis of extraocular } \\
\text { muscles, congenital, } 5\end{array}$ & 16.8 & AR & $\begin{array}{l}\text { CFEOM5 } \\
66219\end{array}$ & $4 \mathrm{q} 25$ & $\begin{array}{l}\text { COL25AI } \\
610004\end{array}$ & $\begin{array}{l}\text { Collagen, type XXV, } \\
\text { alpha-1 }\end{array}$ & Shinwari et al. (2015) & \\
\hline $\begin{array}{l}\text { Arthrogryposis, distal, type } \\
\text { 1A }\end{array}$ & 16.9 & $\mathrm{AD}$ & $\begin{array}{l}\text { DA1A } \\
108120\end{array}$ & $9 \mathrm{p} 13.3$ & $\begin{array}{l}\text { TPM2 } \\
190990\end{array}$ & Tropomyosin-2 (beta) & Sung et al. (2003) & $\begin{array}{l}\text { allelic to NEM4 and CAPM2 } \\
\text { (group 3), DA2B (group 16) }\end{array}$ \\
\hline $\begin{array}{l}\text { Arthrogryposis, distal, type } \\
\text { 1B }\end{array}$ & 16.10 & $\mathrm{AD}$ & $\begin{array}{l}\text { DA1B } \\
614335\end{array}$ & $12 \mathrm{q} 23.2$ & $\begin{array}{l}\text { MYBPC1 } \\
160794\end{array}$ & $\begin{array}{l}\text { Myosin-binding } \\
\text { proteinC, slow type }\end{array}$ & Gurnett et al. (2010) & \\
\hline $\begin{array}{l}\text { Arthrogryposis, distal, type } \\
\text { 2A, Freeman-Sheldon } \\
\text { syndrome }\end{array}$ & 16.11 & $\mathrm{AD}$ & $\begin{array}{l}\text { DA2A } \\
193700\end{array}$ & $17 \mathrm{p} 13.1$ & $\begin{array}{l}\text { MYH3 } \\
160720\end{array}$ & $\begin{array}{l}\text { Myosin heavy chain } \\
3 \text {, skeletal muscle, } \\
\text { embryonic }\end{array}$ & Toydemir et al. (2006) & Allelic to DA2B (group 16) \\
\hline
\end{tabular}




\begin{tabular}{|c|c|c|c|c|c|c|c|c|}
\hline DISEASE NAME & $\begin{array}{l}\text { Item line } \\
\text { in this } \\
\text { group }\end{array}$ & Inheritance & $\begin{array}{l}\text { Locus or } \\
\text { disease symbol } \\
\text { and OMIM } \\
\text { number }\end{array}$ & Chromosome & $\begin{array}{l}\text { Gene symbol } \\
\text { and OMIM } \\
\text { number }\end{array}$ & $\begin{array}{l}\text { Protein } \\
\text { (mitochondrial } \\
\text { proteins indicated } \\
\text { by symbol }[\mathrm{M}] \text { ) }\end{array}$ & Key references & $\begin{array}{l}\text { Other allelic disease(s) (group } \\
\text { in this table) }\end{array}$ \\
\hline $\begin{array}{l}\text { Arthrogryposis, distal, type } \\
\text { 2B1, Sheldon-Hall syndrome }\end{array}$ & 16.12 & $\mathrm{AD}$ & $\begin{array}{l}\text { DA2B1 } \\
601680\end{array}$ & $11 \mathrm{p} 15.5$ & $\begin{array}{l}\text { TNNI2 } \\
191043\end{array}$ & $\begin{array}{l}\text { Troponin I, fast } \\
\text { skeletal }\end{array}$ & $\begin{array}{l}\text { Sung et al. (2003a) } \\
\text { Kimber et al. (2006) }\end{array}$ & \\
\hline $\begin{array}{l}\text { Arthrogryposis, distal, type } \\
\text { 2B2 }\end{array}$ & 16.13 & $\mathrm{AD}$ & $\begin{array}{l}\text { DA2B2 } \\
618435\end{array}$ & $11 \mathrm{p} 15.5$ & $\begin{array}{l}\text { TNNT3 } \\
600692\end{array}$ & $\begin{array}{l}\text { Troponin T3, fast } \\
\text { skeletal }\end{array}$ & Sung et al. (2003) & \\
\hline $\begin{array}{l}\text { Arthrogryposis, distal, type } \\
\text { 2B3 }\end{array}$ & 16.14 & $\mathrm{AD}$ & $\begin{array}{l}\text { DA2B3 } \\
618436\end{array}$ & $17 \mathrm{p} 13.1$ & $\begin{array}{l}\text { МYH3 } \\
160720\end{array}$ & $\begin{array}{l}\text { Myosin heavy chain } \\
3 \text {, skeletal muscle, } \\
\text { embryonic }\end{array}$ & Toydemir et al. (2006) & Allelic to DA2A (group 16) \\
\hline $\begin{array}{l}\text { Arthrogryposis, distal, type } \\
\text { 2B4 }\end{array}$ & 16.15 & $\mathrm{AD}$ & $\begin{array}{l}\text { DA2B4 } \\
108120\end{array}$ & $9 \mathrm{p} 13.3$ & $\begin{array}{l}\text { TPM2 } \\
190990\end{array}$ & Tropomyosin-2 (beta) & $\begin{array}{l}\text { Tajsharghi et al. (2007) } \\
\text { Ochala et al. (2007) }\end{array}$ & $\begin{array}{l}\text { allelic NEM4 and CAPM2 (group } \\
\text { 3), DA1A (group 16) }\end{array}$ \\
\hline Arthrogryposis, distal, type 3 & 16.16 & $\mathrm{AD}$ & $\begin{array}{l}\text { DA3 } \\
114300\end{array}$ & $\begin{array}{l}18 \mathrm{p} 11.22- \\
\text { p11.21 }\end{array}$ & $\begin{array}{l}\text { PIEZO2 } \\
613629\end{array}$ & $\begin{array}{l}\text { Piezo-type } \\
\text { mechanosensitive ion } \\
\text { channe component } 2\end{array}$ & McMillin et al. (2014) & Allelic to DA5 (groupe 16) \\
\hline Arthrogryposis, distal, type 5 & 16.17 & $\mathrm{AD}$ & $\begin{array}{l}\text { DA5 } \\
108145\end{array}$ & $\begin{array}{l}18 \mathrm{p} 11.22- \\
\text { p11.21 }\end{array}$ & $\begin{array}{l}\text { PIEZO2 } \\
613629\end{array}$ & $\begin{array}{l}\text { Piezo-type } \\
\text { mechanosensitive ion } \\
\text { channe component } 2\end{array}$ & Coste et al. (2013) & Allelic to DA3 (groupe 16) \\
\hline $\begin{array}{l}\text { Arthrogryposis, distal, type } \\
\text { 5D }\end{array}$ & 16.18 & $\mathrm{AR}$ & $\begin{array}{l}\text { DA5D } \\
615065\end{array}$ & $2 \mathrm{q} 37.1$ & $\begin{array}{l}\text { ECEL1 } \\
605896\end{array}$ & $\begin{array}{l}\text { Endothelin-converting } \\
\text { enzyme like } 1\end{array}$ & McMillin et al. (2013) & \\
\hline $\begin{array}{l}\text { Atrthrogryposis, Distal, type } \\
7 \text { (Trismus- } \\
\text { pseudocamptodactyly } \\
\text { syndrome) }\end{array}$ & 16.19 & $\mathrm{AD}$ & $\begin{array}{l}\text { DA7 } \\
158300\end{array}$ & $17 \mathrm{p} 13.1$ & $\begin{array}{l}\text { МYH8 } \\
160741\end{array}$ & $\begin{array}{l}\text { Myosin heavy chain, } \\
8, \text { skeletal muscle, } \\
\text { perinatal }\end{array}$ & $\begin{array}{l}\text { Veugelers et al. (2004) } \\
\text { Toydemir et al. (2006b) }\end{array}$ & \\
\hline $\begin{array}{l}\text { Arthrogryposis, distal, type } \\
10\end{array}$ & 16.20 & $\mathrm{AD}$ & $\begin{array}{l}\text { DA10 } \\
187370\end{array}$ & $2 \mathrm{q} 31.3-\mathrm{q} 32.1$ & & & $\begin{array}{l}\text { Stevenson et al. (2006a) } \\
\text { Stevenson et al. (2006b) }\end{array}$ & \\
\hline $\begin{array}{l}\text { Arthrogryposis multiplex } \\
\text { congenita with nesprin-1 } \\
\text { defect }\end{array}$ & 16.21 & $\mathrm{AR}$ & $\mathrm{AMC}$ & $6 \mathrm{q} 25.2$ & $\begin{array}{l}\text { SYNE1 } \\
608441\end{array}$ & $\begin{array}{l}\text { Spectrin repeat } \\
\text { containing, nuclear } \\
\text { envelope } 1 \\
\text { (Nesprin-1) }\end{array}$ & Attali et al. (2009) & $\begin{array}{l}\text { allelic to EDMD4 (group 1), } \\
\text { dilated cardiomyopathy related to } \\
\text { nesprin-1 (group 10A) and } \\
\text { SCAR8 (group 13) }\end{array}$ \\
\hline $\begin{array}{l}\text { Arthrogryposis and } \\
\text { BICD2-related } \\
\text { neuromuscular disease }\end{array}$ & 16.22 & $\mathrm{AD}$ & & $9 \mathrm{q} 22.31$ & $\begin{array}{l}\text { BICD2 } \\
609797\end{array}$ & $\begin{array}{l}\text { Bicaudal D homolog } \\
2 \text { (Drosophila) }\end{array}$ & Storbeck et al. (2017) & $\begin{array}{l}\text { Allelic to SMALED2A and } \\
\text { SMALED2B (group 12) }\end{array}$ \\
\hline $\begin{array}{l}\text { Arthrogryposis and muscular } \\
\text { dysplasia }\end{array}$ & 16.23 & $\mathrm{AD}$ & & $7 \mathrm{q} 31.2$ & $\begin{array}{l}\text { MET } \\
164860\end{array}$ & MET protooncogene & Zhou et al. (2019) & \\
\hline $\begin{array}{l}\text { Arthrogryposis related to } \\
\text { ASCCI }\end{array}$ & 16.24 & $\mathrm{AR}$ & & $10 \mathrm{q} 22.1$ & $\begin{array}{l}\text { ASCC1 } \\
614215\end{array}$ & $\begin{array}{l}\text { Activating signal } \\
\text { cointegrator } 1 \\
\text { complex subunit } 1\end{array}$ & Böhm et al. (2019) & allelic to SMABF2 (group 12) \\
\hline $\begin{array}{l}\text { Lethal congenital contracture } \\
\text { syndrome }\end{array}$ & 16.25 & $\mathrm{AR}$ & $\begin{array}{l}\text { LCCS7 } \\
616286\end{array}$ & $17 \mathrm{q} 21.2$ & $\begin{array}{l}\text { CNTNAP1 } \\
602346\end{array}$ & $\begin{array}{l}\text { Contactin-associated } \\
\text { protein } 1\end{array}$ & Laquerriere et al. (2014) & \\
\hline $\begin{array}{l}\text { Fetal akinesia deformation } \\
\text { sequence } 1\end{array}$ & 16.26 & $\mathrm{AR}$ & $\begin{array}{l}\text { FADS1 } \\
208150\end{array}$ & $9 \mathrm{q} 31.3$ & $\begin{array}{l}\text { MUSK } \\
601296\end{array}$ & $\begin{array}{l}\text { Muscle-specific } \\
\text { receptor tyrosine } \\
\text { kinase }\end{array}$ & $\begin{array}{l}\text { Tan-Sindhunata et al. } \\
\text { (2015) }\end{array}$ & allelic to CMS9 (group 11) \\
\hline $\begin{array}{l}\text { Fetal akinesia deformation } \\
\text { sequence } 3\end{array}$ & 16.27 & $\mathrm{AR}$ & $\begin{array}{l}\text { FADS3 } \\
618389\end{array}$ & $4 \mathrm{p} 16.3$ & $\begin{array}{l}\text { DOK7 } \\
610285\end{array}$ & $\begin{array}{l}\text { Downstream of } \\
\text { tyrosin kinase } 7\end{array}$ & Vogt et al. (2009) & allelic to CMS10 (group 11) \\
\hline $\begin{array}{l}\text { Fetal akinesia deformation } \\
\text { sequence } 2\end{array}$ & 16.28 & $\mathrm{AR}$ & $\begin{array}{l}\text { FADS2 } \\
618388\end{array}$ & $11 \mathrm{p} 11.2$ & $\begin{array}{l}\text { RAPSN } \\
601592\end{array}$ & $\begin{array}{l}\text { Receptor-associated } \\
\text { protein of the } \\
\text { synapse, } 43 \mathrm{kD} \\
\text { (Rapsyn) }\end{array}$ & Vogt et al. (2008) & allelic to CMS11 (group 11) \\
\hline $\begin{array}{l}\text { Fetal akinesia deformation } \\
\text { sequence } 4\end{array}$ & 16.29 & $\mathrm{AR}$ & $\begin{array}{l}\text { FADS4 } \\
618393\end{array}$ & $17 \mathrm{p} 13.2$ & $\begin{array}{l}\text { NUP88 } \\
602552\end{array}$ & Nucleoporin 88kD & Bonnin et al. (2018) & \\
\hline $\begin{array}{l}\text { Fetal akinesia deformation } \\
\text { sequence related to } R Y R I\end{array}$ & 16.30 & $\mathrm{AR}$ & & $19 \mathrm{q} 13.2$ & $\begin{array}{l}\text { RYR1 } \\
180901\end{array}$ & Ryanodine receptor & $\begin{array}{l}\text { Romero et al. (2003) } \\
\text { McKie et al. (2014) } \\
\text { Alkhunaizi et al. (2019) }\end{array}$ & $\begin{array}{l}\text { allelic to CMD related to RYRI } \\
\text { (group 2), CFTD related to } \\
\text { RYRI, CNM related to RYRI, } \\
\text { CCD, CNMDU1, minicore } \\
\text { myopathy with external } \\
\text { ophthalmoplegia (group 3), Late } \\
\text { onset axial myopathy (group 5), } \\
\text { MHS1 (group 8) }\end{array}$ \\
\hline $\begin{array}{l}\text { Severe foetal hypokinesia } \\
\text { related to } S C N 4 A\end{array}$ & 16.31 & $\mathrm{AR}$ & & $17 \mathrm{q} 23.3$ & $\begin{array}{l}\text { SCN4A } \\
603967\end{array}$ & $\begin{array}{l}\text { Sodium channel, } \\
\text { voltage-gated, type } \\
\text { IV, alpha subunit }\end{array}$ & Zaharieva et al. (2016) & $\begin{array}{l}\text { allelic to Congenital Myopathy } \\
\text { related to } S C N 4 A \text { (group 3), } \\
\text { HYPP, HOKPP2, PMC and } \\
\text { K-aggravated myotonia } \\
\text { (group 7), CMS16 (group 11) }\end{array}$ \\
\hline $\begin{array}{l}\text { Progressive external } \\
\text { ophthalmoplegia with } \\
\text { mitochondrial DNA } \\
\text { deletions, autosomal } \\
\text { dominant, 1 }\end{array}$ & 16.32 & $\mathrm{AD}$ & $\begin{array}{l}\text { PEOA1 } \\
157640\end{array}$ & $15 \mathrm{q} 26.1$ & $\begin{array}{l}\text { POLG } \\
174763\end{array}$ & $\begin{array}{l}\text { Polymerase, DNA, } \\
\text { gamma (M) }\end{array}$ & $\begin{array}{l}\text { Van Goethem et al. } \\
\text { (2001) }\end{array}$ & $\begin{array}{l}\text { allelic to SANDO (group 13), } \\
\text { MTDPS4A, MTDPS4B, PEOB1 } \\
\text { (group 16) }\end{array}$ \\
\hline $\begin{array}{l}\text { Progressive external } \\
\text { ophthalmoplegia with } \\
\text { mitochondrial DNA } \\
\text { deletions, autosomal } \\
\text { dominant, } 2\end{array}$ & 16.33 & $\mathrm{AD}$ & $\begin{array}{l}\text { PEOA2 } \\
609283\end{array}$ & $4 q 35$ & $\begin{array}{l}\text { SLC25A4 } \\
103220\end{array}$ & $\begin{array}{l}\text { Solute carrier family } \\
25 \text { (mitochondrial } \\
\text { carrier, adenine } \\
\text { nucleotide } \\
\text { translocator), member } \\
4(\mathbf{M})\end{array}$ & Kaukonen et al. (2000) & $\begin{array}{l}\text { Allelic to MTDPS12A and } \\
\text { MTDPS12B (group 16) }\end{array}$ \\
\hline $\begin{array}{l}\text { Progressive external } \\
\text { ophthalmoplegia with }\end{array}$ & 16.34 & $\mathrm{AD}$ & $\begin{array}{l}\text { PEOA3 } \\
609286\end{array}$ & $10 \mathrm{q} 24.31$ & $\begin{array}{l}\text { TWNK } \\
606075\end{array}$ & $\begin{array}{l}\text { Twinkle, mtDNA } \\
\text { helicase }(\mathbf{M})\end{array}$ & $\begin{array}{l}\text { Suomalinen et al. (1997) } \\
\text { Spelbrink et al. (2001) }\end{array}$ & allelic to IOSCA (group 13) \\
\hline
\end{tabular}




\begin{tabular}{|c|c|c|c|c|c|c|c|c|}
\hline DISEASE NAME & $\begin{array}{l}\text { Item line } \\
\text { in this } \\
\text { group }\end{array}$ & Inheritance & $\begin{array}{l}\text { Locus or } \\
\text { disease symbol } \\
\text { and OMIM } \\
\text { number }\end{array}$ & Chromosome & $\begin{array}{l}\text { Gene symbol } \\
\text { and OMIM } \\
\text { number }\end{array}$ & $\begin{array}{l}\text { Protein } \\
\text { (mitochondrial } \\
\text { proteins indicated } \\
\text { by symbol }[\mathrm{M}] \text { ) }\end{array}$ & Key references & $\begin{array}{l}\text { Other allelic disease(s) (group } \\
\text { in this table) }\end{array}$ \\
\hline $\begin{array}{l}\text { Progressive external } \\
\text { ophthalmoplegia with } \\
\text { mitochondrial DNA } \\
\text { deletions, autosomal } \\
\text { dominant, } 4\end{array}$ & 16.35 & $\mathrm{AD}$ & $\begin{array}{l}\text { PEOA4 } \\
610131\end{array}$ & $17 \mathrm{q} 23.3$ & $\begin{array}{l}\text { POLG2 } \\
604983\end{array}$ & $\begin{array}{l}\text { Polymerase DNA, } \\
\text { gamma } 2(\mathbf{M})\end{array}$ & Longley et al. (2006) & \\
\hline $\begin{array}{l}\text { Progressive external } \\
\text { ophthalmoplegia with } \\
\text { mitochondrial DNA } \\
\text { deletions, autosomal } \\
\text { dominant, } 5\end{array}$ & 16.36 & $\mathrm{AD}$ & $\begin{array}{l}\text { PEOA5 } \\
613077\end{array}$ & $8 \mathrm{q} 22.3$ & $\begin{array}{l}\text { RRM2B } \\
604712\end{array}$ & $\begin{array}{l}\text { Ribonucleotide } \\
\text { reductase, M2 B (M) }\end{array}$ & Tyynismaa et al. (2009) & allelic to MTDP8A (group 16) \\
\hline $\begin{array}{l}\text { Progressive external } \\
\text { ophthalmoplegia with } \\
\text { mitochondrial DNA } \\
\text { deletions, autosomal } \\
\text { dominant, } 6\end{array}$ & 16.37 & $\mathrm{AD}$ & $\begin{array}{l}\text { PEOA6 } \\
615156\end{array}$ & $10 \mathrm{q} 21.3$ & $\begin{array}{l}\text { DNA2 } \\
601810\end{array}$ & $\begin{array}{l}\text { DNA replication } \\
\text { helicase } 2(\mathbf{M})\end{array}$ & Ronchi et al. (2013) & \\
\hline $\begin{array}{l}\text { Progressive external } \\
\text { ophthalmoplegia with } \\
\text { mitochondrial DNA } \\
\text { deletions, autosomal } \\
\text { recessive 1 }\end{array}$ & 16.38 & AR & $\begin{array}{l}\text { PEOB1 } \\
258450\end{array}$ & $15 \mathrm{q} 26.1$ & $\begin{array}{l}\text { POLG } \\
174763\end{array}$ & $\begin{array}{l}\text { Polymerase, DNA, } \\
\text { gamma (M) }\end{array}$ & Deschauer et al. (2007) & $\begin{array}{l}\text { allelic to SANDO (group 13), } \\
\text { MTDPS4A, MTDPS4B, PEOA1 } \\
\text { (group 16) }\end{array}$ \\
\hline $\begin{array}{l}\text { Progressive external } \\
\text { ophthalmoplegia with } \\
\text { mitochondrial DNA } \\
\text { deletions, autosomal } \\
\text { recessive } 2\end{array}$ & 16.39 & $\mathrm{AR}$ & $\begin{array}{l}\text { PEOB2 } \\
616479\end{array}$ & $2 \mathrm{p} 25.3$ & $\begin{array}{l}\text { RNASEHI } \\
604123\end{array}$ & Ribonuclease H1 (M) & Reyes et al. (2015) & \\
\hline $\begin{array}{l}\text { Progressive external } \\
\text { ophthalmoplegia with } \\
\text { mitochondrial DNA } \\
\text { deletions, autosomal } \\
\text { recessive } 3\end{array}$ & 16.40 & $\mathrm{AR}$ & $\begin{array}{l}\text { PEOB3 } \\
617069\end{array}$ & $16 \mathrm{q} 21$ & $\begin{array}{l}\text { TK2 } \\
188250\end{array}$ & $\begin{array}{l}\text { Thymidine kinase, } \\
\text { mitochondrial }(\mathbf{M})\end{array}$ & Tyynismaa et al. (2012) & allelic to MTDPS2 (group 16) \\
\hline $\begin{array}{l}\text { Progressive external } \\
\text { ophthalmoplegia with } \\
\text { mitochondrial DNA } \\
\text { deletions, autosomal } \\
\text { recessive } 4\end{array}$ & 16.41 & AR & $\begin{array}{l}\text { PEOB4 } \\
617070\end{array}$ & $2 \mathrm{p} 13.1$ & $\begin{array}{l}\text { DGUOK } \\
601465\end{array}$ & $\begin{array}{l}\text { Deoxyguanosine } \\
\text { kinase }(\mathbf{M})\end{array}$ & Ronchi et al. (2012) & Allelic to MTDPS3 (group 16) \\
\hline $\begin{array}{l}\text { Progressive external } \\
\text { ophthalmoplegia with } \\
\text { mitochondrial DNA } \\
\text { deletions, autosomal } \\
\text { recessive } 5\end{array}$ & 16.42 & $\mathrm{AR}$ & $\begin{array}{l}\text { PEOB5 } \\
618098\end{array}$ & $17 \mathrm{p} 11.2$ & $\begin{array}{l}\text { TOP3A } \\
601243\end{array}$ & $\begin{array}{l}\text { DNA topoisomerase } \\
\text { III }\end{array}$ & Nicholls et al. (2018) & \\
\hline $\begin{array}{l}\text { Mitochondrial DNA } \\
\text { depletion syndrome } 1 \\
\text { (MNGIE type) }\end{array}$ & 16.43 & AR & $\begin{array}{l}\text { MTDPS1 } \\
603041\end{array}$ & $22 \mathrm{q} 13.33$ & $\begin{array}{l}\text { TYMP } \\
131222\end{array}$ & $\begin{array}{l}\text { Thymidine } \\
\text { phosphorylase }\end{array}$ & Nishino et al. (1999) & \\
\hline $\begin{array}{l}\text { Mitochondrial DNA } \\
\text { depletion syndrome } 2 \\
\text { (myopathic type) }\end{array}$ & 16.44 & $\mathrm{AR}$ & $\begin{array}{l}\text { MTDPS2 } \\
609560\end{array}$ & $16 \mathrm{q} 21$ & $\begin{array}{l}\text { TK2 } \\
188250\end{array}$ & $\begin{array}{l}\text { Thymidine kinase, } \\
\text { mitochondrial (M) }\end{array}$ & Saada et al. (2001) & allelic to PEOB3 (group 16) \\
\hline $\begin{array}{l}\text { Mitochondrial DNA } \\
\text { depletion syndrome } 3 \\
\text { (hepatocerebral type) }\end{array}$ & 16.45 & $\mathrm{AR}$ & $\begin{array}{l}\text { MTDPS3 } \\
251880\end{array}$ & $2 \mathrm{p} 13.1$ & $\begin{array}{l}\text { DGUOK } \\
601465\end{array}$ & $\begin{array}{l}\text { Deoxyguanosine } \\
\text { kinase }(\mathbf{M})\end{array}$ & Mandel et al. (2001) & $\begin{array}{l}\text { Allelic to Progressive external } \\
\text { ophthalmoplegia with } \\
\text { mitochondrial DNA deletions, } \\
\text { autosomal recessive } 4 \\
\text { (group 16) }\end{array}$ \\
\hline $\begin{array}{l}\text { Mitochondrial DNA } \\
\text { depletion syndrome } 4 \mathrm{~A} \\
\text { (Alpers type) }\end{array}$ & 16.46 & $\mathrm{AR}$ & $\begin{array}{l}\text { MTDPS4A } \\
203700\end{array}$ & $15 \mathrm{q} 26.1$ & $\begin{array}{l}\text { POLG } \\
174763\end{array}$ & $\begin{array}{l}\text { Polymerase, DNA, } \\
\text { gamma (M) }\end{array}$ & $\begin{array}{l}\text { Naviaux and Nguyen } \\
\text { (2004) }\end{array}$ & $\begin{array}{l}\text { Allelic to SANDO (group 13), } \\
\text { MTDPS4B, PEOA1 } \\
\text { and PEOB1 (group 16) }\end{array}$ \\
\hline $\begin{array}{l}\text { Mitochondrial DNA } \\
\text { depletion syndrome } 4 \mathrm{~B} \\
\text { (MNGIE type) }\end{array}$ & 16.47 & AR & $\begin{array}{l}\text { MTDPS4B } \\
613662\end{array}$ & $15 \mathrm{q} 26.1$ & $\begin{array}{l}\text { POLG } \\
174763\end{array}$ & $\begin{array}{l}\text { Polymerase, DNA, } \\
\text { gamma (M) }\end{array}$ & $\begin{array}{l}\text { Van Goethem et al. } \\
\text { (2003) }\end{array}$ & $\begin{array}{l}\text { Allelic to SANDO (group 13), } \\
\text { MTDPS4A, PEOA1 } \\
\text { and PEOB1 (group 16) }\end{array}$ \\
\hline $\begin{array}{l}\text { Mitochondrial DNA } \\
\text { depletion syndrome } 5 \\
\text { (encephalomyopathic with or } \\
\text { without methylmalonic } \\
\text { aciduria) }\end{array}$ & 16.48 & $\mathrm{AR}$ & $\begin{array}{l}\text { MTDPS5 } \\
612073\end{array}$ & $13 \mathrm{q} 14.2$ & $\begin{array}{l}\text { SUCLA2 } \\
603921\end{array}$ & $\begin{array}{l}\text { Succinate-CoA } \\
\text { ligase, ADP-forming, } \\
\text { beta subunit }(\mathbf{M})\end{array}$ & Elpeleg et al. (2005) & \\
\hline $\begin{array}{l}\text { Mitochondrial DNA } \\
\text { depletion syndrome } 8 \mathrm{~A} \\
\text { (Encephalomyopathic type } \\
\text { with renal tubulopathy) }\end{array}$ & 16.49 & $\mathrm{AR}$ & $\begin{array}{l}\text { MTDP8A } \\
612075\end{array}$ & $8 \mathrm{q} 22.3$ & $\begin{array}{l}\text { RRM2B } \\
604712\end{array}$ & $\begin{array}{l}\text { Ribonucleotide } \\
\text { reductase, M2B (M) }\end{array}$ & Bourdon et al. (2007) & $\begin{array}{l}\text { allelic to PEOA5 and MTDPS8B } \\
\text { (group 16) }\end{array}$ \\
\hline $\begin{array}{l}\text { Mitochondrial DNA } \\
\text { depletion syndrome } 8 \mathrm{~B} \\
\text { (MNGIE type) }\end{array}$ & 16.50 & $\mathrm{AR}$ & $\begin{array}{l}\text { MTDP8B } \\
612075\end{array}$ & $8 \mathrm{q} 22.3$ & $\begin{array}{l}\text { RRM2B } \\
604712\end{array}$ & $\begin{array}{l}\text { Ribonucleotide } \\
\text { reductase, M2B (M) }\end{array}$ & Bourdon et al. (2007) & $\begin{array}{l}\text { allelic to PEOA5 and MTDPS8A } \\
\text { (group 16) }\end{array}$ \\
\hline $\begin{array}{l}\text { Mitochondrial DNA } \\
\text { depletion syndrome } 9 \\
\text { (Encephalomyopathic type } \\
\text { withmethylmalonic aciduria) }\end{array}$ & 16.51 & $\mathrm{AR}$ & $\begin{array}{l}\text { MTDPS9 } \\
245400\end{array}$ & $2 \mathrm{p} 11.2$ & $\begin{array}{l}\text { SUCLGI } \\
611224\end{array}$ & $\begin{array}{l}\text { Succinate-CoA } \\
\text { ligase, alpha subunit } \\
\text { (M) }\end{array}$ & Ostergaard et al. (2007) & \\
\hline $\begin{array}{l}\text { Mitochondrial DNA } \\
\text { depletion syndrome } 11\end{array}$ & 16.52 & $\mathrm{AR}$ & $\begin{array}{l}\text { MTDPS11 } \\
615084\end{array}$ & $20 \mathrm{p} 11.23$ & $\begin{array}{l}\text { MGME1 } \\
615076\end{array}$ & $\begin{array}{l}\text { Mitochondrial } \\
\text { genome maintenance } \\
\text { exonuclease } 1(\mathbf{M})\end{array}$ & Kornblum et al. (2013) & \\
\hline
\end{tabular}




\begin{tabular}{|c|c|c|c|c|c|c|c|c|}
\hline DISEASE NAME & $\begin{array}{l}\text { Item line } \\
\text { in this } \\
\text { group }\end{array}$ & Inheritance & $\begin{array}{l}\text { Locus or } \\
\text { disease symbol } \\
\text { and OMIM } \\
\text { number }\end{array}$ & Chromosome & $\begin{array}{l}\text { Gene symbol } \\
\text { and OMIM } \\
\text { number }\end{array}$ & $\begin{array}{l}\text { Protein } \\
\text { (mitochondrial } \\
\text { proteins indicated } \\
\text { by symbol }[\mathrm{M}] \text { ) }\end{array}$ & Key references & $\begin{array}{l}\text { Other allelic disease(s) (group } \\
\text { in this table) }\end{array}$ \\
\hline $\begin{array}{l}\text { Mitochondrial DNA } \\
\text { depletion syndrome } 12 \mathrm{~A} \\
\text { (cardiomyopathic type) }\end{array}$ & 16.53 & $\mathrm{AD}$ & $\begin{array}{l}\text { MTDPS12A } \\
617184\end{array}$ & $4 \mathrm{q} 35.1$ & $\begin{array}{l}S L C 25 A 4 \\
103220\end{array}$ & $\begin{array}{l}\text { Solute carrier family } \\
25 \text { (mitochondrial } \\
\text { carrier, adenine } \\
\text { nucleotide } \\
\text { translocator), member } \\
4 \text { (M) }\end{array}$ & Thompson et al. (2016) & $\begin{array}{l}\text { Allelic to PEOA2 and } \\
\text { MTDPS12B (group 16) }\end{array}$ \\
\hline $\begin{array}{l}\text { Mitochondrial DNA } \\
\text { depletion syndrome } 12 \mathrm{~A} \\
\text { (cardiomyopathic type) }\end{array}$ & 16.54 & $\mathrm{AR}$ & $\begin{array}{l}\text { MTDPS12B } \\
615418\end{array}$ & $4 \mathrm{q} 35.1$ & $\begin{array}{l}\text { SLC25A4 } \\
103220\end{array}$ & $\begin{array}{l}\text { Solute carrier family } \\
25 \text { (mitochondrial } \\
\text { carrier, adenine } \\
\text { nucleotide } \\
\text { translocator), member } \\
4 \text { (M) }\end{array}$ & Palmieri et al. (2005) & $\begin{array}{l}\text { Allelic to PEOA2 and } \\
\text { MTDPS12A (group 16) }\end{array}$ \\
\hline $\begin{array}{l}\text { Mitochondrial DNA } \\
\text { depletion syndrome } 13 \\
\text { (encephalomyopathic type) }\end{array}$ & 16.55 & $\mathrm{AR}$ & $\begin{array}{l}\text { MTDPS13 } \\
615471\end{array}$ & $6 \mathrm{q} 16.1-\mathrm{q} 16.2$ & $\begin{array}{l}F B X L 4 \\
605654\end{array}$ & $\begin{array}{l}\text { F-box and } \\
\text { leucine-rich repeat } \\
\text { protein } 4\end{array}$ & $\begin{array}{l}\text { Bonnen et al. (2013) Gai } \\
\text { et al. (2013) }\end{array}$ & \\
\hline $\begin{array}{l}\text { Mitochondrial DNA } \\
\text { depletion syndrome } 14 \\
\text { (cardioencephalomyopathic } \\
\text { type) }\end{array}$ & 16.56 & $\mathrm{AR}$ & $\begin{array}{l}\text { MTDPS14 } \\
616896\end{array}$ & $3 q 29$ & $\begin{array}{l}\text { OPAI } \\
605290\end{array}$ & OPA1 protein (M) & Spiegel et al. (2016) & $\begin{array}{l}\text { Allelic to Progressive external } \\
\text { ophthalmoplegia with optic } \\
\text { atrophy, optic atrophy } 1 \text { with } \\
\text { deafness (group 16) }\end{array}$ \\
\hline $\begin{array}{l}\text { Metabolic crises, recurrent, } \\
\text { with variable } \\
\text { encephalomyopathic features } \\
\text { and neurologic regression }\end{array}$ & 16.57 & $\mathrm{AR}$ & $\begin{array}{l}\text { MECREN } \\
618416\end{array}$ & 19p13.11 & $\begin{array}{l}\text { SLC25A42 } \\
610823\end{array}$ & $\begin{array}{l}\text { Solute carrier family } \\
25, \text { member } 42(\mathbf{M})\end{array}$ & Shamseldin et al. (2015) & \\
\hline $\begin{array}{l}\text { Progressive external } \\
\text { ophthalmoplegia with optic } \\
\text { atrophy, optic atrophy } 1 \text { with } \\
\text { deafness }\end{array}$ & 16.58 & $\mathrm{AD}$ & 125250 & $3 \mathrm{q} 29$ & $\begin{array}{l}\text { OPAI } \\
605290\end{array}$ & OPA1 protein $(\mathbf{M})$ & $\begin{array}{l}\text { Amati-Bonneau et al. } \\
\text { (2008) Hudson et al. } \\
\text { (2008) }\end{array}$ & Allelic to MTDPS14 (group 16) \\
\hline $\begin{array}{l}\text { Myopathy, lactic acidosis, } \\
\text { and sideroblastic anemia } 1\end{array}$ & 16.59 & $\mathrm{AR}$ & $\begin{array}{l}\text { MLASA1 } \\
600462\end{array}$ & $12 \mathrm{q} 24.33$ & $\begin{array}{l}\text { PUS1 } \\
608109\end{array}$ & $\begin{array}{l}\text { Pseudourine synthase } \\
1 \text { (M) }\end{array}$ & $\begin{array}{l}\text { Bykhovskaya et al. } \\
\text { (2004) Fernandez-Vizarra } \\
\text { (2007) }\end{array}$ & \\
\hline $\begin{array}{l}\text { Myopathy, lactic acidosis, } \\
\text { and sideroblastic anemia-2 }\end{array}$ & 16.60 & $\mathrm{AR}$ & $\begin{array}{l}\text { MLASA2 } \\
613561\end{array}$ & $12 \mathrm{p} 11.21$ & $\begin{array}{l}\text { YARS2 } \\
610957\end{array}$ & $\begin{array}{l}\text { Tyrosyl-tRNA } \\
\text { synthetase } 2(\mathbf{M})\end{array}$ & Riley et al. (2010) & Allelic to CMTDIC (group 14) \\
\hline $\begin{array}{l}\text { Isolated mitochondrial } \\
\text { myopathy }\end{array}$ & 16.61 & $\mathrm{AD}$ & $\begin{array}{l}\text { IMMD } \\
616209\end{array}$ & $22 \mathrm{q} 11.23$ & $\begin{array}{l}\text { CHCHD10 } \\
615903\end{array}$ & $\begin{array}{l}\text { Coiled-coil-helix- } \\
\text { coiled-coil-helix } \\
\text { domain containing } 10 \\
\text { (M) }\end{array}$ & $\begin{array}{l}\text { Ajroud-Driss et al. } \\
\text { (2014) }\end{array}$ & $\begin{array}{l}\text { allelic to FTDALS2 and SMAJ } \\
\text { (group 12) }\end{array}$ \\
\hline $\begin{array}{l}\text { Poikiloderma, hereditary } \\
\text { fibrosing, with tendon } \\
\text { contractures, myopathy, and } \\
\text { pulmonary fibrosis }\end{array}$ & 16.62 & $\mathrm{AD}$ & $\begin{array}{l}\text { POIKTMP } \\
615704\end{array}$ & $11 \mathrm{q} 12.1$ & $\begin{array}{l}\text { FAM111B } \\
615584\end{array}$ & $\begin{array}{l}\text { Family with sequence } \\
\text { similarity } 111 \text {, } \\
\text { member B }\end{array}$ & Mercier et al. (2015) & \\
\hline $\begin{array}{l}\text { Combined oxidative } \\
\text { phosphorylation deficiency } \\
6\end{array}$ & 16.63 & $\mathrm{XL}$ & $\begin{array}{l}\text { COXPD6 } \\
300816\end{array}$ & $\mathrm{Xq} 26.1$ & $\begin{array}{l}\text { AIFMI } \\
300169\end{array}$ & $\begin{array}{l}\text { Apoptosis-inducing } \\
\text { factor, mitochondria- } \\
\text { associated, } 1 \\
\text { (M) }\end{array}$ & Morton et al. (2017) & Allelic to COCK (group 14) \\
\hline $\begin{array}{l}\text { Mitochondrial myopathy } \\
\text { with severe neurological } \\
\text { manifestations }\end{array}$ & 16.64 & $\mathrm{AR}$ & & $8 \mathrm{q} 24.13$ & $\begin{array}{l}\text { TMEM65 } \\
616609\end{array}$ & $\begin{array}{l}\text { Transmembrane } \\
\text { protein } 65\end{array}$ & Nasli et al. (2017) & \\
\hline $\begin{array}{l}\text { Mitochondrial complex IV } \\
\text { deficiency }\end{array}$ & 16.65 & $\mathrm{AR}$ & 220110 & $2 \mathrm{q} 33.3$ & $\begin{array}{l}\text { FASTKD2 } \\
612322\end{array}$ & $\begin{array}{l}\text { Fast kinase domains } \\
2(\mathbf{M})\end{array}$ & Yoo et al. (2017) & \\
\hline $\begin{array}{l}\text { Mitochondrial complex IV } \\
\text { deficiency }\end{array}$ & 16.66 & $\mathrm{AR}$ & 220110 & $16 p 11.2$ & $\begin{array}{l}\text { COX6A2 } \\
602009\end{array}$ & $\begin{array}{l}\text { Cytochrome } \\
\text { c-oxidase, subunit } \\
6 \text { A2 }(\mathbf{M})\end{array}$ & Inoue et al. (2019) & \\
\hline $\begin{array}{l}\text { Infantile-onset multisystem } \\
\text { disease with progressive } \\
\text { muscle weakness }\end{array}$ & 16.67 & $\mathrm{AR}$ & $\begin{array}{l}\text { IMNEPD } \\
616263\end{array}$ & $17 \mathrm{q} 23.1$ & $\begin{array}{l}\text { PTRH2 } \\
608625\end{array}$ & $\begin{array}{l}\text { Peptidyl-tRNA } \\
\text { hydrolase } 2\end{array}$ & Hu et al. (2014) & \\
\hline $\begin{array}{l}\text { Dyskinetic cerebral palsy, } \\
\text { partial agenesis of the } \\
\text { corpus callosum and } \\
\text { mitochondrial myopathy }\end{array}$ & 16.68 & AR & & $3 \mathrm{p} 25.1$ & $\begin{array}{l}\text { MRPS25 } \\
611987\end{array}$ & $\begin{array}{l}\text { Mitochondrial } \\
\text { ribosomal protein } \\
\text { S25 (M) }\end{array}$ & Bugiardini et al. (2019) & \\
\hline $\begin{array}{l}\text { Myopathy, mitochondrial } \\
\text { and cerebellar ataxia (also } \\
\text { listed in group } 2 \& 13 \text { ) }\end{array}$ & 16.69 & $\mathrm{AR}$ & $\begin{array}{l}\text { MMYAT } \\
617675\end{array}$ & $1 \mathrm{q} 22$ & $\begin{array}{l}\text { MSTO1 } \\
617619\end{array}$ & $\begin{array}{l}\text { Misato 1, } \\
\text { Mitochondrial } \\
\text { Distribution and } \\
\text { Morphology } \\
\text { Regulator (M) }\end{array}$ & $\begin{array}{l}\text { Nasca et al. (2017) } \\
\text { Ardicli et al. (2019) } \\
\text { Donkervoort et al. (2019) }\end{array}$ & \\
\hline $\begin{array}{l}\text { Early onset of mitochondrial } \\
\text { myopathy }\end{array}$ & 16.70 & $\mathrm{AR}$ & & $17 \mathrm{q} 13.3$ & $\begin{array}{l}\text { TIMM22 } \\
607251\end{array}$ & $\begin{array}{l}\text { Translocase of inner } \\
\text { mitochondrial } \\
\text { membrane } 22 \text { (M) }\end{array}$ & Pacheu-Grau et al. (2018) & \\
\hline Coenzyme Q10 deficiency 1 & 16.71 & $\mathrm{AR}$ & $\begin{array}{l}\text { COQ10D1 } \\
607426\end{array}$ & $4 \mathrm{q} 21.23$ & $\begin{array}{l}\mathrm{COQ2} \\
609825\end{array}$ & Coenzyme Q2 (M) & Quinzii et al. (2006) & \\
\hline $\begin{array}{l}\text { Autosomal recessive } \\
\text { spinocerebellar ataxia, } 9 \\
\text { with ubiquinone deficiency } \\
\text { (also listed in group 13) }\end{array}$ & 16.72 & $\mathrm{AR}$ & $\begin{array}{l}\text { SCAR9 } \\
(\mathrm{COQ} 10 \mathrm{D} 4) \\
612016\end{array}$ & $1 \mathrm{q} 42.13$ & $\begin{array}{l}\text { ADCK3 } \\
(C O Q 8 A, \\
C A B C 1) \\
606980\end{array}$ & Coenzyme Q8A (M) & $\begin{array}{l}\text { Lagier-Tourenne et al. } \\
\text { (2008) Mollet et al. } \\
(2008)\end{array}$ & \\
\hline Coenzyme Q10 deficiency 5 & 16.73 & $\mathrm{AR}$ & $\begin{array}{l}\text { COQ10D5 } \\
614654\end{array}$ & $16 \mathrm{q} 21$ & $\begin{array}{l}\operatorname{COQ}^{9} \\
612837\end{array}$ & Coenzyme Q9 (M) & $\begin{array}{l}\text { Rahman et al. (2001) } \\
\text { Duncan et al. (2009) }\end{array}$ & \\
\hline Coenzyme Q10 deficiency 6 & 16.74 & $\mathrm{AR}$ & $\begin{array}{l}\text { COQ10D6 } \\
614650\end{array}$ & $14 \mathrm{q} 24.3$ & $\begin{array}{l}\text { COQ6 } \\
614647\end{array}$ & Coenzyme Q6 (M) & Heeringa et al. (2011) & \\
\hline
\end{tabular}




\begin{tabular}{|c|c|c|c|c|c|c|c|c|}
\hline DISEASE NAME & $\begin{array}{l}\text { Item line } \\
\text { in this } \\
\text { group }\end{array}$ & Inheritance & $\begin{array}{l}\text { Locus or } \\
\text { disease symbol } \\
\text { and OMIM } \\
\text { number }\end{array}$ & Chromosome & $\begin{array}{l}\text { Gene symbol } \\
\text { and OMIM } \\
\text { number }\end{array}$ & $\begin{array}{l}\text { Protein } \\
\text { (mitochondrial } \\
\text { proteins indicated } \\
\text { by symbol }[\mathrm{M}] \text { ) }\end{array}$ & Key references & $\begin{array}{l}\text { Other allelic disease(s) (group } \\
\text { in this table) }\end{array}$ \\
\hline Coenzyme Q10 deficiency 7 & 16.75 & $\mathrm{AR}$ & $\begin{array}{l}\text { COQ10D7 } \\
607426\end{array}$ & $9 \mathrm{q} 34.11$ & $\begin{array}{l}\mathrm{COQ4} \\
612898\end{array}$ & Coenzyme Q4 (M) & Brea-Calvo et al. (2015) & \\
\hline Coenzyme Q10 deficiency 8 & 16.76 & $\mathrm{AR}$ & $\begin{array}{l}\text { COQ10D8 } \\
616,733\end{array}$ & $16 \mathrm{p} 12.3$ & $\begin{array}{l}\mathrm{COQ} 7 \\
601683\end{array}$ & Coenzyme Q7 (M) & Freyer et al. (2015) & \\
\hline $\begin{array}{l}\text { Sensory motor axonal } \\
\text { neuropathy and myopathy }\end{array}$ & 16.77 & $\mathrm{AR}$ & & $19 \mathrm{p} 13.2$ & $\begin{array}{l}\text { FDX } 2 \\
614585\end{array}$ & Ferredoxin (M) & $\begin{array}{l}\text { Gurgel-Giannetti et al. } \\
\text { (2019) }\end{array}$ & \\
\hline
\end{tabular}

\section{NEW REFERENCES}

\section{GROUP 1. MUSCULAR DYSTROPHIES}

Straub V, Murphy A, Udd B. LGMD workshop study group. 229th ENMC international workshop: Limb girdle muscular dystrophies - Nomenclature and reformed classification. Naarden, the Netherlands, 17-19 March 2017. Neuromuscul Disord. 2018 Aug;28(8):702-710. PMID: 30055862 [Items \#1.13-19; \#1.21-46]

Fichtman B, Zagairy F, Biran N, Barsheshet Y, Chervinsky E, Ben Neriah Z, et al. Combined loss of LAP1B and LAP1C results in an early onset multisystemic, nuclear envelopathy. Nat Commun. 2019 Feb 5;10(1):605. PMID: 30723199 [Items \#1.9 \& 1.55]

Martinez-Thompson JM, Niu Z., Tracy JA, Moore SA, Swenson A, Wieben ED, et al. Autosomal dominant calpainopathy due to heterozygous CAPN3 c.643_663del21. Muscle Nerve. 57: 679-683, 2018. PMID: 28881388 [Item \#1.16]

Vissing J, Barresi R, Witting $\mathrm{N}$, Van Ghelue $\mathrm{M}$, Gammelgaard L, Bindoff LA, et al. A heterozygous 21-bp deletion in CAPN3 causes dominantly inherited limb girdle muscular dystrophy. Brain 139: 2154-2163, 2016. PMID: 27259757 [Item \#1.16]

Jokela M, Lehtinen S, Palmio J, Saukkonen AM, Huovinen S, Vihola A, et al. A novel COL6A2 mutation causing lateonset limb-girdle muscular dystrophy. J Neurol. 2019 Apr 8. PMID: 30963254 [Item \#1.47]

Gavassini BF, Carboni N, Nielsen JE, Danielsen ER, Thomsen C, Svenstrup K, et al. Clinical and molecular characterization of limb-girdle muscular dystrophy due to LAMA2 mutations. Muscle Nerve 44: 703-709, 2011. PMID 21953594 [Item \#1.49]

Endo Y, Dong M, Noguchi S, Ogawa M, Hayashi Y.K, Kuru S. et al. Milder forms of muscular dystrophy associated with POMGNT2 mutations. Neurol Genet. 2015 Dec 10;1(4):e33 PMID: 27066570 [Item \#1.50]

Sainio MT, Välipakka S, Rinaldi B, Lapatto H, Paetau A, Ojanen S, et al. Recessive PYROXD1 mutations cause adultonset limb-girdle-type muscular dystrophy. J Neurol. 2018 Dec 4. PMID: 30515627 [Item \#1.59]

Garibaldi M, Fattori F, Bortolotti CA, Brochier G, Labasse C, Verardo M. Core-rod myopathy due to a novel mutation in BTB/POZ domain of KBTBD13 manifesting as late onset LGMD. Acta Neuropathol Commun. 2018 Sep 13;6(1):94. PMID: 30208948 [Item \#1.60]

\section{GROUP 2. CONGENITAL MUSCULAR DYSTROPHIES}

Shamseldin HE, Bennett AH, Alfadhel M, Gupta V, Alkuraya FS. GOLGA2, encoding a master regulator of golgi apparatus, is mutated in a patient with a neuromuscular disorder. Hum Genet. 2016 Feb;135(2):245-251. PMID: 26742501 [Item \#2.46]

Ardicli D, Sarkozy A, Zaharieva I, Deshpande C, Bodi I, Siddiqui A, et al. A novel case of MSTO1 gene related congenital muscular dystrophy with progressive neurological involvement. Neuromuscul Disord. 2019 Jun;29(6):448-455. PMID: 31130378. [Item \#2.49]

Donkervoort S, Sabouny R, Yun P, Gauquelin L, Chao $\mathrm{KR}$, $\mathrm{Hu} \mathrm{Y}$, et al. MSTO1 mutations cause mtDNA depletion, manifesting as muscular dystrophy with cerebellar involvement. Acta Neuropathol. 2019 Aug 29. PMID: 31463572. [Item \#2.49]

Nasca A, Scotton C, Zaharieva I, Neri M, Selvatici R, Magnusson OT, et al. Recessive mutations in MSTO1 cause mitochondrial dynamics impairment, leading to myopathy and ataxia. Hum Mutat. 2017 Aug;38(8):970-977. PMID: 28544275 [Item \#2.49]

Helbling DC, Mendoza D, McCarrier J, Vanden Avond MA, Harmelink MM, Barkhaus PE, et al. Severe Neonatal RYR1 Myopathy With Pathological Features of Congenital Muscular Dystrophy. J Neuropathol Exp Neurol. 2019 Mar 1;78(3):283-287. PMID: 30715496. [Item \#2.50]

\section{GROUP 3. CONGENITAL MYOPATHIES}

Waterman MA, Barth PG, van Spaendonck-Zwarts KY, Aronica E, Poll-The BT, Brouwer OF, et al. 2013. Recessive MYL2 mutations cause infantile type I muscle fibre disease and cardiomyopathy. Brain 136: 282293. PMID: 31127036 [Item \#3.19]

Ge L, Fu X, Zhang W, Wang D, Wang Z, Yuan Y, et al. Recessive mutations in proximal I-band of TTN gene cause severe congenital multi-minicore disease without cardiac involvement. Neuromuscul Disord. 2019 May;29(5):350-357. PMID 31053406. [Item \#3.32]

Zaharieva I, Sarkozy A, Munot P, Manzur A, O’Grady G, Rendu J, et al. STAC3 variants cause a congenital myopathy with distinctive dysmorphic features and malignant hyperthermia susceptibility. Hum Mutat. 2018 Aug 31. PMID: 30168660 [Item \#3.53] 
Lornage X, Romero NB, Grosgogeat CA, Malfatti E, Donkervoort S, Marchetti MM, et al. ACTN2 mutations cause "Multiple structured Core Disease" (MsCD). Acta Neuropathol. 2019 Jan 30. PMID: 30701273 [Item \#3.54]

Ravenscroft G, Zaharieva I, Bortolotti CA, Lambrughi M, Pignataro M, Borsari M, et al. Bi-allelic mutations in MYL1 cause a severe congenital myopathy. Hum Mol Genet. 2018 Sep 12. PMID: 30215711 [Item \#3.55]

Carter MT, McMillan HJ, Tomin A, Weiss N. Compound heterozygous CACNA1H mutations associated with severe congenital amyotrophy. Channels (Austin). 2019 Dec;13(1):153-161. PMID: 31070086 [Item \#3.56]

Estañ MC, Fernández-Núñez E, Zaki MS, Esteban MI, Donkervoort S, Hawkins C, et al. Recessive mutations in muscle-specific isoforms of FXR1 cause congenital multiminicore myopathy. Nat Commun. 2019 Feb 15;10(1):797. PMID: 30770808 [Item \#3.57]

Feichtinger RG, Mucha BE, Hengel H, Orfi Z, Makowski $\mathrm{C}$, Dort J, et al. Biallelic variants in the transcription factor PAX7 are a new genetic cause of myopathy. Genet Med. 2019 May 16. PMID: 31092906 [Item \#3.58]

Gonorazky HD, Marshall CR, Al-Murshed M, Hazrati LN, Thor MG, Hanna MG, et al. Congenital myopathy with "corona" fibres, selective muscle atrophy, and craniosynostosis associated with novel recessive mutations in SCN4A. Neuromuscul Disord. 2017 Jun;27(6):574-580. PMID: 28262468 [Item \#3.59]

Sloth CK, Denti F, Schmitt N, Bentzen BH, Fagerberg C, Vissing J, et al. Homozygosity for SCN4A Arg1142Gln causes congenital myopathy with variable disease expression. Neurol Genet. 2018 Sep 19;4(5):e267. PMID: 30283817 [Item \#3.59]

Zaharieva IT, Thor MG, Oates EC, van Karnebeek C, Hendson G, Blom E, et al. Loss-of-function mutations in SCN4A cause severe foetal hypokinesia or 'classical' congenital myopathy. Brain. 2016 Mar;139(Pt 3):674-91. PMID: 26700687 [Item \#3.59]

Lornage X, Schartner V, Balbueno I, Biancalana V, Willis T, Echaniz-Laguna A, et al. Clinical, histological, and genetic characterization of PYROXD1-related myopathy. Acta Neuropathol Commun. 2019 Aug 27;7(1):138. PMID: 31455395 [Item \#3.60]

Angelini C, Marozzo R, Pinzan E, Pegoraro V, Molnar MJ, Torella A, et al. A new family with transportinopathy: increased clinical heterogeneity. Ther Adv Neurol Disord. 2019 Jun 9;12:1756286419850433. PMID: 31217819 [Item \#3.61]

Vihola A, Palmio J, Danielsson O, Penttilä S, Louiselle D, Pittman S, et al. Novel mutation in TNPO3 causes congenital limb-girdle myopathy with slow progression. Neurol Genet. 2019 May 2;5(3):e337. PMID: 31192305 [Item \#3.61]

\section{GROUP 4. DISTAL MYOPATHIES}

Al-Tahan S, Weiss L, Yu H, Tang S, Saporta M, Vihola A, et al. New family with HSPB8-associated autosomal dominant rimmed vacuolar myopathy. Neurol Genet. 2019 Jul 10;5(4):e349. 2019 Aug. PMID: 31403083 [Item \#4.21]

\section{GROUP 5. OTHER MYOPATHIES}

Hedberg C, Melberg A, Kuhl A, Jenne D, Oldfors A. Autosomal dominant myofibrillar myopathy with arrhythmogenic right ventricular cardiomyopathy 7 is caused by a DES mutation. Europ. J. Hum. Genet. 20: 984-985, 2012. PMID 22395865 [Item \#5.13]

Ishiura H, Shibata S, Yoshimura J, Suzuki Y, Qu W, Doi $\mathrm{K}$, et al. Noncoding CGG repeat expansions in neuronal intranuclear inclusion disease, oculopharyngodistal myopathy and an overlapping disease. Nat Genet. 2019 Aug;51(8):12221232. Epub 2019 Jul 22. PMID:31332380 [Item \#5.18]

Olivé M, Engvall M, Ravenscroft G, Cabrera-Serrano M, Jiao H, Bortolotti, CA. Myoglobulinopathy is an adultonset autosomal dominant myopathy with characteristic sarcoplasmic inclusions. Nat Commun. 2019 Mar 27;10(1):1396. PMID 30918256 [Item \#5.34]

\section{Group 7. ION CHANNEL MUSCLE DISEASES}

Sampedro Castañeda M, Zanoteli E, Scalco RS, Scaramuzzi V, Marques Caldas V, Conti Reed U, et al. A novel ATP1A2 mutation in a patient with hypokalaemic periodic paralysis and CNS symptoms. Brain. 2018 Nov 12. PMID:30423015 [Item \#7.5]

\section{GROUP 12. SPINAL MUSCULAR ATROPHIES, MOTOR NEURON DISEASES}

Li N, Wang L, Sun X, Lu Z, Suo X, Li J, et al. A novel mutation in VRK1 associated with distal spinal muscular atrophy. J Hum Genet. 2019 Jan 7. PMID: 30617279 [Item \#12.10]

Stoll M, Teoh H, Lee J, Reddel S, Zhu Y, Buckley M, et al. Novel motor phenotypes in patients with VRK1 mutations without pontocerebellar hypoplasia. Neurology Jul 2016, 87 (1) 65-70; PMID: 27281532 [Item \#12.10]

Zhao H, Race V, Matthijs G, De Jonghe P, Robberecht W, Lambrechts D, et al. Exome sequencing reveals HINT1 mutations as a cause of distal hereditary motor neuropathy. Eur J Hum Genet. 2014 Jun;22(6):847-50. Epub 2013 Oct 9. PMID:24105373 [Item \#12.15]

Ravenscroft G, Di Donato N, Hahn G, Davis MR, Craven PD, Poke G, et al. Recurrent de novo BICD2 mutation associated with arthrogryposis multiplex congenita and bilateral perisylvian polymicrogyria. Neuromusc. Disord. 26: 744-748, 2016. PMID 27751653 [Item \#12.34]

Montes-Chinea NI, Guan Z, Coutts M, Vidal C, Courel $\mathrm{S}$, Rebelo AP, et al. Identification of a new SYT2 variant validates an unusual distal motor neuropathy phenotype. Neurol Genet. 2018 Oct 22;4(6):e282. eCollection 2018 Dec. PMID: 30533528 [Item \#12.37]

Beijer D, Deconinck T, De Bleecker JL, Dotti MT, Malandrini A, Urtizberea JA, et al. Nonsense mutations 
in alpha-II spectrin in three families with juvenile onset hereditary motor neuropathy. Brain. 2019 Jul 22. PMID: 31332438 [Item \#12.38]

Nicolas A, Kenna KP, Renton AE, Ticozzi N, Faghri F, Chia R, et al. Genome-wide analyses identify KIF5A as a novel ALS gene. Neuron 97: 1268-1283, 2018. PubMed: 29566793 [Item \#12.67]

Cirulli ET, Lasseigne BN, Petrovski S, Sapp PC, Dion PA, Leblond CS, et al. Exome sequencing in amyotrophic lateral sclerosis identifies risk genes and pathways. Science 347: 1436-1441, 2015. PubMed: 25700176 [Item \#12.74]

Freischmidt A, Wieland T, Richter B, Ruf W, Schaeffer V, Muller K, et al. Haploinsufficiency of TBK1 causes familial ALS and fronto-temporal dementia. Nature Neurosci. 18: 631636, 2015. PubMed: 25803835 [Item \#12.74]

Wojcik MH, Okada K, Prabhu SP, Nowakowski DW, Ramsey K, Balak C, et al. De novo variant in KIF26B is associated with pontocerebellar hypoplasia with infantile spinal muscular atrophy. Am J Med Genet A. 2018 Aug 27. PMID: 30151950 [Item \#12.85]

Choi BO, Kang SH, Hyun YS, Kanwal S, Park SW, Koo $\mathrm{H}$, et al. A complex phenotype of peripheral neuropathy, myopathy, hoarseness, and hearing loss is linked to an autosomal dominant mutation in MYH14. Hum Mutat. 2011 Jun;32(6):669-77. Epub 2011 Apr 7. PMID:21480433 [Item \#12.86]

Di Fonzo A, Ronchi D, Gallia F, Cribiù FM, Trezzi I, Vetro $\mathrm{A}$, et al. Lower motor neuron disease with respiratory failure caused by a novel MAPT mutation. Neurology Jun 2014, 82 (22) 1990-1998; PMID: 24808015 [Item \#12.87]

\section{GROUP 14. HEREDITARY MOTOR SENSORY NEUROPATHIES (HMSN)}

Sun SC, Ma D, Li MY, Zhang RX, Huang C, Huang HJ, et al. Mutations in C1orf194, encoding a calcium regulator, cause dominant Charcot-Marie-Tooth disease. Brain. 2019 Jun 14. PMID: 31199454 [Item \#14.19]

Tey S, Shahrizaila N, Drew AP, Samulong S, Goh $\mathrm{KJ}$, Battaloglu E, et al. Linkage analysis and whole exome sequencing reveals AHNAK2 as a novel genetic cause for autosomal recessive CMT in a Malaysian family. Neurogenetics. 2019 Apr 22. PMID: 31011849 [Item 14.33]

Zuchner S, De Jonghe P, Jordanova A, Claeys KG, Guergueltcheva V, Cherninkova S, et al. Axonal neuropathy with optic atrophy is caused by mutations in mitofusin 2 . Ann. Neurol. 59: 276-281, 2006. PubMed: 16437557 [Item \#14.68]

Leal A, Bogantes-Ledezma S, Ekici AB, Uebe S, Thiel CT, Sticht H, et al. The polynucleotide kinase 3'-phosphatase gene (PNKP) is involved in Charcot-Marie-Tooth disease (CMT2B2) previously related to MED25. Neurogenetics. 2018 Jul 24. PMID:30039206 [Item \#14.74]

Baumann M, Schreiber H, Schlotter-Weigel B, Loscher WN, Stucka R, Karall D, et al. MPV17 mutations in juvenileand adult-onset axonal sensorimotor polyneuropathy. Clin. Genet. 95: 182-186, 2019. PubMed: 30298599 [Item \#14.75]
Choi Y-R, Hong YB, Jung SC, Lee JH, Kim YJ, Park HJ, et al. A novel homozygous MPV17 mutation in two families with axonal sensorimotor polyneuropathy. BMC Neurol. 15: 179, 2015. PubMed: 26437932 [Item \#14.75]

Souza PVS, Bortholin T, Naylor FGM, Pinto WBVR, Oliveira ASB. Early-onset axonal Charcot-Marie-Tooth disease due to SACS mutation. Neuromuscul Disord. 2018 Feb;28(2):169-172. Epub 2017 Nov 24. PMID:29277257 [Item \#14.89]

Ishiura H, Shibata S, Yoshimura J, Suzuki Y, Qu W, Doi $\mathrm{K}$, et al. Noncoding CGG repeat expansions in neuronal intranuclear inclusion disease, oculopharyngodistal myopathy and an overlapping disease. Nat Genet. 2019 Aug;51(8):12221232. Epub 2019 Jul 22. PMID:31332380 [Item \# 14.117]

Sone J, Mitsuhashi S, Fujita A, Mizuguchi T, Hamanaka $\mathrm{K}$, Mori $\mathrm{K}$, et al. Long-read sequencing identifies GGC repeat expansions in NOTCH2NLC associated with neuronal intranuclear inclusion disease. Nat Genet. 2019 Aug;51(8):1215-1221. PMID: 31332381 [Item \# 14.117]

Tian Y, Wang JL, Huang W, Zeng S, Jiao B, Liu $Z$, et al. Expansion of Human-Specific GGC Repeat in Neuronal Intranuclear Inclusion Disease-Related Disorders. PMID: 31178126 [Item \# 14.117]

\section{GROUP 16. OTHER NEUROMUSCULAR DISORDERS}

McMillin MJ, Below JE, Shively KM, Beck AE, Gildersleeve HI, Pinner J, et al. Mutations in ECEL1 cause distal arthrogryposis type 5D. Am. J. Hum. Genet. 92: 150156, 2013. PMID: 23261301 [Item \#16.18]

Stevenson, D. A., Swoboda, K. J., Sanders, R. K., Bamshad, M. A new distal arthrogryposis syndrome characterized by plantar flexion contractures. Am. J. Med. Genet. 140A: 2797-2801, 2006. PMID 17103435 [Item 16.20]

Stevenson, D. A., Toydemir, R., Swoboda, K., Coon, H., Bamshad, M. A new autosomal dominant distal arthrogryposis syndrome characterized by plantar tendon contractures in large Utah kindred maps to 2q. (Abstract) Annual Meeting of the American Society of Human Genetics: New Orleans, La., 2006. P.282. [Item 16.20]

Storbeck M, Horsberg Eriksen B, Unger A, Hölker I, Aukrust I, Martínez-Carrera LA, et al. Phenotypic extremes of BICD2-opathies: from lethal, congenital muscular atrophy with arthrogryposis to asymptomatic with subclinical features. Eur J Hum Genet. 2017 Sep;25(9):1040-1048. Epub 2017 Jun 21. PMID: 28635954. [Item \#16.22]

Zhou H, Lian C, Wang T, Yang X, Xu C, Su D, et al. MET mutation causes muscular dysplasia and arthrogryposis. EMBO Mol Med. 2019 Mar;11(3). PMID: 30777867 [Item \#16.23]

Böhm J, Malfatti E, Oates E, Jones K, Brochier G, Boland A, et al. Novel ASCC1 mutations causing prenatal-onset muscle weakness with arthrogryposis and congenital bone fractures. J Med Genet. 2019 Sep;56(9):617-621. Epub 2018 Oct 16. PMID: 30327447 [Item \#16.24]

Bonnin E, Cabochette P, Filosa A, Juhlen R, Komatsuzaki $\mathrm{S}$, Hezwani $\mathrm{M}$, et al. Bilallelic mutations in nucleoporin 
NUP88 cause lethal fetal akinesia deformation sequence. PLoS Genet. 14: e1007845, 2018. PMID: 30543681 [Item \#16.29]

Alkhunaizi E, Shuster S, Shannon P, Siu VM, Darilek S, Mohila CA, et al. Homozygous/ compound heterozygote RYR1 gene variants: Expanding the clinical spectrum. Am J Med Genet A. 2019 Mar;179(3):386-396. Epub 2019 Jan 16. PMID: 30652412 [Item \#16.30]

McKie AB, Alsaedi A, Vogt J, Stuurman KE, Weiss MM, Shakeel H, et al. Germline mutations in RYR1 are associated with foetal akinesia deformation sequence/lethal multiple pterygium syndrome. Acta Neuropathol Commun. 2014 Dec 5;2:148. PMID: 25476234 [Item \#16.30]

Romero NB, Monnier N, Viollet L, Cortey A, Chevallay $\mathrm{M}$, Leroy JP, et al. Dominant and recessive central core disease associated with RYR1 mutations and fetal akinesia. Brain. 2003 Nov;126(Pt 11):2341-9. Epub 2003 Aug 22. PMID: 12937085 [Item \#16.30]

Zaharieva IT, Thor MG, Oates EC, van Karnebeek C, Hendson G, Blom E, et al. Witting N, Rasmussen M, Gabbett MT. Loss-of-function mutations in SCN4A cause severe foetal hypokinesia or 'classical' congenital myopathy. Brain. 2016 Mar;139(Pt 3):674-91. doi: 10.1093/brain/awv352. Epub 2015 Dec 22. PMID: 26700687 [Item \# 16.31]

Ronchi D, Di Fonzo A, Lin W, Bordoni A, Liu C, Fassone $\mathrm{E}$, et al. Mutations in DNA2 link progressive myopathy to mitochondrial DNA instability. Am. J. Hum. Genet. 92: 293300, 2013. PMID: 23352259 [Item \#16.37]

Nicholls TJ, Nadalutti CA, Motori E, Sommerville EW, Gorman GS, Basu S, et al. Topoisomerase 3-alpha is required for decatenation and segregation of human mtDNA. Molec. Cell 69: 9-23, 2018. PMID: 29290614 [Item \#16.42]

Nishino I, Spinazzola A., Hirano M. Thymidine phosphorylase gene mutations in MNGIE, a human mitochondrial disorder. Science 283: 689-692, 1999. PMID: 9924029 [Item \#16.43]

Mandel H, Szargel R, Labay V, Elpeleg O, Saada A, Shalata A. The deoxyguanosine kinase gene is mutated in individuals with depleted hepatocerebral mitochondrial DNA. Nature Genet. 29: 337-341, 2001. Note: Erratum: Nature Genet. 29: 491 only, 2001. PMID: 11687800 [Item \#16.45]

Naviaux, R. K., Nguyen, K. V. POLG mutations associated with Alpers' syndrome and mitochondrial DNA depletion. Ann. Neurol. 55: 706-712, 2004. PMID: 15122711 [Item \#16.46]

Van Goethem G, Schwartz M, Lofgren A, Dermaut B, Van Broeckhoven C, Vissing J. Novel POLG mutations in progressive external ophthalmoplegia mimicking mitochondrial neurogastrointestinal encephalomyopathy. Europ. J. Hum. Genet. 11: 547-549, 2003. PMID: 12825077 [Item \#16.47]

Bourdon A, Minai L, Serre V, Jais JP, Sarzi E, Aubert $\mathrm{S}$, et al. Mutation of RRM2B, encoding p53-controlled ribonucleotide reductase (p52R2), causes severe mitochondrial DNA depletion. Nat Genet. 2007 Jun;39(6):776-80. Epub 2007 May 7. PMID: 17486094 [Item 16.49]
Ostergaard E, Christensen E, Kristensen E, Mogensen B, Duno M, Shoubridge EA, et al. Deficiency of the alpha subunit of succinate-coenzyme A ligase causes fatal infantile lactic acidosis with mitochondrial DNA depletion. Am. J. Hum. Genet. 81: 383-387, 2007. PMID: 17668387 [Item \# 16.51]

Kornblum C, Nicholls TJ, Haack TB, Scholer S, Peeva $\mathrm{V}$, Danhauser $\mathrm{K}$, et al. Loss-of-function mutations in MGME1 impair mtDNA replication and cause multisystemic mitochondrial disease. Nature Genet. 45: 214-219, 2013. PMID: 23313956 [Item \#16.52]

Thompson K, Majd H, Dallabona C, Reinson K, King MS, Alston CL, et al. Recurrent de novo dominant mutations in SLC25A4 cause severe early-onset mitochondrial disease and loss of mitochondrial DNA copy number. Am. J. Hum. Genet. 99: 860-876, 2016. Note: Erratum: Am. J. Hum. Genet. 99: 1405 only, 2016. PMID: 27693233 [Item \#16.53]

Palmieri L, Alberio S, Pisano I, Lodi T, MeznaricPetrusa M, Zidar J, et al. Complete loss-of-function of the heart/muscle-specific adenine nucleotide translocator is associated with mitochondrial myopathy and cardiomyopathy. Hum. Molec. Genet. 14: 3079-3088, 2005. PMID: 16155110 [Item \#16.54]

Bonnen PE, Yarham JW, Besse A, Wu P, Faqeih EA, Al-Asmari, et al. Mutations in FBXL4 cause mitochondrial encephalopathy and a disorder of mitochondrial DNA maintenance. Am. J. Hum. Genet. 93: 471-481, 2013. Note: Erratum: Am. J. Hum. Genet. 93: 773 only, 2013. PMID: 23993193 [Item \#16.55]

Gai X, Ghezzi D, Johnson MA, Biagosch CA, Shamseldin HE, Haack TB, et al. Mutations in FBXL4, encoding a mitochondrial protein, cause early-onset mitochondrial encephalomyopathy. Am. J. Hum. Genet. 93: 482-495, 2013. PMID 23993194 [Item \#16.55]

Spiegel R, Saada A, Flannery PJ, Burte F, Soiferman D, Khayat $\mathrm{M}$, et al. Fatal infantile mitochondrial encephalomyopathy, hypertrophic cardiomyopathy and optic atrophy associated with a homozygous OPA1 mutation. J. Med. Genet. 53: 127-131, 2016. PMID: 26561570 [Item \#16.56]

Inoue $\mathrm{M}$, Uchino $\mathrm{S}$, Iida $\mathrm{A}$, Noguchi $\mathrm{S}$, Hayashi $\mathrm{S}$, Takahashi T, et al. COX6A2 variants cause a muscle-specific cytochrome c oxidase deficiency. Ann Neurol. 2019 Jun 2. PMID: 31155743 [Item \#16.66]

Bugiardini E, Mitchell AL, Rosa ID, Horning-Do HT, Pitmann A, Poole OV, Holton JL, Shah S, Woodward C, Hargreaves I, Quinlivan R, Amunts A, Wiesner RJ, Houlden H, Holt IJ, Hanna MG, Pitceathly RDS, Spinazzola A. MRPS25 mutations impair mitochondrial translation and cause encephalomyopathy. Hum Mol Genet. 2019 Apr 30. pii: ddz093. doi: 10.1093/hmg/ddz093. PMID: 31039582 [Item 16.68]

Ardicli D, Sarkozy A, Zaharieva I, Deshpande C, Bodi I, Siddiqui A, U-King-Im JM, Selfe A, Phadke R, Jungbluth H, Muntoni F. A novel case of MSTO1 gene related congenital muscular dystrophy with progressive neurological involvement. Neuromuscul Disord. 2019 Jun;29(6): 
448-455. doi: 10.1016/j.nmd.2019.03.011. Epub 2019 Mar 27. PMID:31130378 [Item \#16.69]

Donkervoort S, Sabouny R, Yun P, Gauguelin L, Chao $\mathrm{KR}, \mathrm{Hu} \mathrm{Y}$, et al. MSTO1 mutations cause mtDNA depletion, manifesting as muscular dystrophy with cerebellar involvement. Acta Neuropathol. 2019 Aug 29. PMID: 31463572 [Item 16.69]

Pacheu-Grau D, Callegari S, Emperador S, Thompson K, Aich A, Topol SE, et al. Mutations of the mitochondrial carrier translocase channel subunit TIM22 cause earlyonset mitochondrial myopathy. Hum Mol Genet. 2018 Dec 1;27(23):4135-4144. PMID: 30452684 [Item \#1670]

Quinzii C, Naini A, Salviati L, Trevisson E, Navas P, DiMauro S, et al. A mutation in Para-hydroxybenzoatepolyprenyl transferase (COQ2) causes primary coenzyme Q10 deficiency. Am. J. Hum. Genet. 78: 345-349, 2006. [PubMed: 16400613. [Item \#16.71]

Lagier-Tourenne C, Tazir M, Lopez LC, Quinzii CM, Assoum M, Drouot N, et al. ADCK3, an ancestral kinase, is mutated in a form of recessive ataxia associated with coenzyme $\mathrm{Q}(10)$ deficiency. Am. J. Hum. Genet. 82: 661672, 2008. PMID: 18319074 [Item \#16.72]

Mollet J, Delahodde A, Serre V, Chretien D, Schlemmer $\mathrm{D}$, Lombes $\mathrm{A}$, et al. $\mathrm{CABC} 1$ gene mutations cause ubiquinone deficiency with cerebellar ataxia and seizures. Am. J. Hum. Genet. 82: 623-630, 2008. PMID: 18319072 [Item \#16.72]

Rahman S, Hargreaves I, Clayton P, Heales S. Neonatal presentation of coenzyme Q10 deficiency. J. Pediat. 139: 456458, 2001. PMID: 11562630 [Item \#16.73]
Duncan AJ, Bitner-Glindzicz M, Meunier B, Costello H, Hargreaves IP, Lopez LC, et al. A nonsense mutation in COQ9 causes autosomal-recessive neonatal-onset primary coenzyme Q10 deficiency: a potentially treatable form of mitochondrial disease. Am. J. Hum. Genet. 84: 558-566, 2009. PMID: 19375058 [Item 16.73]

Heeringa SF, Chernin G, Chaki M, Zhou W, Sloan AJ, Ji Z, et al. COQ6 mutations in human patients produce nephrotic syndrome with sensorineural deafness. J. Clin. Invest. 121: 2013-2024, 2011. PMID: 21540551 [Item \#16.74]

Brea-Calvo G, Haack TB, Karall D, Ohtake A, Invernizzi F, Carrozzo R, et al. COQ4 mutations cause a broad spectrum of mitochondrial disorders associated with CoQ10 deficiency. Am. J. Hum. Genet. 96: 309-317, 2015. PMID: 25658047 [Item \#16.75]

Freyer C, Stranneheim H, Naess K, Mourier A, Felse, A, Maffezzini C, et al. Rescue of primary ubiquinone deficiency due to a novel COQ7 defect using 2,4-dihydroxybensoic acid. J. Med. Genet. 52: 779-783, 2015. PMID: 26084283 [Item 16.76]

Gurgel-Giannetti J, Lynch DS, Paiva ARB, Lucato LT, Yamamoto G, Thomsen C, et al. A novel complex neurological phenotype due to a homozygous mutation in FDX2. Brain. 2018 Aug 1;141(8):2289-2298. PMID:30010796 [Item \#16.77] 